ANL/EMR-4

\title{
DEVELOPMENT OF AN HPLC, GC/MS METHOD FOR ANALYSIS OF HYGAS OIL SAMPLES
}

\author{
by \\ Leo A. Raphaelian
}

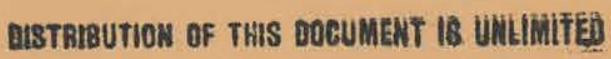

\section{ENERGY \& MINERAL RESOURCES PROGRAMS}

ENERGY \& ENVIRONMENTAL SYSTEMS DIVISION ARGONNE NATIONAL LABORATORY 


\section{DISCLAIMER}

This report was prepared as an account of work sponsored by an agency of the United States Government. Neither the United States Government nor any agency Thereof, nor any of their employees, makes any warranty, express or implied, or assumes any legal liability or responsibility for the accuracy, completeness, or usefulness of any information, apparatus, product, or process disclosed, or represents that its use would not infringe privately owned rights. Reference herein to any specific commercial product, process, or service by trade name, trademark, manufacturer, or otherwise does not necessarily constitute or imply its endorsement, recommendation, or favoring by the United States Government or any agency thereof. The views and opinions of authors expressed herein do not necessarily state or reflect those of the United States Government or any agency thereof. 


\section{DISCLAIMER}

Portions of this document may be illegible in electronic image products. Images are produced from the best available original document. 
The facilities of Argonne National Laboratory are owned by the United States Government. Under the terms of a contract (W-31-109-Eng-38) among the U. S. Department of Energy, Argonne Universities Association and The University of Chicago, the University employs the staff and operates the Laboratory in accordance with policies and programs formulated, approved and reviewed by the Association.

\section{MEMBERS OF ARGONNE UNIVERSITIES ASSOCIATION}

The University of Arizona

Carnegie-Mellon University

Case Western Reserve University

The University of Chicago

University of Cincinnati

Illinois Institute of Technology

University of Illinois

Indiana University

The University of Iowa

Iowa State University
The University of Kansas

Kansas State University

Loyola University of Chicago

Marquette University

The University of Michigan

Michigan State University

University of Minnesota

University of Missouri

Northwestern University

University of Notre Dame
The Ohio State University

Ohio University

The Pennsylvania State University

Purdue University

Saint Louis University

Southern Illinois University

The University of Texas at Austin

Washington University

Wayne State University

The University of Wisconsin-Madison

\section{NOTICE}

This report was prepared as an account of work sponsored by an agency of the United States Government. Neither the United States nor any agency thereof, nor any of their employees, makes any warranty, expressed or implied, or assumes any legal liability or responsibility for any third party's use or the results of such use of any information, apparatus, product or process disclosed in this report, or represents that its use by such third party would not infringe privately owned rights. Mention of commercial products, their manufacturers, or their suppliers in this publication does not imply or connote approval or disapproval of the product by Argonne National Laboratory or the United States Government.

Printed in the United States of America

Available from

National Technical Information Service

U. S. Department of Commerce

5285 Port Royal Road

Springfield, VA 22161

NTIS price codes

Printed copy: A07

Microfiche copy: A01 
Distribution Category:

Coal Conversion and

Utilization-Coal

Gasification (UC-90c)

\section{ARGONNE NATIONAL LABORATORY}

9700 South Cass Avenue

Argonne, Illinois 60439

DEVELOPMENT OF AN HPLC, GC/MS METHOD

FOR ANALYSIS OF ·HYGAS OIL SAMPLES

by

Leo A. Raphaelian

Energy and Environmental Systems Division

June. 1979

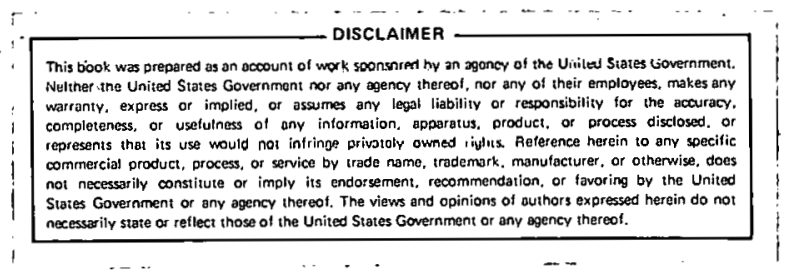

Work Sponsored by

U.S. Department of Energy

Assistant Secretary for Energy Technology

Office of Fossil Energy Programs 
TABLE OF CONTENTS

Page

ABSTRACT . . . . . . . . . . . . . . . . . . . . . . . 1

1 SEPARATION INTO FRACTIONS BY HPLC. . . . . . . . . . . . . 2

1.1 INTRODUCTION. . . . . . . . . . . . . . . . . . . 2

1.1.1 Objective. . . . . . .............2

1.1 .2 Background .................... 2

1.1.3 HPLC Method Development. ............... 3

1.2 EXPERIMENTAL PROCEDURES . . . . . . . . . . . . . . . 5

1.2.1 HYGAS Oil Sample . . . . . . . . . . . . . . . 5

1.2.2 Standard Solutions . . . . . . . . . . . . . 6

1.2.3 Solvents................... . 6

1.2 .4 HPLC Columns... . . . . . . . . . . . . . 6

1.2 .5 Equipment. . . . . . . ............6 6

1.3 RESULTS AND DISCUSSION. . . . . . . . . . . . . . 6

1.3.1 Separation of Non-Polar and Weakly Polar

Compounds with $\mu$ Bondapak $\mathrm{NH}_{2}$. . . . . . . . . . 6

1.3.2 Separation of Medium and Highly Polar

Compounds into Fractions with $\mu$ Bondapak

Phenyl and $\mu$ Bondapak CN. . . . . . . . . . . . 12

1.3.2.1 Specific Problems to be Addressed

in the Separation .............. . 12

1.3.2.2 Development of a Method . . . . . . . . . . 12

1.3.3 Summary and Conclusions . . . . . . . . . . . 16

2 DERIVATIZATION OF POLAR HPLC FRACTIONS . . . . . . . . . . . . . 24

2.1 INTRODUCTION . . . . . . . . . . . . . . . . . 24

2.1 .1 objective .. . . . . . . . . . . . . . 24

2.1.2 Background ...................... . 24

2.1.3 Derivatization Method Development .......... . 25

2.2 EXPERIMENTAL PROCEDURES . . . . . . . . . . . . . . . . . 25

2.2.1 Standard Solutions . . . . . . . . . . . . . 25

2.2.2 Derivatization of Standard Solutions... . . . . . . 26

2.2.3 GC/MS of Derivatized Standard Solutions . . . . . . . 27 
TABLE OF CONTENTS (Contd.)

Page

2.3 RESULTS AND DISCUSSION. . . . . . . . . . . . . . . . . 27

2.3.1 Determination of the Best Procedure for

Derivatization . . . . . . . . . . . . . . 27

2.3.2 Determination of Lower Limit of Detection. . . . . . . 28

2.3.3 Recommended Method ............... . . 34

2.4 SUMMARY AND CONCLUSIONS . . . . . . . . . . . . . . . . 35

3 TESTING OF THE METHOD ON A hygas OIL SAMPLE. . . . . . . . . . . . . 36

3.1 INTRODUCTION . . . . . . . . . . . . . . . . . . . . . . 36

3.2 EXPERIMENTAL PROCEDURES . . . . . . . . . . . . . ...36

3.2.1 HYGAS Oil Sample . . . . . . . . . . . . . . . . 36

3.2 .2 Solvents....................... . . . . . . . . . . .

3.2.3 Equipment. . . . . . . . . . . . . . . . . . 36

3.2.4 Determination of the Flow Time Between

the UV Detector and Outlet of the HPLC . . . . . . . . . 37

3.2.5 HPLC Separation of HYGAS Oil Sample into

Fractions . . . . . . . . . . . . . 37

3.2.6 Mass Spectral Interpretation . . . . . . . . . 38

3.3 RESULTS AND DISCUSSION . . . . . . . . . . . . . . 38

3.3.1 HPLC Separation of HYGAS Oil Sample into

Fractions .. . . . . . . . . . . . . . . . . 38

3.3.2 Derivatization of the Fractions. . . . . . . . . . . 39

3.3.3 Capillary Column GC/MS Investigation

of the Fractions . . . . . . . . . . . . . . . . 39

3.3.4 Problems with the Analysis and Modifications

that Might Lead to Better Analysis. . . . . . . . . . 45

3.3.5 Recommended Modifications for the Analytical

Method . . . . . . . . . . . . . . . . 47

3.4 SUMMARY AND CONCLUSIONS . . . . . . . . . . . . . . . . . . . . . . . .

ACKNOWLEDGMENTS . . . . . . . . . . . . . . . . . . . . . . . . . . . . . . .

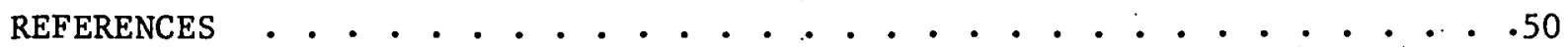

APPENDIX A ANL Bulk Sample Log-In Record. . . . . . . . . . . . . .51

APPENDIX B Mass Spectra of Derivatized Standards. . . . . . . . . .53

APPENDIX C Representative Mass Spectra of Compounds in

Fractions 1,2,3, and 4; Tentative Identifications. . . . .63 


\section{LIST OF FIGURES}

No.

$\underline{\text { Title }}$

$\underline{\text { Page }}$

1.1 Schematic Diagram Illustrating Amount of Sample

Required for Separation into Five Fractions

Suitable for Analysis by Capillary Column GC/MS . . . . . . . . : 4

1.2 HPLC of HYGAS Oil Sample, 72/H/G/0/3, Using a $\mu$ Bondapak $\mathrm{NH}_{2}$ : Column, Heptane Solvent, a $1.5 \mathrm{~mL} / \mathrm{min}$

Flow Rate and Detection by $\Delta \mathrm{RI}$ and $\mathrm{UV}$ at $254 \mathrm{~nm}$. . . . . . . . . 10

1.3 HPLC of HYGAS Oil Sample, $72 / \mathrm{H} / \mathrm{G} / 0 / 3$, Using a $\mu$ Bondapak $\mathrm{NH}_{2}$ Column, Heptane Solvent, a $1.5 \mathrm{~mL} / \mathrm{min}$ Flow Rate, and Detection by UV at 313 and $365 \mathrm{~nm}$. . . . . . . 10

1.4 HPLC of $20 \mu \mathrm{L}$ HYGAS Oil Sample, $72 / \mathrm{H} / \mathrm{G} / 0 / 3, \mu$ Bondapak

CN Column, $2 \mathrm{~mL} / \mathrm{min}$ Flow, Linear Gradient, 0-25\% THF

in Hexane in $10 \mathrm{~min}$, UV Detection at $254 \mathrm{~nm}$. . . . . . . . 14

1.5 HPLC of $20 \mu \mathrm{L}$ HYGAS Oil Sample, $72 / \mathrm{H} / \mathrm{G} / 0 / 3, \mu$ Bondapak

$\mathrm{CN}$ Column, $2 \mathrm{~mL} / \mathrm{min}$ Flow, Linear Gradient, $0-5 \%$ in

$20 \mathrm{~min}, 5-10 \%$ in $10 \mathrm{~min}, 10-100 \%$ THF in Hexane in

$10 \mathrm{~min}$, UV Detection at $254 \mathrm{~nm}$. . . . . . . . . . . . 14

1.6 HPLC of $20 \mu \mathrm{L}$ HYGAS Oil Sample, 72/H/G/0/3, $\mu$ Bondapak

$\mathrm{CN}$ Column, $2 \mathrm{~mL} / \mathrm{min} \mathrm{Flow}$, Hexane for $5 \mathrm{~min}$, Linear

Gradient, $0-5 \%$ in $20 \mathrm{~min}, 5-10 \%$ in $10 \mathrm{~min}, 10-100 \%$

THF in Hexane in $10 \mathrm{~min}$, UV Detection at $254 \mathrm{~nm} . . . . . . . .15$

1.7 HPLC of $20 \mu \mathrm{L}$ HYGAS 0il Sample, 72/H/G/0/3, $\mu$ Bondapak

CN Column, $2 \mathrm{~mL} / \mathrm{min}$ Flow, Hexane for $16 \mathrm{~min}$, Linear

Gradient, $0-5 \%$. in $20 \mathrm{~min}, 5-10 \%$ in $10 \mathrm{~min}, 10-100 \%$

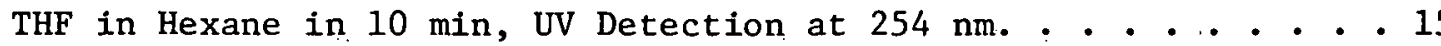

1.8 HPLC of $20 \mu \mathrm{L}$ HYGAS Oil Sample, $72 / \mathrm{H} / \mathrm{G} / 0 / 3, \mu$ Bondapak

CN Column, $2 \mathrm{~mL} / \mathrm{min}$ Flow, Hexane for $16 \mathrm{~min}$, Linear

Gradient, $0-1 \%$ in $10 \mathrm{~min}, 1-5 \%$ in $10 \mathrm{~min}, 10-100 \% \mathrm{THF}$

in Hexane in $10 \mathrm{~min}$, UV Detection at $254 \mathrm{~nm}$. . . . . . . . . 17

1.9 HPLC of $20 \mu \mathrm{L}$ HYGAS 0il Sample, $72 / \mathrm{H} / \mathrm{G} / 0 / 3, . \mu$ Bondapak

CN Column, $2 \mathrm{~mL} / \mathrm{min}$ Flow, Hexane for $16 \mathrm{~min}$, Linear

Gradient, $0-1 \%$ in $10 \mathrm{~min}, 1-5 \%$ in $10 \mathrm{~min}, 5-100 \% \mathrm{THF}$

in Hexane in $10 \mathrm{~min}$, UV Detection at $254 \mathrm{~nm}$. . . . . . . . 17

1.10 HPLC of $20 \mu \mathrm{L}$ HYGAS 011 Sample, 72/H/G/0/3, $\mu$ Bondapak Phenyl Column $2 \mathrm{~mL} / \mathrm{min}$ Flow, Hexane for $16 \mathrm{~min}$, Linear Gradient, $0-1 \%$ in $10 \mathrm{~min}, 1-5 \%$ in $10 \mathrm{~min}, 5-100 \% \mathrm{THF}$ in

Hexane in $10 \mathrm{~min}$, UV Detection at $254 \mathrm{~nm}$. . . . . . . . . . 18 


\section{LIST OF FIGURES (Contd.)}

No.

$\underline{\text { Title }}$

Page

1.11 HPLC of $50 \mu \mathrm{L}$ HYGAS Oil Sample, 72/H/G/0/3, $\mu$ Bondapak

CN Column, $2 \mathrm{~mL} / \mathrm{min}$ Flow, Hexane for $16 \mathrm{~min}$, Linear

Gradient, $0-1 \%$ in $10 \mathrm{~min}, 1-5 \%$ in $10 \mathrm{~min}, 5-100 \% \mathrm{THF}$

in Hexane in $10 \mathrm{~min}$, UV Detection at $254 \mathrm{~nm}$. . . . . . . . 18

1.12 HPLC of $100 \mu \mathrm{L}$ HYGAS Oil Sample, 72/H/G/0/3, $\mu$ Bondapak

CN Column, $2 \mathrm{~mL} / \mathrm{min}$ Flow, Hexane for $16 \mathrm{~min}$, Linear

Gradient, $0-1 \%$ in $10 \mathrm{~min}, 1-5 \%$ in $10 \mathrm{~min}, 5-100 \% \mathrm{THF}$

in Hexane in $10 \mathrm{~min}$, UV Detection at $254 \mathrm{~nm}$. . . . . . . . . . . 19

1.13 HPLC of $200 \mu \mathrm{L}$ HYGAS Oil Sample, $72 / \mathrm{H} / \mathrm{G} / 0 / 3, \mu$ Bondapak

CN Column, $2 \mathrm{~mL} / \mathrm{min}$ Flow, Hexane for $16 \mathrm{~min}$, Linear

Gradient, $0-1 \%$ in $10 \mathrm{~min}, 1-5 \%$ in $10 \mathrm{~min}, 5-100 \% \mathrm{THF}$

in Hexane in $10 \mathrm{~min}$, UV Detection at $254 \mathrm{~nm}$. . . . . . . . 19

1.14 Comparison of HPLC Chromatograms of $20 \mu \mathrm{L}$ and $50 \mu \mathrm{L}$ HYGAS Oil Sample, 72/H/G/0/3, $\mu$ Bondapak CN Column, $2 \mathrm{~mL} / \mathrm{min}$ Flow, Hexane for $16 \mathrm{~min}$, Linear Gradient, $0-1 \%$ in $10 \mathrm{~min}, 1-5 \%$ in $10 \mathrm{~min}, 5-100 \% \mathrm{THF}$ in Hexane in $10 \mathrm{~min}$, UV Detection at $254 \mathrm{~nm}$, Curves Offset . . . . . . . 20

1.15 Comparison of HPLC Chromatograms of $50 \mu \mathrm{L}$ and $100 \mu \mathrm{L}$ HYGAS Oil Sample, 72/H/G/0/3, $\mu$ Bondapak CN Column, 2. $\mathrm{mL} / \mathrm{min}$ Flow, Hexane for $16 \mathrm{~min}$, Linear Gradient, $0-1 \%$ in $10 \mathrm{~min}, 1-5 \%$ in $10 \mathrm{~min}, 5-100 \% \mathrm{THF}$ in Hexane in $10 \mathrm{~min}$, UV Detection at $254 \mathrm{~nm}$, Curves Offset . . . . . . 20

1.16 Comparison of HPLC Chromatograms of $100 \mu \mathrm{L}$ and $200 \mu \mathrm{L}$ HYGAS Oil Sample, 72/H/G/0/3, $\mu$ Bondapak CN Column, $2 \mathrm{~mL} / \mathrm{min}$ Flow, Hexane for $16 \mathrm{~min}$, Linear Gradient, $0-1 \%$ in $10 \mathrm{~min}, 1-5 \%$ in $10 \mathrm{~min}, 5-100 \% \mathrm{THF}$ in Hexane in $10 \mathrm{~min}$, UV Detection at $254 \mathrm{~nm}$, Curves Offset . . . . . . 21

3.1 HPLC Separation into Seven Fractions of HYGAS Oil Sample; Approximately 2.2 AUFS . . . . . . . . . . . . . 38

3.2 Portion of Total Ion Chromatogram of Fraction 4, Derivatized with BSA ................. 440

3.3 Retention Time Ranges of Some Phenols and Hydroxy PNAs, Derivatized with BSA, in Fractions 2,3, and 4. . . . . . 40 
LIST OF, TABLES

No.

Title

$\underline{\text { Page }}$

1.1 Specifications of Waters Micro Columns. . . . . . . . . . 5

1.2 Sources of Standards. . . . . . . . . . . . . . . 7

1.3 HPLC Retention Times of a PNA Mixture with $\mu$ Bondapak $\mathrm{NH}_{2}$ Column and Hexane as Solvent as a Function of Flow Rate and Flow Programming. . . . . . . . . . 9

1.4 HPLC Retention Times of Selected PNAs with $\mu$ Bondapak $\mathrm{NH}_{2}$ Column and Hexane as Solvent, Flow Programmed from $1-4 \mathrm{~mL} / \mathrm{min}$, Curve 10 , $20 \mathrm{~min}$.

1.5 Retention Time Range of Selected PNAs as a Function of the Number of Rings . . . . . . . . . . . . . . 11

1.6 Retention Times of Selected Compounds on $\mu$ Bondapak Pheny 1 and $\mu$ Bondapak CN; Linear Gradient, Hexane to $25 \%$ THF in Hexane in

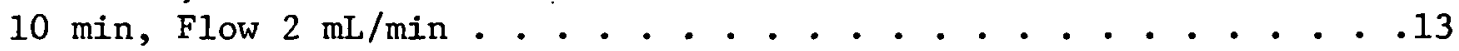

1.7 Measurement of Tailing Characteristics of Toluene as a Function of Peak Height and Time . . . . . . . . . 21

1.8 Measurement of Ability of Gallic Acid, a Very Polar Compound with Several Adsorptive Sites, to Pass Through a $\mu$ Bondapak $\mathrm{CN}$ Column Programmed with a Linear 10-min Gradient of Varying Initial Concentrations of THF in Hexane to $100 \%$ THF . . . . . . . . . 22

1.9 Retention Times of Non-Polar and Polar Compounds on $\mu$ Bondapak $\mathrm{CN}$. . . . . . . . . . . . . . . . . . . 22

2.1 Sources of Standards. . . . . . . . . . . . . . . 26

2.2 Total Ion Count of Peaks of Ten Derivatized

Polar Compounds; Derivatizing Agents: Tri-Sil

Concentrate, BSA, and Methyl-8 Concentrate. . . . . . . . . . 29

2.3 Selected Ion Count of Peak of Ten Derivatized

Polar Compounds; Derivatizing Agents, Tri-Sil

Concentrate, BSA, Methyl-8 Concentrate. . . . . . . . . . . . 30

2.4 Relative Ratings of Derivatization Methods Investigated. . . . . . . . . . . . . . ...... . 31

2.5 Total Ion Count and Selected Ion Count of Derivatized Polar Compounds as a Function of Concentration; Derivatizing Agents: BSA and Methyl-8 Concentrate. . . . . . . . . . . . . . . 32 


\section{LIST OF TABLES (Contd.)}

No. $\underline{\text { Title }}$

2.6 Estimated Minimum Concentration of Polar Compounds Required for Derivatization and Identification by Capillary Column GC/MS; Derivatizing Agents: $\mathrm{BSA}$ and Methy1-8 Concentrate ........................ . . . . . . . . . .

3.1 Tentative Identification and Total Ion Count of Compounds in Fraction 2. . . . . . . . . . . . . . . . .41

3.2 Tentative Identification and Total Ion Count of Compounds in Fraction 3. . . . . . . . . . . . . . . . 42

3.3 Tentative Identification and Total Ion Count of Compounds in Fraction 4. . . . . . . . . . . . . . . .43

3.4 Summary of Tables 3.1, 3.2, and 3.3 Allowing Comparisons of Total Ion Count of Classes of Compounds Versus Fraction . . . . . . . . . . . . . . . 44

3.5 A Partial Listing of Tentative Identifications of Compounds in the Methyl-8 Concentrate Derivatized Fraction 3. . . . . . . . . . . . . . . . . .46

3.6 A Partial Listing of Tentative Identification of Compounds in the Tri-Deuter-8 Derivatized Fraction 4. . . . . . . . . . . . . . . . . . . .47

3.7 A Partial Listing of Tentative Identifications of Compounds in Fraction 1. . . . . . . . . . . . . . .48 
DEVELOPMENT OF AN HPLC GC/MS METHOD FOR ANALYSIS OF HYGAS OIL SAMPLES

by

Leo A. Raphaelian

\section{ABSTRACT}

Direct analysis of a HYGAS oil sample by gas chromatography/. mass spectrometry (GC/MS) or capillary column GC/MS is difficult for at least two reasons: (1) due to the large number (probably over 400) of compounds present in the mixture, many overlapping peaks occur, resulting in mass spectra that are often confusing, and (2) moderately to highly polar compounds are not easily chromatographable.

In Part 1 of this study, high performance liquid chromatographic (HPLC) methods for separating the complex HYGAS oil samples into fractions were investigated. A satisfactory separation of a HYGAS oil sample into seven fractions varying from non-polar or weakly. polar to highly polar was achieved on a $\mu$ Bondapak CN column with a complex gradient of hexane to THF.

In Part 2, derivatization as a means for making polar compounds more amenable to identification by capillary column GC/MS was explored. With the use of standard phenols, carboxylic acids, amines, and alcohols, it was found that BSA (a silylating agent) was most effective in derivatizing phenols and alcohols and Methy 1-8 Concentrate (an alkylating agent) was most effective in derivatizing carboxylic acids and amines. The lower limit of detection by capillary column GC/MS was in the range of less than 10 to $20 \mathrm{ng} / \mu \mathrm{L}$ per underivatized compound.

In Part 3, a preliminary study of the methods developed in Parts 1 and 2, namely HPLC separation into fractions and derivatization of the polar fractions, was undertaken on an authentic HYGAS oil sample to determine whether the methods would make the sample more amenable to analysis by capillary column GC/MS. It: was found that, with HPLC, the complex mixtures of HYGAS oil samples are separated. Into simpler complex mixtures and, with derivatization of the polar fractions, the identification by capillary column GC/MS of polar compounds not normally chromatographable. was enhanced. Many previously unreported hydroxy PNAs were found. 


\subsection{INTRODUCTION}

\subsubsection{Objective}

The objective of this part of the study was to determine whether high performance liquid chromatography (HPLC) could be used to separate HYGAS oil samples into fractions that would be more amenable to analysis by capillary column gas chromatography/mass spectrometry (GC/MS) than the bulk sample.

\subsubsection{Background}

In preliminary analyses by GC/MS, it was found that HYGAS oil samples contain a variety of compounds including toluene, the start-up and make-up oil, aromatic hydrocarbons, phenols, anilines, pyridines, thiophenes, benzonitriles, and PNAs. Direct analysis of the mixture by GC/MS is at best difficult for at least two reasons: (1) due to the large number (probably over 400) of compounds present in the mixture, many overlapping peaks occur, resulting in mass spectra that are often confusing; (2) capillary columns that give good separation of non-polar compounds are not adequate for the separation of polar compounds. Therefore, there is a definite need for a preliminary separation of the complex mixtures in HYGAS oil samples.

Ideally, for use in cap1llary column GC/MS, the preliminary separation scheme (fractionation) should give non-polar or very weakly polar, weakly polar, moderately polar, polar, and very polar fractions. Alternatively, a separation scheme that would provide fractions of classes of compounds, such as hydrocarbons, alcohols, phenols, amines, etc., would also be useful, particularly for use in developing specific derivatizations.

For the separation of petroleum, fractional distillation, extraction, complex formation, and column chromatography, including adsorption, partition, and gel permeation, are among the methods that have been used. Each method has certain advantages and disadvantages. With fractional distillation, the toluene, which represents a major portion of a HYGAS oil sample, could be removed. However, this method suffers from the fact that any distillation, fractional or otherwise, requires heat and decomposition and reaction between components in the mixture typically takes place, altering the composition. With such extractions as the acid/base liquid-liquid type, recoveries of individual components of the mixture are not only variable but also of ten low, particularly with polar compounds; moreover, some matrix effects frequently occur affecting recoveries. Complex formation is not only too limited to be of use but also not applicable in this case since the complexes would not be chromatographable by GC. Column chromatography, although useful, suffers from being long and tedious and requires the use and workup of large amounts of solvent; it is not recommended for a large number of samples.

It can be stated, generally, that separations that can be done by column chromatography can also be done considerably better by HPLC. When 
compared to column chromatography, HPLC gives much better resolution, much shorter run times, and much less solvent. However, the amount of sample that can be processed per run is considerably less than with column chromatography. To overcome this disadvantage, several runs of the sample can be made with the attendant advantages of time, workup of much less solvent, and resolution.

In the petroleum field, HPLC has been used predominantly for identification of components in a mixture ${ }^{1,2}$ or for fingerprinting oil samples. 3 Little attention has been paid to the use of HPLC as a means of performing gross separation 4-6 although, in certain instances, investigators have isolated peaks and identified the compound or compounds by GC/MS or mass spectrometry. Although HPLC/MS instruments are available, HPLC does not have the resolution capillary column GC and, as a result, HPLC/MS is not as useful as capillary column GC/MS for the analysis of complex mixtures.

As mentioned, HYGAS oil samples contain a variety of compounds with a wide range of polarities, with toluene as the major component. Since many of the compounds of interest are present only in low concentrations, the problem of isolating and separating into fractions sufficient quantities of these compounds for capillary column GC/MS analysis must be addressed.

The use of HPLC for preliminary fractionation of samples from coal conversion plants was based on the following calculations and assumptions (Fig. 1.1). Typically, complex mixtures that are to be analyzed by capillary column GC/MS are concentrated or diluted to give a range of concentration for each compound of $500 \mathrm{pg} / \mu \mathrm{L}$ to $200 \mathrm{ng} / \mu \mathrm{L}$. The average component in such a mixture has a concentration of $20 \mathrm{ng} / \mu \mathrm{L}$ with the majority of the components falling in the range of $10-50 \mathrm{ng} / \mu \mathrm{L}$. If one assumes that the average component has a concentration of $20 \mathrm{ng} / \mu \mathrm{L}$ in the sample to be injected into the capillary column of the GC/MS and there are 100 components in the mixture of one of the five fractions, then there would be $2 \mu \mathrm{g} / \mu \mathrm{L}$ for each fraction or $1 \mathrm{mg}$ for the five fractions. If one assumes that $95 \%$ of the HYGAS sample is toluene, to identify the remaining components, one would require $20 \mathrm{mg}$ of sample. The limit for HPLC high resolution micro columns is $20-60 \mathrm{mg}$ of sample. Thus, a separation in just one HPLC run of a HYGAS sample into five fractions suitable for analysis by capillary column GC/MS appeared to be well within the realm of possibility.

\subsubsection{HPLC Method Deve Zopment}

Several approaches to the separation of HYGAS oil samples into fractions suitable for analysis by capillary column GC/MS can be considered. First, with reverse phase $\mathrm{HPLC}$, using $\mu$ Bondapak $\mathrm{C}_{18}$, for example, polar compounds readily pass through the column and relatively non-polar compounds are retained and separated. Thus, a fairly easy separation of polar compounds from nonpolar compounds is accomplished. However, since aqueous systems are used in this case, an additional step of liquid-liquid extraction, whose deficiencies have been pointed out above, would be required. 
$20 \mathrm{ng} / \mu \mathrm{L}$ average/component/fraction

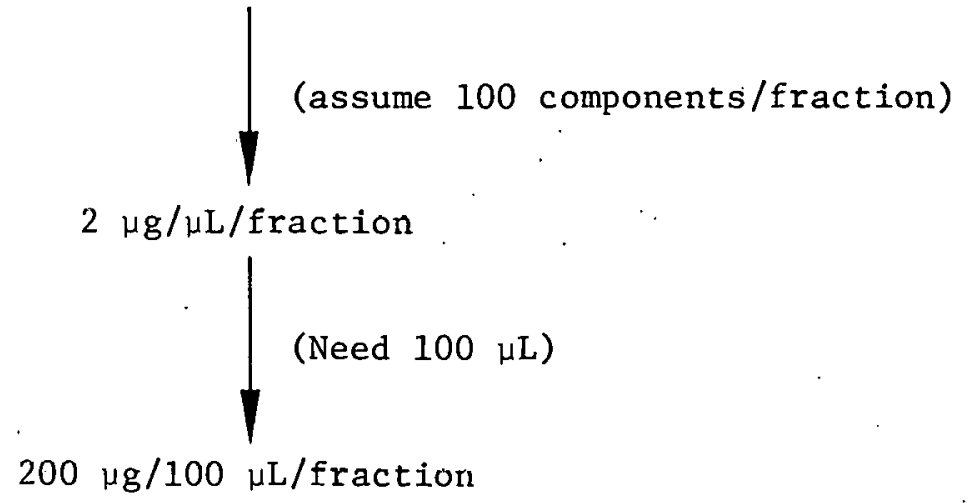

$1 \mathrm{mg}$-- total sample less solvent, toluene

$20 \mathrm{mg}$-- total sample required for separation into five fractions, each of which is analyzed by capillary column GC/MS

Fig. 1.1. Schematic Diagram Illustrating Amount of Sample Required for Separation into Five Fractions Suitable for Analysis by Capillary Column GC/MS

Having considered reverse phase HPLC, one can deduce criteria desirable in the HPLC method for separating HYGAS oil samples into fractions suitable for use in capillary column GC/MS. Ideally, the preliminary separation scheme (fractionation) should give nonpolar or very weakly polar, weakly polar, and moderately polar, polar, and very polar fractions in typical organic solvents that are suitable for GC/MS and derivatization and that are easily removed by evaporation such as pentane, hexane, acetonitrile, methylene chloride, and THF. It would be preferable also to remove the toluene as a separate fraction so that sufficient quantities of the other components in the HYGAS oil samples could be identified by capillary column GC/MS.

of the high resolution micro columns available from Waters Associates, Inc. (Table 1.1), the following columns were considered potentially most useful for separating the HYGAS oil samples into fractions. 
Table 1.1. Specifications of Waters Micro Columns $(3.9 \mathrm{~mm}$ ID $\times 30 \mathrm{~cm})$ (Data from Waters Associates, Inc.)

\begin{tabular}{lccc}
\hline \multicolumn{1}{c}{ Column } & Polarity & $\begin{array}{c}\text { Plates/Meter at } \\
\text { Specified Linear Velocity }\end{array}$ & $\begin{array}{c}\text { Sample Loading } \\
\text { Limit (mg) }\end{array}$ \\
\hline$\mu$ Bondapak $\mathrm{C}_{18}$ & Very low & 9000 at $0.44 \mathrm{~cm} / \mathrm{sec}$ & $20-60$ \\
$\mu$ Bondapak Pheny1 & Low & 9000 at $0.53 \mathrm{~cm} / \mathrm{sec}$ & $20-60$ \\
$\mu$ Bondapak CN & Medium & 9000 at $0.53 \mathrm{~cm} / \mathrm{sec}$ & $20-60$ \\
$\mu$ Bondapak $\mathrm{NH}_{2}$ & High & 9000 at $0.44 \mathrm{~cm} / \mathrm{sec}$ & $20-60$ \\
\hline
\end{tabular}

It would be expected that $\mu$ Bondapak $\mathrm{NH}_{2}$ columns (in this case, the normal phase mode) would be most useful for providing good separations of relatively non-polar compounds, whereas the more polar compounds would remain on the column and require elution by backwashing. On the other end of the polarity scale, $\mu$ Bondapak $\mathrm{C}_{18}$ columns are too non-polar to be useful for separations in the normal phase mode and, therefore, were not investigated in this study. It appeared that the $\mu$ Bondapak Phenyl and $\mu$ Bondapak $C N$ columns were the most promising for bringing about the separation into fractions of weakly polar through highly polar compounds. Although some separation of relatively nonpolar compounds, which, aside from the solvent toluene, represent a large portion of a HYGAS oil sample, would take place, resolution would not be expected to be good.

Therefore, the study of methods development of a separation of HYGAS oil samples into fractions suitable for analysis by capillary column GC/MS and/or for derivatization and subsequent analysis by capillary column GC/MS would involve the following:

1. Investigation of the separation ability of $\mu$ Bondapak $\mathrm{NH}_{2}$, $\mu$ Bondapak $\mathrm{CN}$, and $\mu$ Bondapak Phenyl columns with solvents easily removed by evaporation and suitable for use in capillary column GC/MS and/or for derivatization and use in capillary column GC/MS.

2. Development of a means of separating the major component, toluene, from the rest of the compounds present so that sufficient concentrations of compound are available in each of five fractions for analysis by capillary column GC/MS and/or for derivatization and subsequent analysis by capillary column GC/MS.

\subsection{EXPERIMENTAL PROCEDURES}

\subsubsection{HYGAS OiZ Sample}

The HYGAS oil sample $(72 / \mathrm{H} / \mathrm{G} / 0 / 3)$, a further description of which can be found in Appendix $A$, was filtered with a sample clarification kit (Waters Associates, Inc., Milford, MA 01757) to remove unreacted coal. 


\subsubsection{Standard Solutions}

With the exception of gallic acid monohydrate, each of the standards was dissolved in benzene. Gallic acid monohydrate was dissolved in THF. The source of the standards is shown in Table 1.2.

\subsubsection{Solvents}

For the preparation of standards, Burdick \& Jackson Solvents (Burdick \& Jackson Laboratories Inc, Muskegon, Michigan 49442) were used. For the mobile phase in HPLC runs, Waters solvents were used. They were hexane (No. 84911), 2,2,4-Trimethylpentane (No. 84915), THF (UV) (No. 84901), methylene chloride (No. 84913), and acetonitrile (No. 84905). Where low concentrations of THF in hexane were used, such as $1,2.5,5$, and $10 \%$, the solvents were premixed because solvent gradients at low concentrations led to erractic mixing of solvents.

\subsubsection{HPLC Columns}

The HPLC columns were from Waters and were $3.9 \mathrm{~mm}$ ID $\times 30 \mathrm{~cm}$ : $\mu$ Bondapak $\mathrm{NH}_{2}$ (No. 84040), $\mu$ Bondapak Pheny1. (No. 27198), and $\mu$ Bondapak CN (No. 84042).

\subsubsection{Equipment}

The HPLC equipment was Waters, consisting of two $6000 \mathrm{~A}$ Solvent Delivery Systems, a 660 Solvent Programmer, U6K Universal Liquid Chromatograph Injector, 440 Absorbance Detector (UV), and R-400 Differential Refractometer $(\triangle R I)$. Detection was done at 254,313 , and $365 \mathrm{~nm}$ in the UV.

The flow rate of each pump was determined by measuring the volume of solvent at exhaust with a stop watch after which adjustments were made to give the desired flow rate. A six-way Valco air-activated selenoid valve was used for backflushing. Flow programming was done by connecting pump " $A$ " to the " $B$ " inlet of the solvent programmer normally used for solvent gradients.

\subsection{RESULTS AND DISCUSSION}

\subsubsection{Separation of Non-Polar and Weakly Polar Compounds with $\mu$ Bondopak $\mathrm{NH}_{2}$}

Dark $^{3}$ has done an extensive study of the differences in petroleumbased products with $\mu$ Bondapak $\mathrm{NH}_{2}$, and $\mathrm{n}$-heptane as solvent, at a flow rate of $2 \mathrm{~mL} / \mathrm{min}$. Although the method is useful for fingerprinting (for which it was intended), it was found that separation of low PNAs was not. sufficient, particularly for collection of fractions. Thus, with constant flow rate, the alkyl benzenes and lower PNAs tend to come together making separation into fractions and collection of those fractions difficult and the higher PNAs take a long time to come off the column, resulting in excessively long runs. 
Table 1.2. Sources of Standards

\begin{tabular}{|c|c|c|c|}
\hline Compound & Company & Specification & $\begin{array}{l}\text { Catalog Number } \\
\text { or Kit Number }\end{array}$ \\
\hline anil ine $-2,3,4,5,6-d_{5}$ & Aldrich & $99+$ atom $\%$ & $17,569-2$ \\
\hline anthracene & Analabs & $99 \%(\min )$ & RNH004 \\
\hline anthracene-d 10 & Stohler & 98 atom \% & D33 \\
\hline benzaldehyde & Aldrich & $98+\%$ & B133-4 \\
\hline 2,3-benzanthracene & Analabs & $99 \%$ (min) & RNH060 \\
\hline benz $(a)$ phenanthrene & RFR & $95 \%$ (min) & $\mathrm{RAH}-7$ \\
\hline benz (a) pyrene & Analabs & $98 \%$ (min) & RNH033 \\
\hline benzoic acid & Aldrich & $99 \%$ & $10,947-9$ \\
\hline benzonitrile & Aldrich & $99 \%$ & B895-9 \\
\hline benzyl alcohol & Aldrich & $99+\%$ & $\mathrm{~B} 1,620-8$ \\
\hline benzyl amine & Aldrich & $99 \%$ & $18,570-1$ \\
\hline chrysene & Analabs & $99 \%$ (min) & PRH012 \\
\hline o-cresol & Polyscience & Qual & 170BX \\
\hline $1,2,3,4$-dibenzanthracene & Analabs & $99 \%(\min )$ & RNH016 \\
\hline $1,2,5,6$-dibenzanthracene & Analabs & $99 \%$ (min) & RNHO17 \\
\hline dibenzofuran & Aldrich & $98 \%$ & $13,568-2$ \\
\hline 2,6-dimethyl aniline & Eastman & -- & 1736 \\
\hline 9,10-dimethyi anthracene & RFR & $99 \%(\min )$ & $\mathrm{RAH}-24$ \\
\hline $\begin{array}{l}\text { 7,12-dimethyl- } \\
2,3 \text {-benzanthracene }\end{array}$ & $\mathrm{ACL}$ & - & -- \\
\hline $\begin{array}{l}9,10 \text {-dimethyl- } \\
2,3 \text {-benzanthracene }\end{array}$ & ACL & -- & -- \\
\hline 3,6-dimethyl phenanthrene & ACL & -- & -- \\
\hline gallic acid monohydrate. & Aldrich & -- & $14,791-5$ \\
\hline 2,4-lutidine & Aldrich & $96+\%$ & L360-9 \\
\hline 2-methyl anthracene & Analabs & $99 \%$ (min) & RNH039 \\
\hline 1-methyl naphthalene & Aldrich & $97 \%$ & M5, 680-8 \\
\hline 2-methy1-1-naphthol & Aldrich & $98 \%$ & $16,284-1$ \\
\hline 1-methyl phenanthrene & Analabs & $99 \%$ (min) & RNH044 \\
\hline 2-methyl phenanthrene & Analabs & $99 \%(\min )$ & RNH045 \\
\hline 1-methyl pyrene & ACL & -- & -- \\
\hline 3-methyl pyrene & ACL & -- & -- \\
\hline naphthalene & Aldrich & $98 \%$ & $18,560-4$ \\
\hline
\end{tabular}


Table 1.2. (Contd.)

\begin{tabular}{|c|c|c|c|}
\hline Compound & Company & Specification & $\begin{array}{l}\text { Catalog Number } \\
\text { or Kit Number }\end{array}$ \\
\hline 1-naphthalene acetic acid & Aldrich & $99 \%$ & $N 386-4$ \\
\hline 1-naphthol & Aldrich & $99+\%$ & N199-2 \\
\hline pentacene & Analabs & $98 \%(\min )$ & RNH048 \\
\hline perylene & Analabs & $99 \%$ (min) & RNH049 \\
\hline phenanthrene & Aldrich & $98+\%$ & $P 1,140-9$ \\
\hline pheno1 & Polyscience & Qual & $.170 \mathrm{BX}$ \\
\hline 2-picoline & Aldrich & $9.8 \%$ & $10,983-5$ \\
\hline pyrene & Analabs & $99 \%$ (min) & RNH057 \\
\hline pyridine & Fisher & $\operatorname{ACS}$ & $\mathrm{P}-368$ \\
\hline quinoline & Aldrich & $96 \%$ & Q125-5 \\
\hline $\begin{array}{c}2,3,5-t r \text { imethy } 1 \\
\text { naphthalene }\end{array}$ & Aldrich & -- & T7,740-2 \\
\hline triphenylene & Analabs & $99 \%$ (min) & RNH064 \\
\hline 2,4-xylenol & Polyscience & Qual & 170BX \\
\hline
\end{tabular}

Aldrich Chemical Co., 940 West Saint Paul Avenue, Milwaukee, WI 53233

Analabs, Inc., 80 Republic Drive, North Haven, CT 06473

Stohler Isotope Chemicals, 92 Beckwith Place, Rutherford, NJ 07070

RFR Corp., I Main Street, Hope, R.I. 02831

Polyscience Corp., 8366 Gross Point Road, Niles, IL 60648

Eastman Kodak Co., Rochester, N.Y. 14650.

ACL: Benzene solutions $(1.00 \mathrm{mg} / \mathrm{mL})$ from Analytical Chemistry Laboratory, Argonne National Laboratory

Fisher Scientific Co.,' Fair Lawn, N.J. 07410 
Since it was desirable to modify this procedure to spread out the separation of the alkyl benzenes and lower PNAs, a study was made of the effect of flow rate on the retention time of some model PNAs, benzene, naphthalene, anthracene, chrysene, and 1,2,3,4-dibenzanthracene (Table 1.3). As might be expected, with constant flow rate, retention time increases with lower flow rates and decreases with higher flow rates.

For the best separation, it would appear that if one were to program the flow of solvent such that it is initially low and increases progressively, a separation of the lower PNAs could be accomplished while performing the separation of the higher PNAs in a reasonable amount of time. (A slow solvent gradient was unacceptable because it tended to push everything off the column.) Curve 10 on the Waters Model 660 Solvent Programmer, with a slowly rising exponential-type slope, was chosen for the flow programming. The results of three such runs on the five model compounds are shown in Table 1.3. After a number of runs with a variety of PNAs, it appeared that the best separation could be achieved with curve 10 flow programmed from 1-4 mL over a time period of 20 -minutes. The retention times of a number of PNAs and benzene under these conditions are shown in Table 1.4. It can be seen that retention time falls into a series of groups, as shown in Table 1.5, and the condensed 4-ring PNAs fall nicely between 3 and 4-ring PNAs and the condensed 5-ring PNAs fall between the 4 and 5-ring PNAs.

The use of the $\mu$ Bondapak $\mathrm{NH}_{2}$ as a stationary phase was excellent for the separation of non-polar or weakly polar compounds; however, with polar compounds, the phase was too retentive and, although moderately polar compounds might pass through the column with a gradient, highly polar compounds. would be retained. It is possible to backwash the highly polar compounds but no separation into fractions of the polar compounds would be achieved. An example of this is shown in Figs. $1: 2$ and 1.3. It can be seen that the polar compounds came off the column after backwash as one broad peak.

Table 1.3. HPLC Retention Times of a PNA Mixture with $\mu$ Bondapak $\mathrm{NH}_{2}$ Column and Hexane as Solvent as a Function of Flow Rate and Flow Programing

\begin{tabular}{|c|c|c|c|c|c|c|c|}
\hline \multirow[b]{2}{*}{$\begin{array}{c}\text { Flow } \\
(\mathrm{mL} / \mathrm{mL})\end{array}$} & \multirow[b]{2}{*}{$(\min )$} & \multirow[b]{2}{*}{ Curve } & \multicolumn{5}{|c|}{ Retention T1me (M1nutes) } \\
\hline & & & Benzene & Naphthalene & Anthracene & Chrysene & $\begin{array}{l}1,2,3,4-D 1 \text { benz- } \\
\text { Anthracene }\end{array}$ \\
\hline 1.0 & -- & $-\infty$ & 4.2 & 5.2 & 6.7 & 10.4 & 16.5 \\
\hline 1.5 & -- & -- & 2.8 & 3.3 & 4.3 & 5.5 & 10.3 \\
\hline $2.0^{a}$ & -- & -- & 2.1 & 2.5 & 3.2 & 5.0 & 7.8 \\
\hline 2.5 & -- & $-\because$ & 1.7 & $2.0^{\prime}$ & 2.6 & 4.0 & 6.3 \\
\hline 3.0 & -- & -- & 1.4 & 1.7 & 2.2 & 3.3 & 5.3 \\
\hline 4.0 & -- & -- & 1.1 & 1.3 & 1.7 & 2.5 & 4.0 \\
\hline 1.0 to 4.0 & 20 & 10 & 4.2 & 5.0 & 6.5 & 10.0 & 14.8 \\
\hline 2.0 to 4.0 & 5 & 10 & 2.1 & 2.5 & 3.2 & 4.6 & 6.0 \\
\hline 2.0 to 4.0 & 4 & 10 & 2.1 & 2.5 & 3.2 & 4.2 & 5.7 \\
\hline
\end{tabular}

awo runs, almost identical retention times. 


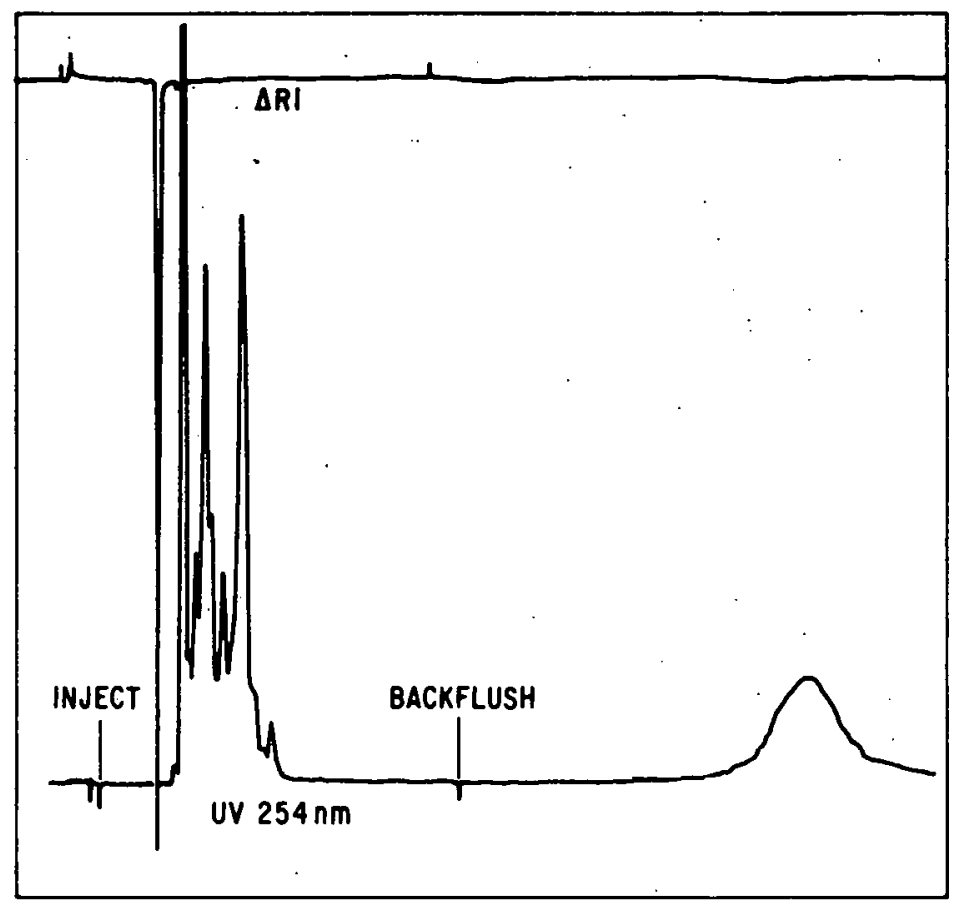

Fig: 1.2. HPLC of HYGAS Oil Sample, $72 / \mathrm{H} / \mathrm{G} / \mathrm{O} / 3$, Using a $\mu$ Bondapak $\mathrm{NH}_{2}$ Column, Heptane Solvent, a $1.5 \mathrm{~mL} / \mathrm{min}$ Flow Rate and Detec- 2 tion by $\triangle R I$ and $U V$ at $254 \mathrm{~nm}$

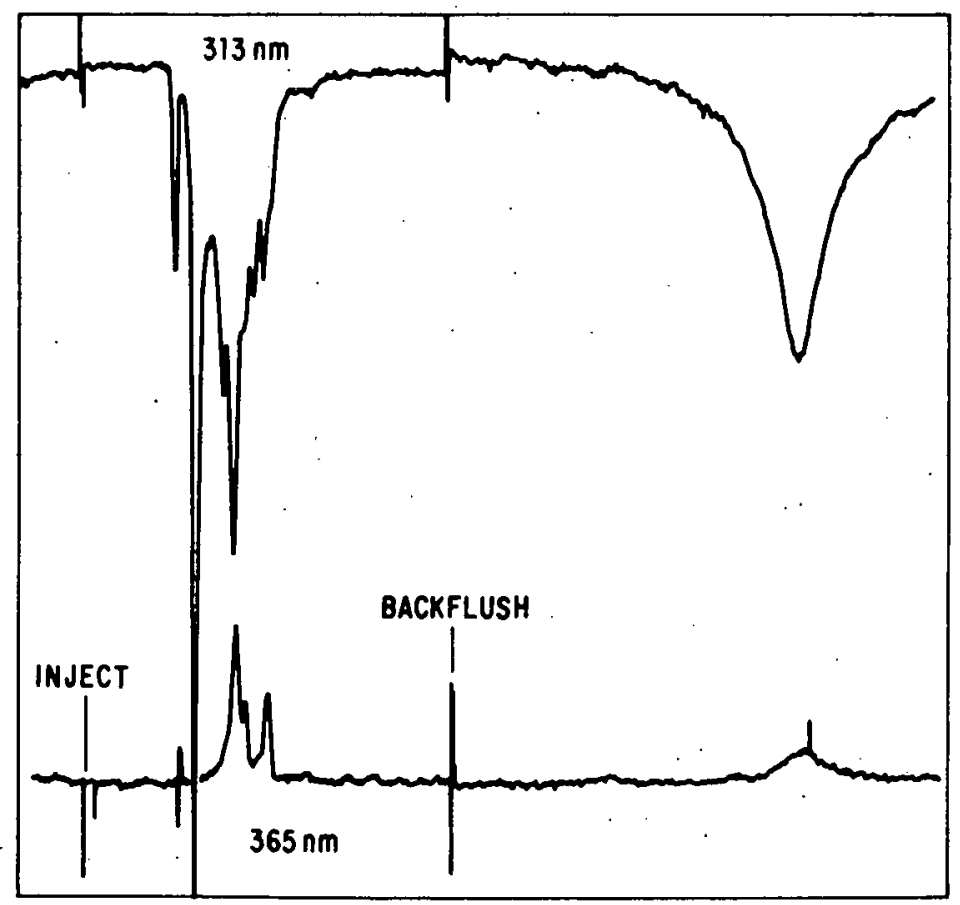

Fig. 1.3. HPLC of HYGAS Oil Sample, 72/H/G/0/3, Using a $\mu$ Bondapak $\mathrm{NH}_{2}$ Column, Heptane Solvent; a $1.5 \mathrm{~mL} / \mathrm{min}$ Flow Rate, and Detec tion by UV at. 313 and $365 \mathrm{~nm}$. 
Table 1.4. HPLC Retention Times of Selected PNAs with $\mu$ Bondapak $\mathrm{NH}_{2}$ Column and Hexane as Solvent, Flow Programmed from $1-4 \mathrm{~mL} / \mathrm{min}$, Curve $10,20 \mathrm{~min}$

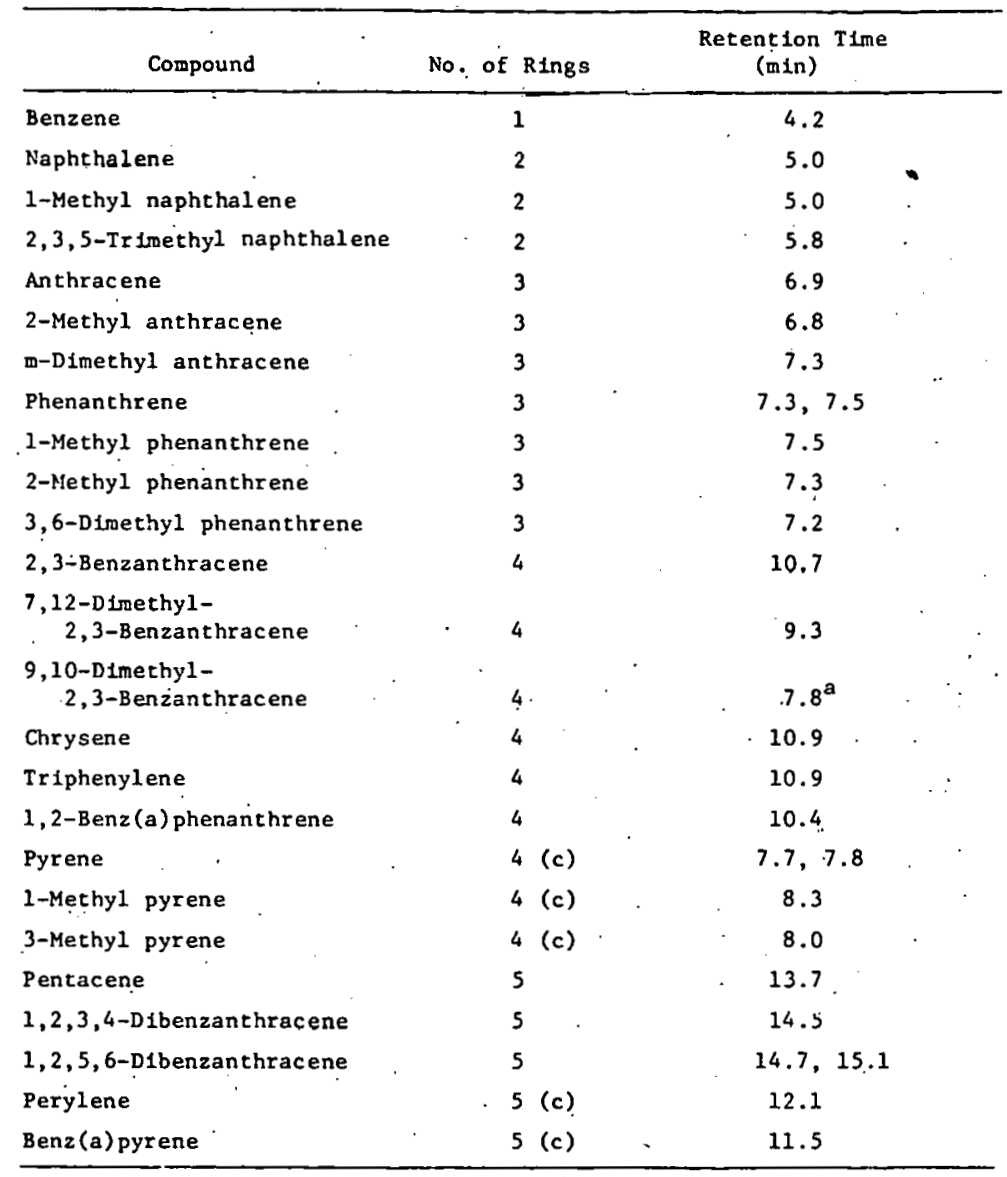

appears not to be designated compound

(c) Condensed ring system

Table 1.5. Retention Time Range of Selected PiNAs as a Function of the Number of Rings ( $\mu$ Bondapak $\mathrm{NH}_{2}$, Hexane Solvent, Flow Programmed 1-4 mL/min, $20 \mathrm{~min}$, Curve 10)

\begin{tabular}{ccc}
\hline $\begin{array}{c}\text { Number of } \\
\text { Kings }\end{array}$ & \multicolumn{2}{c}{ Retention Time Range (Minutes) } \\
\cline { 2 - 3 } & Noncondensed & Condensed \\
\hline 1 & $4.2(1)$ & NA \\
3 & $5.0-5.8(3)$ & -- \\
4 & $6.8-7.5(7)$ & $7.7-8.3(3)$ \\
5 & $9.3-10.9(5)$ & $11.5-12.1$ (2) \\
\hline
\end{tabular}

( ) Number of compounds from which range was determined

NA Not Applicable 
Thus, $\mu$ Bondapak $\mathrm{NH}_{2}$ can be used to separate non-polar and weakly polar compounds into fractions but is ineffective with moderately and highly polar compounds. Such a separation into fractions can be very useful for identifying a complex mixture that contains predominantly compounds that are relatively non-polar, since GC conditions can be tailor-made to each fraction. It would be particularly useful forvidentifying the higher PNAs.

\subsubsection{Separation of Medium and Highly Polar Compounds into Fractions with $\mu$ Bondapak Pheny $\mathrm{Z}$ and $\mu$ Bondopak $\mathrm{CN}$}

\subsubsection{Specific Problems To Be Addressed in the Separation}

Whereas HPLC with a $\mu$ Bondapak $\mathrm{NH}_{2}$ column affords a good separation of non-polar compounds, it is not useful, as stated, for separating the polar compounds into fractions. It appeared that the weakly polar stationary phases, $\mu$ Bondapak Phenyl and $\mu$ Bondapak $\mathrm{CN}$, might be more useful in this regard. The best approach appeared to be to try to get the non-polar compounds to elute initially as one fraction and then to do a separation into fractions of the compounds of varying polarity with typical normal phase HPLC and gradient elution. Therefore, several criteria, as listed below, had to be met in the separation:

1. The non-polar and weakly polar compounds should elute in one fraction, preferably along with toluene, the major component of HYGAS recycle oil, since a suitable chromatographic method could then be worked out for these compounds,

2. The moderately and highly polar compounds should be separated into at least 4-6 fractions,

3. The highly polar must elute from the column so that there is no need for backwashing,

4. The separation into fractions should be complete in a reasonable amount of time (say, within one hour), and

5. The separation of a HYGAS oil sample should yield fractions of sufficient quantity so that analyses by GC/MS and/or derivatization and analyses by GC/MS could be done satisfactorily.

In such an HPLC study, the variables are numerous; for example, solvents, gradient curve, time of start of gradient, and duration of gradient. Although a considerable number of experiments were performed, only a few are described here.

\subsubsection{DeveZopment of a Method}

In initial experiments with a variety of standard polar compounds, it was found that gradients of hexane (a non-polar solvent) to acetonitrile (a moderately polar solvent) and hexane to methylene chloride (a polar solvent) 
did not work as well as a gradient of hexane to THF (a polar solvent). With a linear 10 -min gradient, hexane to $25 \% \mathrm{THF}$ in hexane, a group of compounds with varying polarity can be separated on $\mu$ Bondapak Phenyl and $\mu$ Bondapak $C N$ as shown in Table 1.6. The $\mu$ Bondapak $C N$ column appears to provide a little better separation of the relatively non-polar compounds, dibenzofuran, benzaldehyde, and benzonitrile, than of the more polar compounds. The $\mu$ Bondapak Phenyl column also appears to be more retentive than the $\mu$ Bondapak CN column. Although separation appears fairly good for these model polar compounds with a $20 \mu \mathrm{L}$ HYGAS oil sample it is poor (with a $\mu$ Bondapak $\mathrm{CN}$ column) because of the complexity of the sample (Fig. 1.4). The polar compounds come off the column too quickly and are not separated into fractions. Even with a slower change in concentration of THF (1inear gradient, 0-5\% THF in hexane in $20 \mathrm{~min}, 5-10 \% \mathrm{THF}$ in $10 \mathrm{~min}$, and $10-100 \% \mathrm{THF}$ in $10 \mathrm{~min}$ ), bunching of the polar compounds still occurs at the beginning of the chromatogram and separation is poor (Fig. 1.5). If one uses pure hexane for 5 min and then runs the same program as in the preceding example, separation of the non-polars from the polars appears adequate but separation of the polars into fractions is inadequate (Fig. 1.6). To spread out the polar compounds, one can hold off the above gradient for $16 \mathrm{~min}$ (Fig. 1.7). The moderately polar to highly polar compounds (center of chromatogram, around 25 min Fig. 1.7) can then be spread out by going to a slower initial gradient, $0 \%$ for $16 \mathrm{~min}, 0-1 \%$ in $10 \mathrm{~min}, 1-5 \%$ in $10 \mathrm{~min}, 5-10 \%$ in $10 \mathrm{~min}$; and $10-100 \% \mathrm{THF}$

Table 1.6. Retention Times of Selected Compounds on $\mu$ Bondapak Pheny 1 and $\mu$ Bondapak $\mathrm{CN}$; Linear Gradient, Hexane to $25 \% \mathrm{THF}$ in Hexane in $10 \mathrm{~min}$, Flow $2 \mathrm{~mL} / \mathrm{min}$

\begin{tabular}{lcc}
\hline \multicolumn{1}{c}{ Compound } & \multicolumn{2}{c}{ Retention Time (Minutes) } \\
\cline { 2 - 3 } HBondapak Phenyl & $\mu$ Bondapak CN \\
\hline Benzene & 1.7 & 1.7 \\
Dibenzofuran & 2.2 & 2.1 \\
Benzaldehyde & 5.5 & 3.1 \\
Benzonitrile & 5.8 & 3.8 \\
2-Methyl-1-naphthol & 5.8 & 6.9 \\
o-Cresol & 5.8 & 6.6 \\
2,6-Dimethy1 an11ine & 6.0 & 3.3 \\
Phenol & 6.2 & 7.6 \\
Benzoic acid & 7.3 & 6.8 \\
Quinoline & 8.0 & 6.0 \\
2-Picoline & 8.6 & 5.8 \\
Pyridine & 8.7 & 6.5 \\
2,4-Lutidine & 9.7 & 6.6 \\
\hline
\end{tabular}




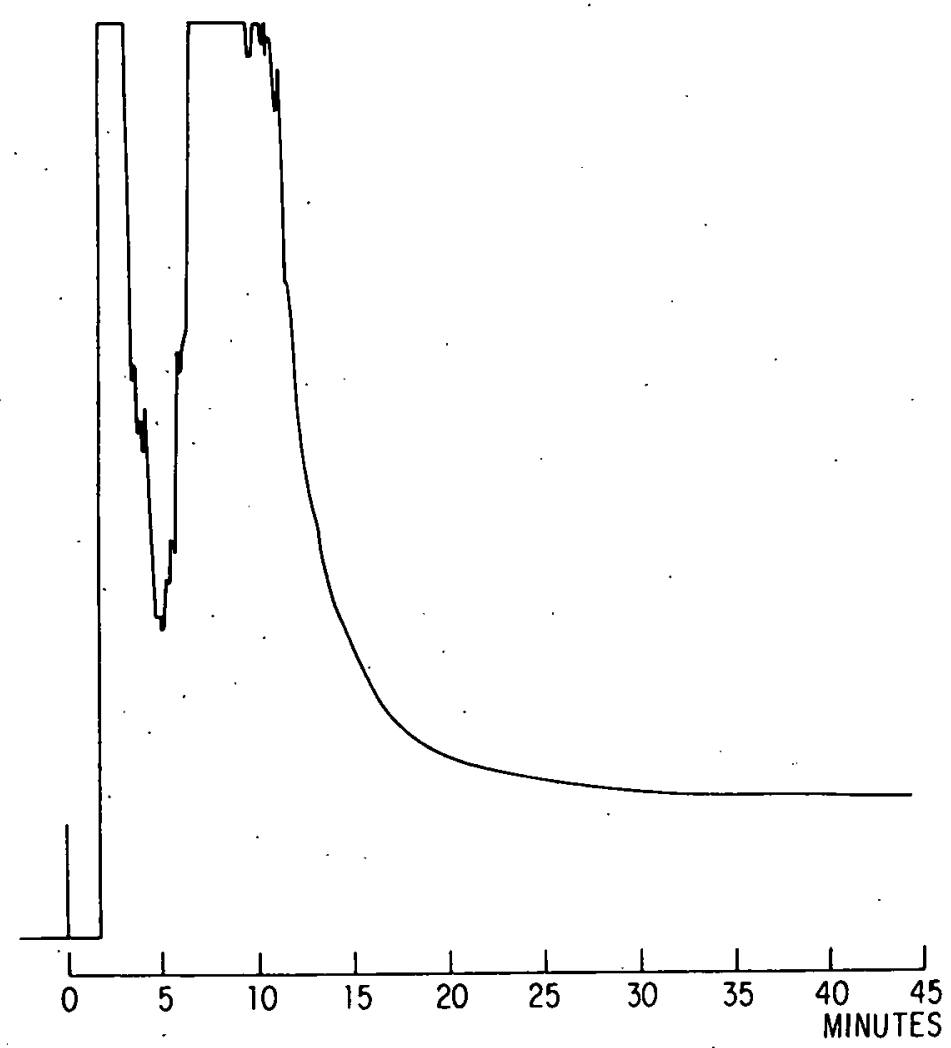

Fig. 1.4

HPLC of $20 \mu \mathrm{L}$ HYGAS Oil Sample, $72 / \mathrm{H} / \mathrm{G} / 0 / 3$, $\mu$ Bondapak $\mathrm{CN}$ Column, $2 \mathrm{~mL} / \mathrm{min} \mathrm{Flow}$, Linear (Curve 6) Gradient, 0-25\% THF in Hexane in $10 \mathrm{~min}$, UV Detection at $254 \mathrm{~nm}$

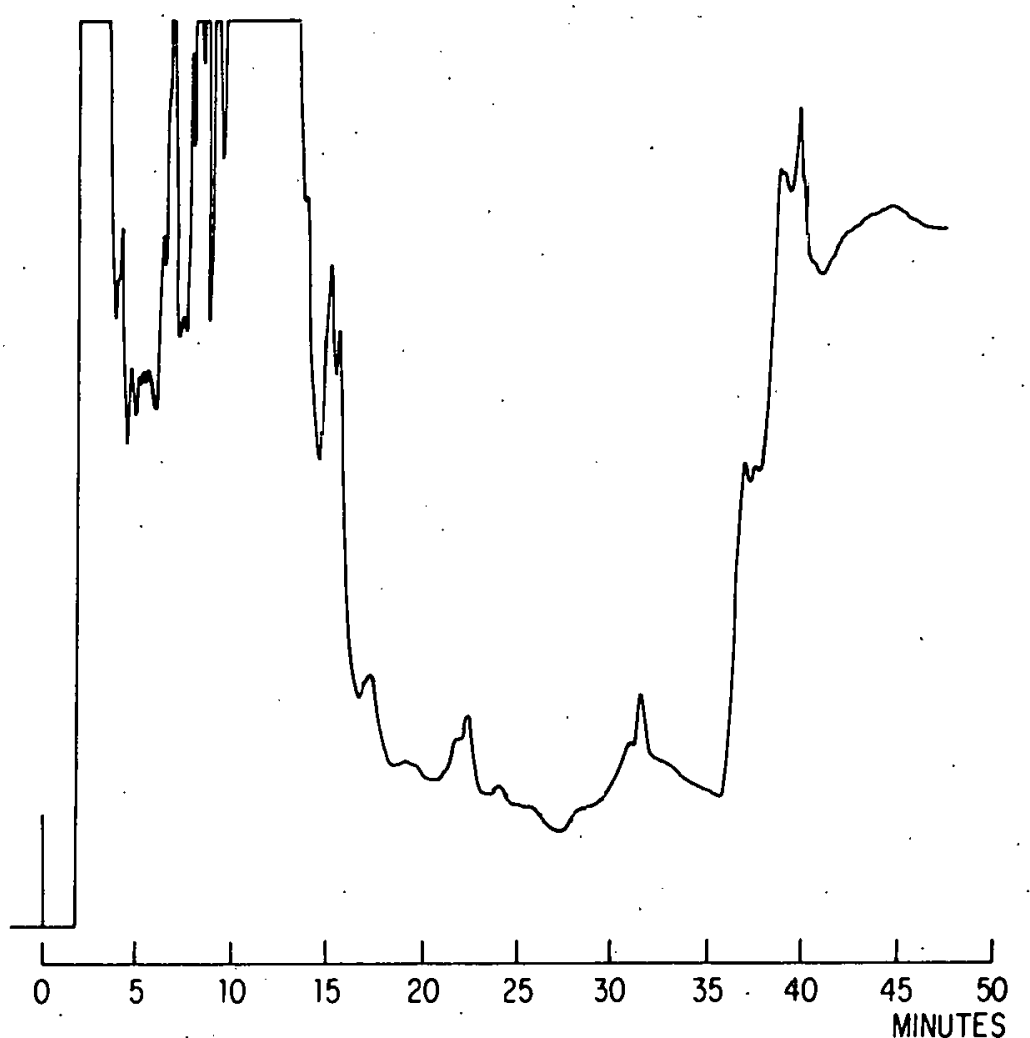

Fig. 1.5

HPLC of $20 \mu \mathrm{L}$ HYGAS $0 i 1$ Sample, 72/H/G/O/3, $\mu$ Bondapak CN Column, $2 \mathrm{~mL} / \mathrm{min}$ Flow, Linear (Curve 6) Gradient, $0-5 \%$ in $20 \mathrm{~min}, 5-10 \%$ in 10 min, $1.0-100 \%$ THF in Hexane in $10 \mathrm{~min}$, UV Detection at $254 \mathrm{~nm}$ 


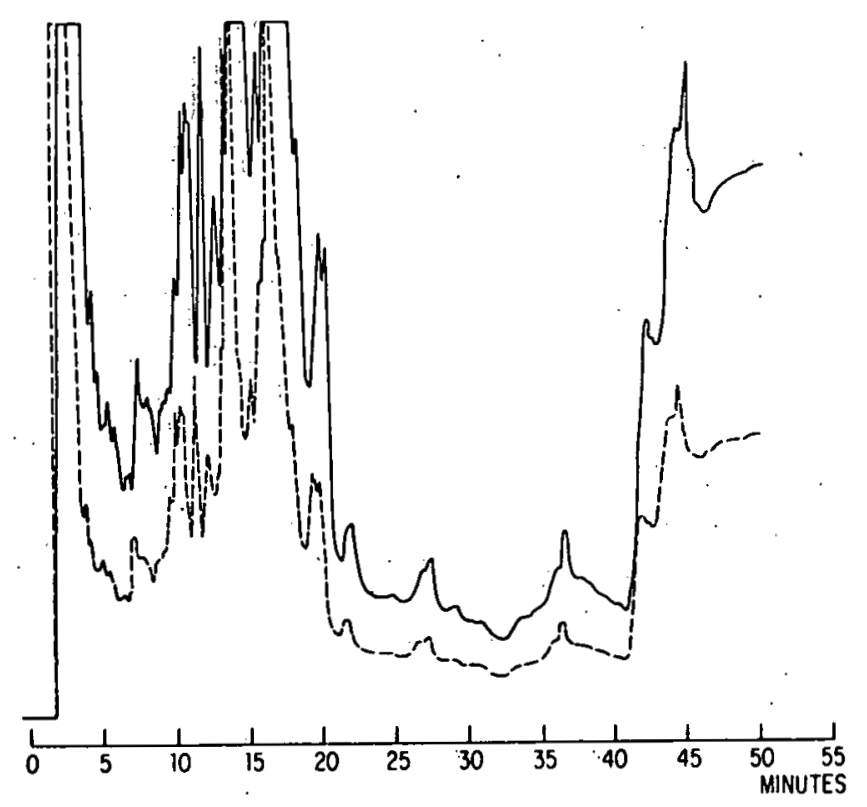

Fig. 1.6

HPLC of $20 \mu \mathrm{L}$ HYGAS Oil Sample, $72 / \mathrm{H} / \mathrm{G} / 0 / 3, \mu$ Bondapak CN Column, $2 \mathrm{~mL} / \mathrm{min}$ Flow, Hexane for $5 \mathrm{~min}$, Linear (Curve 6) Gradient, $0-5 \%$ in $20 \mathrm{~min}, 5-10 \%$ in $10 \mathrm{~min}$, 10-100\% THF in Hexane in $10 \mathrm{~min}$, UV Detection at $254 \mathrm{~nm}$

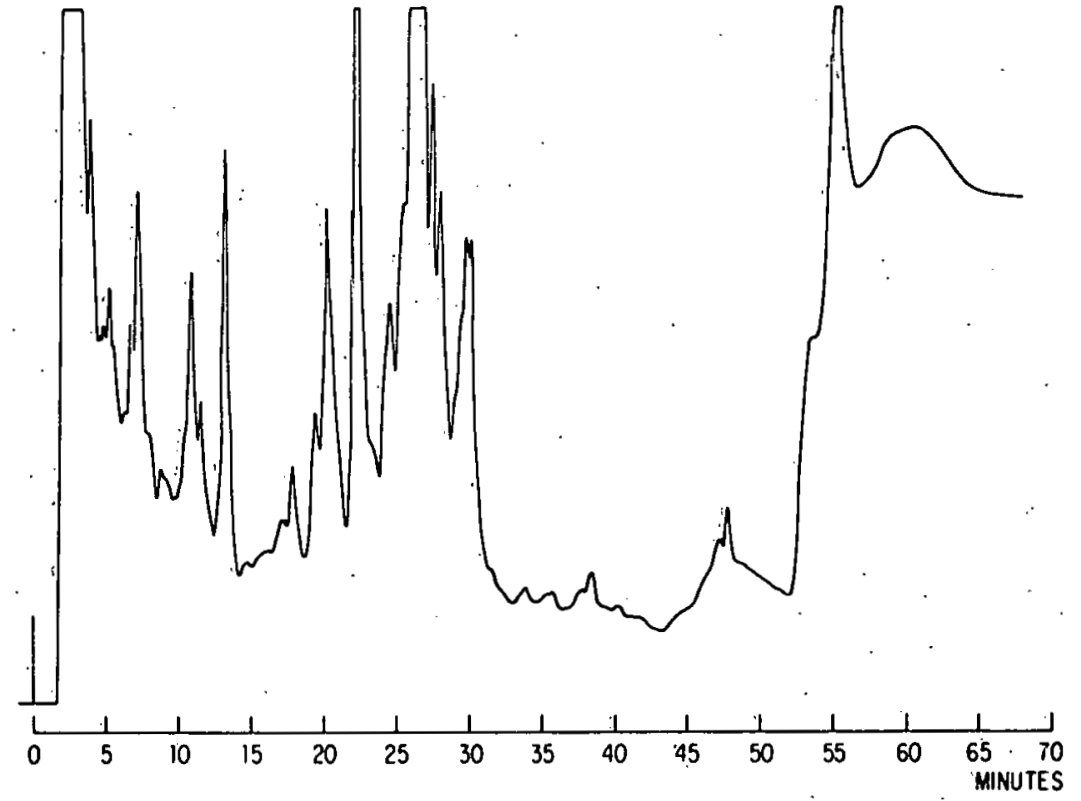

Fig. 1.7

HPLC of $20 \mu \mathrm{L}$ HYGAS 0il Sample, $72 / \mathrm{H} / \mathrm{G} / 0 / 3$, $\mu$ Bondapak CN Column, $2 \mathrm{~mL} / \mathrm{min}$ Flow, Hexane for $16 \mathrm{~min}$, Linear (Curve 6) Gradient, $0-5 \%$ in $20 \mathrm{~min}, 5-10 \%$ in $10 \mathrm{~min}$, $10-100 \% \mathrm{THF}$ in Hexane in $10 \mathrm{~min}$, UV Detection at $254 \mathrm{~nm}$ 
in hexane in $10 \mathrm{~min}$ (Fig. 1.8). Finally, in order to make the very polar compounds elute quickly without affecting the separation of the moderately polar compounds, the following gradient was used: $0 \%$ THF for $16 \mathrm{~min}, 0-1 \%$ THF in hexane in $10 \mathrm{~min}, 1-5 \%$ in $10 \mathrm{~min}$, and $5-100 \%$ THF in hexane in $10 \mathrm{~min}$ (Fig. 1.9); this sequence gives a satisfactory separation of the HYGAS oil sample into fractions. (Under similar conditions, not quite as nice a separation is achieved with a HBondapak Phenyl column; Fig. 1.10.)

The preceding chromatograms were run with $20 \mu \mathrm{L}$ (equivalent to approximately $20 \mathrm{mg}$ ) of HYGAS oil sample injected on the column. Although $20 \mathrm{mg}$ is sufficient sample for carrying out a separation of a HYGAS oil sample into five fractions and for analysis by capillary column GC/MS and/or derivatization and subsequent analysis by capillary column GC/MS of each of the fractions, it appeared worthwhile to determine how much sample could be injected on the $\mu$ Bondapak $\mathrm{CN}$ column before overloading and loss of resolution takes place. Conceivably, with large quantities of sample, the toluene, the major component of the mixture and the first peak in the chromatogram, could be separated provided there was not excessive tailing of the toluene peak and resolution of the more polar compounds was not lost. Initially, a study of toluene itself was done; as can be seen in Table 1.7, the tailing becomes excessive at above $200 \mu \mathrm{L}$. It is possible that the toluene solvent could have an effect on the resolution of the polar compounds because toluene is more polar than the initial elutant, hexane; hence, an investigation of an actual HYGAS oil sample was undertaken. Figures 1.9 and $1.11-1.13$ are chromatograms of $20,50,100$, and $200 \mu \mathrm{L}$ of HYGAS oil sample as injected on-column and Figs. 1.14-1.16 are comparisons of 20 vs $50 \mu \mathrm{L}, 50$ vs 100 , and 100 vs 200, respectively, with the attentuation adjusted so that the chromatograms would be approximately equivalent in intensity. Some loss of resolution is apparent with $200 \mu \mathrm{L}$ injected on the column but little loss of resolution appears with $100 \mu \mathrm{L}$.

To make certain that highly polar compounds will pass through the column, gallic acid was used as a test compound. (Gallic acid is a particularly attractive compound for such a test because besides being polar it also has several sites capable of being adsorbed on the stationary phase.) Since gallic acid is insoluble in non-polar and weakly polar solvents, the test was run with a relatively polar mobile phase. Table 1.8 shows no hold-up with $100 \%$ THF and only a slight holdup with a linear gradient from $40 \%$ to $100 \% \mathrm{THF}$ in hexane in $10 \mathrm{~min}$. Thus, it is expected that even the most polar compounds will elute from the column with approximately $30-40 \% \mathrm{THF}$ in hexane. The retention times of a number of polar compounds run under the same conditions as the HYGAS sample ( $100 \%$ hexane for $16 \mathrm{~min}$, linear gradient to $1 \% \mathrm{THF}$ in hexane in $10 \mathrm{~min}, 1-5 \% \mathrm{THF}$ and $5-100 \% \mathrm{THF}$ in $10 \mathrm{~min}$ ) are shown in Table 1.9.

\subsubsection{Summary and Conclusions}

Based on the results of this study,

1) $\mu$ Bondapak $\mathrm{NH}_{2}$ is an excellent stationary phase for the separation of non-polar or weakly polar compounds into fractions but is not suitable for the separation of more polar compounds. Such a separation can be very useful for identifying a complex mixture 


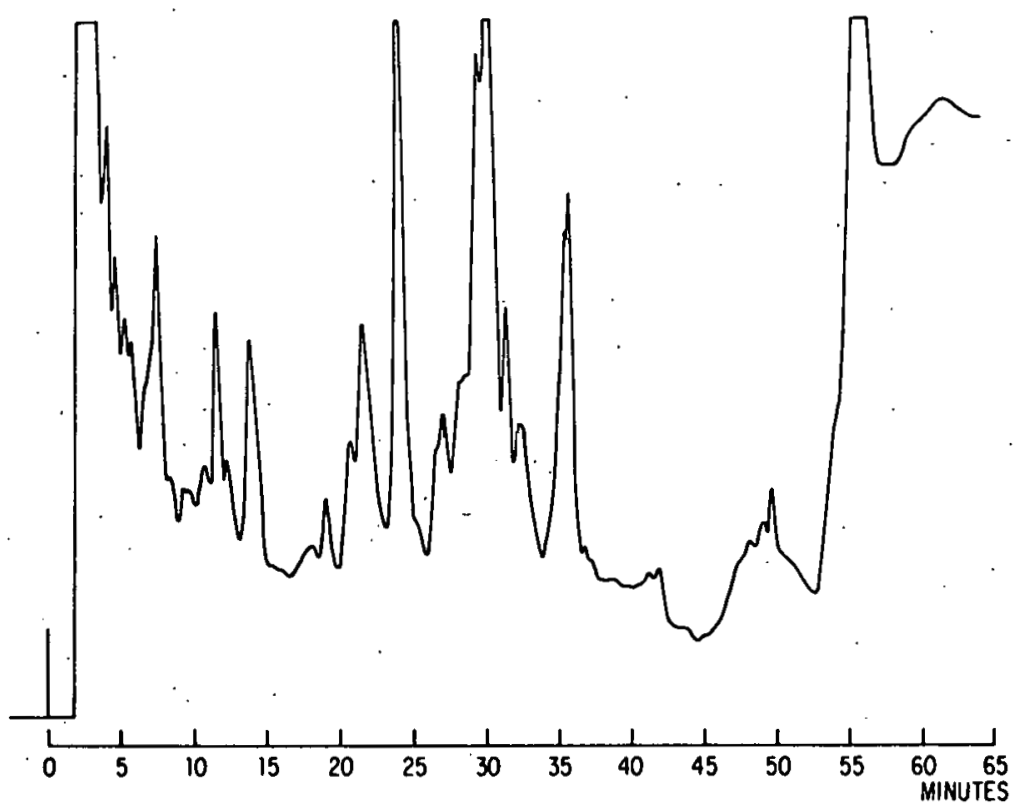

Fig. 1.8

HPLC of $20 \mu \mathrm{L}$ HYGAS Oil Sample, 72/H/G/0/3, $\mu$ Bondapak CN Column, $2 \mathrm{~mL} / \mathrm{min}$ Flow, Hexane for $16 \mathrm{~min}$, Linear (Curve 6) Gradient, 0-1\% in $10 \mathrm{~min}, 1-5 \%$ in $10 \mathrm{~min}, 10-100 \% \mathrm{THF}$ in Hexane in $10 \mathrm{~min}$, UV Detection at $254 \mathrm{~nm}$

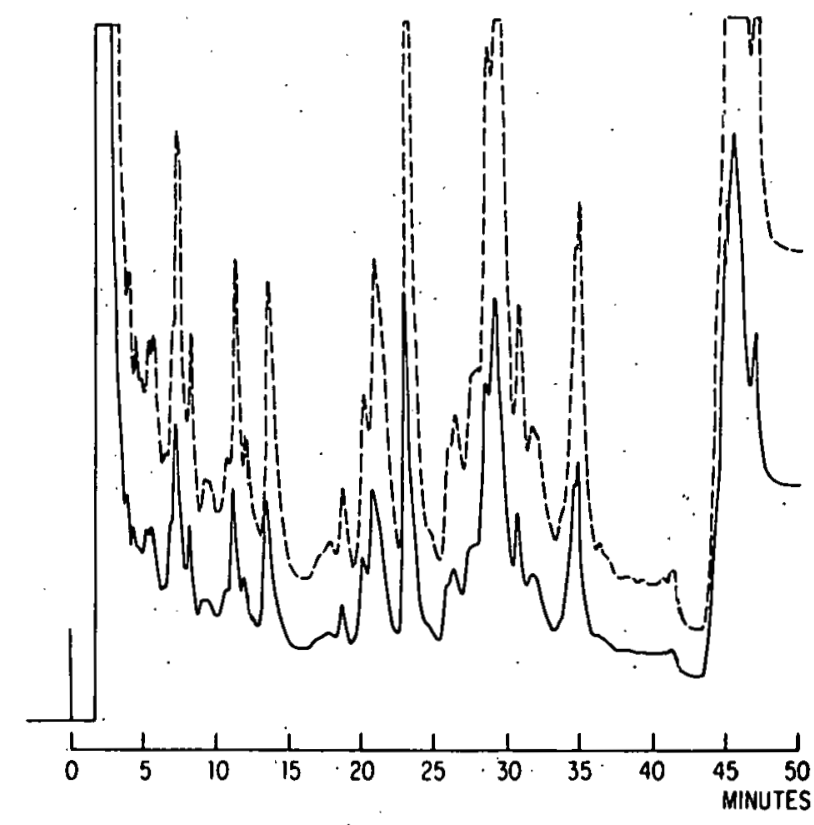

Fig. 1.9

HPLC of $20 \mu \mathrm{L}$ HYGAS 0il Sample, 72/H/G/0/3, $\mu$ Bondapak CN Column, $2 \mathrm{~mL} / \mathrm{min}$ Flow, Hexane for $16 \mathrm{~min}$, Linear (Curve 6) Gradient, 0-1\% in $10 \mathrm{~min}, 1-5 \%$ in $10 \mathrm{~min}, 5-100 \% \mathrm{THF}$ in Hexane in $10 \mathrm{~min}$, UV Detection at $254 \mathrm{~nm}$ 


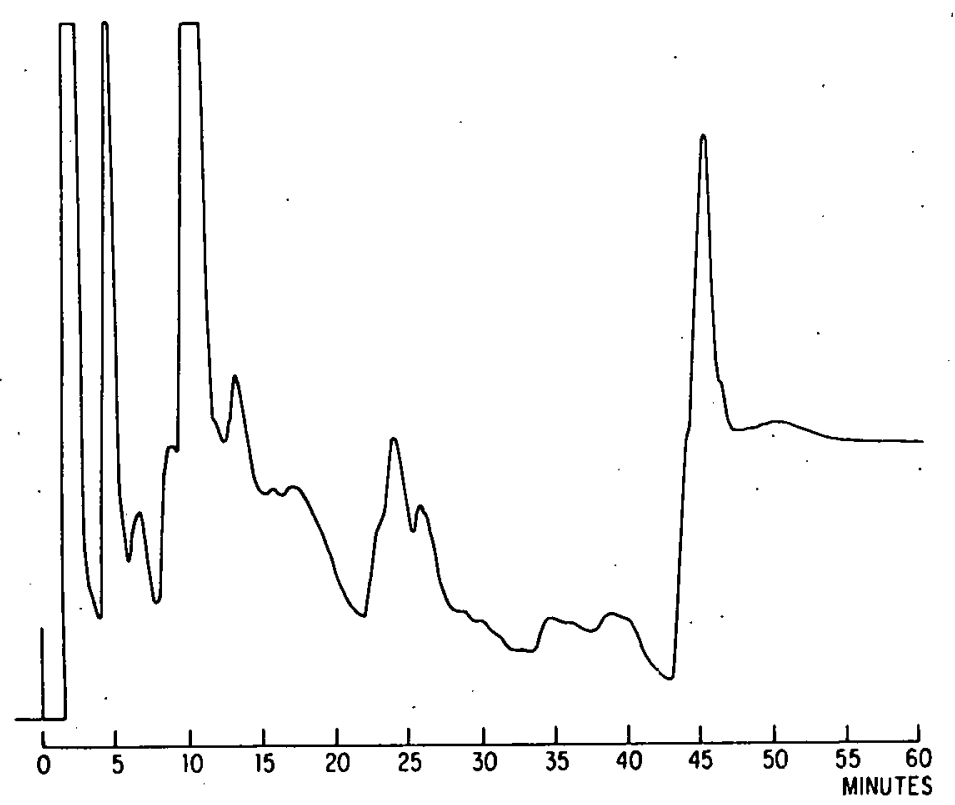

Fig. 1.10

HPLC of $20 \mu \mathrm{L}$ HYGAS Oil Sample, $72 / \mathrm{H} / \mathrm{G} / 0 / 3$, $\mu$ Bondapak Phenyl Column, $2 \mathrm{~mL} / \mathrm{min}$ Flow, Hexane for $16 \mathrm{~min}$, Linear (Curve 6) Gradient, $0-1 \%, 1-5 \%, 5-100 \% \mathrm{THF}$ in Hexane in $10 \mathrm{~min}$, UV Detection at $254 \mathrm{~nm}$

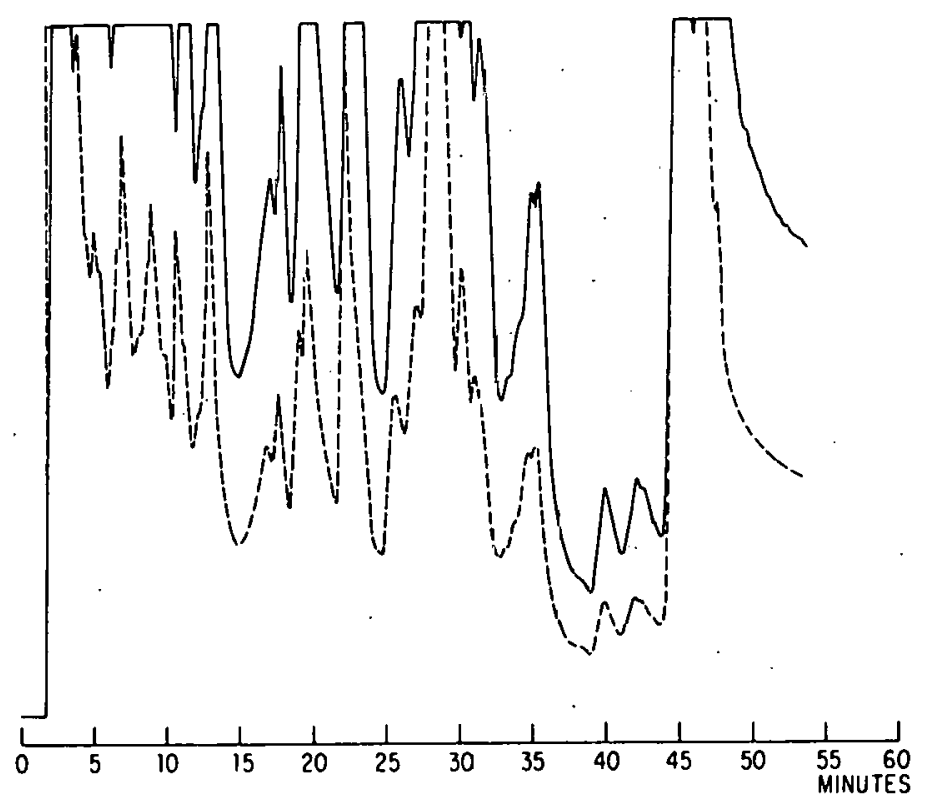

Fig. 1.11

HPLC of $50 \mu \mathrm{L}$ HYGAS 0il Sample, $72 / \mathrm{H} / \mathrm{G} / \mathrm{O} / 3$, uBondapak CN Column, $2 \mathrm{~mL} / \mathrm{min}$ Flow, Hexane for $16 \mathrm{~min}$, Linear (Curve 6) Gradient, 0-1\% $1-5 \%, 5-100 \% \mathrm{THF}$ in Hexane in $10 \mathrm{~min}$, UV Detection at $254 \mathrm{~nm}$ 


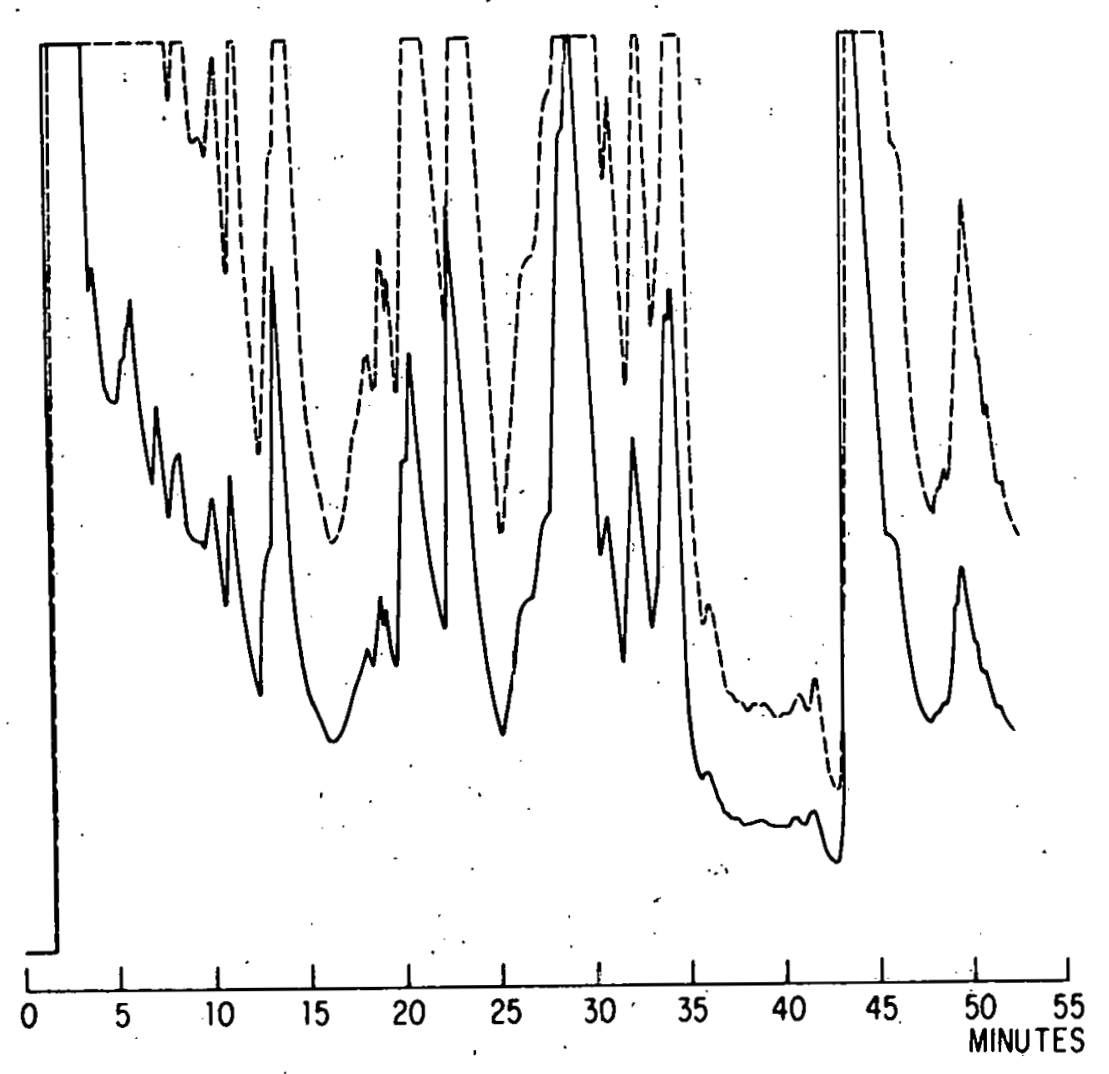

Fig. 1.12

HPLC OF $100 \mu \mathrm{L}$ HYGAS $0 i 1$ Sample, 72/H/G/0/3, uBondapak.CN Column, $2 \mathrm{~mL} / \mathrm{min}$ Flow, Hexane for $16 \mathrm{~min}$, Linear (Curve 6) Gradient, $0-1 \%$ in 10 min, $1-5 \%$ in $10 \mathrm{~min}, 5-100 \% \mathrm{THF}$ in Hexane in 10 min, UV Detection at $254 \mathrm{~nm}$

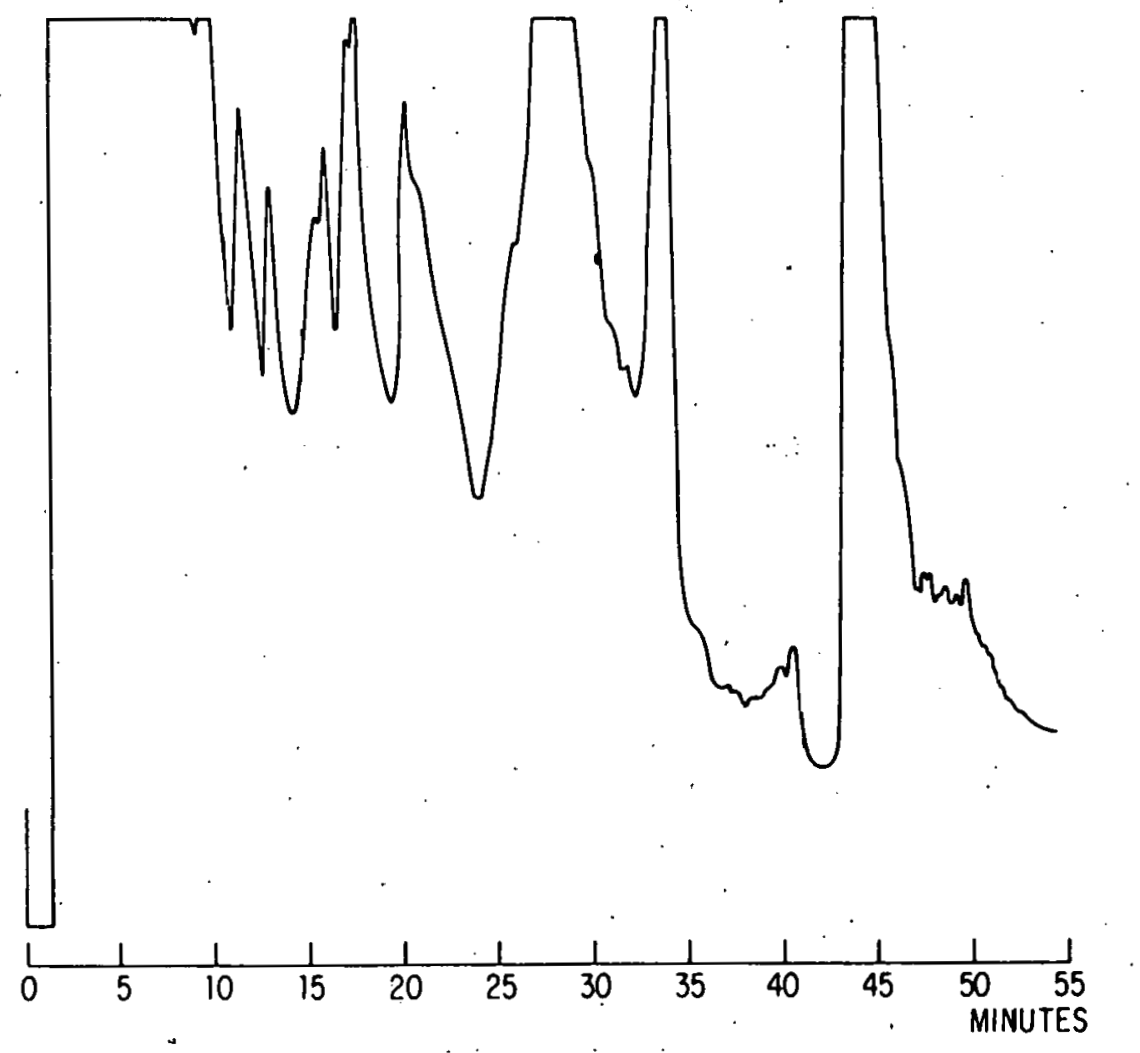

Fig. 1.13

HPLC of $200 \mu \mathrm{L}$ HYGAS 0il Sample, 72/H/G/0/3, $\mu$ Bondapak CN Column, $2 \mathrm{~mL} / \mathrm{min}$ Flow, Hexane for $16 \mathrm{~min}$, Linear (Curve 6) Gradient, $0-1 \%$ in 10 $\min , 1-5 \%$ in $10 \mathrm{~min}, 5-100 \% \mathrm{THF}$ in Hexane in $10 \mathrm{~min}$, UV Detection at $254 \mathrm{~nm}$ 


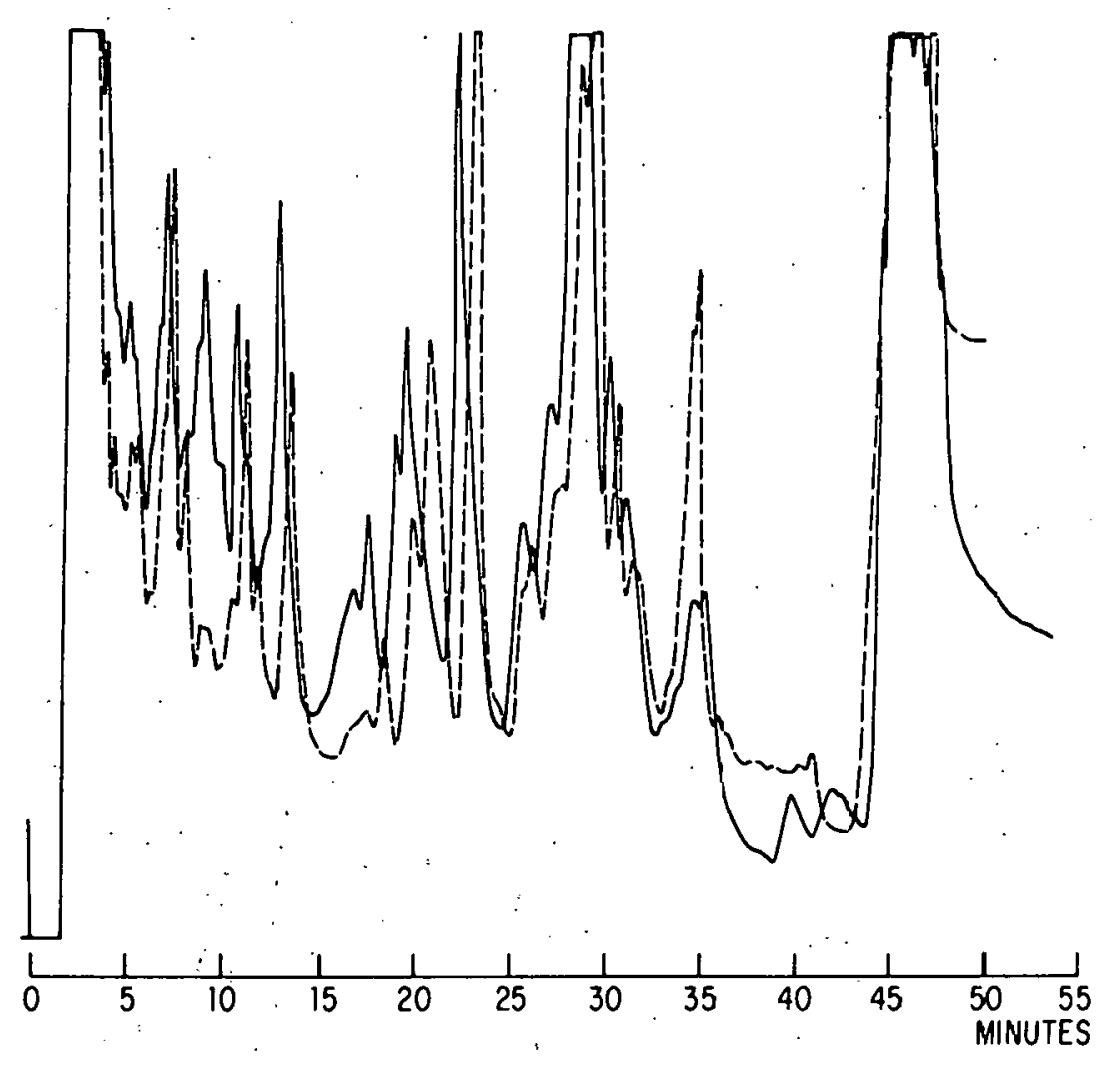

Fig. 1.14

Comparison of HPLC Chromatograms of $20 \mu \mathrm{L}$ (Dashed) and $50 \mu \mathrm{L}$ (Solid) HYGAS Oil Sample, 72/H/G/0/3, $\mu$ Bondapak $\mathrm{CN}$ Column, $2 \mathrm{~mL} / \mathrm{min}$ Flow, Hexane for 16 min, Linear. (Curve 6) Gradient, Hexane to $1 \% \mathrm{THF}$ in Hexane in $10 \mathrm{~min}, 0-1 \%, 1-5 \%, 5-100 \% \mathrm{THF}$ in Hexane in $10 \mathrm{~min}$, UV Detection at $254 \mathrm{~nm}$, Curves offset

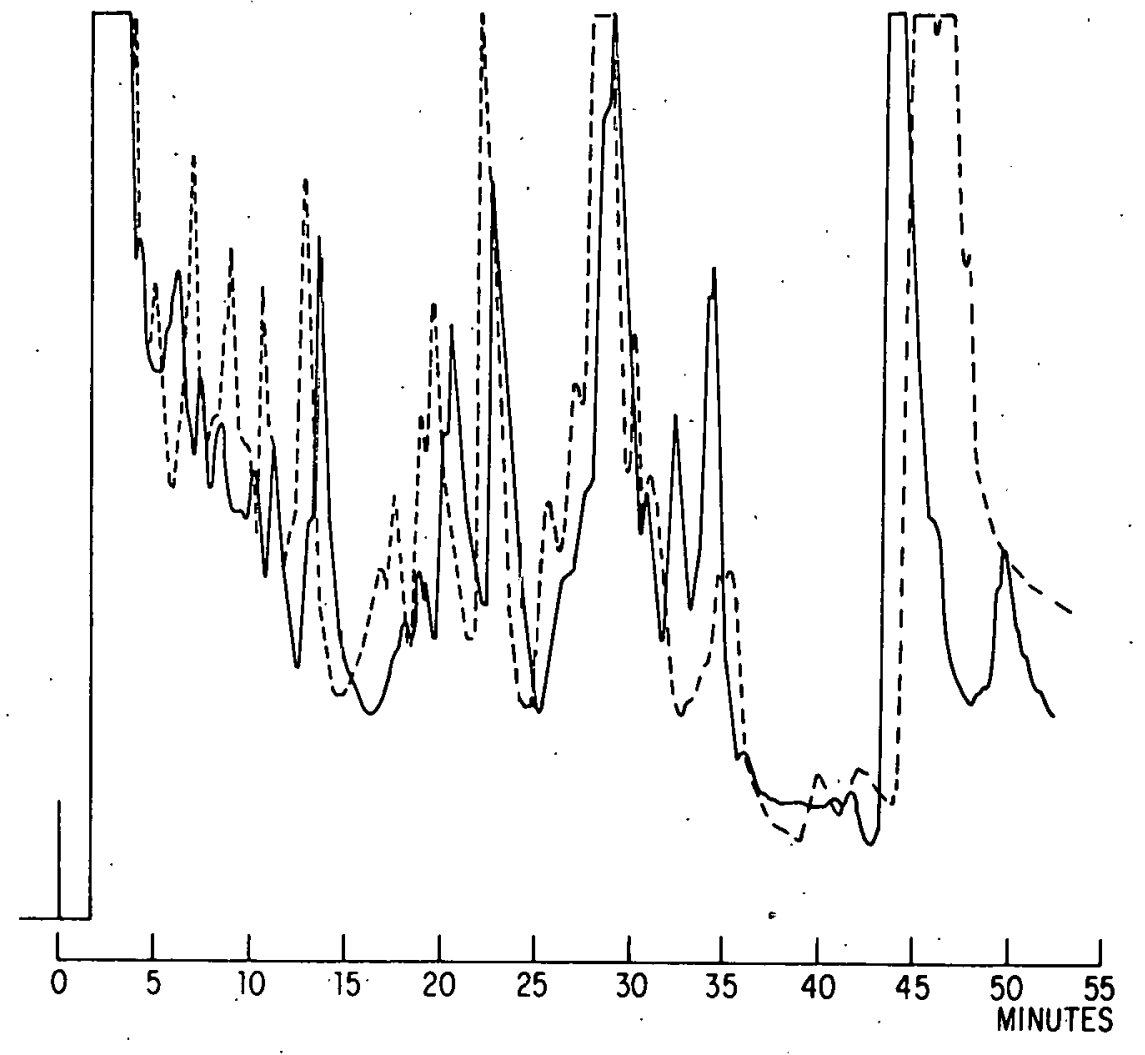

Fig. 1.15

Comparison of HPLC Chromatograms of $50 \mu \mathrm{L}$ (Dashed) and $100 \mu \mathrm{L}$ (Solid) HYGAS Oil Sample, 72/H/G/0/3, $\mu$ Bondapak CN Column, $2 \mathrm{~mL} / \mathrm{min}$ Flow, Hexane for $16 \mathrm{~min}$, Linear (Curve 6) Gradient, $0-1 \%, 1-5 \%$, $5-100 \% \mathrm{THF}$ in Hexane in $10 \mathrm{~min}$, UV Detection at $254 \mathrm{~nm}$, Curves of fset 


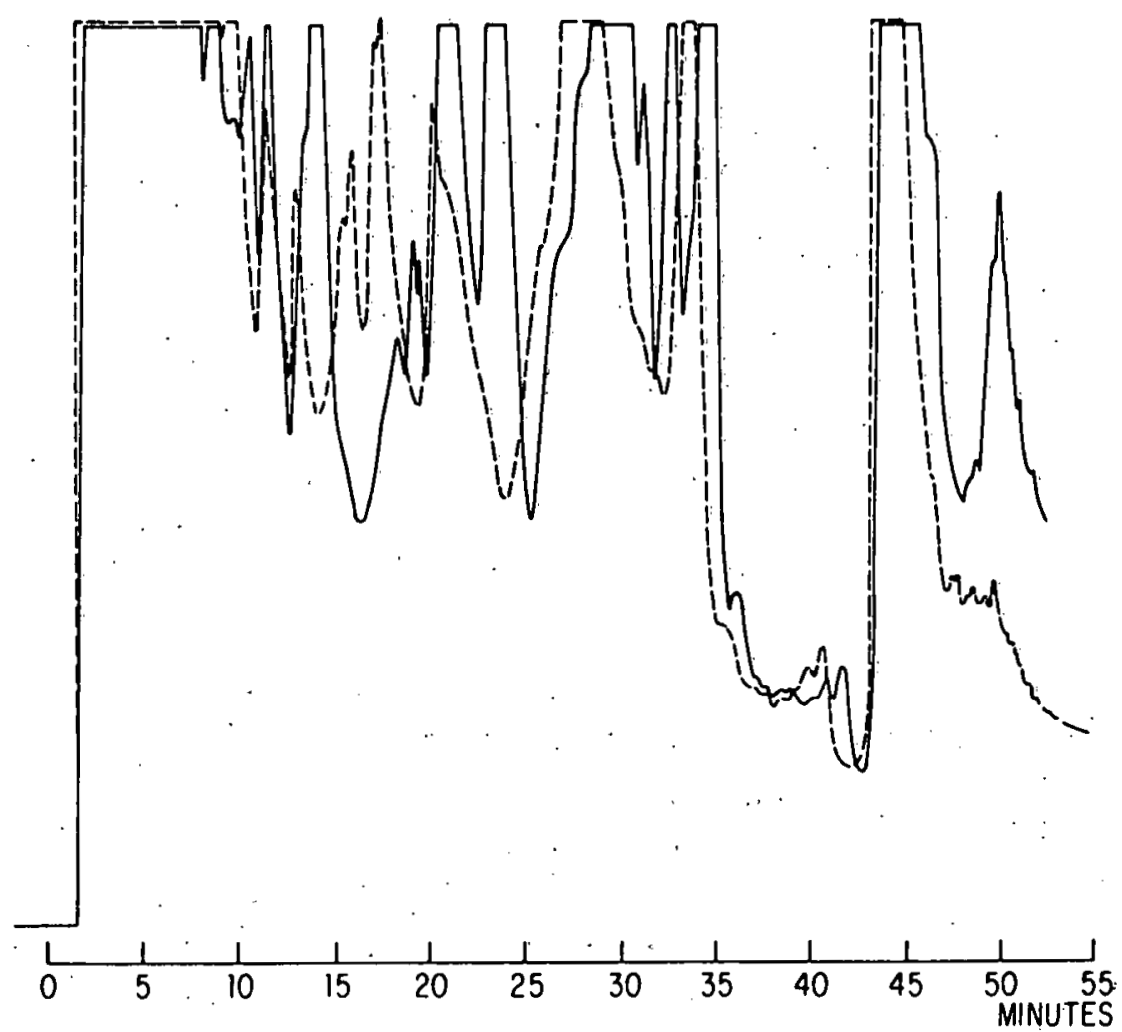

Fig. 1.16. Comparison of HPLC Chromatograms of $100 \mu \mathrm{L}$ (Solid) and $200 \mu \mathrm{L}$. (Dạshed) HYGAS 0il Sample, $72 / \mathrm{H} / \mathrm{G} / \mathrm{O} / 3$, $\mu$ Bondapak CN Column, $2 \mathrm{~mL} / \mathrm{min}$ Flow, Hexane for $16 \mathrm{~min}$, Linear (Curve 6) Gradient. $0-1 \%$ in $10 \mathrm{~min}, 1-5 \%$ in $10 \mathrm{~min}, 5-100 \% \mathrm{THF}$ in Hexane in $10 \mathrm{~min}$, UV Detection at $254 \mathrm{~nm}$, Curves offset

Table 1.7. Measurement of Talling Characteristics of Toluene as a Function of Peak Height and Time

\begin{tabular}{|c|c|c|c|c|}
\hline \multirow{2}{*}{$\begin{array}{l}\text { Amount of } \\
\text { Toluene } \\
\text { Injected }(\mu \mathrm{L})\end{array}$} & \multicolumn{4}{|c|}{ Time (min) } \\
\hline & $\begin{array}{l}\text { Start } \\
\text { of Peak }\end{array}$ & $\begin{array}{l}\text { Downside } \\
0.25 \mathrm{AU}\end{array}$ & $\begin{array}{l}\text { Downside } \\
0.10 \mathrm{AU}\end{array}$ & $\begin{array}{l}\text { Downside } \\
0.010 \mathrm{AU}\end{array}$ \\
\hline 2 & 1.7 & 2.2 & -- & 2.7 \\
\hline 20 & 1.7 & 2.4 & - & 4.7 \\
\hline 100 & 1.7 & 3.2 & - & $\mathrm{NM}$ \\
\hline 200 & 1.6 & 3.6 & -- & 5.4 \\
\hline 1000 & 1.6 & 5.0 & 6.5 & $\mathrm{~T}$ \\
\hline
\end{tabular}

NM Not measured

T Tailing 
Table 1.8. Measurement of Ability of Gailic Acid, a Very Polar Compound with Several Adsorptive Sites, to Pass Through a $\mu$ Bondapak CN Column Programmed with a Linear 10-min Gradient of Varying Initial Concentrations of THF in Hexane to $100 \%$ THF

\begin{tabular}{cc}
$\begin{array}{c}\text { Gradient } \\
\text { Start Concentration } \\
\text { (Percent THF in Hexane) }\end{array}$ & $\begin{array}{c}\text { Time (min) } \\
\text { (Start of Peak) }\end{array}$ \\
\hline $100 \%^{\mathrm{a}}$ & $1.7^{\mathrm{b}}$ \\
$40 \%$ & 2.3 \\
$30 \%$ & 2.5 \\
$20 \%$ & 5.1 \\
\hline
\end{tabular}

a

${ }^{b}$ No holdup since it takes $1.7 \mathrm{~min}$ for a sample that is not adsorbed by the stationary phase to reach the detector

Table 1.9. Retention Times of Non-Polar and Polar Compounds on $\mu$ Bondapak $\mathrm{CN}$ (see Gradient Program below)

\begin{tabular}{lc}
\hline \multicolumn{1}{c}{ Compound } & Time (min) \\
\hline anthracene-d 10 & 2.5 \\
2,6-dimethyl aniline & 3.7 \\
aniline-d 5 & 5.3 \\
pyridine & 6.2 \\
2,4-lutidine & 9.0 \\
quinoline & 9.1 \\
benzyl alcohol & 10.0 \\
2,6-xylenol & 10.7 \\
phenol & 21.3 \\
1-naphthol & 25.7 \\
1-naphthalene acetic acid & 33.2 \\
benzyl amine & 45.5 \\
\hline
\end{tabular}

Gradient Program: $100 \%$ hexane for $16 \mathrm{~min}$, linear gradient to $1 \%$ THF in hexane in $10 \mathrm{~min}$, $1 \%$ to $5 \%$ THF in $10 \mathrm{~min}$, and $5 \%$ to $100 \%$ THF in hexane in $10 \mathrm{~min}$ 
that contains predominantly relatively non-polar compounds, since GC conditions can be tailor-made to each fraction. It would be particularly useful for identifying the higher PNAs.

2) $\mu$ Bondapak $\mathrm{CN}$, used with the proper gradient program, is a satisfactory stationary phase for the general separation of HYGAS oil samples into a non-polar or weakly polar fraction, which contains the major component, toluene, and at least five other fractions varying in polarity from slightly polar to highly polar. «Bondapak CN appears to be slightly better than $\mu$ Bondapak Phenyl in this separation.

Thus, the recommended method for a general separation of HYGAS oil samples into fractions is as follows:

1) Inject up to $100 \mu \mathrm{L}$ of the HYGAS oil samples onto a Waters . $\mu$ Bondapak $\mathrm{CN}$ column $(3.9 \mathrm{~mm}$ ID $\times 30 \mathrm{~cm})$ with a flow rate of $2 \mathrm{~mL} / \mathrm{min}$.

2) Run the following linear gradlent:
a) $0-16 \mathrm{~min}, 100 \%$ hexane,
b) $16-26 \mathrm{~min}, 0 \%$ to $1 \% \mathrm{THF}$ in hexane,
c) $26-36 \mathrm{~min}, 1 \%$ to $5 \% \mathrm{THF}$ in hexane,
d) $36-46 \mathrm{~min}, 5 \%$ to $100 \% \mathrm{THF}$ in hexane, and
e) beyond $46 \mathrm{~min}, 100 \% \mathrm{THF}$.

With this gradient program, very polar.compounds such as gallic acid will elute from the column.

For, a separation of the non-polar or weakly polar compounds of a HYGAS oil sample into fractions, the recommended method is as follows:

1. Inject sample into a Waters $\mu$ Bondapak $\mathrm{NH}_{2}$ column $(3.9 \mathrm{~mm}$ ID $\times$ $30 \mathrm{~cm}$ ) and flow program from 1 to $4 \mathrm{~mL} / \mathrm{min}$ with curve 10 , an exponential-type curve.

2. Backwash after approximately 25 min to remove the polar compounds. 


\subsection{INTRODUCTION}

\subsubsection{Objective}

The objective of this part of the study was to determine which derivatizing agents are suitable for derivatizing the polar compounds typically found in HYGAS samples to make the compounds more amenable to identification by $\mathrm{GC} / \mathrm{MS}$.

\subsubsection{Background}

In preliminary analyses by GC/MS, it was found that HYGAS oil samples contain a variety of compounds, including toluene, the start-up and make-up oil, aromatic hydrocarbons, phenols, anilines, pyridines, thiophenes, benzonitriles, and PNAs. Direct analysis of the mixture by GC/MS is at best difficult for at least two reasons: (1) due to the large number (probably over 400) of compounds present in the mixture, many overlapping peaks occur, resulting in mass spectra that are often confusing; (2) capillary columns that give good separation of non-polar compounds are not adequate for the separation of polar compounds.

In Part I of this report, a HPLC method was developed in which complex mixtures of HYGAS oil samples could be separated into a number of fractions. However, many polar compounds in these fractions, such as phenols, anilines, and carboxylic acids are either not chromatographable by GC or give excessively broad peaks, frequently with excessive tailings as well. Therefore, in the past, identification of HYGAS, petroleum, and environmental samples has of ten been limited to the non-polar compounds, such as aliphatic and aromatic hydrocarbons, PNAs, thiophenes, and benzonitriles, and the polar compounds have been neglected.

Derivatization of the polar compounds appeared to be the simplest and most direct approach to making the'polar compounds more amenable to identification by GC/MS. Of the numerous methods available for derivatizing polar compounds, only two, silylation and alkylation, were investigated in this study. Many silylating agents are available commercially (Pierce Chemical Co., Rockford, IL 61105). Some of these are:

For trimethylsilyl derivatives, trimethylchlorosilane, hexamethyldisilazane, N,O-bis(trimethylsilyl) acetamide (BSA), trimethylsilylimidazole, and trimethylsilyldiethylamine;

For dimethylsilyl derivatives, dimethylchlorosilane, tetramethyldisilazane, N,0-bis (dimethylsilyl) acetamide, and

For chloromethyldimethylsilyl derivatives suitable for electron capture detectors, chloromethyldimethylchlorosilane. 
of these silylating agents, N,O-bis(trimethylsilyl) acetamide (BSA) and Tri-Sil Concentrate, a 2:1 mixture of hexamethyldisilazane and trimethy1chlorosilane, were chosen for study in this investigation on the basis of their high reactivity and wide range of reactivity. of the various alkylating agents commercially available, only dimethylformamide dimethyl acetal (Methyl-8 Concentrate) was studied in this investigation.

\subsubsection{Derivatiation Method Development}

It was anticipated that the fractions obtained from an HPLC run on a HYGAS oil sample could be evaporated under nitrogen to dryness. Each of these fractions could then be taken up in $50 \mu \mathrm{L}$ of methylene chloride to which the derivatizing agent could be added. Alternatively, the fraction could be taken up in pyridine, which is known to be a good solvent for silylation. Thus, the procedure tested was to take the residue up in $50 \mu \mathrm{L}$ of methylene chloride or pyridine, add $50 \mu \mathrm{L}$ of the derivatizing agent, heat to $50-60^{\circ} \mathrm{C}$ for $5-10 \mathrm{~min}$, and inject $3 \mu \mathrm{L}$ into the $\mathrm{GC}$. A second run was done in each case $20 \mathrm{hr}$ later to determine if further derivatization had taken place. This procedure was used on 10 standards: three phenolic compounds, pheno1, 2,4-xylenol, and 1-naphthol, three carboxylic acids, benzoic acid, phenoxyacetic acid, and 1-naphthalene acetic acid, three amines, aniline-d 5 , 2,6-dimethyl aniline, and benzyl amine, and 1 alcohol, benzyl alcohol. (2,4-Xylenol, 2,6-dimethyl aniline, and, to a lesser extent, 1-naphthol have hindered reactive sites and are, therefore, excellent standards for testing the reactivity of the derivatizing agents.) The total ion count and a specific ion count associated with each of the derivatized standards was inspected to determine whether identification of the derivatized standard could be made. As a rule, when the total ion count of a peak falls below 3000 counts, identification of a compound becomes difficult.)

The various procedures were tested at $100 \mathrm{ng} / \mu \mathrm{L}$ concentration per standard (50 $\mathrm{ng} / \mu \mathrm{L}$ in the derivatized solution and $150 \mathrm{ng} / \mu \mathrm{L}$ on-column based on a $3 \mu \mathrm{L}$ injection). Procedures that appeared to be the most promising were then tested at 50,20 , and $10 \mathrm{ng} / \mu \mathrm{L}$ per standard in order to determine the lower limit of detection for each of the 10 standards.

No attempt was made to determine the actual yield of derivative for each standard.

\subsection{EXPERIMENTAL PROCEDURES}

\subsubsection{Standard Solutions}

Ten polar compounds were chosen for investigating the derivatization procedures. These compounds were obtained from the following sources (Table 2.1): 
Table 2.1. Sources of Standards

\begin{tabular}{|c|c|c|c|}
\hline Compound & Company & Specification & $\begin{array}{l}\text { Catalog } \\
\text { or Kit No. }\end{array}$ \\
\hline Phenol & Polyscience & Qual & 170BX \\
\hline 2,4-Xylenol & Polyscience & Qual & $170 \mathrm{BX}$ \\
\hline 1-Naphthol & Aldrich & $99+\%$ & N199-2 \\
\hline Benzoic acid & Aldrich & $\dot{y} \dot{y} \%$ & $10,947-9$ \\
\hline Phenoxyacetic acid & Aldrich & $98+\%$ & $15,851-8$ \\
\hline 1-Naphthalene acetic acid & Aldrich & $.99 \%$ & N380-4 \\
\hline Aniline-2, $3,4,5,6-\mathrm{d}_{5}$ & Aldrich & $99+$ atom $\%$ & $17,569-2$ \\
\hline 2,6-Dimethylaniline & Eastman & -- & 1736 \\
\hline Benzyl amine & Aldrich & $99 \%$ & $18,570-1$ \\
\hline Benzyl alcohol & Aldrich & $99+\%$ & $\mathrm{BI}, 620-8$ \\
\hline
\end{tabular}

Polyscience Corp., 8366 Gross Point Road, Niles, IL 60648

Aldrich Chemical Co., 940 West Saint Paul Avenue, Milwaukee, WI 53233

Eastman Kodak Co., Rochester, N.Y. 14650

The standard solution was prepared as follows: $0.20 \mathrm{~g}$ of each of the phenolic compounds and carboxylic acids was placed in a 100-mL volumetric flask and methylene chloride (Burdick \& Jackson Laboratories Inc., Muskegon, MI 49442, Pesticide Quality) was added to give $100 \mathrm{~mL}$ of a $2 \mathrm{mg} / \mathrm{mL} /$ compound solution, which was diluted several times to give a $200 \mathrm{ng} / \mu \mathrm{L} /$ compound solution. Similarly, a $200 \mathrm{ng} / \mu \mathrm{L} /$ compound solution was prepared of the amines and benzyl alcohol. The two solutions were combined to give a $100 \mathrm{ng} / \mu \mathrm{L} /$ compound solution from which 50,20 , and $10 \mathrm{ng} / \mu \mathrm{L} /$ compound solutions were prepared.

\subsubsection{Derivatization of Standard Solutions}

With Methylene Chloride as Solvent. To $50 \mu \mathrm{L}$ of the standard solution, $50 \mu \mathrm{L}$ of the derivatizing agent (Tri-Sil Concentrate No. 49005, BSA No. 38837, or Methy1-8 Concentrate No. 49355, products of the Pierce Chemical Co., P.0. Box 117, Rockford, IL 61105) was added in a vial, No. 5080-8712, obtained from the Hewlett-Packard, Route 41, Avondale, PA 19311. The vial was sealed with a cap, shaken for one minute, heated at $50-60^{\circ} \mathrm{C}$ for $5-10$ minutes, and cooled to room temperature. 
With Pyridine as Solvent. The standard solution (50 $\mu \mathrm{L})$ was added to a vial and a stream of nitrogen was allowed to pass over the solution until all the methylene chloride had evaporated. Silylation grade pyridine, $50 \mu \mathrm{L}$, (No. 27530, Pierce Chemical Co.) was added to the vial along with $50 \mu \mathrm{L}$ of the derivatizing agent. The vial was sealed with a cap, shaken for one minute, heated at $50-60^{\circ} \mathrm{C}$ for $5-10 \mathrm{~min}$, and cooled to room temperature.

\subsubsection{GC/MS of Derivatized Standard Solutions}

Analyses of the derivatized standard solutions were performed on a Hewlett-Packard GC/MS equipped with a $50 \mathrm{~m}$, OV-101 capillary column (No. 0097980, Perkin-E1mer Corp., Norwalk, CT 06856). The GC/MS was a 5982A modified with a $5830 \mathrm{GC}$ upgraded to a $5840 \mathrm{GC}$. The GC was equipped with a modified Hewlett-Packard split/splitless Grob-type injection system and splitless injection with $3 \mu \mathrm{L}$ was used in the study. Temperature programming of $20-240^{\circ} \mathrm{C}$ at $2^{\circ} /$ minute with 2 min hold at $20^{\circ} \mathrm{C}$ was employed. For pyridine solutions, the start temperature was $80^{\circ} \mathrm{C}$. Mass spectra of each of the derivatives along with the retention time are shown in Appendix $B$. The data system was an HP 5934 consisting of a 21MX Computer, 5948A Data Subsystem (A/D and D/A Converters), 7900 Dual Disc Drive, and a Tektronix 4012 Display Terminal. Peripheral equipment included a Tektronix 4631 Hard Copy Unit and a Zeta 130-10 Incremental Plotter.

The parameters used for scanning were as follows: run time, 120 minutes; mass range, 40-400 AMU; A/D conversions, 1; thresholds, 5, 5; and mass offset, -0.2 .

\subsection{RESULTS AND DISCUSSION}

\subsubsection{Determination of the Best Procedure for Derivatization}

In order to determine the best procedure for derivatization, a solution was prepared containing 10 standards at $100 \mathrm{ng} / \mu \mathrm{L}$ each. It consisted of three phenolic compounds, pheno1, 2,4-xylenol, and 1-naphthol, three carboxylic acids, benzoic acid, phenoxyacetic acid, and 1-naphthalene acetic acid, three amines, aniline-d $d_{5}, 2,6$-dimethyl aniline, and benzyl amine, and one alcohol, benzyl alcohol. (2,4-Xylenol and 2,6-dimethyl aniline with a highly hindered reactive hydroxy and amine and 1-naphthol with a slightly hindered reactive hydroxy were chosen because they would be expected to be difficult to derivatize.) The derivatizing agent, Tri-Sil Concentrate, BSA, or Methyl-8 Concentrate $(50 \mu \mathrm{L})$, was added to $50 \mu \mathrm{L}$ of each of the standards that were dissolved in either methylene chloride or pyridine. The mixture was heated to $50-60^{\circ} \mathrm{C}$ for 10 minutes and then analyzed by capillary column GC/MS immediately and $20 \mathrm{hr}$ later. The following runs were made:

1. Tri-Sil Concentrate/methylene chloride at $0.5 \mathrm{hr}$

2. Tri-Sil Concentrate/methylene chloride at $20 \mathrm{hr}$

3. Tri-Sil Concentrate/pyridine at $0.5 \mathrm{hr}$

4. BSA/methylene chloride at $0.5 \mathrm{hr}$

5. BSA/methylene chloride at $20 \mathrm{hr}$

6. BSA/pyridine at $0.5 \mathrm{hr}$ 
7. Methy1-8 Concentrate/methylene chloride at $0.5 \mathrm{hr}$

8. Methyl-8 Concentrate/methylene chloride at $20 \mathrm{hr}$

(Runs of Tri-Sil Concentrate/pyridine and BSA/pyridine at $20 \mathrm{hr}$ were not made because results from the 0.5-hr runs were not as good as the corresponding runs for Tri-Sil Concentrate/methylene chloride and BSA/methylene chloride.) The total ion count and selected ion count for these eight runs of each of the 10 standards can be found in Tables 2.2 and 2.3 , respectively.

As shown in the tables, Tri-Sil Concentrate does effectively derivatize the phenolic compounds and benzyl alcohol but is ineffective in derivatizing the carboxylic acids or amines. BSA is effective in derivatizing the phenolic compounds, the amines, and benzyl alcohol but is ineffective in derivatizing the carboxylic acids. Methyl-8 Concentrate is effective in derivatizing the carboxylic acids and amines but gives only poor results with the phenolic compounds and apparently gives a non-chromatographable product with benzyl alcohol. However, with amines, the products were $\mathrm{N}, \mathrm{N}$-dimethyl formamidines rather than the expected methylated derivatives. These derivatives were easily identifiable by mass spectrometry and had very low limits of detection. It can also be seen that there is no distinct advantage in allowing the derivatized solution to stand at room temperature overnight. Relative ratings of these derivatization procedures for the four types of compounds are shown in Table 2.4 .

\subsubsection{Determination of Lower Limit of Detection}

From the results in the preceding tables, it appears that two procedures for derivatization are required because the silylating agents do not derivatize carboxylic acids (at least, at these low concentrations) and Methy1-8 Concentrate is not useful for phenolic compounds or alcohols. It was decided therefore to investigate BSA/methylene chloride and Methy1-8 Concentrate further. Thus, runs in methylene chloride were made with the 10 standards at concentration levels of $100,50,20$ and $10 \mathrm{ng} / \mu \mathrm{L}$ per standard spectra could be obtained. The total ion and selected ion counts for these experiments are shown in Table 2.5. From these results and by inspection of the mass spectra of the derivatized standards, estimated detection limits were determined as shown in Table 2.6. It can be seen that BSA is useful as a derivatizing agent for phenols and alcohols and Methyl-8 Concentrate for carboxylic acids and amines. Moreover, neither derivatizing agent by itself is acceptable for the whole range of polar standards.

With the use of derivatization, one has to ascertain whether a specific compound was or was not actually in the mixture before derivatization. In the case of silylation, no ambiguity exists, since trimethylsilyl compounds do not occur naturally. With the use of Methyl-8 Concentrate, however, the $\mathrm{N}, \mathrm{N}$-dimethyl formamidines do not pose a problem, but the methyl esters formed from the carboxylic acids can do so. In such cases, Tri-Deuter-8, the deuterated analog of. Methy1-8 Concentrate, can be used.

The methods described herein can be said to be fairly foolproof, easyto-perform methods for the analysis of polar compounds. For example, the detection limits could be decreased by working with smaller quantities of materials in cone-shaped vials; however, this method would involve somewhat 
Table 2.2. Total Ion Count of Peaks of Ten Derivatized Polar Compounds (50 ng/ $\mathrm{L} /$ compound); Derivatizing Agents:- Tri-Sil Concentrate, BSA, and Methy1-8 Concentrate

\begin{tabular}{|c|c|c|c|c|c|c|c|c|}
\hline Compound & $\begin{array}{c}\text { Tri-Sil } \\
\text { Concentrate/ } \\
\text { Methylene } \\
\text { Chloride } \\
(0.5 \mathrm{hr})\end{array}$ & $\begin{array}{l}\text { Tri-Sil } \\
\text { Concentrate/ } \\
\text { Methylene } \\
\text { Chloride } \\
(20 \mathrm{hr})\end{array}$ & $\begin{array}{c}\text { Total Ion } \\
\text { Tri-Sil } \\
\text { Concentrate/ } \\
\text { Pyridine } \\
(0.5 \mathrm{hr})\end{array}$ & $\begin{array}{c}\text { Count of Pe } \\
\text { BSA/ } \\
\text { Methylene } \\
\text { Chloride } \\
(0.5 \text { hr })\end{array}$ & $\begin{array}{l}\text { in (in Thous } \\
\text { BSA' } \\
\text { Methylene } \\
\text { Chloride } \\
(20 \mathrm{hr})\end{array}$ & $\begin{array}{c}\text { BSAl } \\
\text { Pyridine } \\
(0.5 \mathrm{hr})\end{array}$ & $\begin{array}{c}\text { Methyl-8 } \\
\text { Concentrate/ } \\
\text { Methylene } \\
\text { Chloride } \\
(0.5 \mathrm{hr})\end{array}$ & $\begin{array}{c}\text { Methyl-8 } \\
\text { Concentrate/ } \\
\text { Methylene } \\
\text { Chloride } \\
(20 \mathrm{hr})\end{array}$ \\
\hline Phenol & 97 & 94 & 55 & 127 & 100 & 54 & 8 & 8 \\
\hline 2,4 -xylenol & 87 & 79 & 49 & 68 & 76 & 49 & 4 & 5 \\
\hline 1-Naphthol & 69 & 64. & 59 & $49^{\circ}$ & 67 & 46 & 4 & $\mathbf{I}$ \\
\hline Benzoic acid & $\mathrm{T}$ & $\mathbf{T}$ & $\mathrm{I}$ & $\mathrm{T}$ & $\mathrm{T}$ & $\mathrm{T}^{\circ}$ & 39 & 40 \\
\hline Phenoxyacetic acid & - & -- & - & -- & -- & -- & 18 & 25 \\
\hline 1-Naphthalene acetic acid & -- & -- & - & -- & -- & -- & 14 & 14 \\
\hline Aniline- $d_{5}$ & -- & -- & 36 & 83 & 105 & 42 & 57 & 60 \\
\hline 2,6-Dimethyl aniline & -- & -- & 10 & 25 & 23 & 9. & 36 & 56 \\
\hline Benzyl amine & $T$ & $\mathrm{~T}$ & - & 11 & 53 & 17 & 33 & NM \\
\hline Benzyl alcohol & 103 & 98 & & 86 & 100 & 60 & -- & -- \\
\hline
\end{tabular}

T Trace

I Interfering peak preveated determination of total ion count

NM Not measurable

-- Not found 


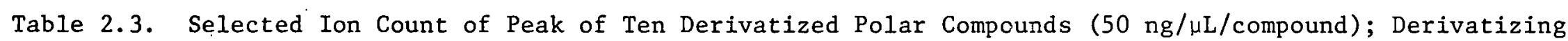
Agents, Tri-Sil Concentrate, BSA, Methy1-8 Concentrate

\begin{tabular}{|c|c|c|c|c|c|c|c|c|c|c|}
\hline \multirow[b]{2}{*}{ Compound } & \multicolumn{10}{|c|}{ Selected Ion Count of Peak } \\
\hline & 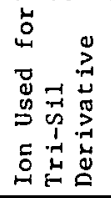 & 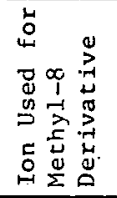 & $\begin{array}{l}\text { Tri-Sil } \\
\text { Concentrate/ } \\
\text { Methylene } \\
\text { Chloride } \\
(0.5 \text { hr })\end{array}$ & $\begin{array}{l}\text { Tri-Sil } \\
\text { Concentrate/ } \\
\text { Methylene } \\
\text { Chloride } \\
(20 \mathrm{hr})\end{array}$ & $\begin{array}{c}\text { Tri-Sil } \\
\text { Concentrate/ } \\
\text { Pyridine } \\
(0.5 \mathrm{hr})\end{array}$ & $\begin{array}{c}\text { BSA/ } \\
\text { Methylene } \\
\text { Chlorite } \\
(0.5 \mathrm{hr})\end{array}$ & $\begin{array}{c}\text { BSA/ } \\
\text { Methylene } \\
\text { Chloride } \\
(20 \mathrm{hr})\end{array}$ & $\begin{array}{c}\text { BSA/ } \\
\text { Pyridine } \\
(0.5 \mathrm{hr})\end{array}$ & $\begin{array}{c}\text { Methyl-8 } \\
\text { Concentrate/ } \\
\text { Methylene } \\
\text { Chloride } \\
(0.5 \mathrm{hr})\end{array}$ & $\begin{array}{c}\text { Methyl-8 } \\
\text { Concentrate/ } \\
\text { Methylene } \\
\text { Chloride } \\
(20 \mathrm{hr})\end{array}$ \\
\hline Phenol & 151 & 108 & 44159 & 41121 & 27570 & 38325 & 34209 & 22793 & 2690 & 2758 \\
\hline 2,4-Xyleriol & 194 & 136 & 11347 & 10613 & 7100 & 8133 & 11049 & 5925 & 1299 & 6340 \\
\hline 1-Naphthol & 216 & 158 & 13665 & 12176 & 10556 & 8397 & 12410 & 3359 & 985 & -- \\
\hline Benzoic acid & $=-$ & 105 & -- & -- & -- & -- & - & -- & 17381 & 17068. \\
\hline Phenoxyacetic acid & -- & 107 & -- & -- & -- & -- & - & - & 5181 & 6862 \\
\hline 1-Naphthalene acetic acid & -- & 141 & - & -- & -- & -- & -- & - & 6913 & 6654 \\
\hline Aniline-d ${ }_{5}$ & 155 & 153 & -- & -- & 16505 & 34684 & 50067 & 19254 & 10845 & 11929 \\
\hline 2,6-Dimethyl aniline & 178 & 132 & -- & -- & 2362 & 5941 & 6391 & 902 & 5461 & 10554 \\
\hline Benzyl amine & 135 & 162 & 350 & 298 & -- & 1702 & 14816 & 4751 & $5 €: 06$ & NM \\
\hline Benzyl alcohol & 135 & -- & .22099 & 20640 & 7288 & 15487 & 19401 & 12008 & -- & -- \\
\hline
\end{tabular}

NM Not measurable

-. Not found 
Table 2.4. Relative Ratings (Poor, Fair, and Good) of Derivatization Methods Investigated

\begin{tabular}{|c|c|c|c|c|c|c|c|c|}
\hline $\begin{array}{l}\text { Class of } \\
\text { Compound }\end{array}$ & $\begin{array}{l}\text { Tri-Sil } \\
\text { Concentrate/ } \\
\text { Methylene } \\
\text { Chloride } \\
(0.5 \mathrm{hr})\end{array}$ & $\begin{array}{l}\text { Tri-Sil } \\
\text { Concentrate/ } \\
\text { Methylene } \\
\text { Chloride } \\
(20 \mathrm{hr})\end{array}$ & $\begin{array}{c}\text { Tri-Sil } \\
\text { Concentrate/ } \\
\text { Pyridine } \\
(0.5 \mathrm{hr})\end{array}$ & $\begin{array}{l}\quad \text { BSA/ } \\
\text { Methylene } \\
\text { Chloride } \\
(0.5 \mathrm{hr})\end{array}$ & $\begin{array}{l}\quad \text { BSA/ } \\
\text { Methylene } \\
\text { Chloride } \\
(20 \mathrm{hr})\end{array}$ & $\begin{array}{l}\text { BSA/ } \\
\text { Pyridine } \\
(0.5 \mathrm{hr})\end{array}$ & $\begin{array}{l}\text { Methyl-8 } \\
\text { Concentrate/ } \\
\text { Methylene } \\
\text { Chloride } \\
(0.5 \mathrm{hr})\end{array}$ & $\begin{array}{l}\text { Methyl-8 } \\
\text { Concentrate/ } \\
\text { Methylene } \\
\text { Chloride } \\
(20 \mathrm{hr})\end{array}$ \\
\hline Phenols & GOOD & GOOD & GOOD & GOOD & GOOD & FAIR & FAIR & FAIR \\
\hline Carboxylic Acids & -- & -- & $\because-$ & -- & -- & -- & $\begin{array}{l}\text { FAIR TO } \\
\text { GOOD }\end{array}$ & $\begin{array}{l}\text { FAIR TO } \\
\text { GOOD }\end{array}$ \\
\hline Amines & -- & $\therefore$ & POOR & $\begin{array}{l}\text { POOR TO } \\
\text { GOOD }\end{array}$ & $\begin{array}{l}\text { FAIR TO } \\
\text { GOOD }\end{array}$ & $\begin{array}{l}\text { POOR TO } \\
\text { GOOD }\end{array}$ & $\begin{array}{l}\text { FAIR TO. } \\
\text { GOOD }\end{array}$ & $\begin{array}{l}\text { FAIR TO } \\
\text { GOOD }\end{array}$ \\
\hline Alcohols & GOOD & GOOD & POOR & GOOD & GOOD & FAIR & -- & -- \\
\hline
\end{tabular}

Note: Methyl-8 Concentrate derivatives were rated somewhat higher because of easy identification and favorable peak shape. 
Table 2.5. Total Ion Count and Selected Ion Count of Derivatized Polar Compounds as a Function of Concentration; Derivatizing Agents: BSA and Methy]-8 Concentrate

\begin{tabular}{|c|c|c|c|c|c|c|c|c|}
\hline Compound & $\begin{array}{c}\mathrm{BSA} \\
100 \mathrm{ng} / \mu \mathrm{L}\end{array}$ & $\begin{array}{l}\text { Methyl-8 } \\
100 \mathrm{ng} / \mu \mathrm{L}\end{array}$ & $\begin{array}{c}\text { BSA } \\
50 \mathrm{ng} / \mu \mathrm{L}\end{array}$ & $\begin{array}{l}\text { Methyl-8 } \\
50 \mathrm{ng} / \mu \mathrm{L}\end{array}$ & $\begin{array}{c}\text { BSA } \\
20 \mathrm{ng} / \mu \mathrm{L}\end{array}$ & $\begin{array}{l}\text { Methyl-8 } \\
20 \mathrm{ng} / \mu \mathrm{L}\end{array}$ & $\begin{array}{c}\text { BSA } \\
10 \mathrm{ng} / \mu \mathrm{L}\end{array}$ & $\begin{array}{l}\text { Methy } 1-8 \\
10 \mathrm{ng} / \mu \mathrm{L}\end{array}$ \\
\hline Phenol & $126750(38325)$ & $7612(2690)$ & $50323(24360)$ & $2252(638)$ & $23485(9371)$ & $1330(341)$ & $16094(6616)$ & $--(191)$ \\
\hline 2,4-xylenol & $67823(8133)$ & $4327(1299)$ & $41548(5537)$ & $--(287)$ & $16969(1957)$ & $--(190)$ & $8735(871)$ & $--(85)$ \\
\hline 1-Napht hol & $48574(8397)$ & $3597(985)$ & $34350(6222)$ & $--(48)$ & $11531(2173)$ & $--(14)$ & $6124(938)$ & $--\quad--$ \\
\hline Benzolc acid & -- & $38662(17381)$ & -- & $12644(5550)$ & -- & $5955(2792)$ & -- & $2854(1180)$ \\
\hline Phenoxyacet ic acid & $-\quad--$ & $17980(5181)$ & -- & $9925(2872)$ & -- & $3805(1203)$ & -- & $1409(413)$ \\
\hline 1-Naphthalene acetic acid & -- & $13838(6913)$ & -- & $6098(3266)$ & -- & $2056(1098)$ & -- & $1365(679)$ \\
\hline Anfline- $d_{5}$ & $82936(34684)$ & $56876(10845)$ & $35559(16784)$ & $23950(4323)$ & $11170(5045)$ & $10510(1340)$ & $4085(1895)$ & $4826(850)$ \\
\hline 2,6-Dimethyl aniline & $24944(59411)$ & $35903(5461)$ & NM $(132)$ & $8637(1736)$ & - & $5765(1178)$ & $--\quad--$ & $2906(529)$ \\
\hline Benzyl amine & $7859(1702)$ & $33288(5606)$ & $--(.874)$ & $17114(2698)$ & $--(181)$ & $6.767(1233)$ & $--(239)$ & $2587(558)$ \\
\hline Benzyl alcohol & $85833(34684)$ & -- & $54163(10612)$ & -- & $18620(3833)$ & -- & $8696(1645)$ & -- \\
\hline
\end{tabular}

(1) Ions used are shown in Table

NM Not measurable 
Table 2.6. Estimated Minimum Concentration (Detection Limit) of Polar Compounds Required for Derivatization and Identification by Capillary Column GC/MS; Derivatizing Agents: BSA and Methy1-8 Concentrate ${ }^{a}$

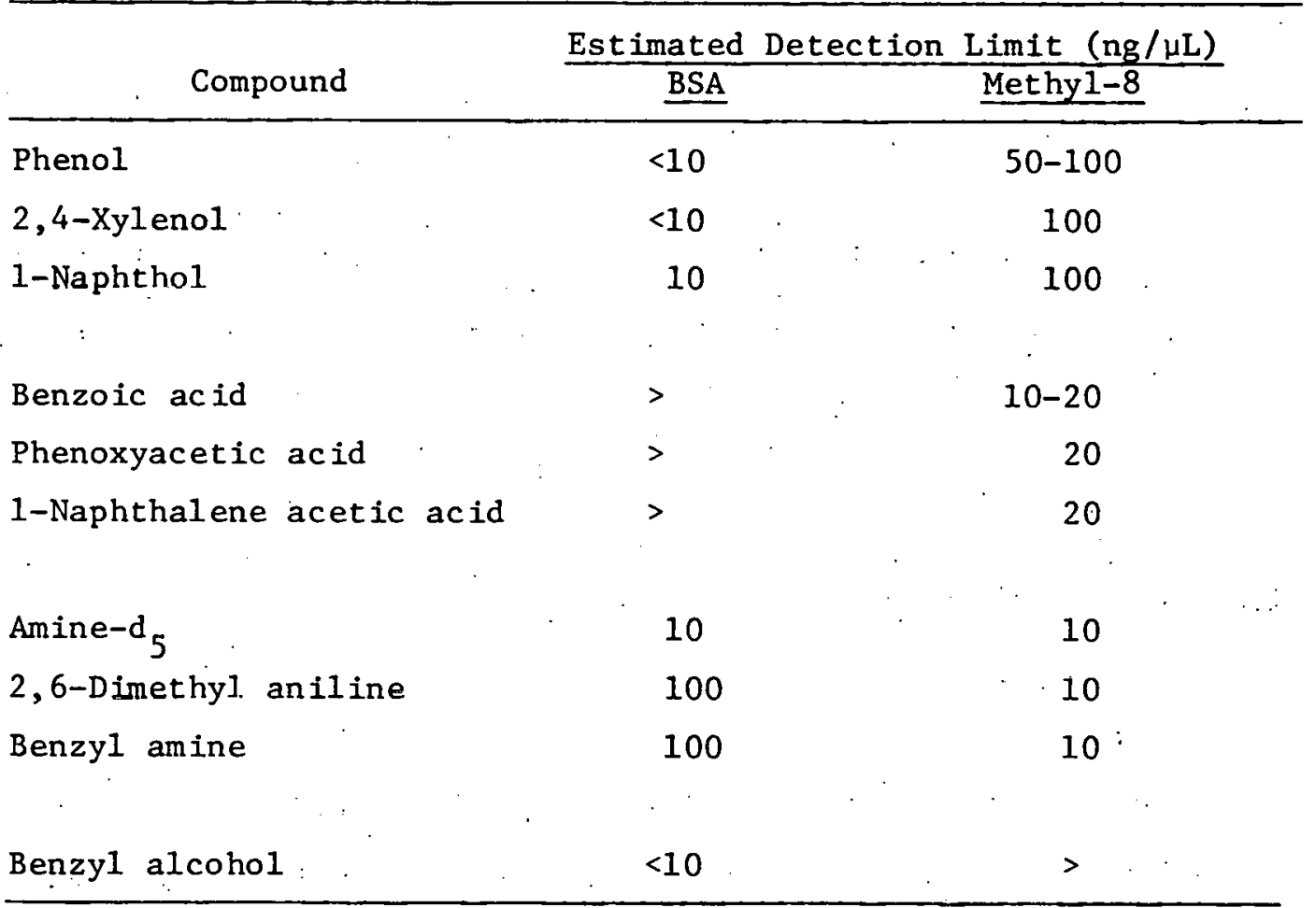

aAn estimate is based not only on a lower limit of 5000 counts for the total ion count of the peak, since mass spectra can typically be interpreted when there are at least 3000 to. 5000 counts, but also on visual inspection of specific spectra of derivatives that have approximately 5000 counts

$>$ Indicates greater than the highest concentration measured, that is, $100 \mathrm{ng} / \mu \mathrm{L}$ 
intricate procedures that could possibly lead to errors due to contamination. It can be said further that by modifying the procedures or substituting other derivatizing agents, one might be able to achieve more sensitivity or more easily identifiable mass spectra. However, the methods described herein do work well and are fairly simple. The hindered phenols, 2,4-xylenol and 1-naphtho1, and the hindered amine, 2,6-dimethyl aniline, also can be determined at fairly low levels.

\subsubsection{Recommended Method}

Based on the results achieved in this part of the study, it appears that:

1. No one silylating or alkylating agent is capable of derivatizing the whole spectrum of polar compounds.

2. The preferred silylating agent is BSA and the preferred alkylating agent is Methy1-8 Concentrate except where there is ambiguity as to the source of the derivatized products. In such cases, the deuterated analog of Methyl-8 Concentrate, Tri-Deuter-8, should be used.

3. There is no advantage in allowing the derivatized solution to stand for $20 \mathrm{hr}$.

Thus, the recommended method for derivatization of polar compounds from HYGAS oil samples is as follows:

1. Evaporate each fraction from the HPLC to dryness under a stream of nitrogen.

2. Take up the residue in $100 \mu \mathrm{L}$ of methylene chloride.

3. Split the $100 \mu \mathrm{L}$ solution into two $50 \mu \mathrm{L}$ solutions and place in two vials sealable with caps.

4. Add $50 \mu \mathrm{L}$ of BSA to one vial and $50 \mu \mathrm{L}$ of Methyl-8 Concentrate (or Tri-Deuter-8) to the other vial.

5. Seal each vial with a cap and heat to $50-60^{\circ} \mathrm{C}$ for $5-10 \mathrm{~min}$.

6. Perform capillary column (splitless) GC/MS analysis on each derivatized solution. (The starting temperature of the programmed run would be $20^{\circ} \mathrm{C}$.)

The preceding method is for the polar HPLC fractions of HYGAS oil samples. However, for the initial nonpolar HPLC fraction of HYGAS oil samples, there is no need to derivatize. Moreover, this fraction (Fraction 1) contains predominantly toluene, which is difficult to remove. Therefore, the recommended method for analyzing this fraction is as follows: 
1. Evaporate the nonpolar HPLC fraction with a stream of nitrogen to remove the low-boiling solvents used in the HPLC run to give a toluene solution of the nonpolar compounds.

2. Perform capillary column (splitless) GC/MS analysis of the toluene solution of the nonpolar compounds. (In this case, the starting temperature of the programmed run would be approximately $90^{\circ} \mathrm{C}$.)

\subsection{SUMMARY AND CONCLUSIONS}

An investigation was undertaken to determine suitable agents for derivatizing the polar compounds typically found in HYGAS samples so that these compounds would be more amenable to identification by GC/MS. Of the silylating and alkylating agents investigated, no one by itself is capable of derivatizing the whole spectrum of compounds. The preferred silylating agent was BSA, which was effective for phenols and alcohols, and the preferred alkylating agent was Methyl-8 Concentrate, which was effective for carboxylic acids and amines. The lower limit of detection by capillary column GC/MS was in the range of less than $10-20 \mathrm{ng} / \mu \mathrm{L}$ of polar compound. 


\section{1 INTRODUCTION}

In Part 1 of this report, an HPLC method was described for separating HYGAS oil samples into fractions. In Part 2, methods were presented for derivatizing the polar compounds, phenols, carboxylic acids, amines, and alcohols. In this part of the report, a HYGAS oil sample was separated into fractions by HPLC and some of the polar fractions were derivatized and analyzed by capillary column GC/MS to determine whether the separation and derivatization methods had simplified identification of the complex mixtures of HYGAS oil samples.

\section{2 EXPERIMENTAL PROCEDURES}

\subsection{HYGAS Oiz Somple}

The HYGAS oil sample $(72 / \mathrm{H} / \mathrm{G} / 0 / 3)$, whose description can be found in Appendix A, was filtered with a sample clarification kit (Waters Associates Inc., Milford, MA 01757) to remove unreacted coal.

\subsubsection{Solvents}

For the mobile phase in the HPLC run, Waters solvents were used. They were hexane (No. 84911) and THF (UV) (No. 94801). Where low concentrations of $\mathrm{THF}$ in hexane were used, such as 1 and $5 \%$, the solvents were premixed because solvent gradients at low concontrations lead to their being mixed erratically. The methylene chloride used as a solvent for derivatization is the Burdick \& Jackson pesticide quality (Burdick \& Jackson Laboratories Inc., Muskegon, MI 49442).

\subsubsection{Equipment}

The HPLC equipment was that of Waters, Inc., consisting of two $6000 \mathrm{~A}$ Solvent Delivery Systems, a 660 Solvent Programmer, U.6K Universal Liquid Chromatograph Injector, 440 Absorbance Detector (UV), and a $\mu$ Bondapak CN (No. 84042) column. UV Detection was at $254 \mathrm{~nm}$.

The flow rate of each pump was determined by measuring the volume of solvent at exhaust with a stop watch, after which adjustments were made to give the desired flow.

Analyses of the fractions were performed on a Hewlett-Packard GC/MS equipped with a 50-m OV-101 capillary column (No. 009-7980, Perkin-Elmer Corp., Norwalk, CT 06856). The GC/MS was a 5982A modified with a $5830 \mathrm{GC}$ upgraded to a $5840 \mathrm{GC}$. The GC was equipped with a modified Hewlett-Packard split/splitless Grob-type injection system, and splitless injection with $3 \mu \mathrm{L}$ was used in the study. Temperature programming, $20-240^{\circ} \mathrm{C}$ at $2 \% / \mathrm{min}$ with 2 -min hold at $20^{\circ} \mathrm{C}$, was employed. Mass spectra of some of the compounds 
found are shown in Appendix C. The data system was an HP 5934 consisting of a 21MX Computer, 5948A Data Subsystem (A/D and D/A Converters), 7900 Dual Disc Drive, and a Tektronix 4012 Display lerminal. Peripheral equipment included a Tektronix 4631 Hard Copy Unit and a Zeta 130-10 Incremental Plotter.

The parameters used for scanning were as follows: run time, $120 \mathrm{~min}$; mass range, 40-450 AMU; A/D conversions, 1; thresholds, 5, 5; and mass offset, -0.2 .

\subsubsection{Determination of the Flow Time Between the UV Detector and Outlet of the HPLC}

To determine the time lag between UV detection of a peak and the outlet of the HPLC, a solution of benzoic acid in THF was injected onto the $\mu$ Bondapak $\mathrm{CN}$ column and 10-sec fractions were taken after the initial appearance of the peak. The fractions were evaporated to dryness under a stream of nitrogen and allowed to stand at room temperature. The approximate start of a peak could then be determined by looking for the presence of benzoic acid. Having determined the approximate lag time, the experiment was repeated at 5- and $2-\mathrm{sec}$ intervals. The lag time was found to be approximately $20 \mathrm{sec}$ at a flow rate of $2 \mathrm{~mL} / \mathrm{min}$.

\subsubsection{HPLC Separation of HYGAS Oil Sample into Fractions}

To determine the approximate time at which fractions should be taken and make certain that conditions for separation into fractions were satisfactory, an initial HPLC run with $100 \mu \mathrm{L}$ of. HYGAS oil sample and a flow rate of $2 \mathrm{~mL} / \mathrm{min}$ was undertaken under the following conditions:

$\begin{aligned} \text { 0-16 min, } & 100 \% \text { hexane, } 0 \% \mathrm{THF} \\ 16-26 \mathrm{~min}, & 0-1 \% \mathrm{THF} \text { in hexane, linear (curve 6) gradient } \\ 26-36 \mathrm{~min}, & 1-5 \% \mathrm{THF} \text { in hexane, linear (curve 6) gradient } \\ 36-46 \mathrm{~min}, & 5 \% \mathrm{THF} \text { in hexane to } 100 \% \mathrm{THF} \text {, linear (curve 6) gradient } \\ 46-60 \mathrm{~min}, & 100 \% \mathrm{THF}, 0 \% \text { hexane }\end{aligned}$

The run was then repeated, after washing the column at length with THF under the same conditions, and fractions were collected as shown in Fig. 3.1 and as follows (with a time $1 \mathrm{ag}$ of $20 \mathrm{sec}$ ):

$\begin{array}{cc}\text { Fraction } & \frac{\text { Time (Min) }}{1.8-9.4} \\ 1 & 9.4-13.4 \\ 2 & 13.4-21.5 \\ 3 & 21.5-28.7 \\ 4 & 28.7-33.0 \\ 5 & 33.0-40.2 \\ 6 & 40.2-49.0 \\ 7 & \end{array}$

Each of the fractions was evaporated to dryness under a stream of nitrogen and, with the exception of Fraction 1, the nonpolar or weakly polar fraction, was taken up in approximately $200 \mu \mathrm{L}$ of methylene chloride and 


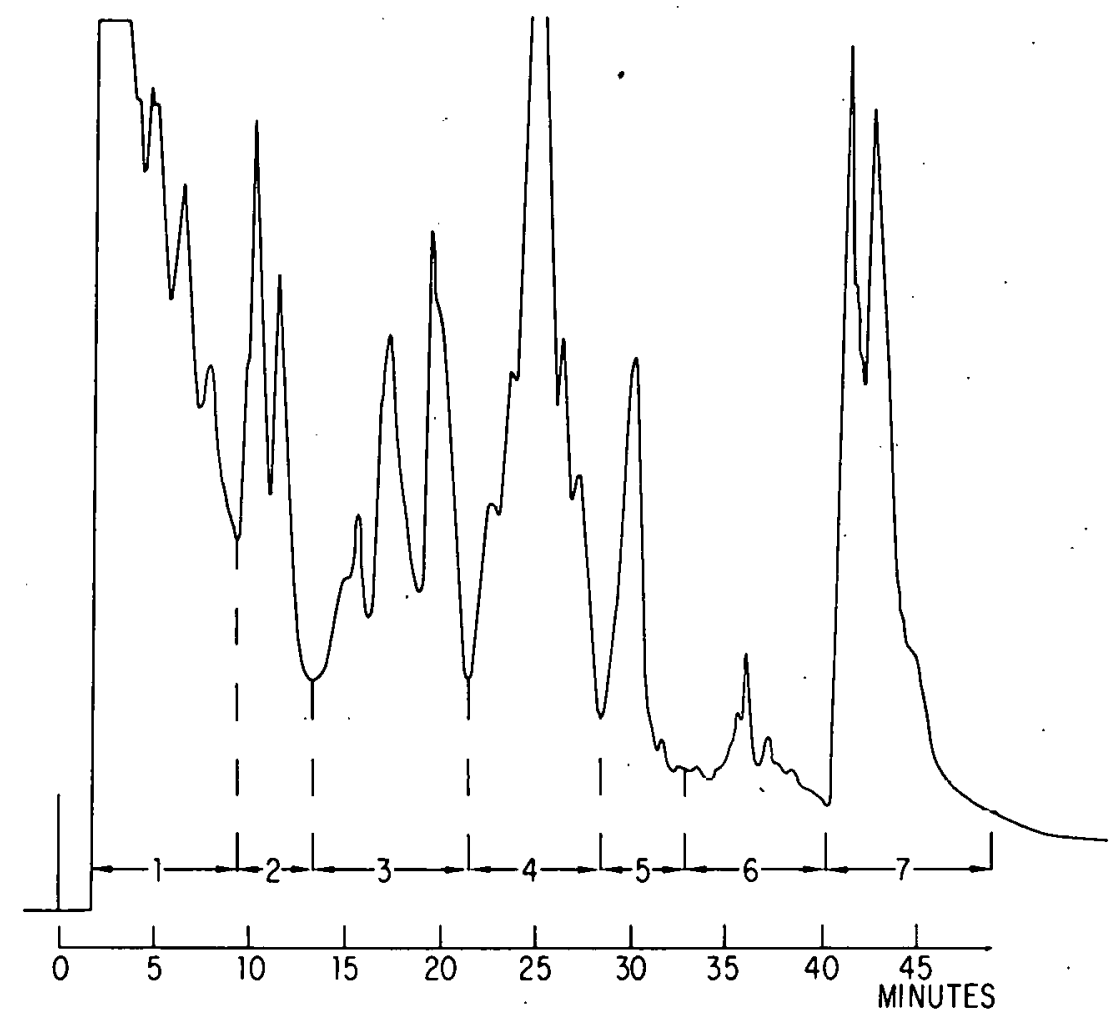

Fig. 3.1. HPLC Separation into Seven Fractions of HYGAS Oil Sample; Approximately 2.2 AUFS

split and placed into two vials (No. 5080-8712, Hewlett-Packard, Route 41, Avondale, PA 19311). The $100 \mu \mathrm{L}$ solutions in each vial were then evaporated under a stream of nitrogen to $50 \mu \mathrm{L}$ after which $50 \mu \mathrm{L}$ of the derivatizing agent, BSA or Methyl-8 Concentrate, was added. The vial was sealed, shaken, heated to $50-60^{\circ} \mathrm{C}$ for $5-10 \mathrm{~min}$, cooled, and $3 \mu \mathrm{L}$ of solution was injected into the GC column. In the case of Fraction 1, the residue was taken up in $200 \mu \mathrm{L}$ of methylene chloride, transferred to a vial, evaporated to $50 \mu \mathrm{L}$ under a stream of nitrogen, and $3 \mu \mathrm{L}$ was injected onto the GC column.

\subsubsection{Mass Spectral Interpretation}

Interpretation of the data was done by inspecting the mass spectrum of each peak or shoulder and by generating and inspecting massgrams. Mass spectra of selected compounds found in the HYGAS oil sample are shown in Appendix $C$.

\subsection{RESULTS AND DISCUSSION}

\subsubsection{HPLC Separation of HYGAS Oiz Sample into Fractions}

A $100 \mu \mathrm{L}$ sample of prefiltered HYGAS oil sample was injected into the HPLC with a $\mu$ Bondapak $C N$ as the column with a flow rate of $2 \mathrm{~mL} / \mathrm{min}$. The 
gradient program was as follows:

$\begin{aligned} 0-16 \text { min, } & 100 \% \text { hexane, } 0 \% \text { THF } \\ 16-26 \mathrm{~min}, & 0-1 \% \mathrm{THF} \text { in hexane, linear gradient } \\ 26-36 \mathrm{~min}, & 1-5 \% \mathrm{THF} \text { in hexane, linear gradient } \\ 36-46 \mathrm{~min}, & 5 \% \mathrm{THF} \text { in hexane to } 100 \% \mathrm{THF}, \text { linear gradient } \\ 46-60 \mathrm{~min}, & 100 \% \mathrm{THF}, 0 \% \text { hexane }\end{aligned}$

Seven fractions were collected at the following intervals, as shown in Fig. 3.1:

\begin{tabular}{cc} 
Fraction & Time (Min) \\
\hline 1 & $1.8-9.4$ \\
2 & $9.4-13.4$ \\
3 & $13.4-21.5$ \\
4 & $21.5-28.7$ \\
5 & $28.7-33.0$ \\
6 & $33.0-40.2$ \\
7 & $40.2-49.0$
\end{tabular}

No attempt was made to collect a fraction before $1.8 \mathrm{~min}$, which would contain predominantly alkanes.

\subsubsection{Derivatization of the Fractions}

In this limited study, Fractions 2, 3, and 4 were derivatized with BSA, a silylating agent, Fraction 3 with Methy1-8 Concentrate, an alkylating agent, and Fraction 4 with Tri-Deuter-8, an alkylating agent. Fraction 1 , the nonpolar or weakly polar fraction, was not derivatized. Fractions 5, 6, and 7 were not investigated at this time.

\subsubsection{Capizlary Colum GC/MS Investigation. of the Fractions}

A portion of a typical total ion chromatogram of one of the derivatized fractions is shown in Fig. 3.1. Peaks are sharp and resolution is good. Poor peak shape is due to overlapping of peaks. This particular fraction (Fig. 3.2) contains a variety of hydroxy aromatic compounds that would not be chromatographable under normal conditions without derivatization. It is noteworthy that, even with fractionation of the original HYGAS oil sample, the capillary column GC/MS total ion chromatogram is still complex, indicative of the several hundred compounds in the HYGAS oll sample.

In order to determine how well the separations had taken place, an analysis of the derivatized fractions was undertaken. The identification and total ion count (in thousands) of the BSA derivatized compounds in Fractions 2, 3, and 4 is shown in Tables 3.1-3.3. A summarized table (Table 3.4) permits comparisons of these fractions. The retention time ranges are shown in Fig. 3.3. Surprisingly, these fractions contain not only some alkylated phenols but also some higher hydroxy PNAs, which have not been reported previously. By careful inspection of the spectra and retention times for these three fractions, only a small overlap of compounds 


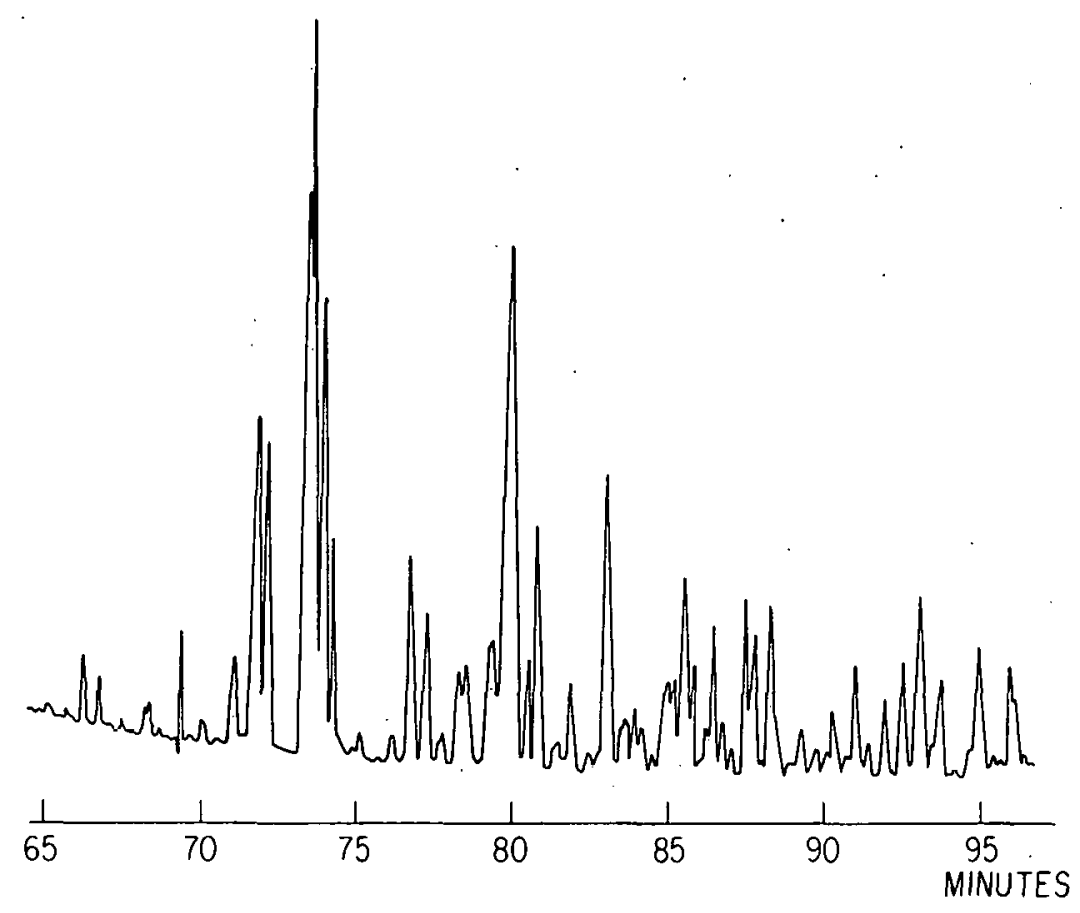

Fig. 3.2. Portion of Total Ion Chromatogram of Fraction 4, Derivatized with BSA
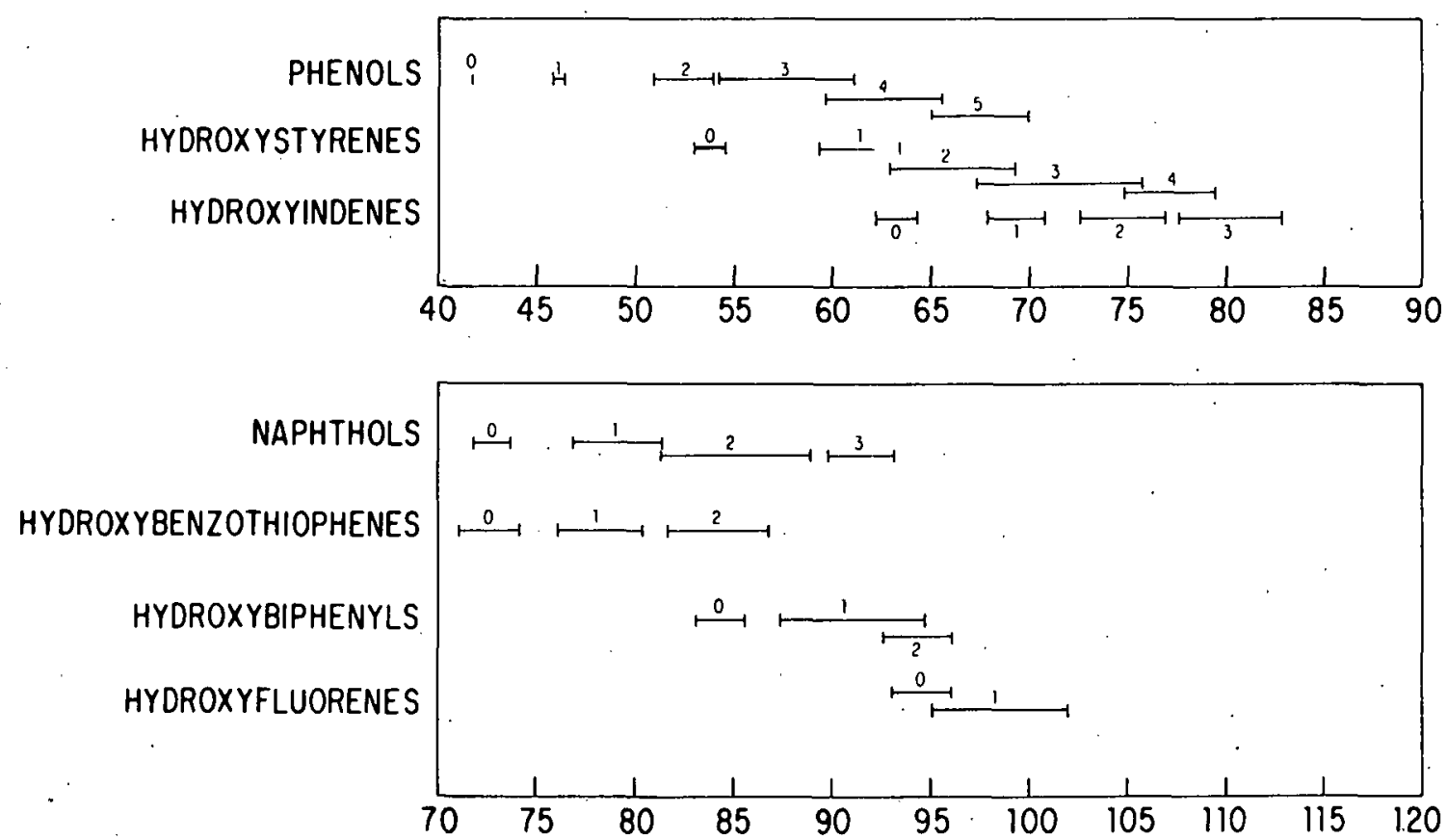

Fig. 3.3. Retention Time Ranges of Some Phenols and Hydroxy PNAs, Derivatized with BSA, in Fractions 2,3, and 4 
Table 3.1. Tentative Identification and Total Ion Count (in thousands) of Compounds (as TMS ethers) in Fraction 2

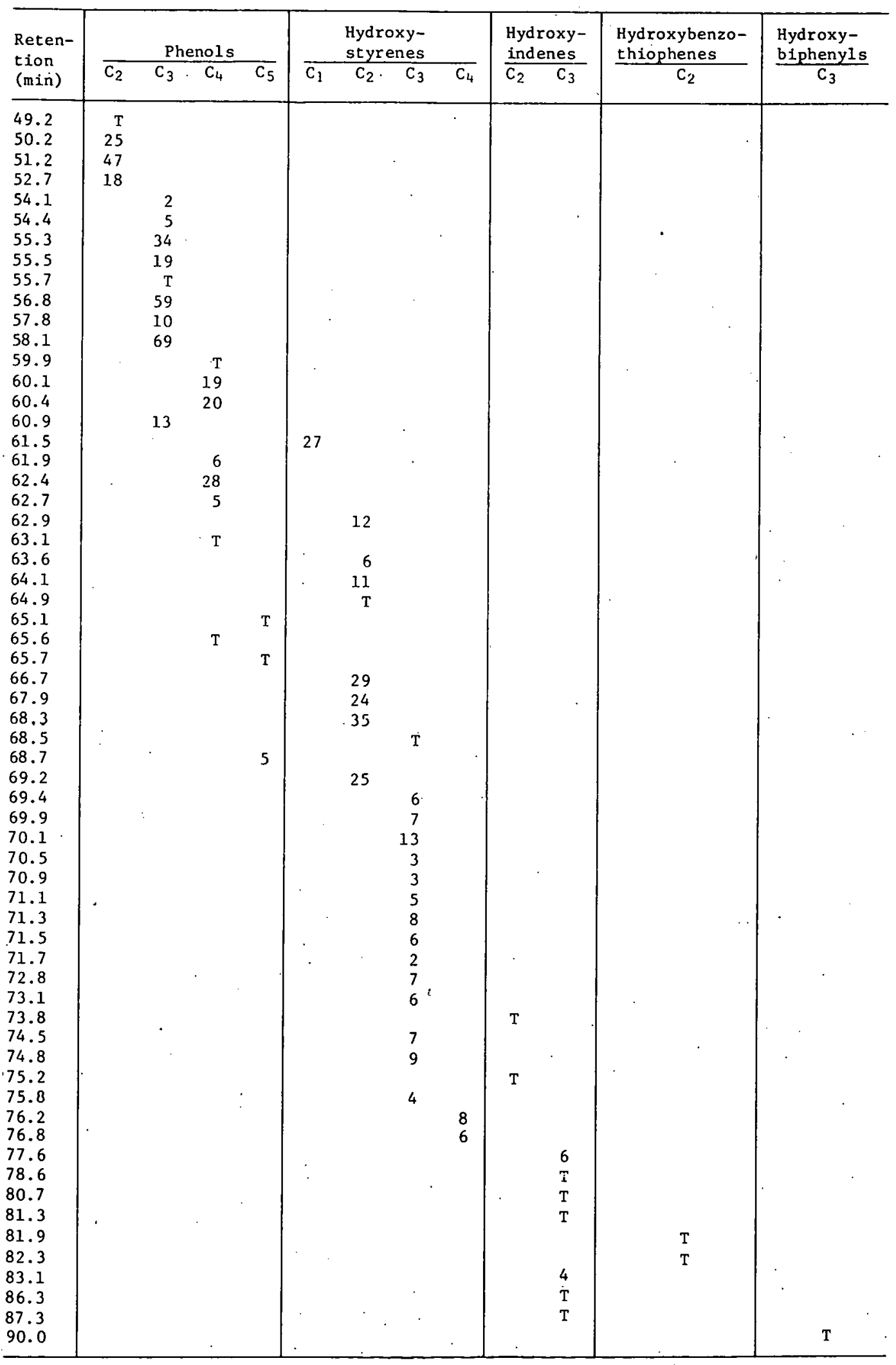

T. Trace 
Table 3.2. Tentative Identification and Total Ion Count (in thousands) of Compounds (as TMS ethers) in Fraction 3

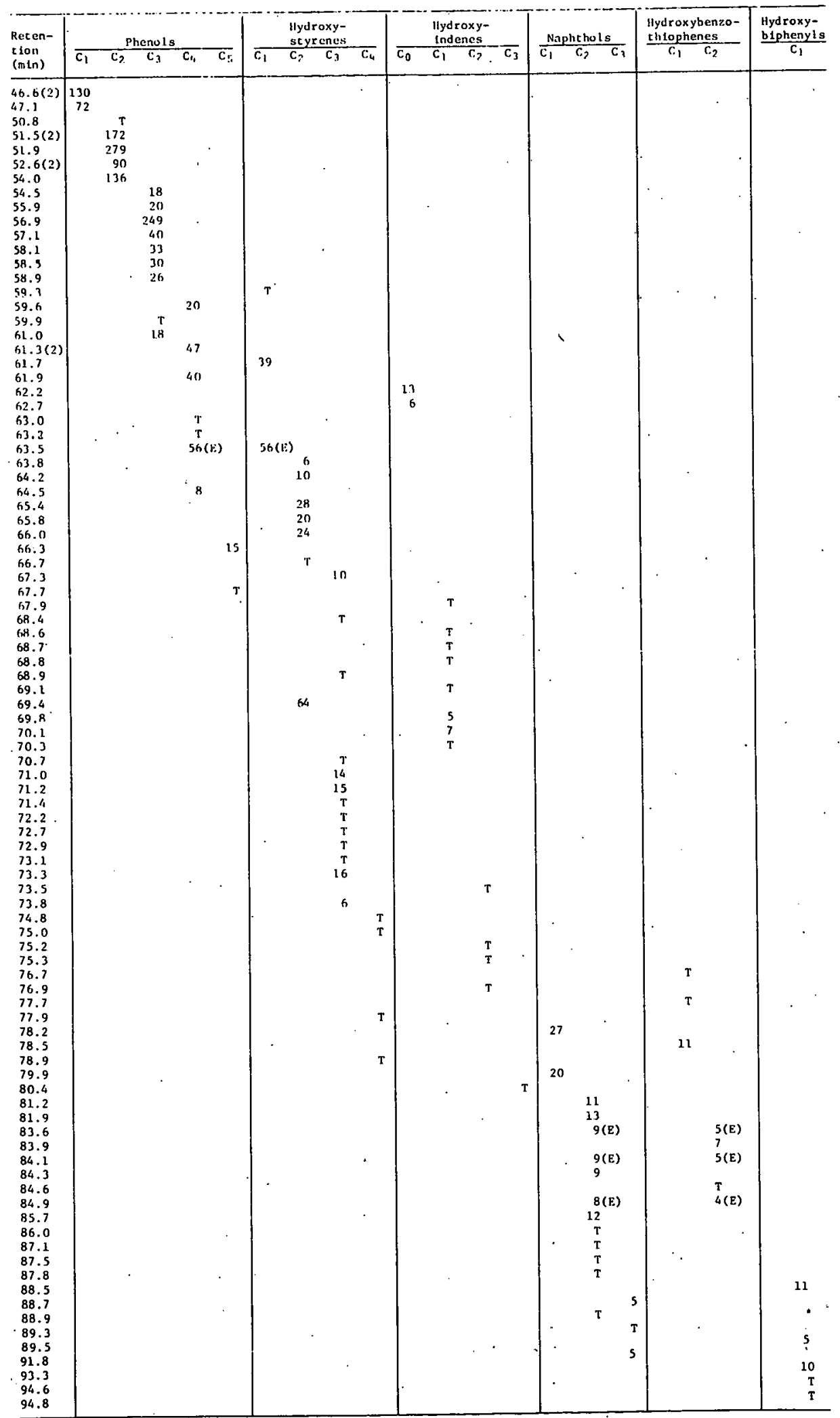

T Trace

(E) Estimated due to overlapping penks 
Table 3.3. Tentative Identification and Total Ion Count (in thousands) of Compounds (as TMS ethers) in Fraction 4

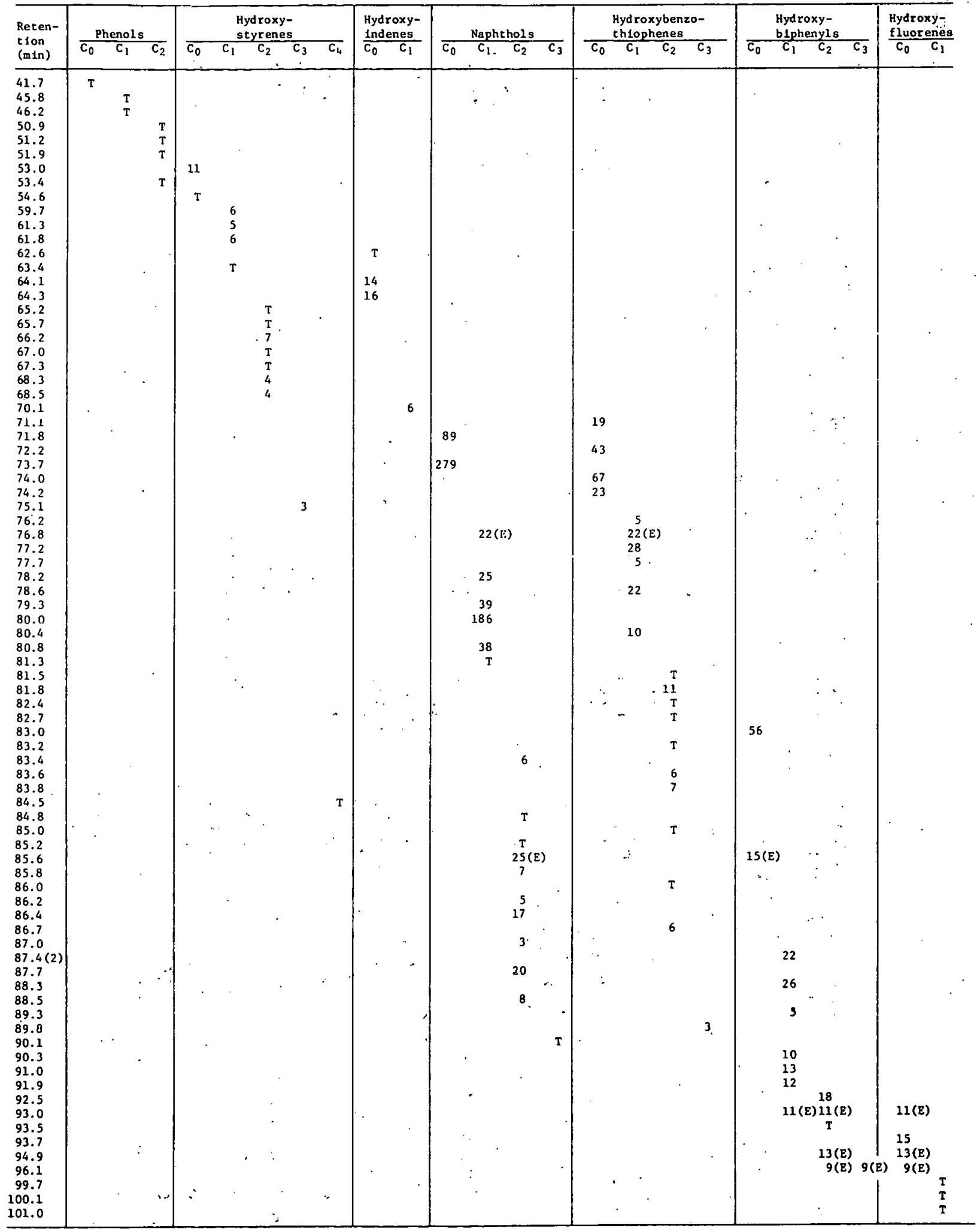

I Trace

(E) Estimated due to overlapping peaks 
Table 3.4 Summary of Tables $3.1,3.2$, and 3.3 Allowing Comparisons of Total Ion Count (in thousands) of Classes of Compounds Versus Fraction

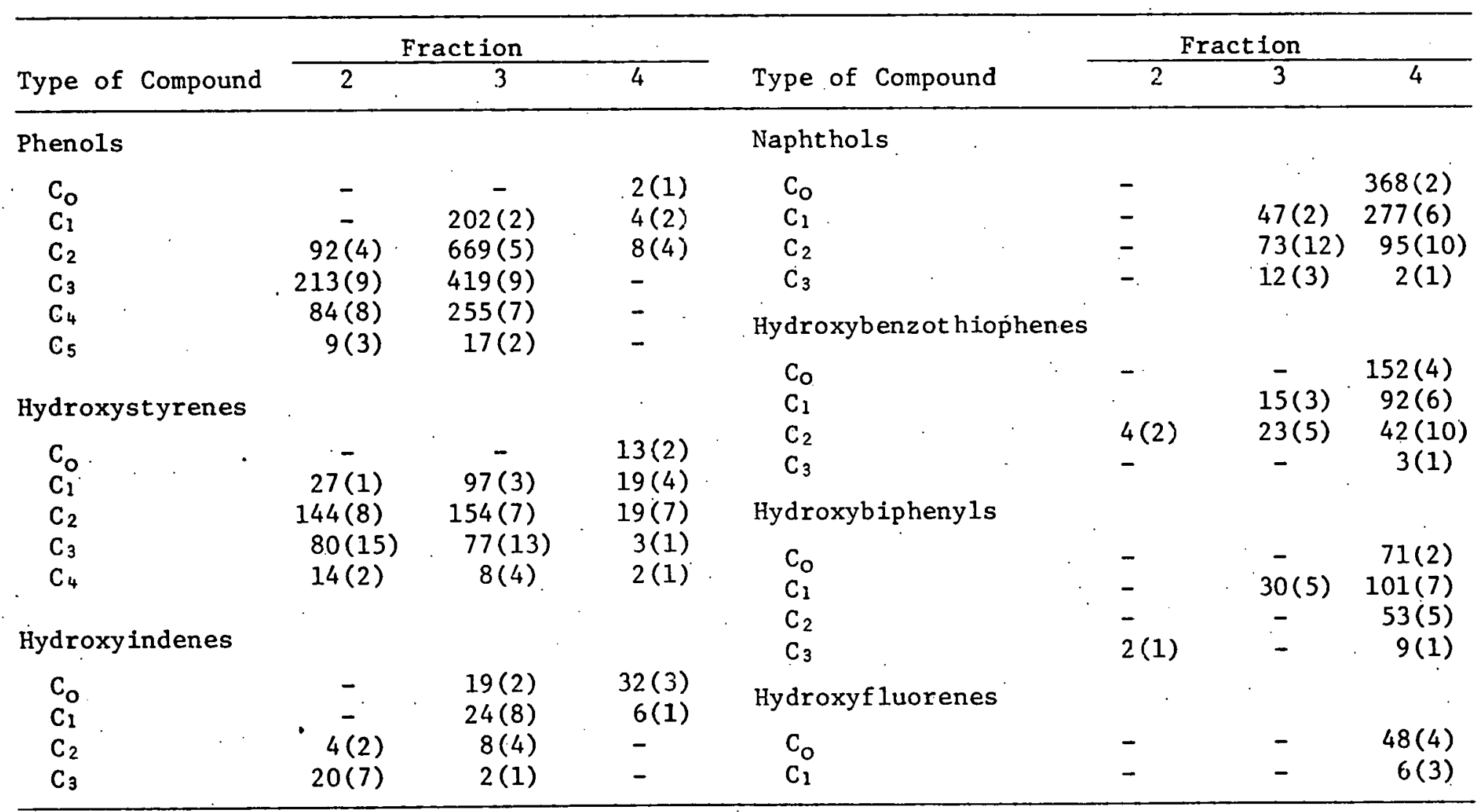


was found in certain instances, that is, compounds appearing in two adjacent fractions. By inspection of the total ion chromatograms and massgrams, there appears to be over three hundred of these phenolic-like compounds! This estimation does not include the higher hydroxy PNAs for which the chromatographic conditions were not suitable.

It is interesting to note that, as expected, the more highly alkylated compounds appear in the earlier fractions, since they are relatively more nonpolar than the less highly alkylated compounds. Fraction 2 contains predominantly the more alkylated phenols and hydroxystyrenes; Fraction 3 contains large quantities of partially alkylated phenols, hydroxystyrenes, hydroxyindenes, and naphthols; and Fraction 4 contains the parent hydroxy aromatic compounds along with some partially alkylated derivatives.

The presence of a variety of alkylated phenolic-like compounds in Fraction 3 (Table 3.5) was verified in the sample derivatized with Methy1-8 Concentrate. Some $\mathrm{C}_{2}$ and $\mathrm{C}_{3}$-pyridines were found as well. Pyridine and picolines could not be identified because the by-products of the derivatization interfere with the detection of these compounds. (This condition applies to silylation with BSA.) No anilines or carboxylic acids were found in Fraction 3; these compounds probably occur in later fractions.

Verification of the presence of a variety of phenolic-like PNAs in Fraction 4 was found in the Tri-Deuter-8 derivatized sample (Table 3.6). However, by-products of the derivatization interfere with the determination of lower boiling compounds.

As expected, Fraction 1 contains a variety of the weakly polar PNAs as shown in Table 3.7. Alkyl benzenes were missing, apparently because of workup conditions. (Evaporation of the sample to $100 \mu \mathrm{L}$ of toluene, rather than to dryness, would probably prevent the loss of the alkyl benzenes.) The higher PNAs were also missing, due to the chromatographic conditions.

\subsubsection{Problems with the Analysis and Modifications that Might Lead to Better Analysis}

Although only a limited study of the HYGAS oil sample was undertaken, a few minor problems seem to be associated with the procedures outlined in parts 1 and 2 of this report. These problems are due in part to the complexity of HYGAS oil samples wherein there is a wide range of boiling points and polarities of compounds in the mixture.

With respect to Fraction 1, evaporation of toluene results in the loss of the lower alkyl aromatics.' (With a higher temperature program or shorter column, the higher PNAs would elute from the column.) In regard to the other fractions, a split of each fraction into three parts would allow derivatization with BSA and Methy1-8 Concentrate, along with the possibility of injecting the sample "as is" to detect the underivatized pyridines and sulfides. A higher temperature program also would permit identification of the higher hydroxy PNAs. Finally, the total ion chromatogram of Fraction 4 contains too many overlapping peaks so that further separation by slowing down the gradient is warranted. 
Table 3.5. A Partial Listing of Tentative Identifications of Compounds in the Methy1-8 Concentrated Derivatized Fraction 3

\begin{tabular}{|c|c|}
\hline $\begin{array}{l}\text { Retention Time } \\
\text { (Minutes) }\end{array}$ & Tentative Identification $^{\mathrm{a}}$ \\
\hline $\begin{array}{l}28.1 \\
28.4 \\
34.3 \\
35.1 \\
39.4 \\
40.9 \\
41.6 \\
41.8 \\
42.6 \\
44.2 \\
45.7 \\
46.3 \\
48.1 \\
48.4 \\
48.7 \\
50.1 \\
50.3 \\
52.5 \\
53.6 \\
54.0 \\
54.2 \\
54.5 \\
54.8 \\
55.0 \\
57.8 \\
58.1 \\
61.3 \\
62.1 \\
62.7 \\
64.9 \\
65.1 \\
65.6 \\
66.2 \\
72.7 \\
73.2 \\
78.6 \\
79.1 \\
79.4 \\
80.3 \\
81.0\end{array}$ & 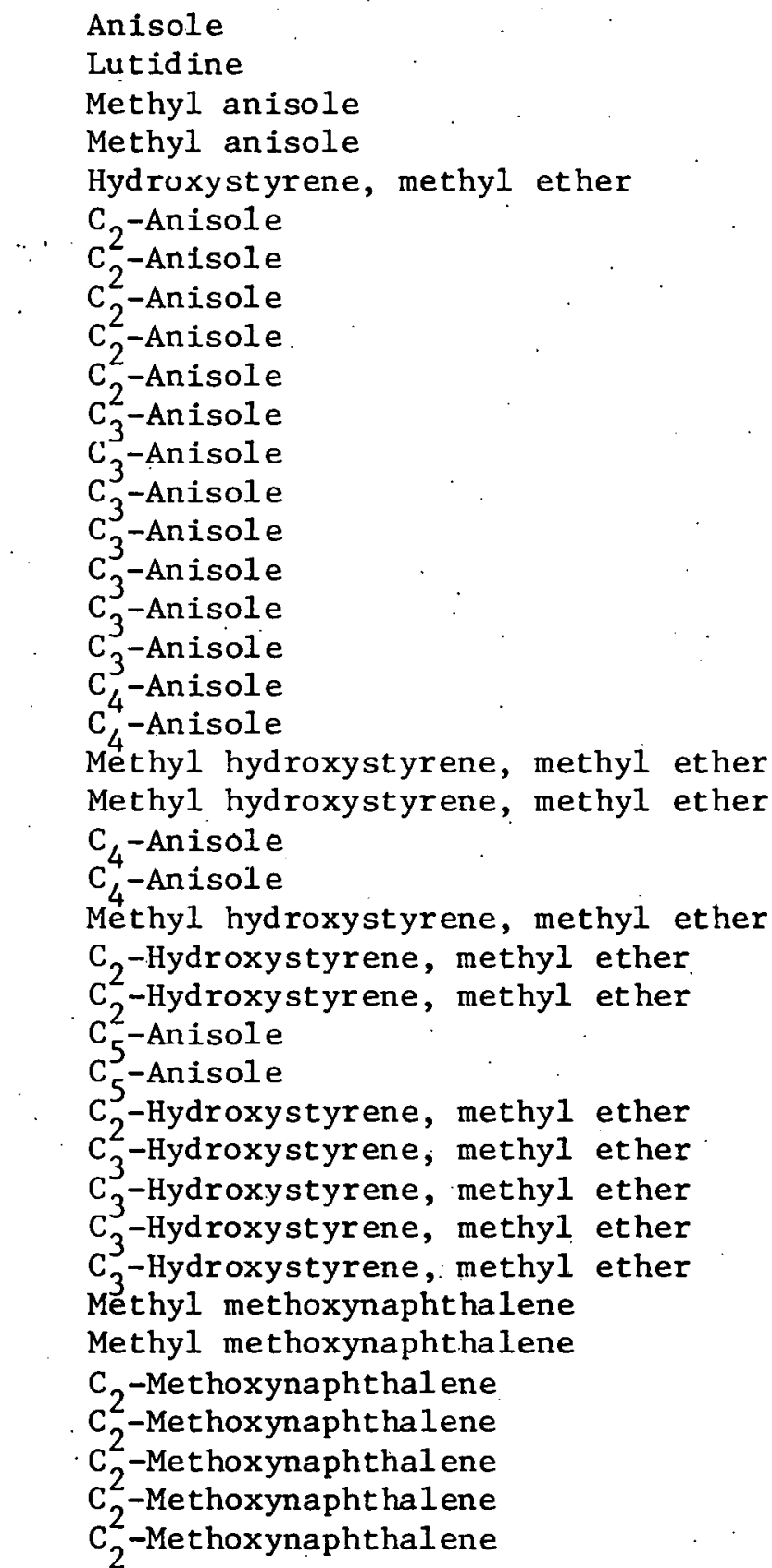 \\
\hline
\end{tabular}

This represents only a partial listing of compounds in the Methyl-8 Concentrate derivatized Fraction 3. 
Table 3.6. A Partial Listing of Tentative Identification of Compounds in the Tri-Deuter-8 Derivatized Fraction 4

\begin{tabular}{|c|c|}
\hline $\begin{array}{l}\text { Retention Time } \\
\text { (Minutes) }\end{array}$ & Tentative Identification ${ }^{a}$ \\
\hline 68.7 & Hydroxybenzothiophene, methyl-d 3 ether \\
\hline 73.8 & Methyl hydroxybenzothiophene, methy $1-d_{3}$ ether \\
\hline 74.0 & Methyl naphthol, methyl- $\mathrm{d}_{3}$ ether \\
\hline 75.1 & Methyl naphthol, methyl- $d_{3}$ ether \\
\hline 78.1 & Hydroxybiphenyl, methyl- $d_{3}$ ether \\
\hline .79 .2 & Hydroxybiphenyl, methy $1-d_{3}$ ether \\
\hline 82.0 & $\mathrm{C}_{2}$-Naphttiol, methyl-d ${ }_{3}$ ether \\
\hline 83.6 & $c_{1}$-Hydroxybiphenyl, methyl-d 3 ether \\
\hline 83.9 & $\mathrm{C}_{1}$-Hydroxybiphenyl, methyl- $\mathrm{d}_{3}$ ether \\
\hline 85.0 & $C_{1}$-Hydroxybiphenyl, methyl-d 3 ether \\
\hline 86.7 & $C_{1}$-Hydroxybipheny1, methyl-d $d_{3}$ ether \\
\hline 87.0 & $\mathrm{C}_{1}$-Hydroxybipheny 1 , methyl- $\mathrm{d}_{3}$ ether \\
\hline 87.5 & $C_{1}$-Hydroxybiphenyl, methyl-d ${ }_{3}$ ether. \\
\hline 89.0 & $C_{2}$-Hydroxybiphenyl, methyl- $d_{3}$ ether \\
\hline 91.8 & $\mathrm{C}_{2}$-Hydroxybiphenyl, methyl- $\mathrm{d}_{3}$ ether \\
\hline 92.7 & $\mathrm{C}_{2}$-Hydroxybiphenyl, methy1- $\mathrm{d}_{3}$ ether \\
\hline
\end{tabular}

\subsubsection{Recommended Modifications for the Analytical Method}

Although the modifications alluded to in the previous section may make the analysis of HYGAS oil samples unduly complicated, it must be remembered that HYGAS oil samples contain such a wide variety of compounds that analysis must involve several procedures. The major problems in the present analytical scheme are:

1. Analysis of higher boiling PNAs is not possible with the present temperature program or chromatographic conditions.

2. Under the preparative conditions used for Fraction 1, certain lower boiling aromatic compounds are lost.

3. Certain lower boiling pyridines and sulfides cannot be detected due to derivatization by-products.

Thus, the modifications or additions to the procedures outlined in parts 1 and 2 of this report are:

1. Run all fractions, including those derivatized, on both a 50-meter OV-101 column and a 20-meter OV-101 or similar column. 
Table 3.7. A Partial Listing of Tentative Identifications of Compounds in Fraction 1

\begin{tabular}{|c|c|c|c|}
\hline $\begin{array}{l}\text { Retention } \\
\quad(\text { min) }\end{array}$ & $\begin{array}{l}\text { Tentative } \\
\text { Identification }\end{array}$ & $\begin{array}{l}\text { Retention } \\
\text { (min) }\end{array}$ & $\begin{array}{l}\text { Tentative } \\
\text { Identification }\end{array}$ \\
\hline 55.1 & Methyl naphthalene & 84.1 & $C_{3}-$ Bipheny 1 \\
\hline 56.3 & Methyl naphthalene & 84.6 & $\mathrm{C}_{2}$-Acenaphthene \\
\hline 61.0 & Biphenyl & 84.9 & $\mathrm{C}_{2}$-Acenaph thene \\
\hline 61.3 & $\mathrm{C}_{2}$-Benzothiophene & 86.5 & Phenanthrene \\
\hline 61.7 & $\mathrm{C}_{2}$-Naphthalene & 81.0 & Anthracene \\
\hline 62.0 & $\mathrm{C}_{2}$-Benzothiophene & 91.0 & Methy 1 \\
\hline 62.4 & $\mathrm{C}_{2}$-Benzothiophene & & dibenzothiophene \\
\hline 62.4 & $\mathrm{C}_{2}$-Naphthalene & 92.3 & Methy 1 phenanthrene/ \\
\hline 62.4 & $\mathrm{C}_{2}$-Naphthalene & & anthracene \\
\hline 63.5 & $\mathrm{C}_{2}$-Naphthalene & 92.6 & Methyl phenanthrene/ \\
\hline 63.7 & $\mathrm{C}_{2}$-Naphthalene & & anthracene \\
\hline 64.9 & $\mathrm{C}_{2}$-Naphthalene & 94.0 & Methy1 phenanthrene/ \\
\hline 65.8 & $\mathrm{C}_{2}$-Naphthalene & & anthracene \\
\hline 65.8 & $\mathrm{C}_{2}$-Naphthalene & 96.2 & Aceanthrene \\
\hline 67.6 & Acenaphthene & 101.5 & Pyrene \\
\hline 67.8 & Methyl biphenyl & & \\
\hline 68.3 & Methyl bipheny1 & - & \\
\hline 68.7 & $\mathrm{C}_{3}$-Naphthalene & & $\cdot$ \\
\hline 68.9 & $\mathrm{C}_{3}$-Benzothiophene & & \\
\hline 69.1 & $C_{3}$-Naphthalene & & \\
\hline 69.5 & $\mathrm{C}_{3}$-Naphthalene & & . \\
\hline 69.9 & $\mathrm{C}_{3}$-Naphthalene & & \\
\hline 70.4 & Methyl biphenyl & & \\
\hline 70.7 & $\mathrm{C}_{3}$-Naphthalene & . & \\
\hline 71.6 & $\mathrm{C}_{3}$-Naphthalene & & . \\
\hline 71.8 & $\mathrm{C}_{3}$-Naphthalene & & \\
\hline 72.6 & $\mathrm{C}_{3}$-Naphthalene & & \\
\hline 72.8 & $\mathrm{C}_{3}$-Naphthalene & & \\
\hline 74.1 & $\mathrm{C}_{3}$-Naphthalene & & \\
\hline 74.3 & Fluorene & & \\
\hline 74.6 & Methy1 acenaphthene & & \\
\hline 76.6 & $\mathrm{C}_{2}$-Bipheny 1 & & \\
\hline 77.5 & $\mathrm{C}_{2}$-Bipheny 1 & & \\
\hline 78.0 & $\mathrm{C}_{2}$-Bipheny1 & & \\
\hline 79.1 & Dibenzothiophene & & . \\
\hline 80.9 & Methyl fluorene & & \\
\hline 81.6 & Methyl fluorene & & \\
\hline 82.0 & Methyl fluorene & & \\
\hline 83.0 & $\mathrm{C}_{3}$-Bipheny 1 & & \\
\hline 83.2 & $\mathrm{C}_{3}-\mathrm{Bipheny} 1$ & & \\
\hline
\end{tabular}

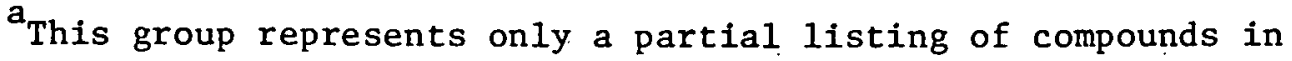
underivatized Fraction 1 
2. Evaporate Fraction 1 to $100 \mu \mathrm{L}$ of. toluene solvent rather than to dryness.

3. Prepare a split of three rather than two of the polar fractions and analyze, an underivatized sample for each fraction.

\subsection{SUMMARY AND CONCLUSIONS}

A preliminary study of the methods for analysis of complex oil samples as described in parts 1 and 2 of this report, namely, HPLC separation into fractions and derivatization of polar fractions, was undertaken on an authentic HYGAS oil sample to determine whether the method would make HYGAS oil samples more amenable to analysis by capillary column GC/MS. It was found that:

1. HPLC does separate, based on polarity, the complex mixtures of HYGAS oil samples into less complex mixtures.

2. Derivatization, of the polar fractions does enhance the identification of compounds by capillary column GC/MS.

3. Small modifications or additions of the method will be required for analysis of pyridines, sulfides, and other underivatized polar compounds that are highly volatile, due to interferences from by-products of the derivatization reactions.

4. Additional capillary column GC/MS identifications under slightly different conditions will. be required for analysis. of the higher boiling PNAs and hydroxy PNAs.

A wide variety of previously unreported hydroxy PNAs were found in the HYGAS oil sample. 


\section{ACKNOWLEDGMENTS}

The author acknowledges the useful discussions with Bill Dark of Waters Associates, Inc. Wyman Harrison of Argonne and Professor Larry T. Taylor of Virginia Polytechnic Institute and State University reviewed the manuscript.

\section{REFERENCES}

1. Dark, W.A., Determination of PNA's and BAP in Mineral Oil Based Cutting Fluids, unpublished results.

2. Das, B.J. and G.H. Thomas, 1978, Fluorescence Detection in High Performance Liquid Chromatographic Determination of Polycyclic Aromatic Hydrocarbons, Anal. Chem., v. 50, p. 967-973.

3. Dark, W.A., and W.H. McFadden and D.L. Bradford, 1977, Fractionation of Coal Liquids by HPLC with Structural Characterization by LC-MS, J. Chrom. Sc., v. 15, p. 454-460.

4. Dark, W.A. and W.H. McFadden, The Role of HPLC in the Separation and Characterization of Coal Liquefaction Products, J. Chrom. Sc., v. 16, p. 289-293.

5. Galya, L.G. and J.C. Suatoni, Rapid SARA Separations by HPLC, Pittsburgh Conference, 1979, paper 292.

6. Farcasiu, M., Fractionation and Structural Characterization of Coal Liquids, Fuel, v. 56, p. 9-14. 
APPENDIX A

ANL Bulk Sample Log-In Record 
ANL BULK SAMPLE LOG-IN RECORD

SAMPLE I.D. NO. $72 / \mathrm{H} / \mathrm{G} / \mathrm{O} / 3$

Pilot Plant: HYGAS

Run No.:

72

Date Collection: 25 May 78

Time Collected: $\quad 1150 \mathrm{hr}$

Transport to ANL

$\begin{array}{ll}\text { Person: } & \text { Sather } \\ \text { Time: } & 2: 30 \\ \text { Date: } & 25 \text { May } 78 \\ & \\ & \text { "F Code } 10534040 " \\ & \text { 0il Slurry Auto } \\ & \text { DT3012 } \\ & 1-1 \text { gal bottle } \\ \end{array}$

Comments:

The sample was taken during a steady-state period of test run 72 from the pilot plant oil-char slurry feed.stream which is the recirculating oil stream to slurry the coal prior to injection into the reactor. Initially, this stream contains commercial-grade toluene, which is gradually replaced during a test run with product oil.

Special Comments:

500 psi run

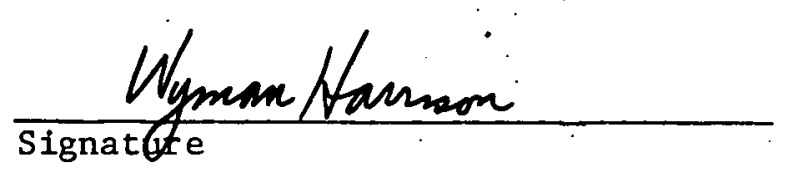


APPENDIX B

Mass Spectra of Derivatized Standards 
Rezention Time 40.6 minutes

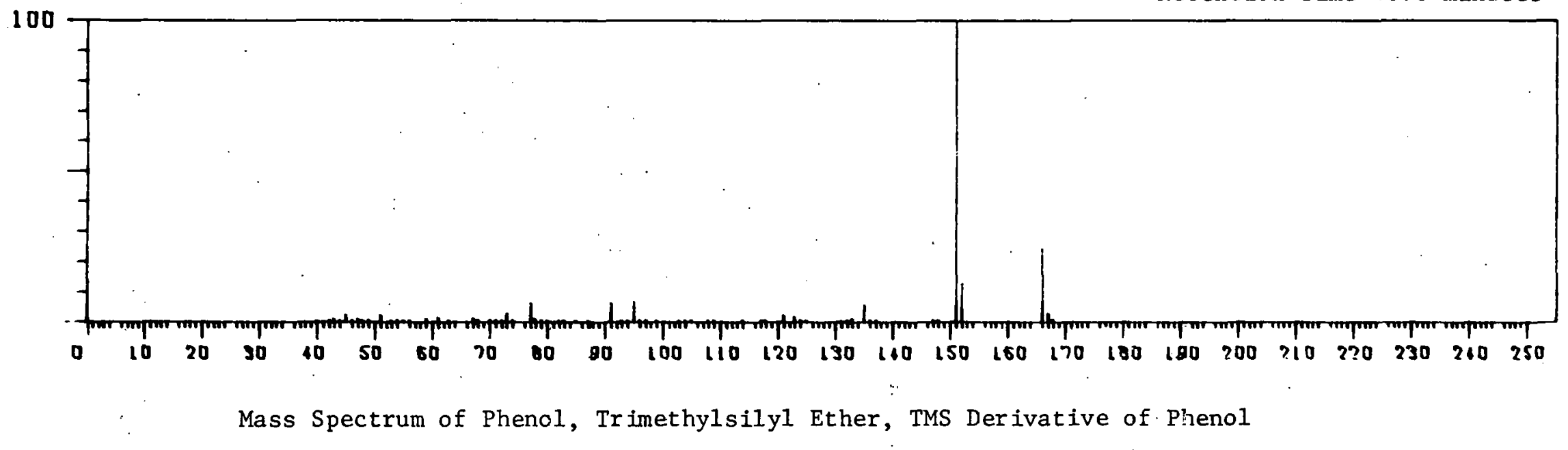

Fetention Time 51.2 minutes

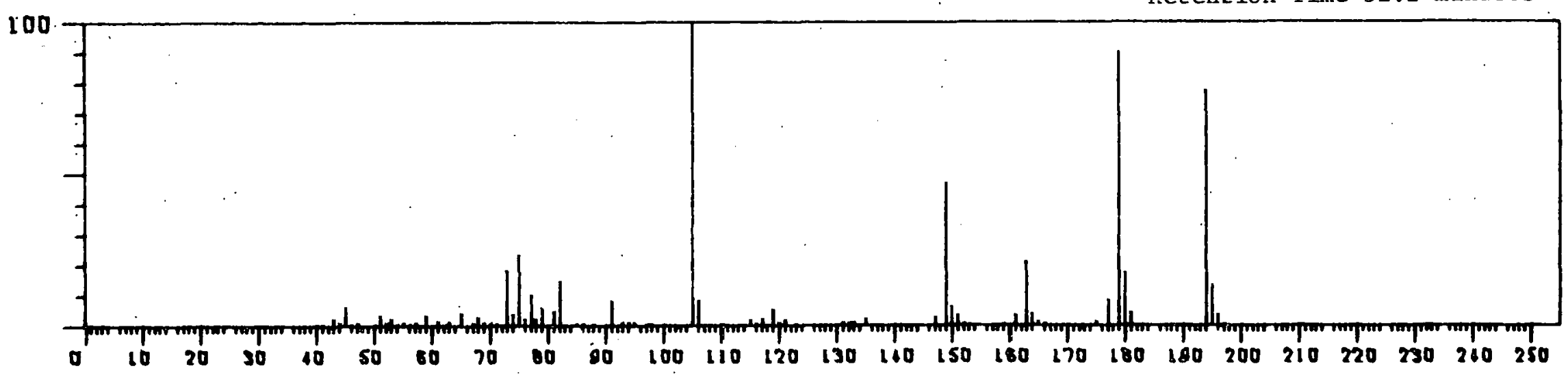

Mass Spectrum of 2,4-Xylenol, Trimethylsilyl. Ether, TMS Derivative of 2,4-Xylenol 
Retention Time 71.5 minutes

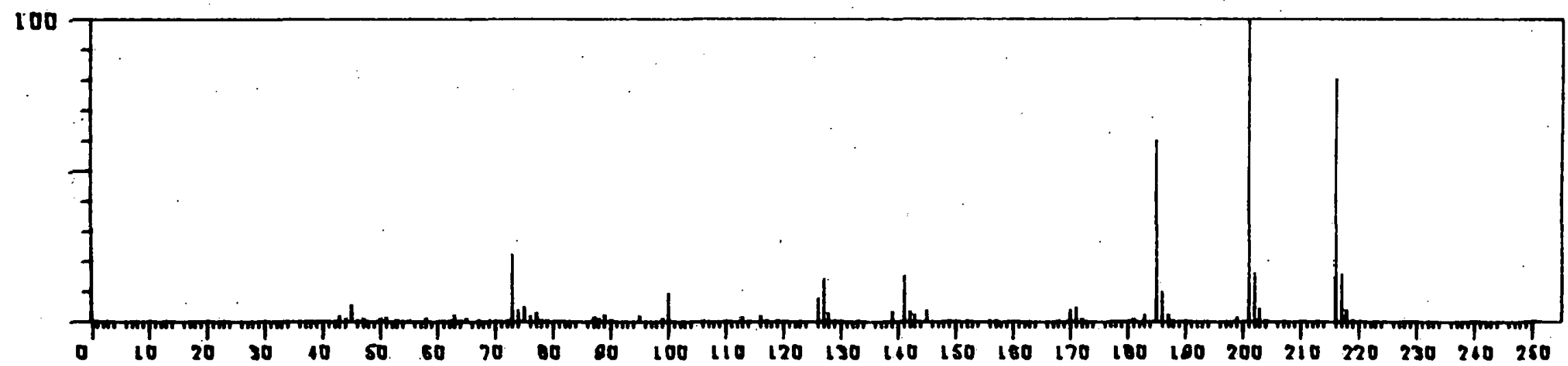

Mass Spectrum of 1-Naphthol, Trimethylsilyl Ether, TMS Derivative of 1-Naphthol

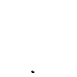

Retention Time 49.7 minutes

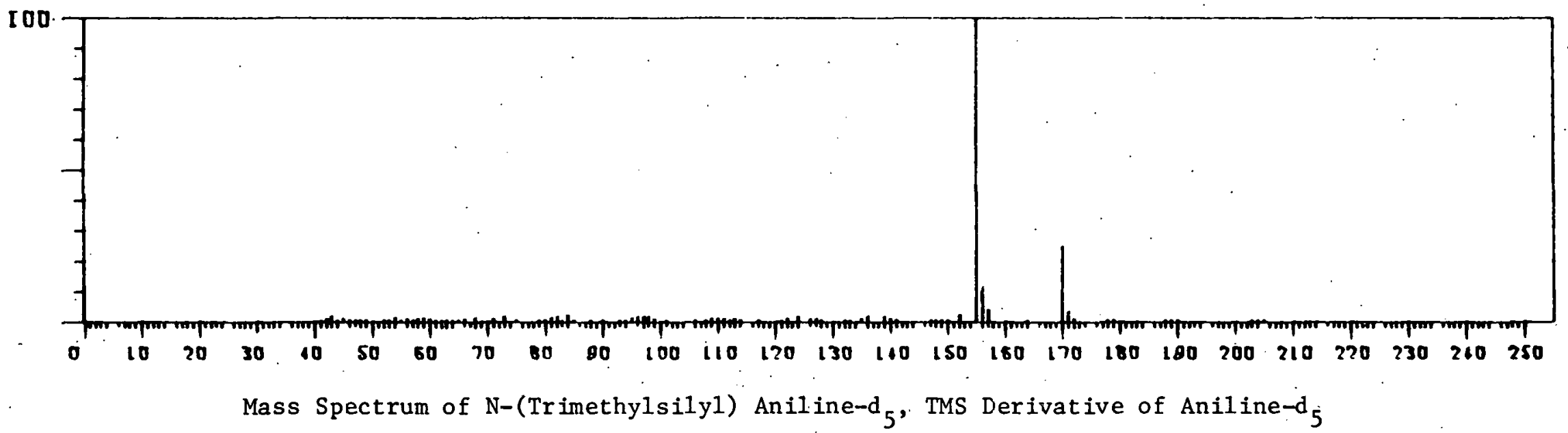


Retention Time 56.5 minutes

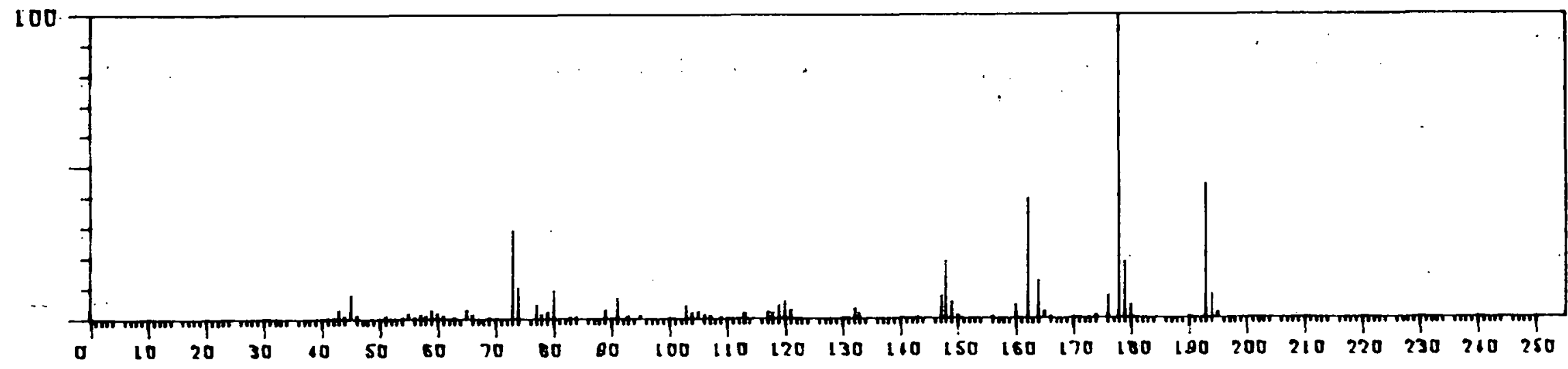

Mass Spectrum of $\mathrm{N}-($ Trimethylsilyl) 2,6-Dimethyl Aniline, TMS Derivative of 2,6-Dimethyl Aniline

Retention Time 50.5 minutes

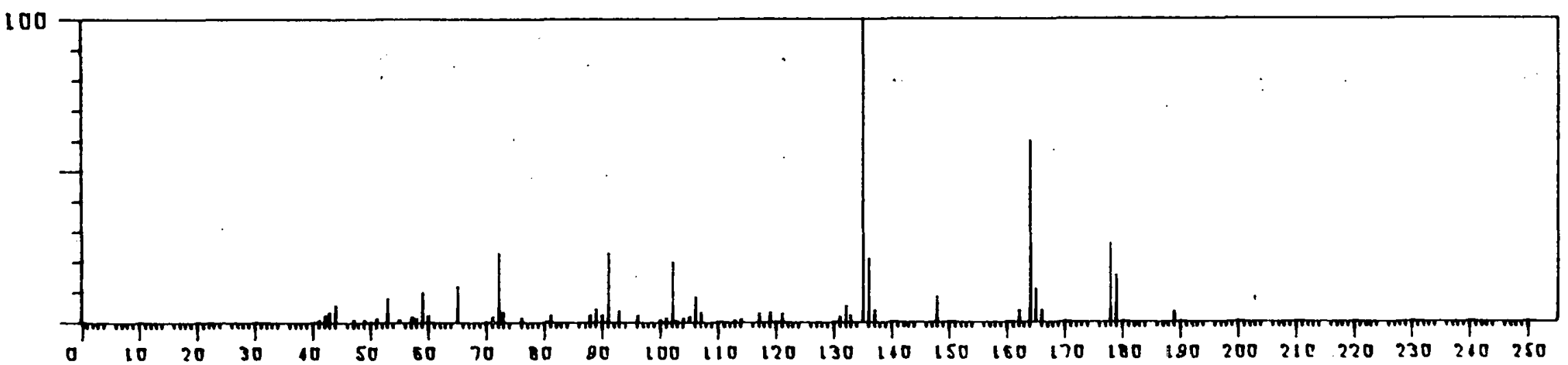

Mass Spectrum of N-(Trimethylsilyl) Benzyl Amine, TMS Derivative of Benzyl Amine 
Retention Time 46.4 minutes

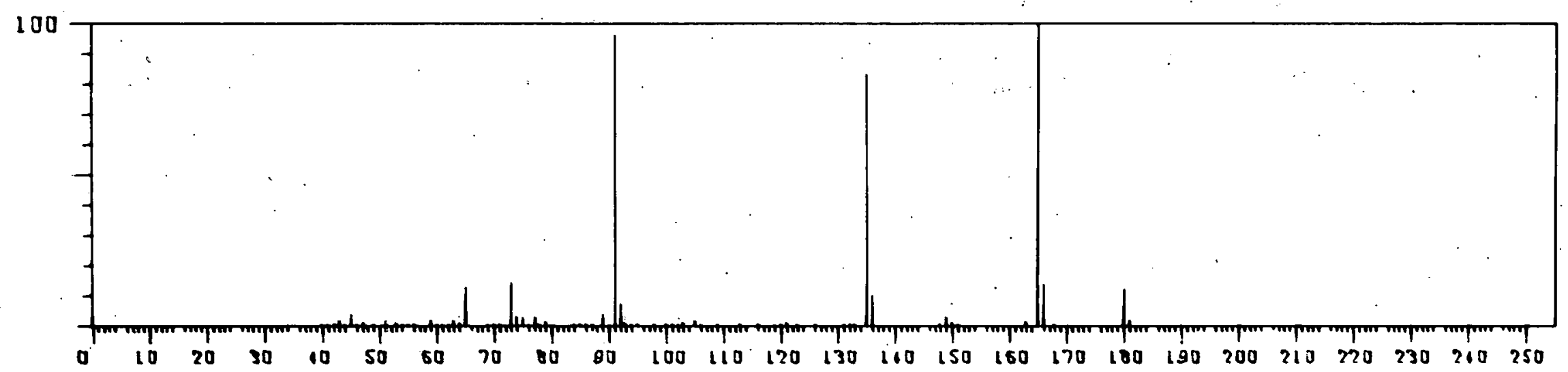

Mass Spectrum of Benzyl Alcoho1, Trimethylsily1 Ether, TMS Derivative of Benzyl Alcohol

Retention Time 27.4 minutes

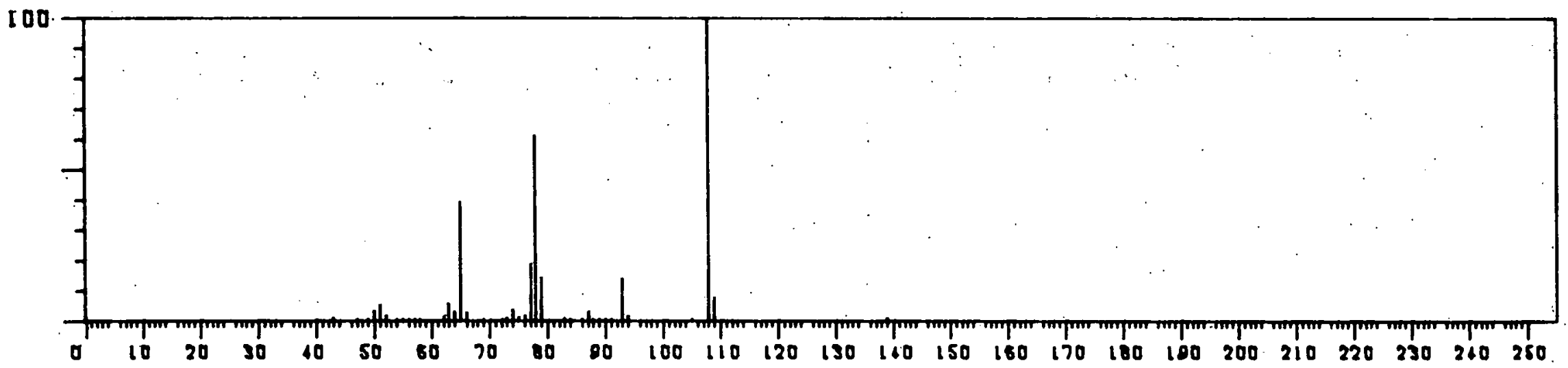

Mass Spectrum of Methoxybenzene, Methy1-8. Derivative of Phenol 
Retention Time 41.2 minutes

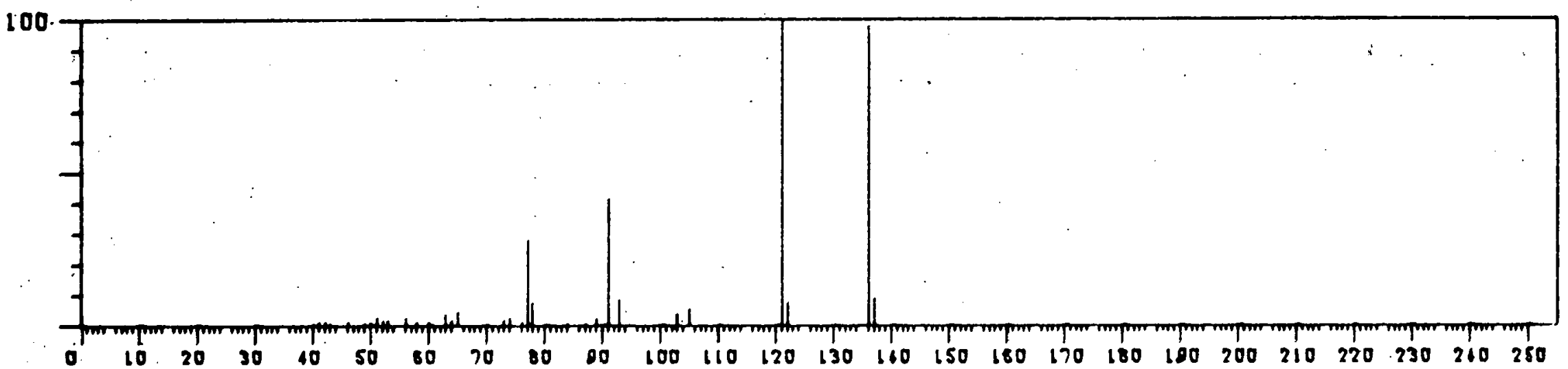

Mass Spectrum of 1-Methoxy-2,4-Dimethyl Benzene, Methyl-8 Derivative of 2,4-Xylenol

Retention Time 66.1 minutes

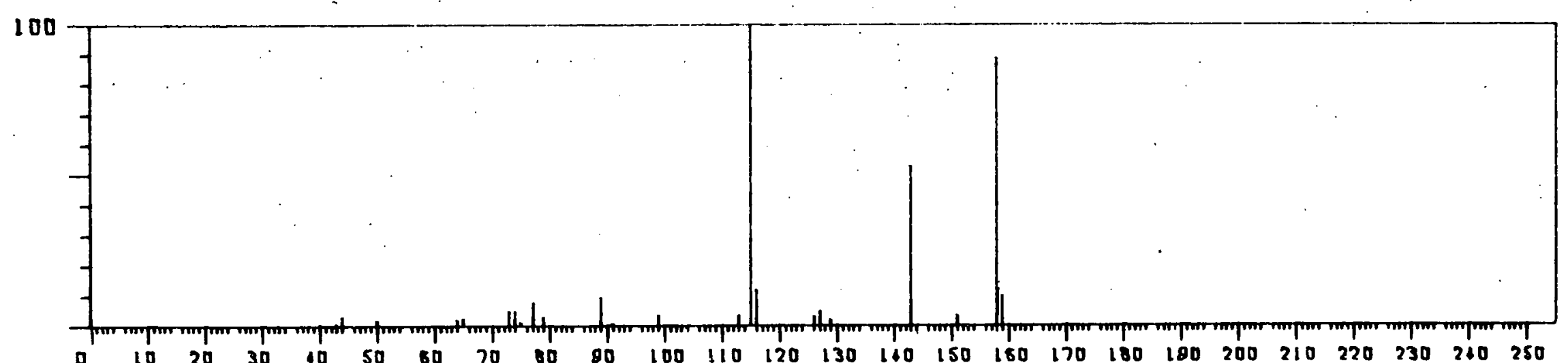

Mass Spectrum of 1-Methoxy Naphthalene, Methyl-8 Derivative of 1-Naphtho1 


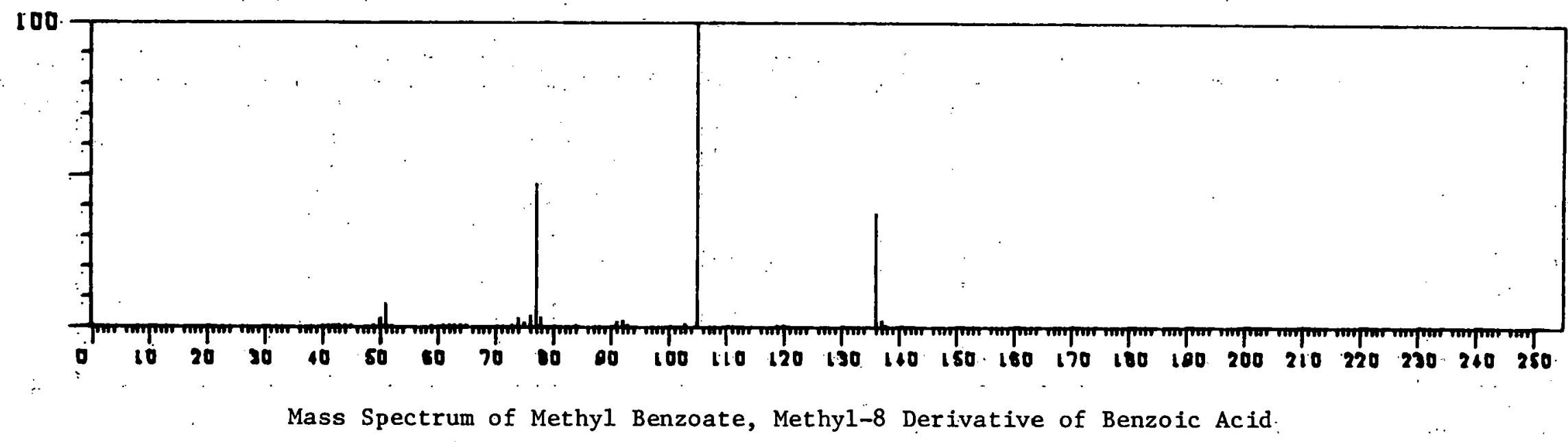

Retention Time 57.6. minutes

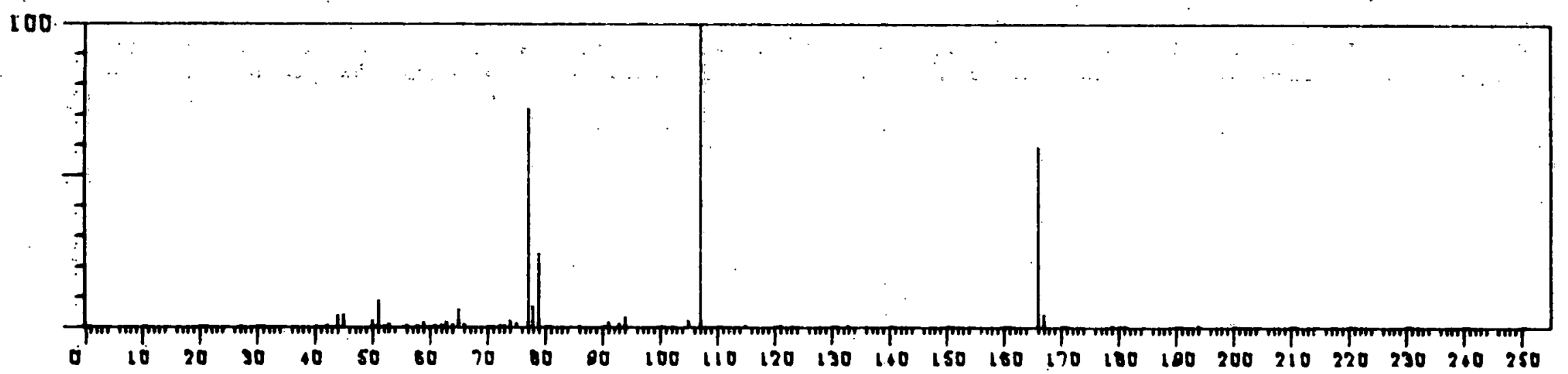

Mass Spectrum of Phenoxyacetic Acid, Methyl Ester, Methyl-8 Derivative of Phenoxyacetic Acid. 
Retention Time 82.2 minutes

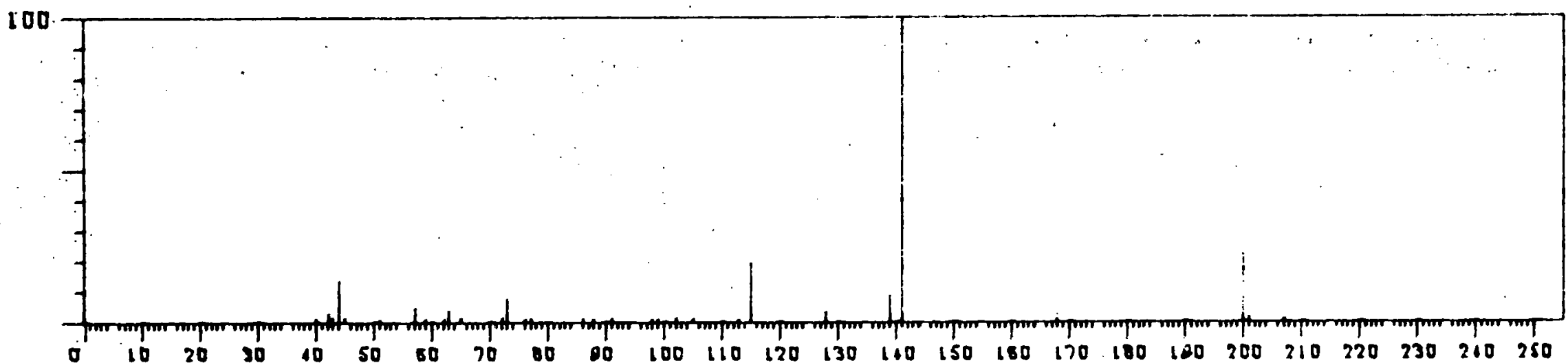

Mass Spectrum of 1-Naphthalene Acetic Acid, Methyl Ester, Methyl-8 Derivative of 1-Naphthalene Acetic Acid

Retention Time 61.7 minutes

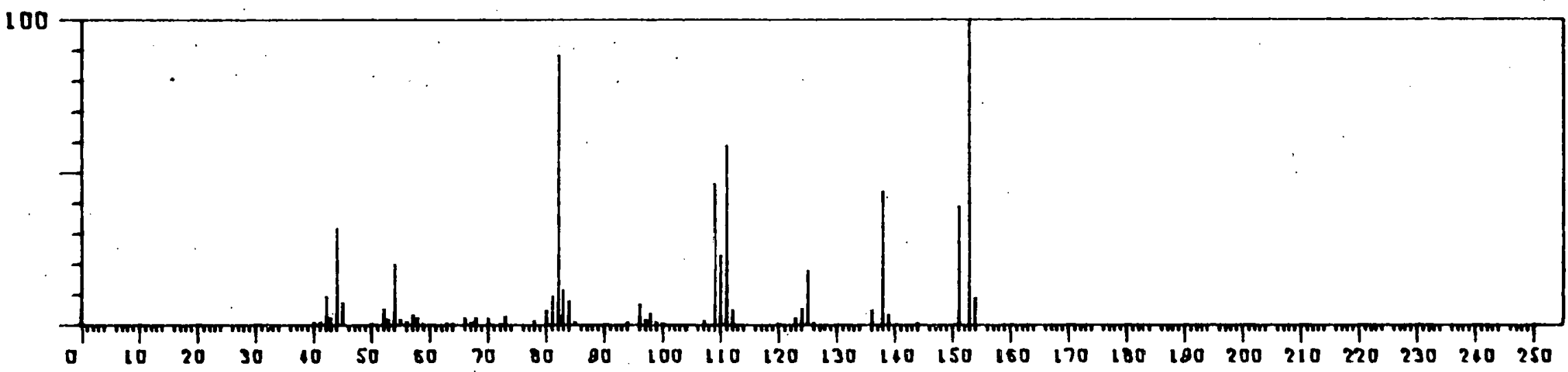

Mass Spectrum of N,N-Dimethyl-N'-Phenyl-d ${ }_{5}$ Formamidine, Methyl-8 Derivative of Aniline-d 5 
Retention Time 67.0 minutes

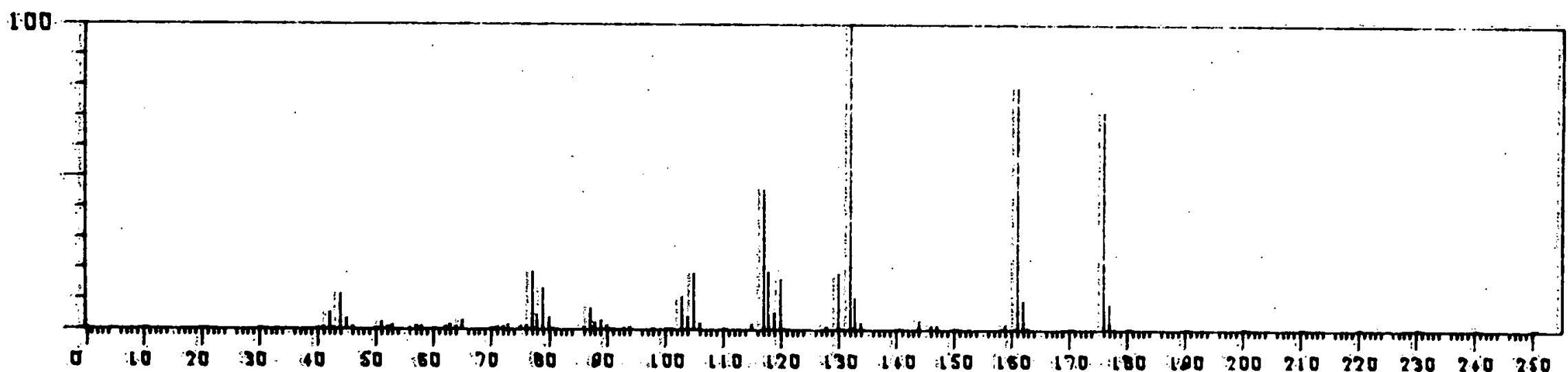

Mass Spectrum of $\mathrm{N}, \mathrm{N}^{\mathrm{N}}$-Dimethyl-N'-(2,6-Dimethylpheny1) Formamidine, Methy.1-8 Derivative of 2,6-Dimethyl Aniline

Retention Time 62.7 minutes

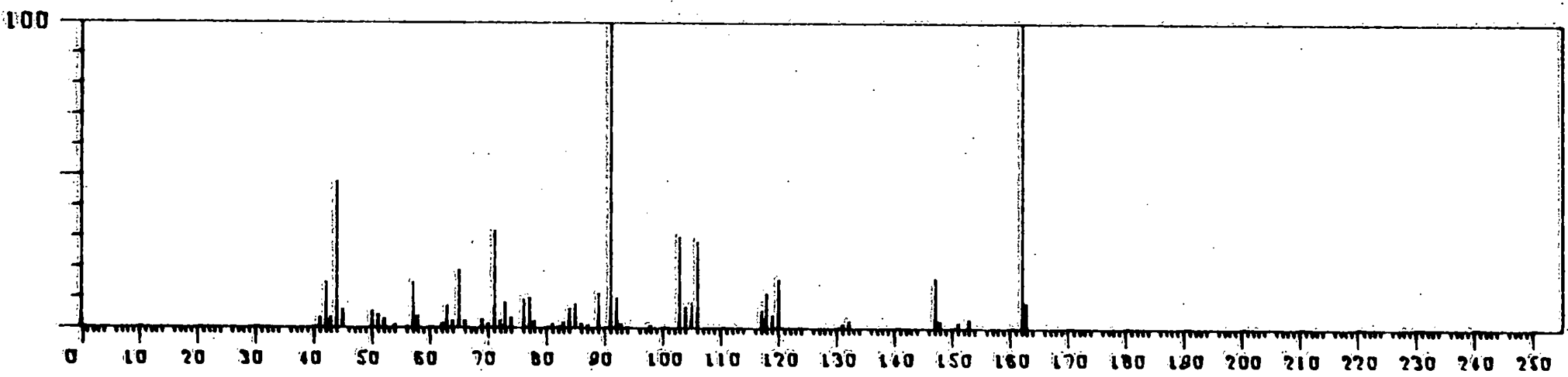

Mass Spectrum of $N, N-D i m e t h y 1-N^{\prime}-(B e n z y 1)$ Formamidine, Methyl-8 Derivative of Benzyl Amine 
THIS PAGE

\section{WAS INTENTIONALLY}

LEFT BLANK 


\begin{abstract}
APPENDIX C
REPRESENTATIVE MASS SPECTRA OF COMPOUNDS

IN FRACTIONS 1,2,3, AND 4;

TENTATIVE IDENTIFICATIONS
\end{abstract}

Retention Time

(Minutes)

50.2

51.2

52.7

56.8

58.1

60.1

60.4

60.9

61.5

62.4

62.9

64.1

66.7

67.9

68.3

69.0

69.2

70.1

74.5

76.2

46.6

47.1

51.5

51.9

52.6

54.0

54.5

55.9

56.9

57.1

58.1

58.5

59.6

61.0

61.3

61.7

62.2

62.7 .

64.2

64.5

65.4

66.0

66.3

67.3
Fraction

Compound

Page

$\mathrm{C}_{2}$-Pheno1, TMS ether

$\mathrm{C}_{2}^{2}$-Phenol, TMS ether

$\mathrm{C}_{2}^{2}$-Phenol, TMS ether

$\mathrm{C}_{3}^{2}$-Phenol, TMS ether

$\mathrm{C}_{3}^{3}$-Phenol, TMS ether

$\mathrm{C}_{4}^{3}$-Phenol, TMS ether

$\mathrm{C}_{4}^{4}$-Pheno1, TMS ether

$\mathrm{C}_{3}^{4}$-Pheno1, TMS ether

$\mathrm{C}_{1}^{3}$-Hydroxystyrene, TMS ether $\quad 70$

$\mathrm{C}_{4}^{1}$-Phenol; TMS ether $\quad 70$

$\mathrm{C}_{2}^{4}$-Hydroxystyrene, TMS ether 71

$\mathrm{C}_{2}^{2}$-Hydroxystyrene, TMS ether 71

$\mathrm{C}_{2}^{2}$-Hydroxystyrene, TMS ether $\quad 72$

$\mathrm{C}_{2}^{2}$-Hydroxystyrene, TMS ether $\quad 72$

$\mathrm{C}_{2}^{2}$-Hydroxystyrene, TMS ether 73

$\mathrm{C}_{3}^{2}$-Hydroxystyrene, TMS ether 73

$\mathrm{C}_{2}^{3}$-Hydroxystyrene, TMS ether $\quad 74$

$\mathrm{C}_{3}^{2}$-Hydroxystyrene, TMS ether $\quad 74$

$\mathrm{C}_{3}^{3}$-Hydroxystyrene, TMS ether. 75

$\mathrm{C}_{4}^{3}$-Hydroxystyrene, TMS ether 75

Cresol, TMS ether 76

Cresol, TMS ether 76

$\mathrm{C}_{2}$-Pheno1, TMS ether $\quad 77$

$\mathrm{C}_{2}^{2}$-Phenol, TMS ether $\quad 77$

$\mathrm{C}_{2}^{2}$-Phenol, TMS ether. 78

$\mathrm{C}_{2}^{2}$-Pheno1, TMS ether 78

$\mathrm{C}_{3}^{2}$-Phenol, TMS ether $\quad 79$

$\mathrm{C}_{3}^{3}$-Phenol, TMS ether 79.

$\mathrm{C}_{3}^{3}$-Pheno1, TMS ether 80

$\mathrm{C}_{3}^{3}$-Phenol, TMS ether 80

$\mathrm{C}_{3}^{3}$-Phenol, TMS ether. 81

$\mathrm{C}_{3}^{3}$-Phenol, TMS ether 81

$\mathrm{C}_{4}$-Phenol, TMS ether 82

$\mathrm{C}_{3}$-Phenol, TMS ether $\quad 82$

$\mathrm{C}_{4}^{3}$-Phenol, TMS ether 83

$\mathrm{C}_{1}^{4}$-Hydroxystyrene, TMS ether 83

Hydroxyindene, TMS ether 84

Hydroxyindene, TMS ether 84

$\mathrm{C}_{4}$-Phenol, TMS ether $\quad 85$

$\mathrm{C}_{4}^{4}$-Phenol, TMS ether 85

$\mathrm{C}_{2}^{4}$-Hydroxystyrene, TMS ether 86

$\mathrm{C}_{2}^{2}$-Hydroxystyrene, TMS ether 86

$\mathrm{C}_{5}^{2}$-Phenol, TMS ether 87

$\begin{array}{ll}\mathrm{C}_{3} \text {-Hydroxystyrene, TMS ether } & 87\end{array}$ 
APPENDIX C (Contd.)

Retention Time (Minutes)

$\underline{\text { Fraction }}$

Compound

Page

69.4

3

69.8

$\mathrm{C}_{2}$-Hydroxystyrene, TMS ether

71.0

Methyl hydroxyindene, TMS ether 88

71.2

$\mathrm{C}_{3}$-Hydroxystyrene, TMS ether

73.8

$\mathrm{C}_{3}^{3}$-Hydroxystyrene, TMS ether

89

$\mathrm{C}_{3}$-Hydroxystyrene, TMS ether 90

74.8

$\mathrm{C}_{4}^{3}$-Hydroxystyrene, TMS ether.

90

76.9

$\mathrm{C}_{2}^{4}$-Hydroxyindene, TMS ether

78.5

53.0

59.7

Methyl hydroxybenzothiophene, TMS ether 91

61.8

64.1

64.3

66.2

Hydroxystyrene, TMS ether

$\mathrm{C}_{1}$-Hydroxystyrene, TMS ether

$\mathrm{C}_{1}^{1}$-Hydroxystyrene, TMS ether

Hydroxyindene, TMS ether

Hydroxyindene, TMS ether

$\mathrm{C}_{2}$-Hydroxystyrene, TMS ether

Methyl hydroxyindene, TMS ether

Hydroxy benzothiophene, TMS ether

Naphthol, TMS ether

Hydroxybenzothiophene, TMS ether

Hydroxybenzothiophene, TMS ether

Methyl hydroxybenzothiophene, TMS ether

Methyl hydroxybenzothiophene, TMS ether

Methyl naphtho1, TMS ether.

Methyl naphthol, TMS ether

Methyl hydroxybenzothiophene, TMS ether

Methyl naphthol, TMS ether

$\mathrm{C}_{2}$-Hydroxybenzothiophene, TMS ether, 100

Hydroxybiphenyl, TMS ether

101

$\mathrm{C}_{2}$-Naphthol, TMS ether

101

$\mathrm{C}_{2}^{2}$-Naphthol, TMS ether

102

$\mathrm{C}_{2}^{2}$-Naphthol; TMS ether

102

Methyl hydroxybiphenyl, TMS ether 103

$\mathrm{C}_{2}$-Naphthol, TMS ether .. 104

Methyl hydroxybipheny1, TMS ether 105

Methyl hydroxybiphenyl, TMS ether 106

$\mathrm{C}_{2}$-Hydroxybipheny1, TMS ether 107

Hydroxyfluorene, TMS ether . 108

Anisole

109

$\mathrm{C}_{2}$-Pyridine 109

Methyl anisole 110

Hydroxystyrene, methyl ether 110

$\mathrm{C}_{2}$-Anisole 111

$\mathrm{C}_{2}^{2}$-Anisole $\quad 111$

$\mathrm{C}_{2}^{2}$-Anisole $\quad 112$

$\mathrm{C}_{2}^{2}$-Anisole $\quad 112$

$\mathrm{C}_{2}^{2}$-Anisole 113

$\mathrm{C}_{3}^{2}$-Anisole 113

48.1

48.4

$\mathrm{C}_{3}$-Anisole

114 
APPENDIX C (Contd.)

Retention Time (Minutes)

Fraction

Compound

Page

48.7

$\mathrm{C}_{3}$-Anisole

114

50.1

$\mathrm{C}_{3}^{3}$-Anisole

115

50.3

$\mathrm{C}_{3}^{3}$-Anisole

115

52.5

$\mathrm{C}_{4}$-Anisole

116

54.5

$\mathrm{C}_{4}^{4}$-Anisole

116

54.8

$\mathrm{C}_{4}^{4}$-Anisole

117

55.0

Methyl hydroxystyrene, methyl ether

117

$\mathrm{C}_{2}$-Hydroxystyrene, methyl ether

118

68.7

75.1

78.2

79.3

83.8

85.1

89.0

91.8

55.2

63.5

Hydroxybenzothiophene, methyl-d

Methyl naphthol, methyl-d 3 ether

Hyd roxybiphenyl, methyl-d $\mathrm{d}_{3}^{3}$ ether

Hydroxybipheny1, methyl-d $\mathrm{d}_{3}$ ether

$\mathrm{C}_{1}$-Hydroxybiphenyl, methyl- $\mathrm{d}_{3}$ ether

$\mathrm{C}_{1}^{1}$-Hydroxybipheny1, methyl-d $\mathrm{d}_{3}^{3}$ ether

$\mathrm{C}_{2}^{1}$-Hydroxybiphenyl, methyl- $\mathrm{d}_{3}^{3}$ ether

$\mathrm{C}_{2}^{2}$-Hydroxybiphenyl, methyl- $\mathrm{d}_{3}^{3}$ ether

Methyl naphthalene

118

119

119

120

120

121

121

122

122

$\mathrm{C}_{2}$-Naphthalene

123

Methy 1 biphenyl

123

$\mathrm{C}_{3}$-Naphthalene

124

70.9

$\mathrm{C}_{3}$-Naphthalene

124

Fluorene

125

$\mathrm{C}_{2}$-Acenaphthene

125

$\mathrm{C}_{2}^{2}$-Acenaphthene 126

77.6

$\mathrm{C}_{3}^{2}$-Acenaphthene

126

$\mathrm{C}_{3}$-Ac enaphthene

127

$C_{2}^{3}$-Biphenyl

127

Phenanthrene

128

Anthracene

128

Aceant hrene/Acephenanthrene

129

96.2

101.6

Pyrene 


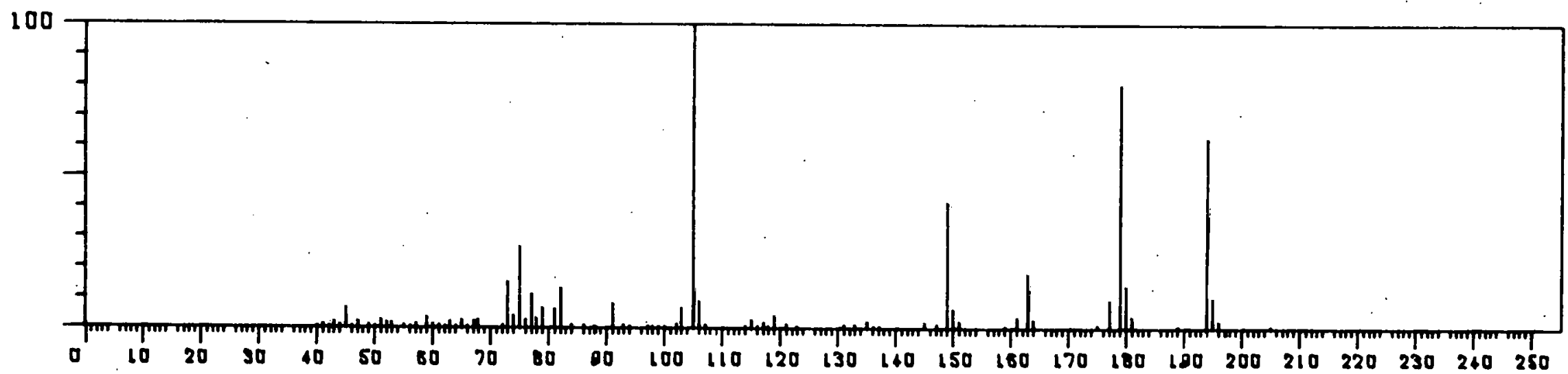

$\mathrm{C}_{2}$-Phenol, TMS ether

Retention Time 50.2

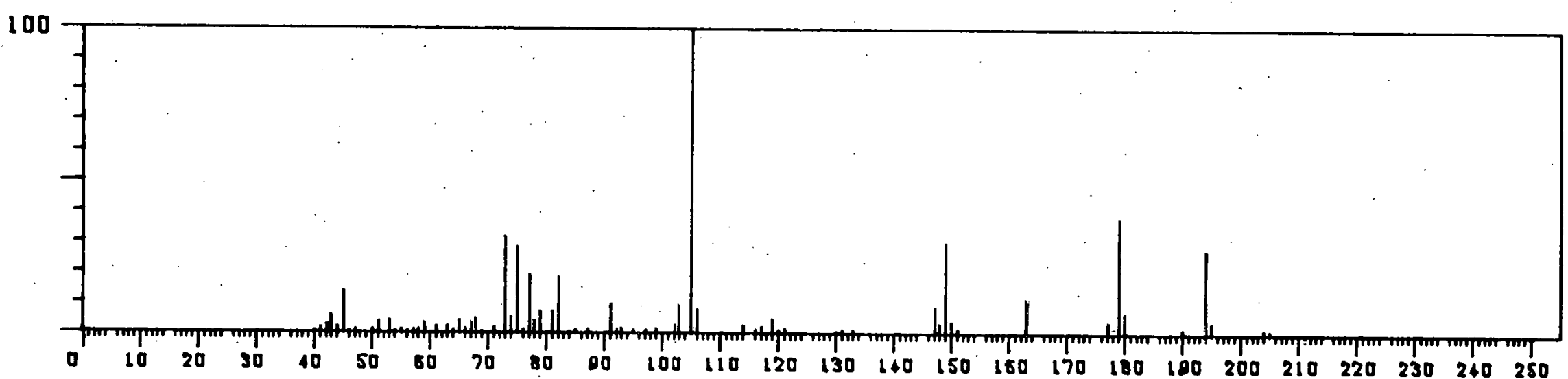

$\mathrm{C}_{2}$-Phenol, TMS ether

Retention Time 51.2 


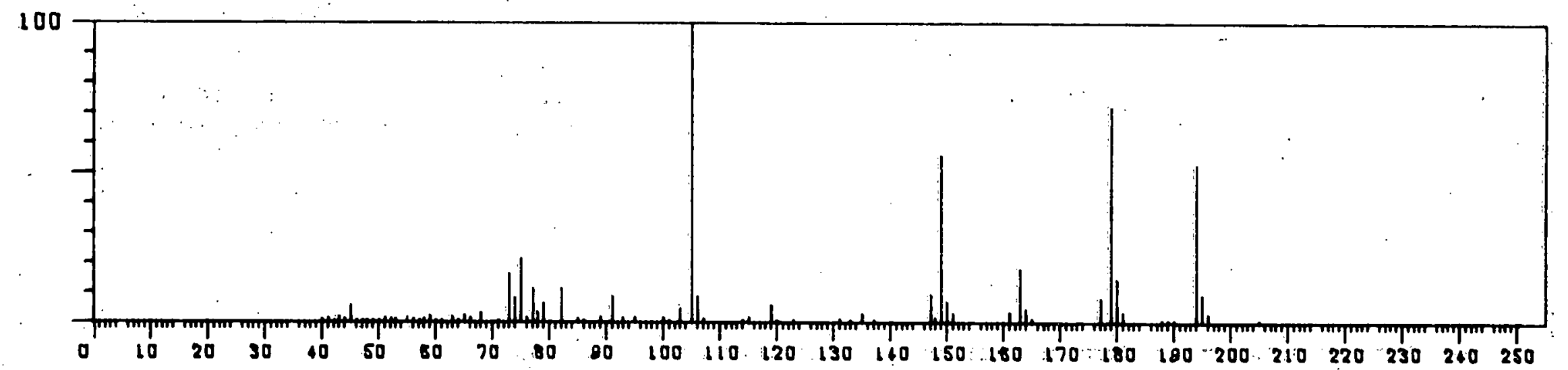

$C_{2}$-Phenol, TMS ether

Retention Time $\mathbf{5 2 . 7}$

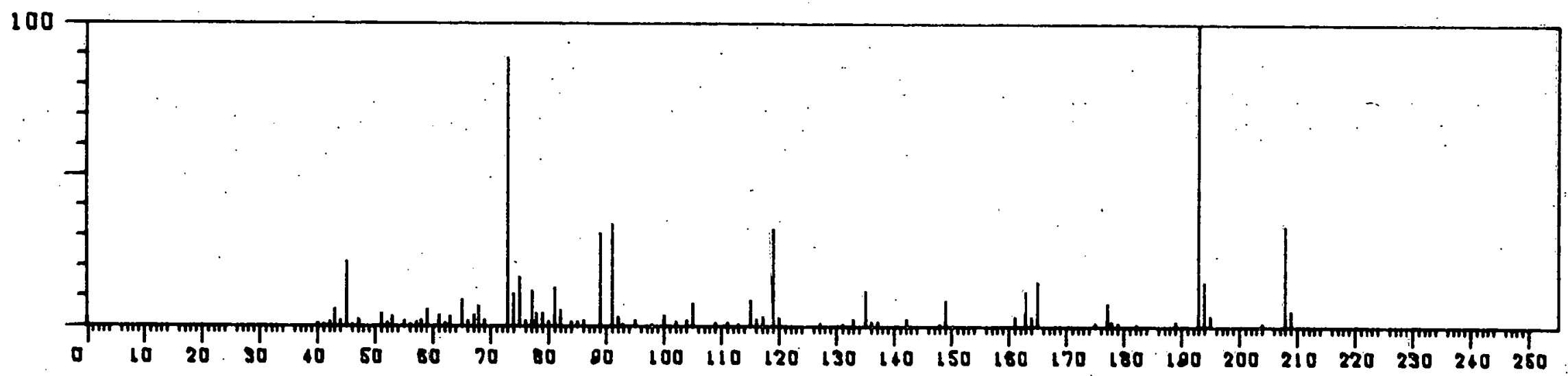

$C_{3}$-Phenol, TMS ether

Retention Time 56.8 


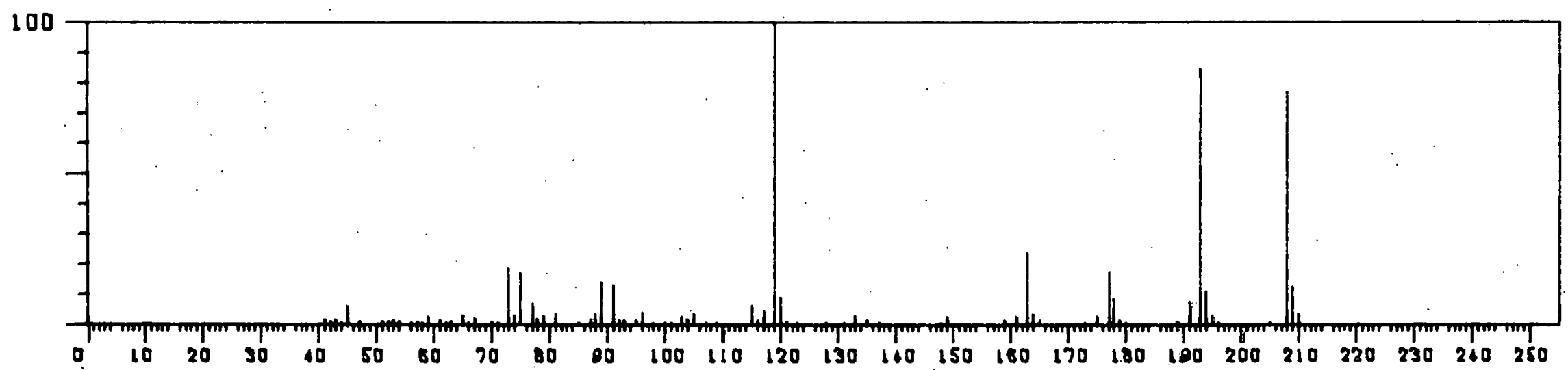

$\mathrm{C}_{3}$-Pheno1, TMS ether

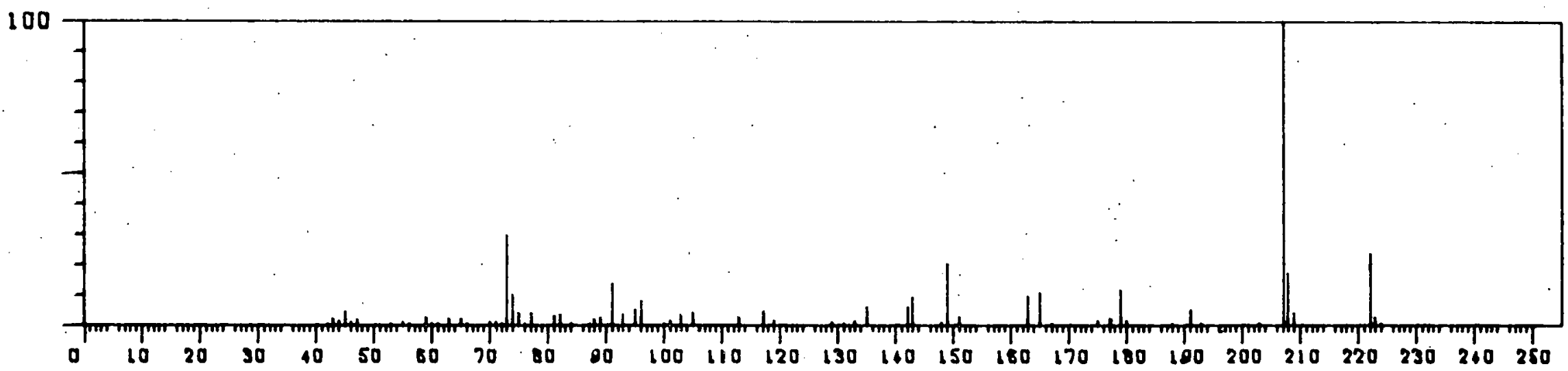

$\mathrm{C}_{4}$-Phenol, TMS ether

Retention Time 60.1 


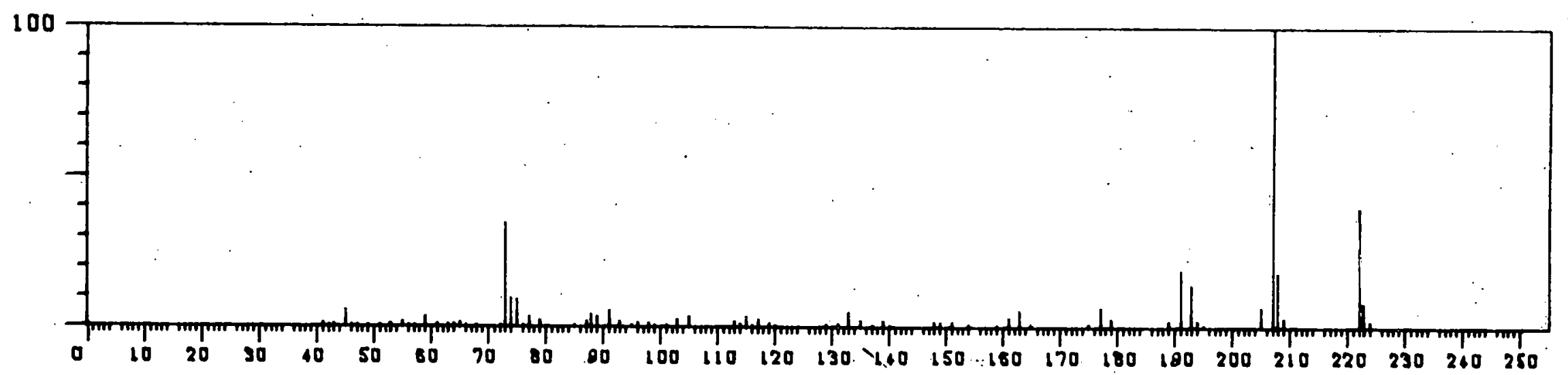

$\mathrm{C}_{4}$-Phenol, TMS ether

Retention Time 60.4

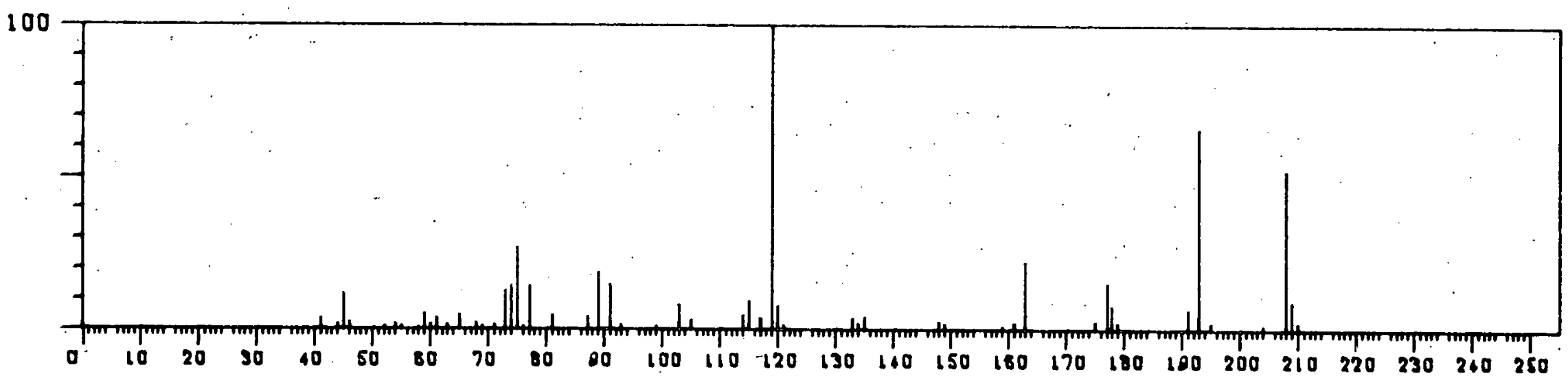

$\mathrm{C}_{3}$-Pheno1, TMS ether

Retention Time 60.9 


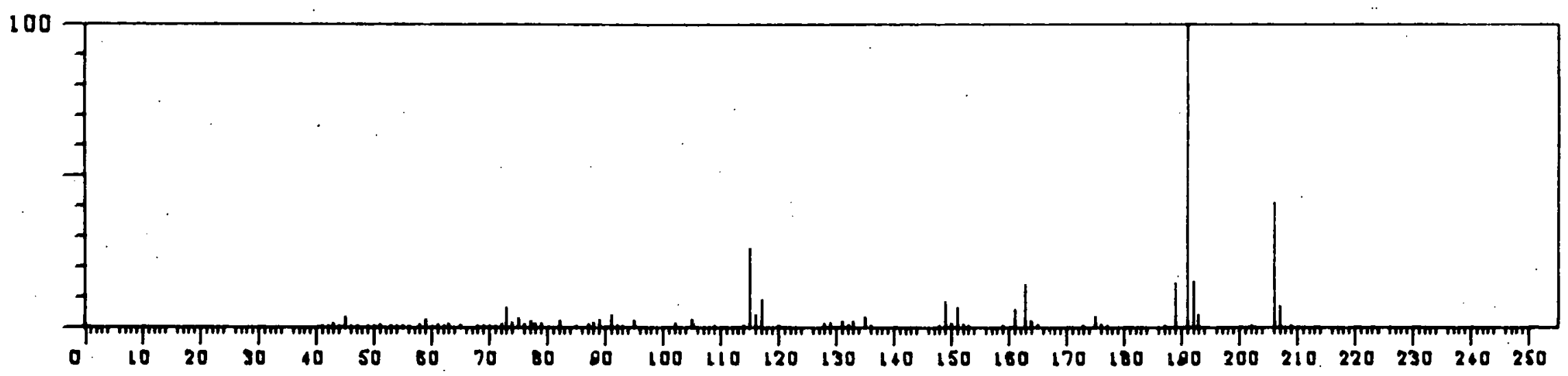

$\mathrm{C}_{1}$-Hydroxystyrene, TMS ether

Retention Time 61.5

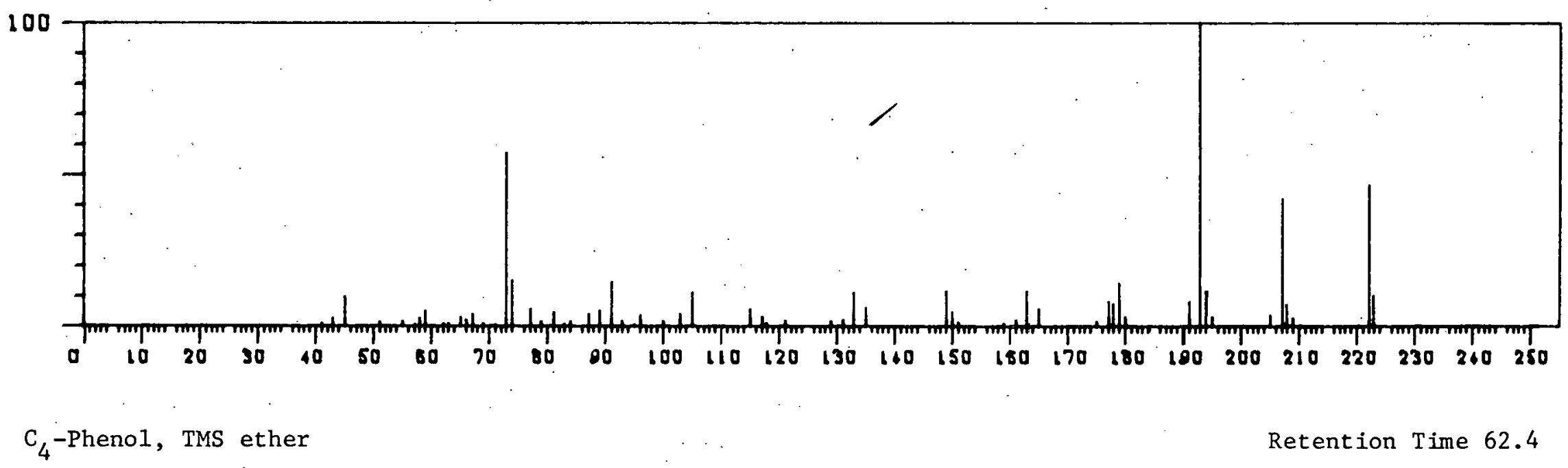




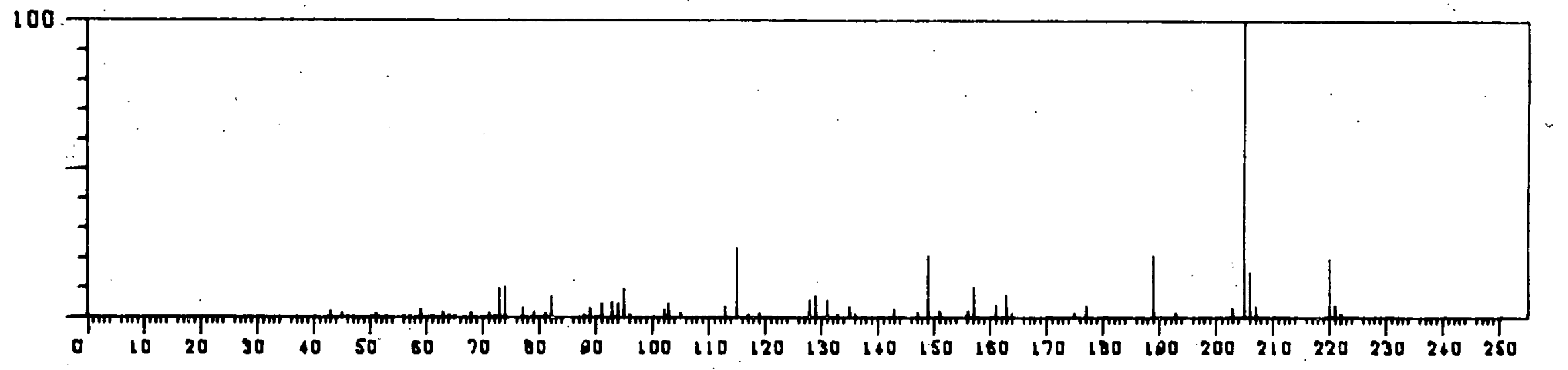

$\mathrm{C}_{2}$-Hydroxystyrene, TMS ether

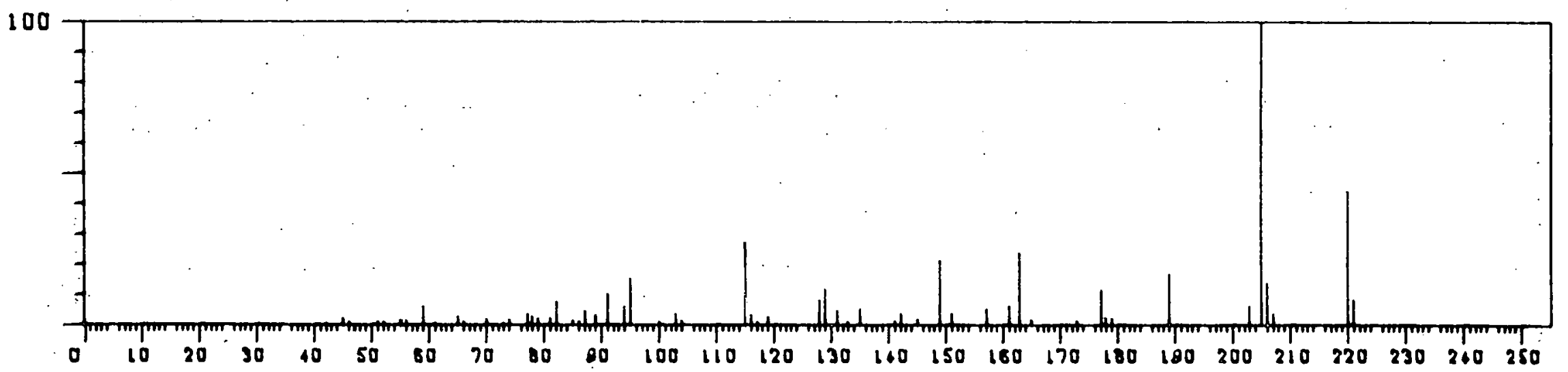

$C_{2}$-Hydroxystyrene, TMS ether

Retention Time 64.1 


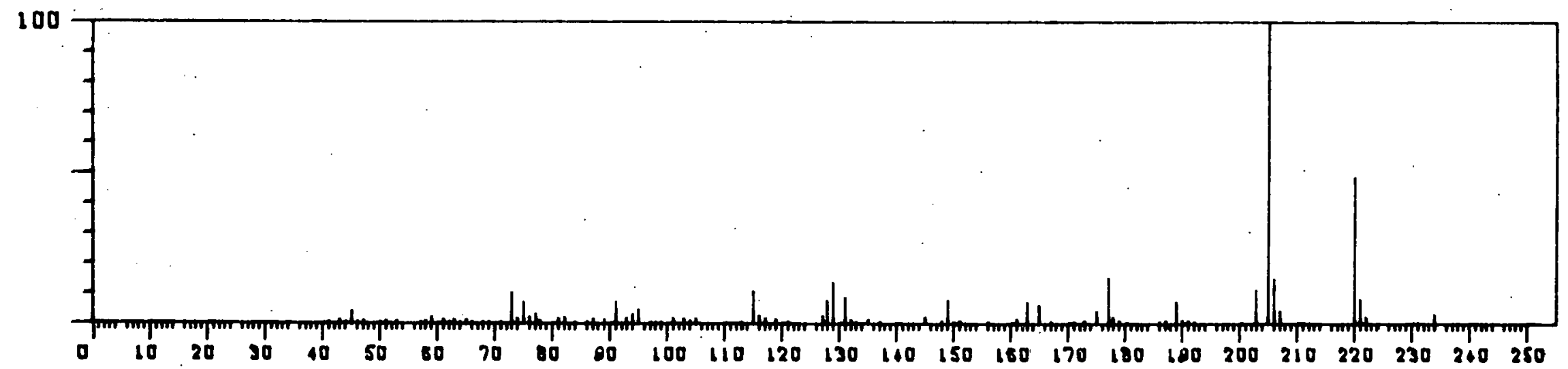

$C_{2}$-Hydroxystyrene, TMS ether

Retention Time 66.7

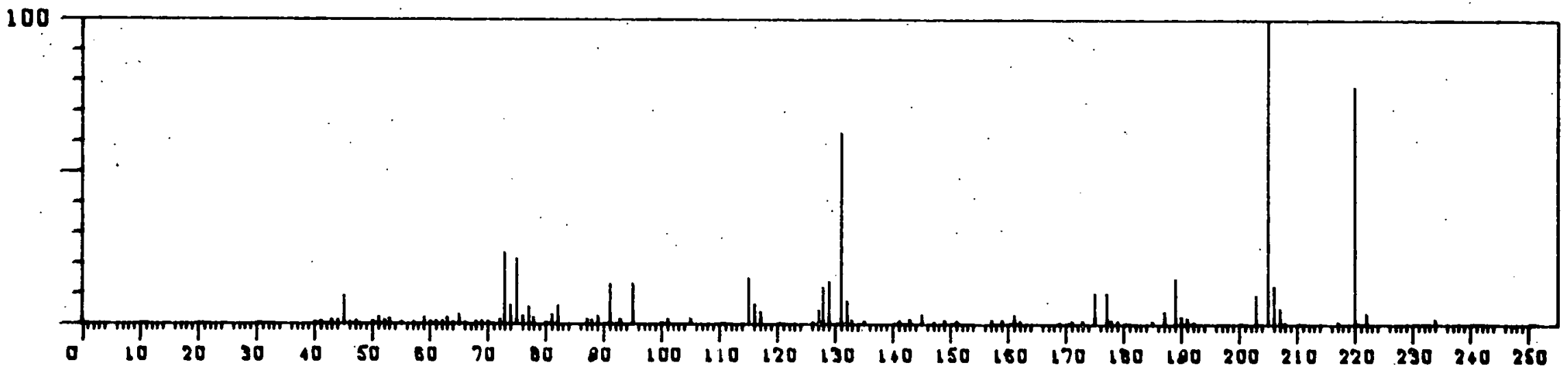

$\mathrm{C}_{2}$-Hydroxystyrene, TMS ether Retention Time 67.9 


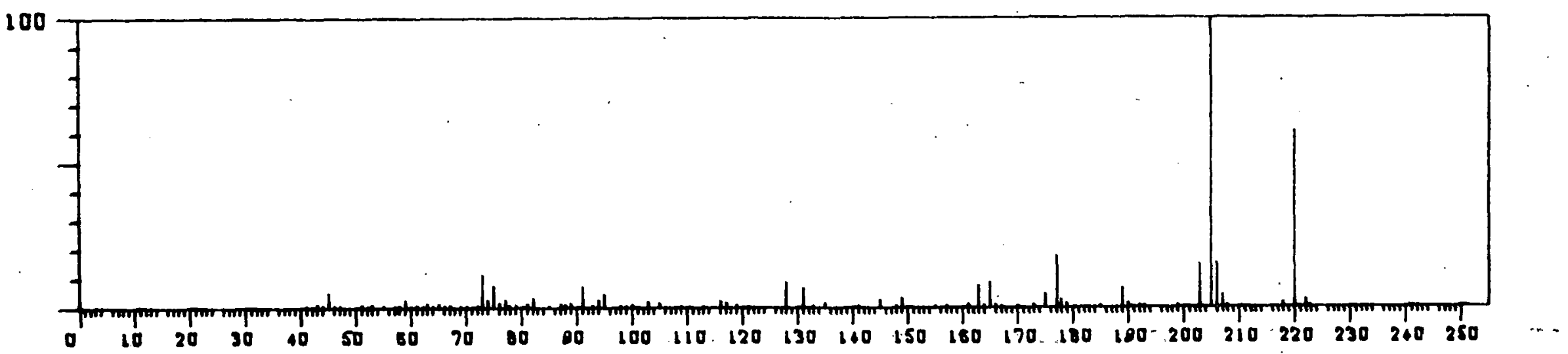

$\mathrm{C}_{2}$-Hydroxystyrene, TMS ether

Retention Time 68.3

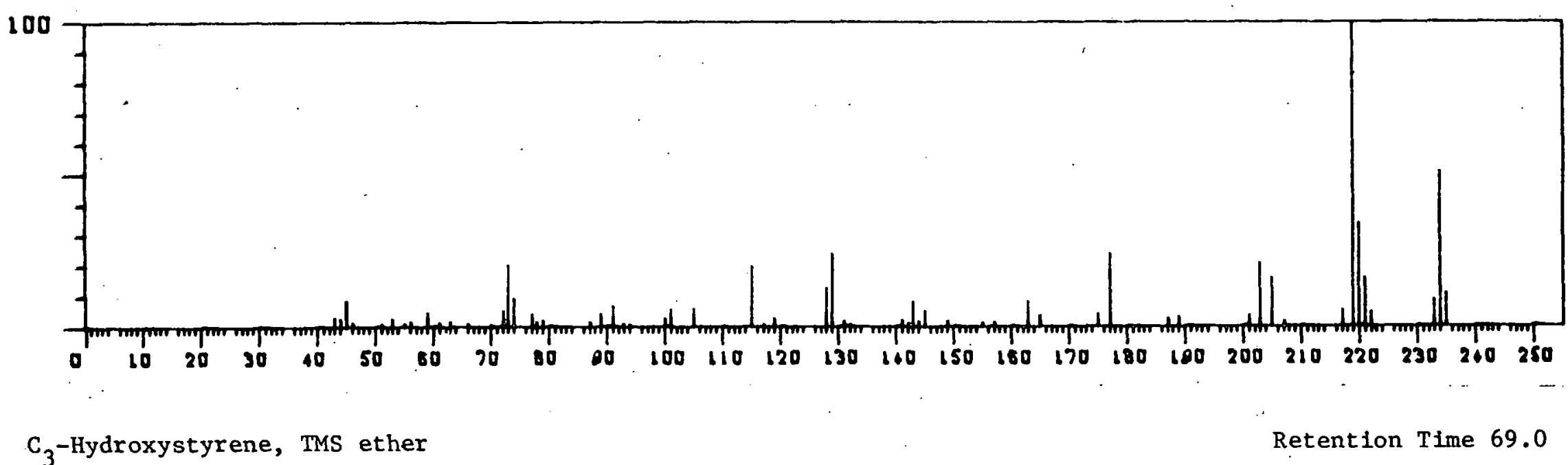




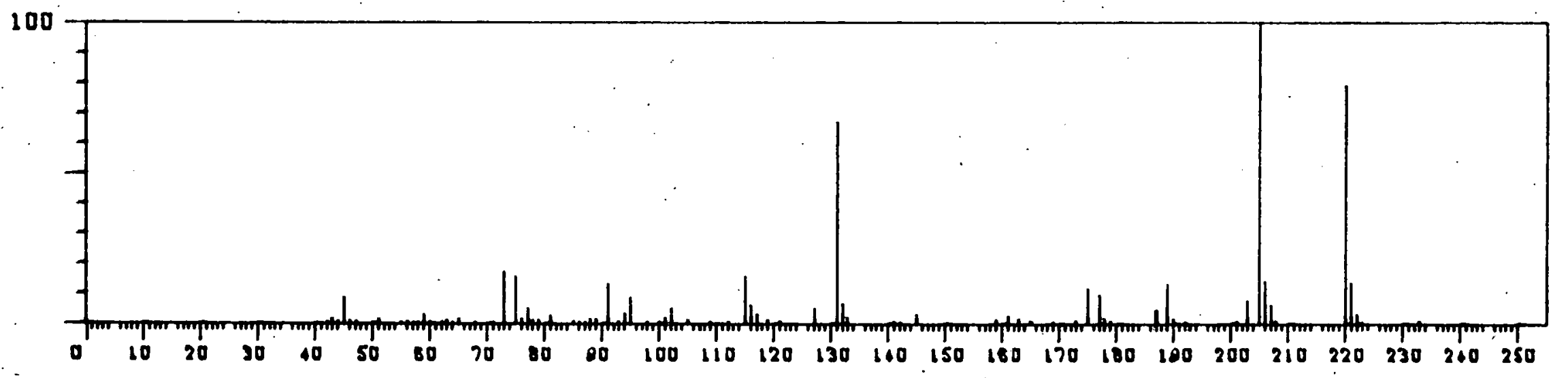

$c_{2}$-Hydroxyst yrene, TMS ether

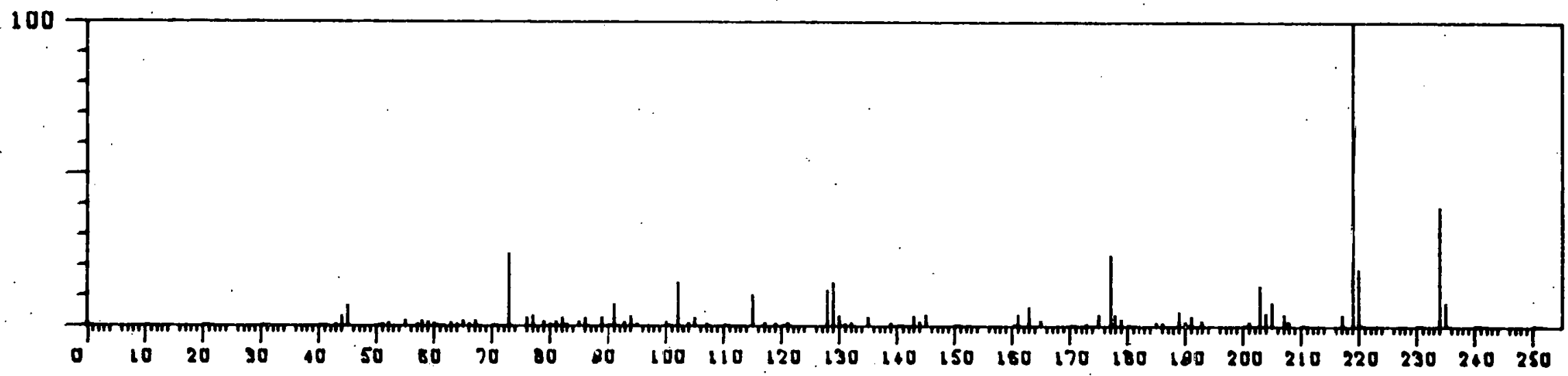

$\mathrm{C}_{3}$-Hydroxystyrene, TMS ether 


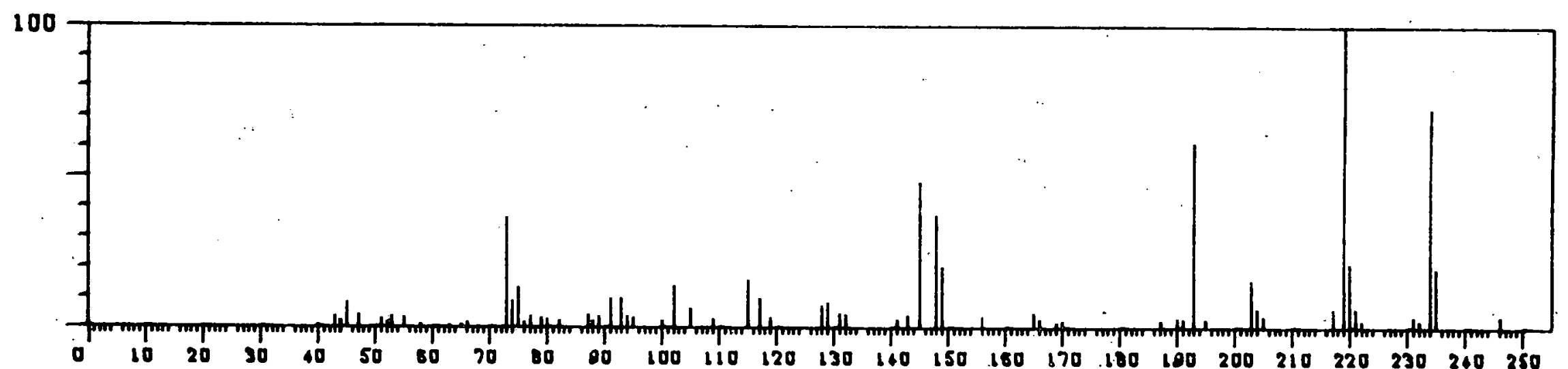

$\mathrm{C}_{3}$-Hydroxystyrene, TMS ether

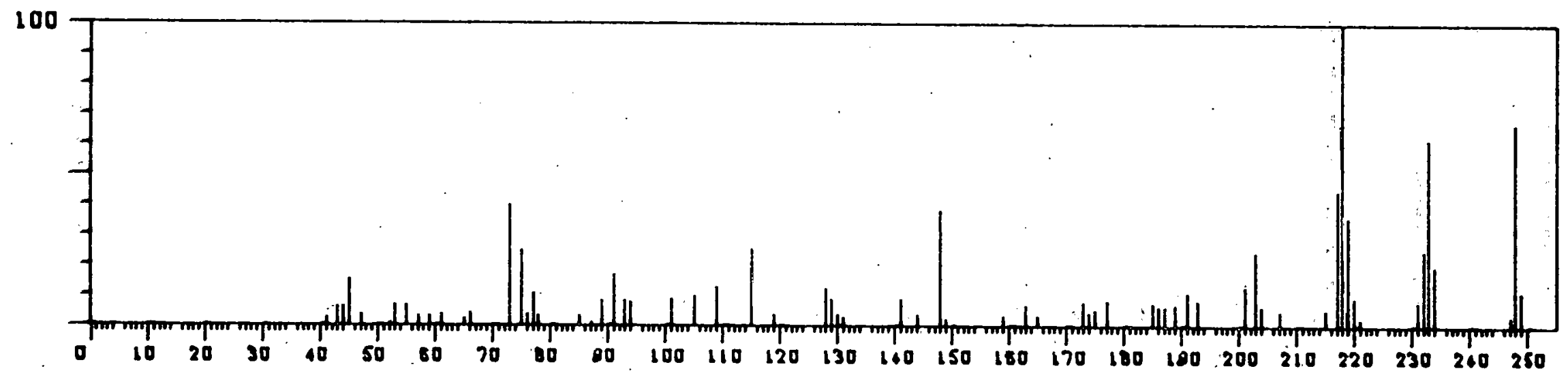

$\mathrm{C}_{4}$-Hydroxystyrene, TMS ether 


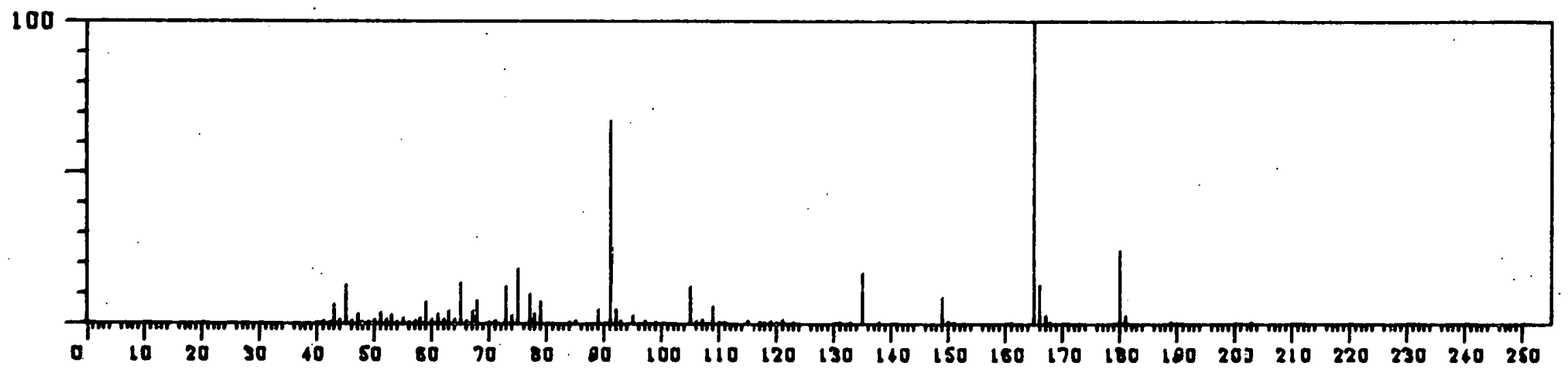

Creso1, TMS ether

Retention Time 46.6

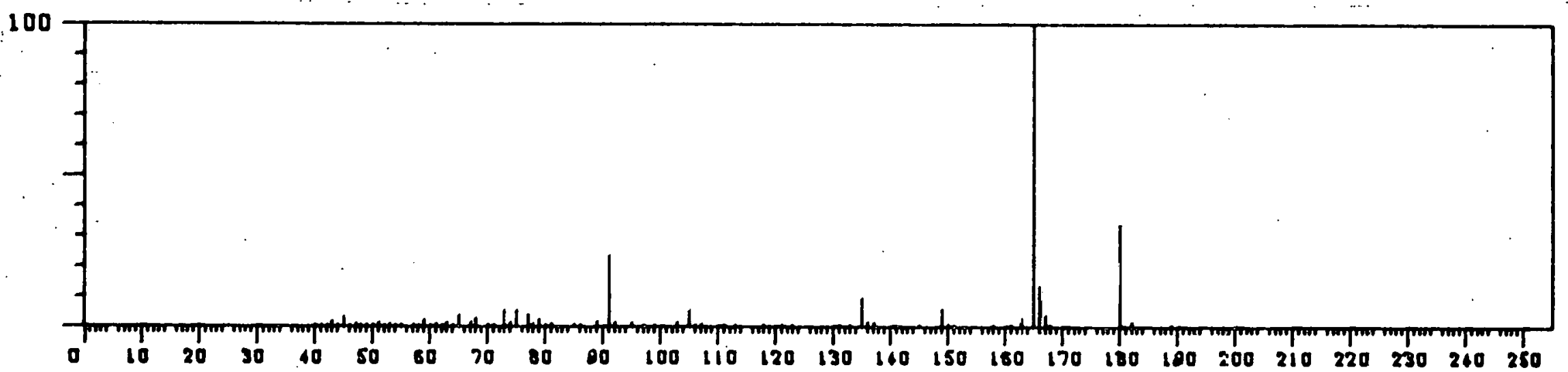

Cresol, TMS ether

Retention Time 47.1 


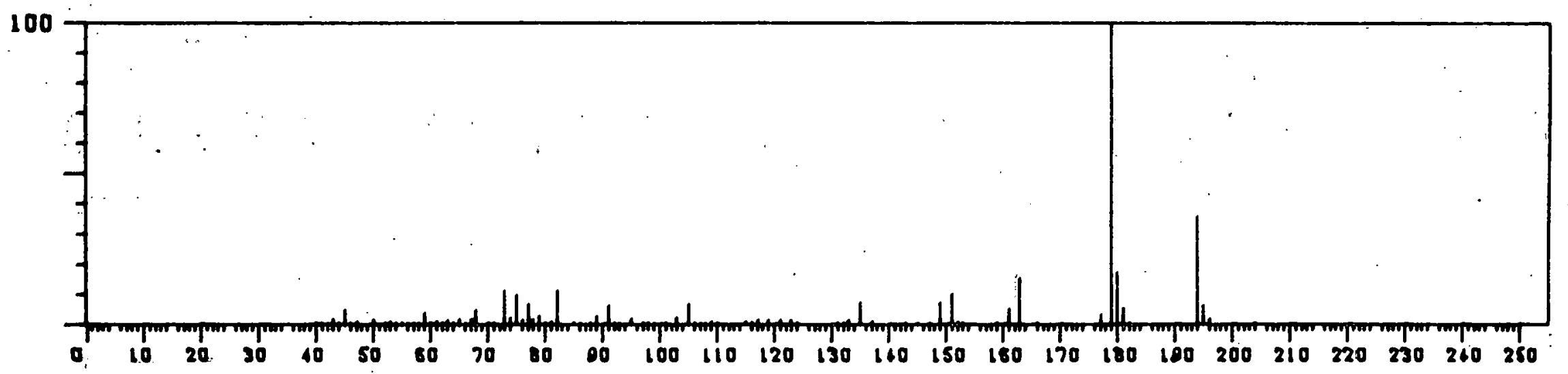

$\mathrm{C}_{2}$-Pheno1, TMS ether.

Retention Time 51.5

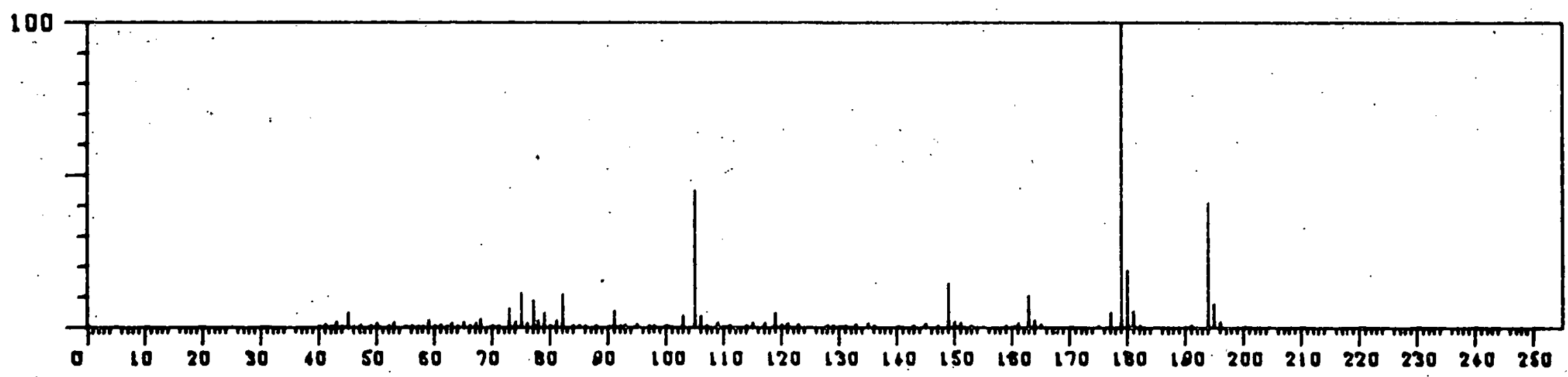

$C_{2}$-Phenol, TMS ether

Retention Time 51.9 


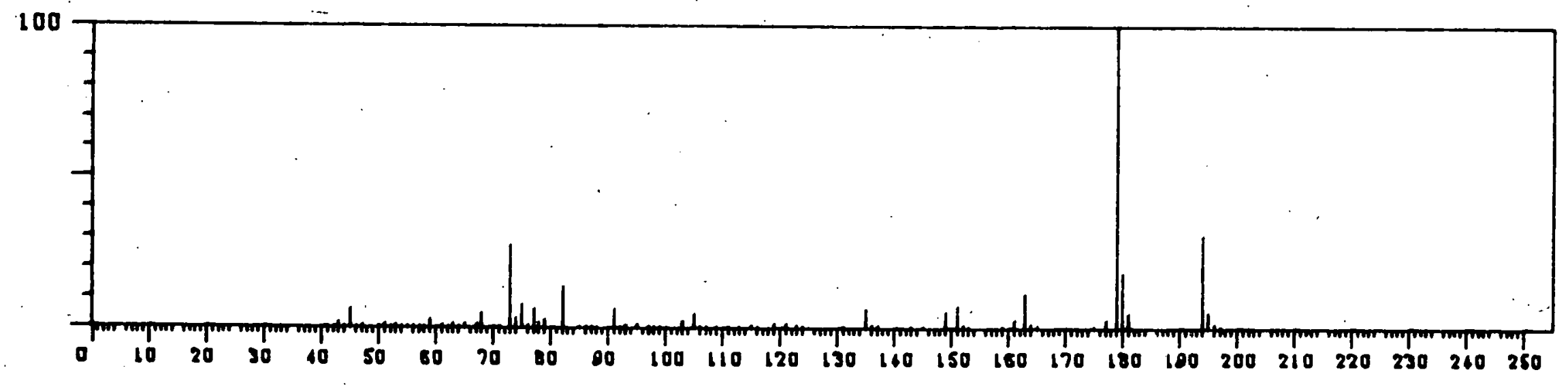

$\mathrm{C}_{2}$-Phenol, TMS ether

Retention Time 52.6

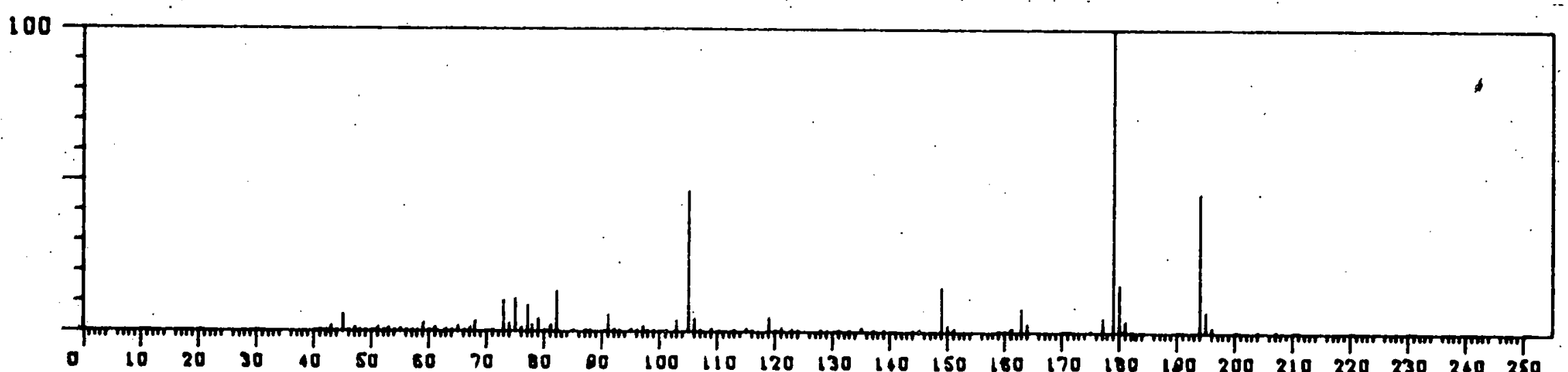

$\mathrm{C}_{2}$-Pheno1, TMS ether

Retention Time 54.0 


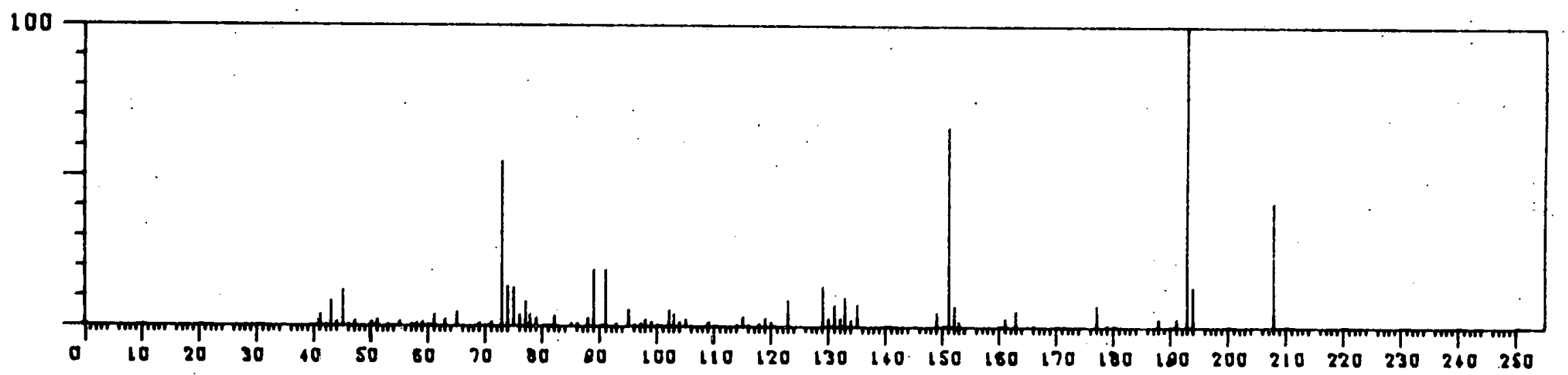

$\mathrm{C}_{3}$-Phenol, TMS ether

Retention Time 54.5

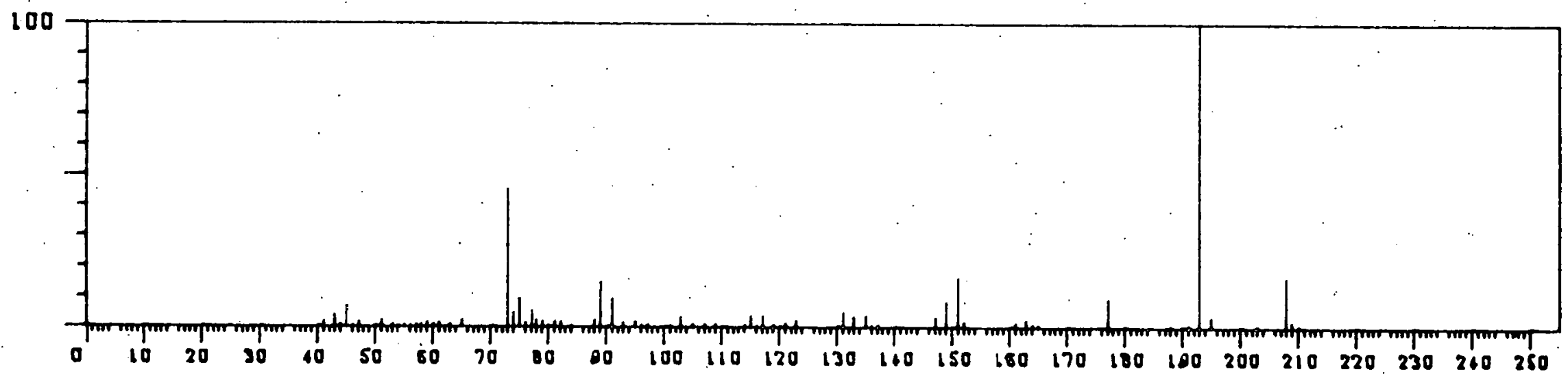

$\mathrm{C}_{3}$-Phenol, TMS ether

Retention Time 55.9 


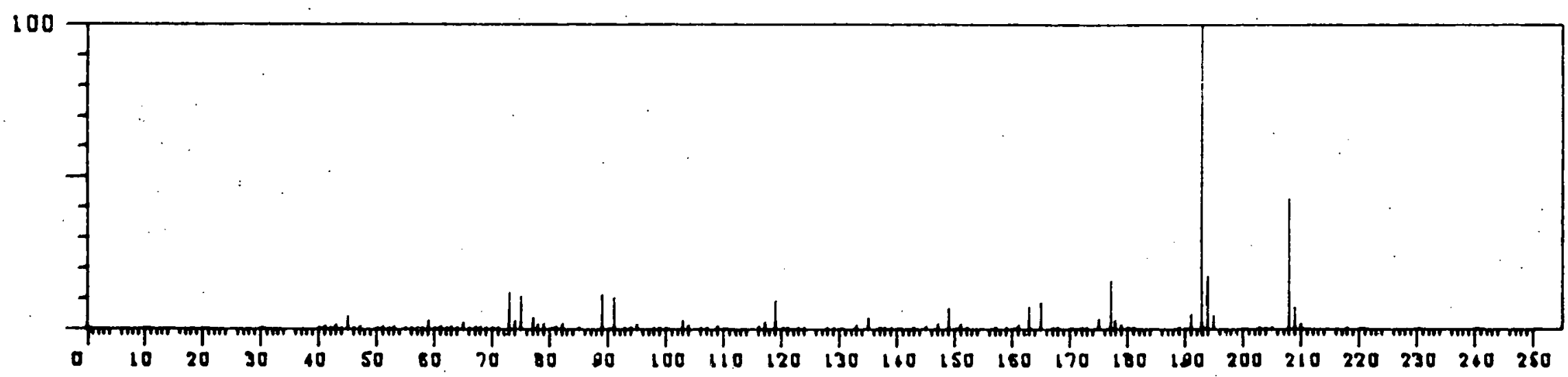

$\mathrm{C}_{3}$-Phenol, TMS ether

Retention Time 56.9

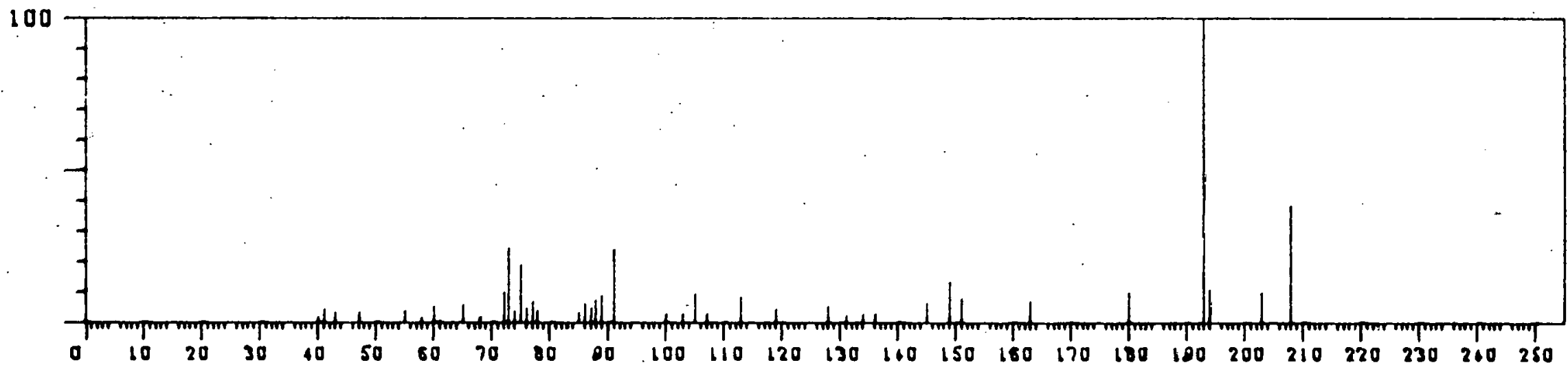

$\mathrm{C}_{3}$-Phenol, TMS ether 


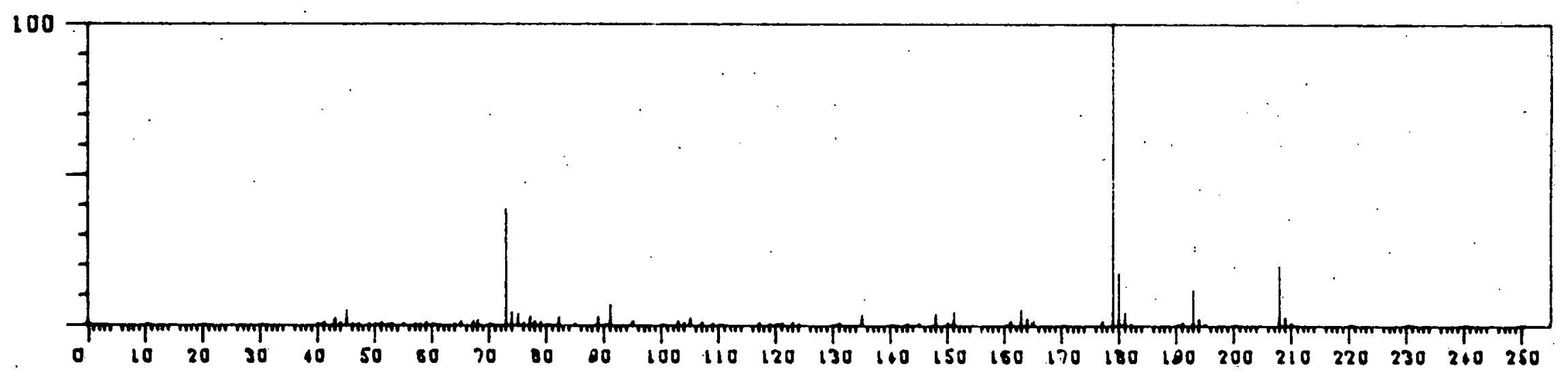

$C_{3}$-Pheno1, TMS ether

Retention Time 58.1

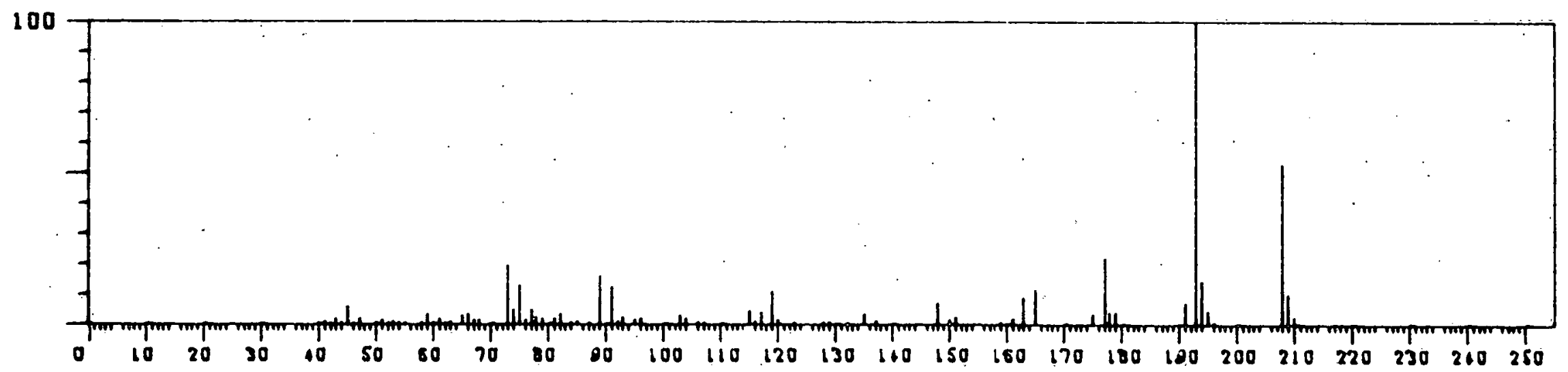

$C_{3}$-Phenol, TMS ether

Retention Time 58.5 


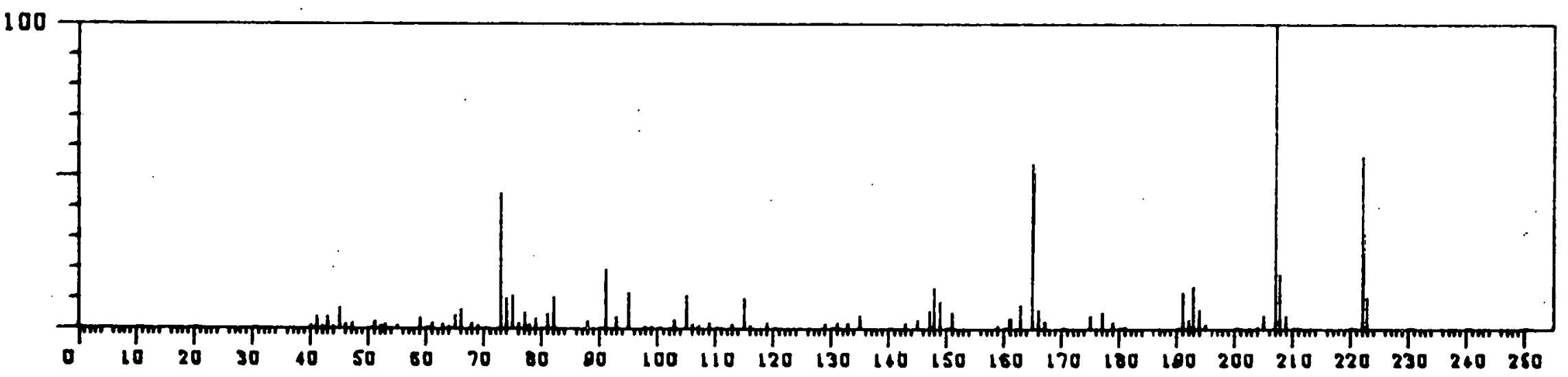

$\mathrm{C}_{4}$-Phenol, TMS ether

Retention Time 59.6

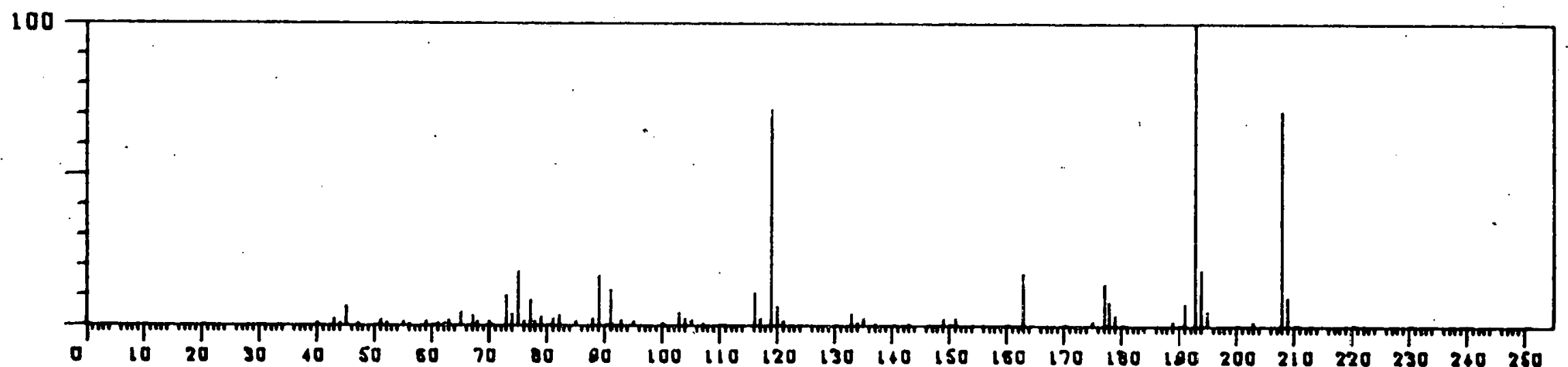

$\mathrm{C}_{3}$-Pheno1, TMS ether

Retention Time 61.0 


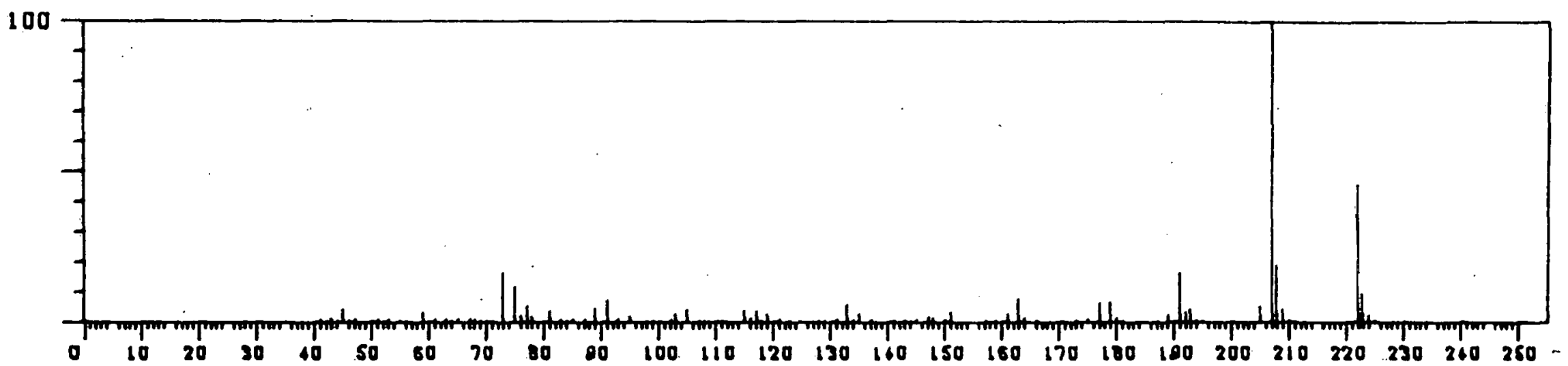

$\mathrm{C}_{4}$-Phenol, TMS ether

- Retention Time 61.3

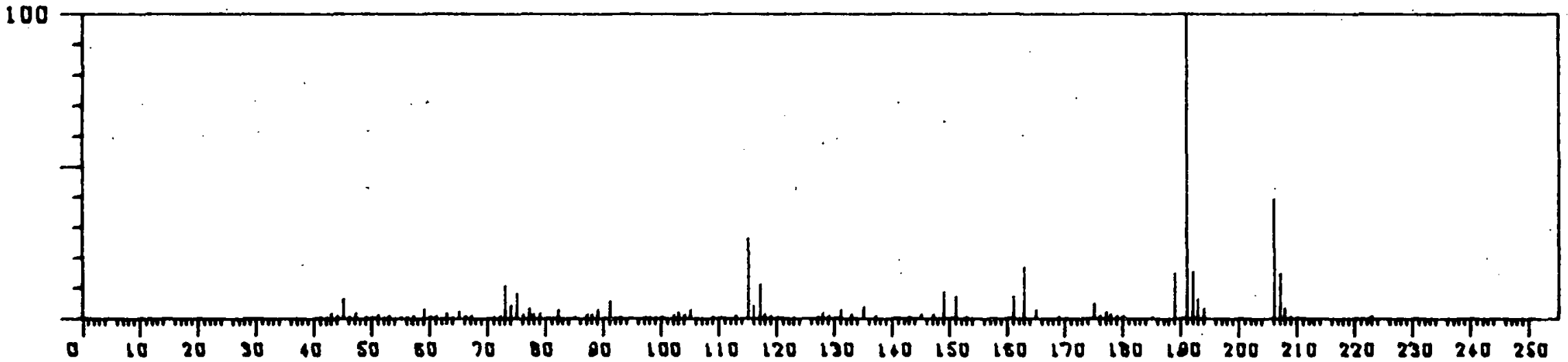

$\mathrm{C}_{1}$-Hydroxystyrene, TMS ether

Retention Time 61.7 


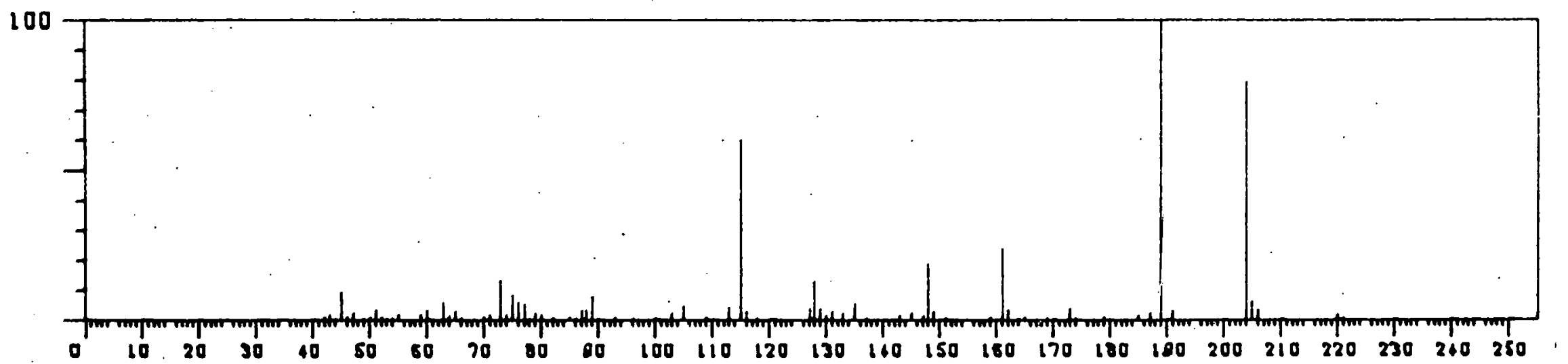

Hydroxyindene, TMS ether

Retention Time 62.2

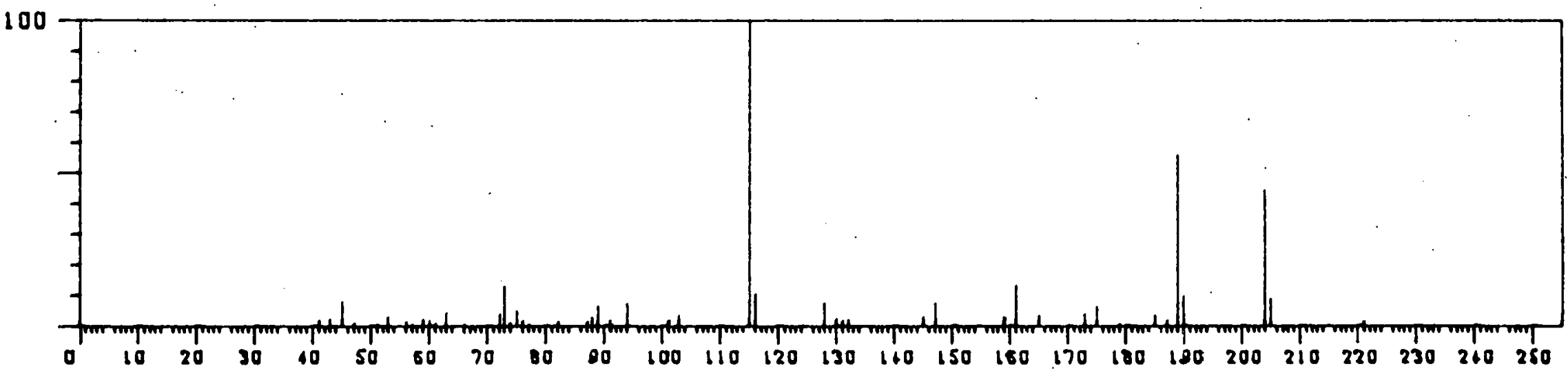

Hydroxy indene, TMS ether

Retention Time 62.7 


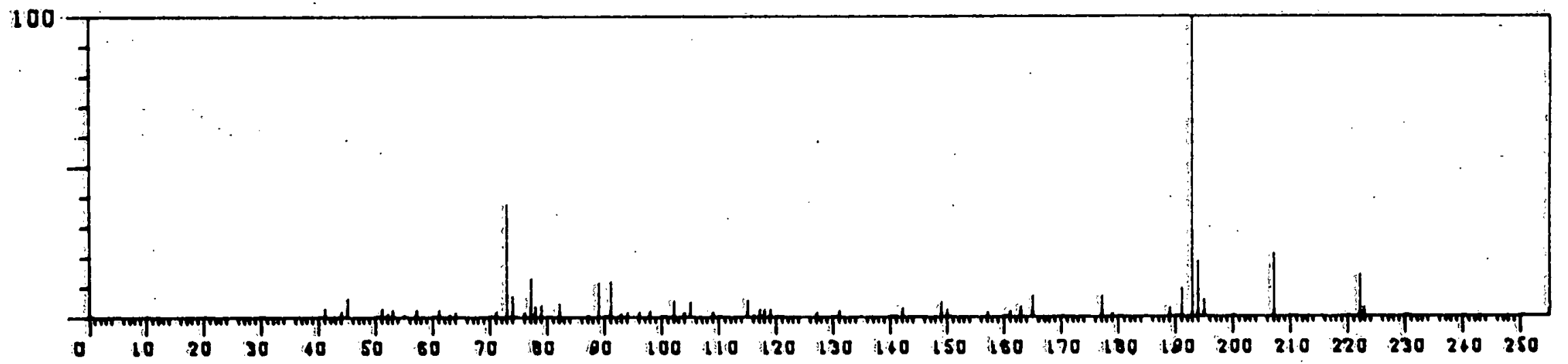

$C_{i 4}$-Pheno1, "TMS ether

Retention Time 64.2

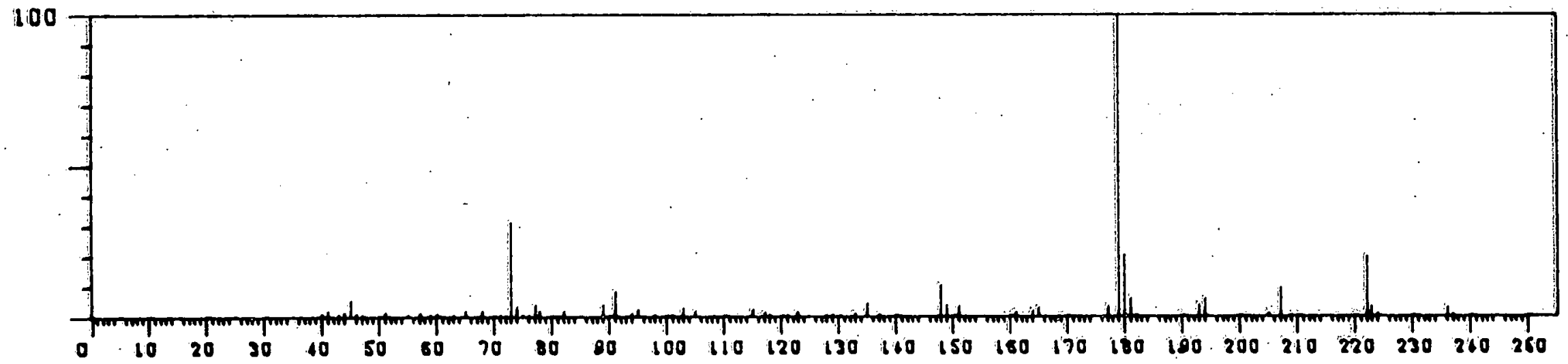

C4-Phenol, TMS ether

Rétention Time 64.5 


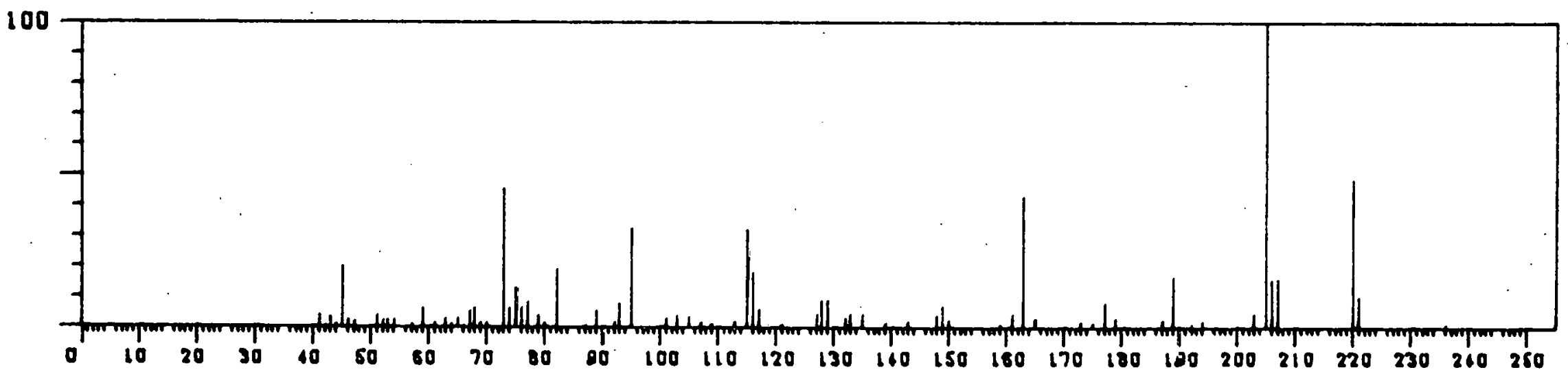

$C_{2}$-Hydroxystyrene, TMS ether

Retention Time 65.4

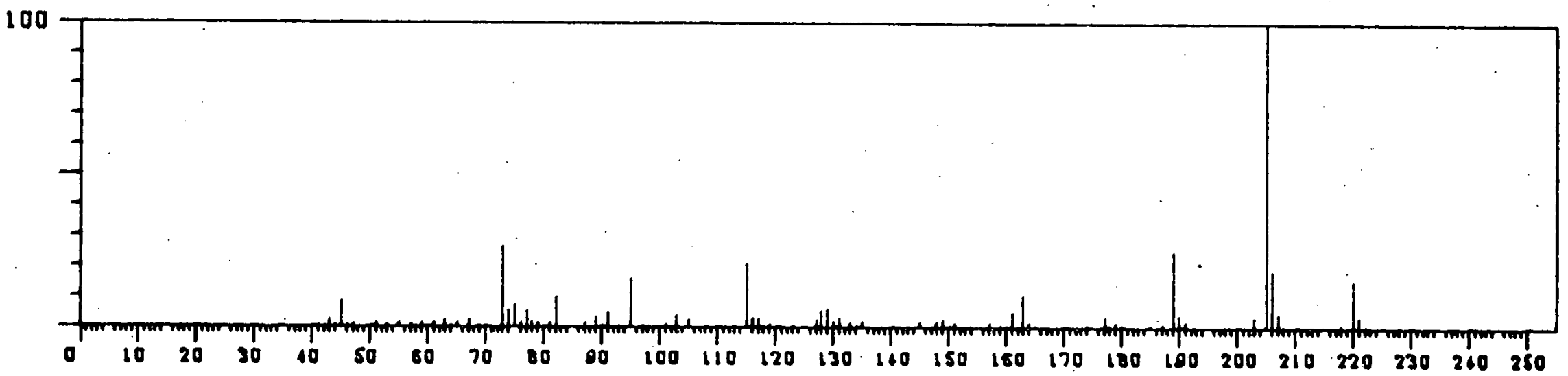

$\mathrm{C}_{2}$-Hydroxystyrene, TMS ether.

Retention Time 66.0 


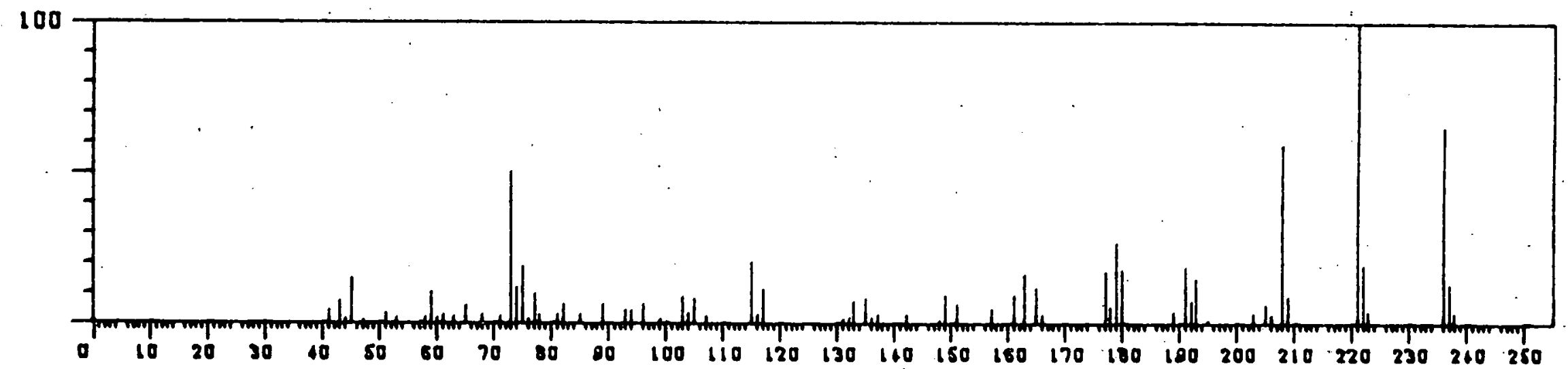

$C_{5}$-Phenol, TMS ether

Retention Time 66.3

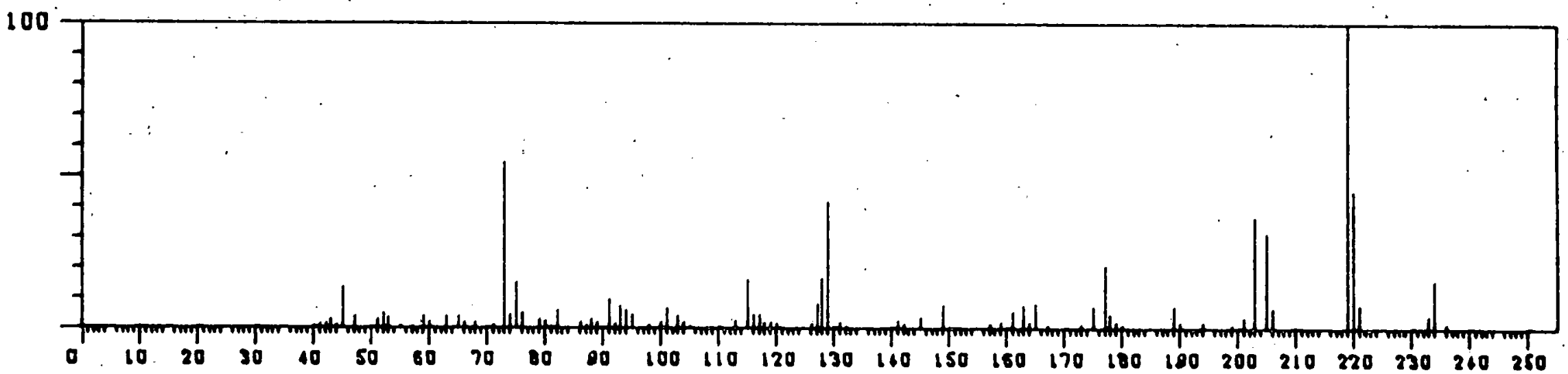

$\mathrm{C}_{3}$-Hydroxystyrene, TMS ether 


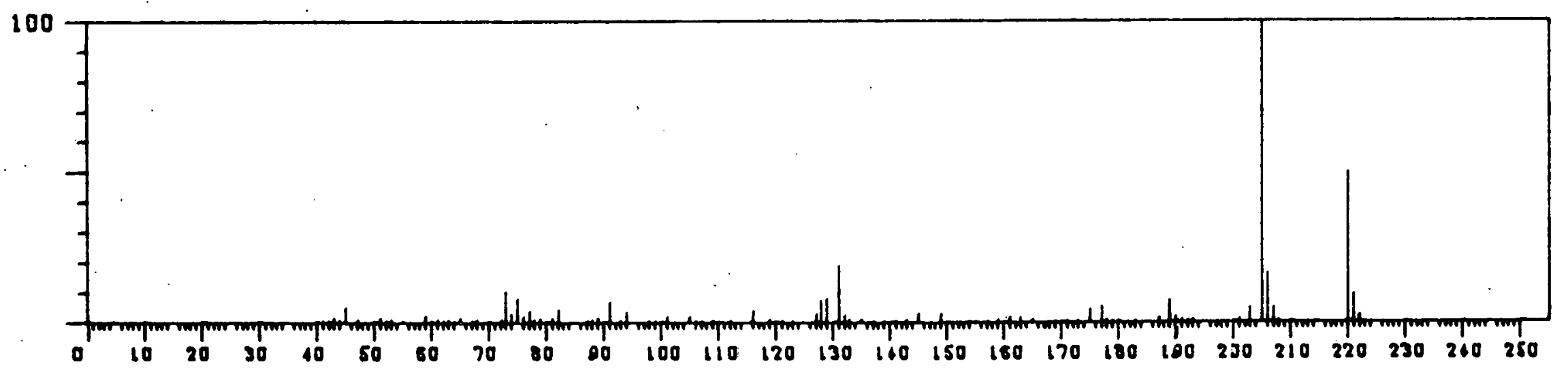

$\mathrm{C}_{2}$-Hydroxystyrene, TMS ether

Retention Time 69.4

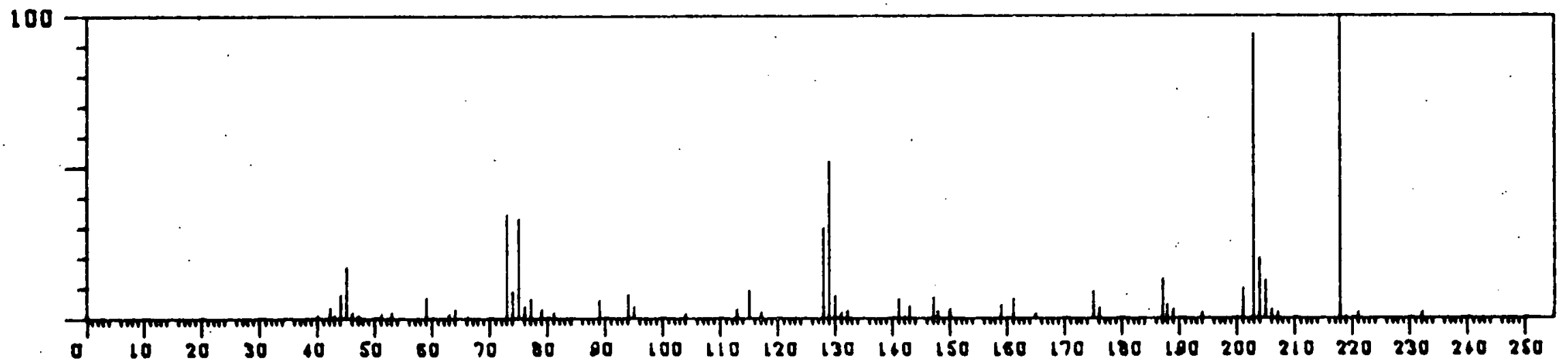

Methyl hydroxyindene, TMS ether 


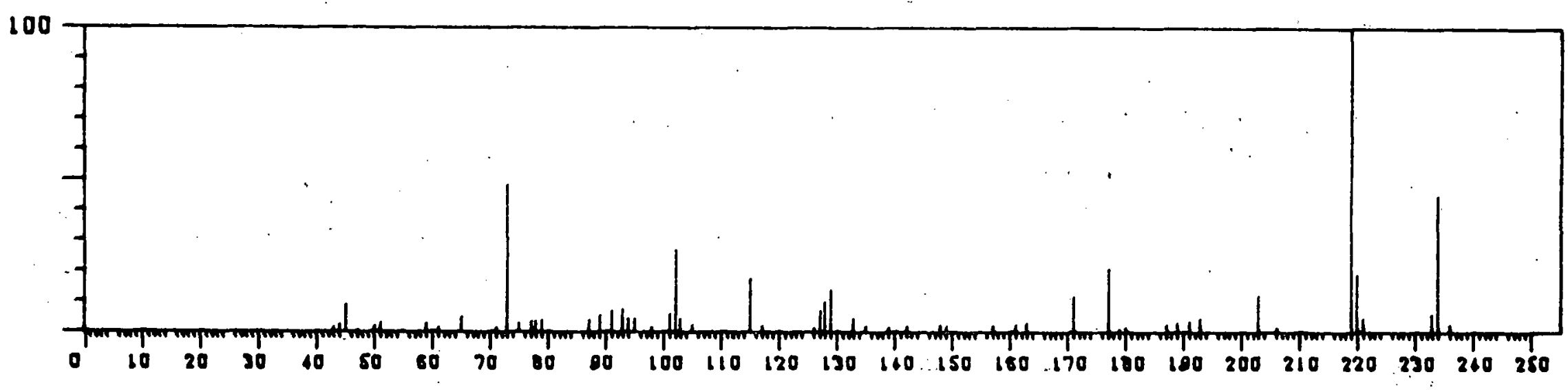

$C_{3}$-Hydroxystyrene, TMS ether

Retention Time 71.0

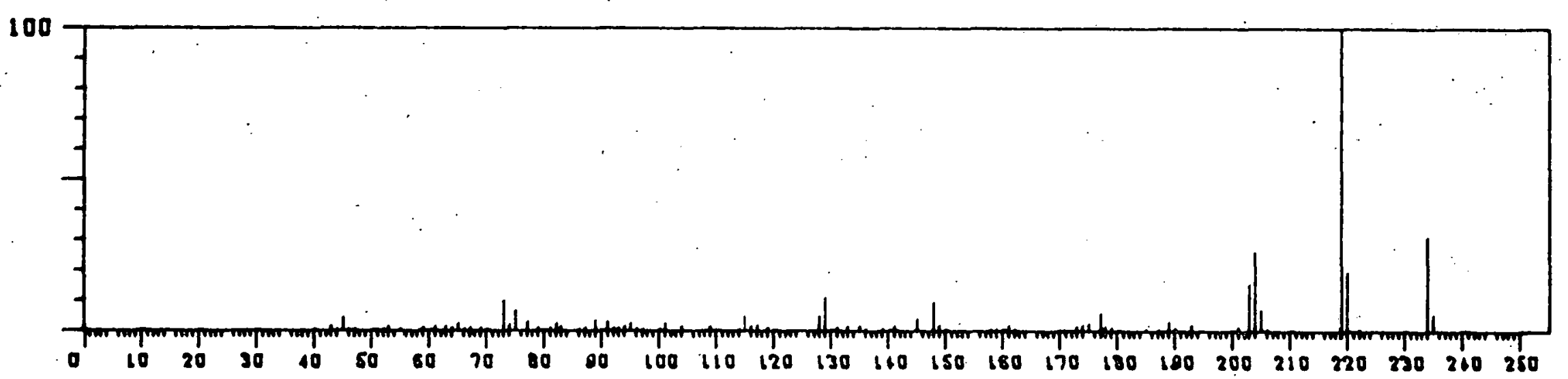

$C_{3}$-Hydroxystyrene, TMS ether

Retention Time 71.2 


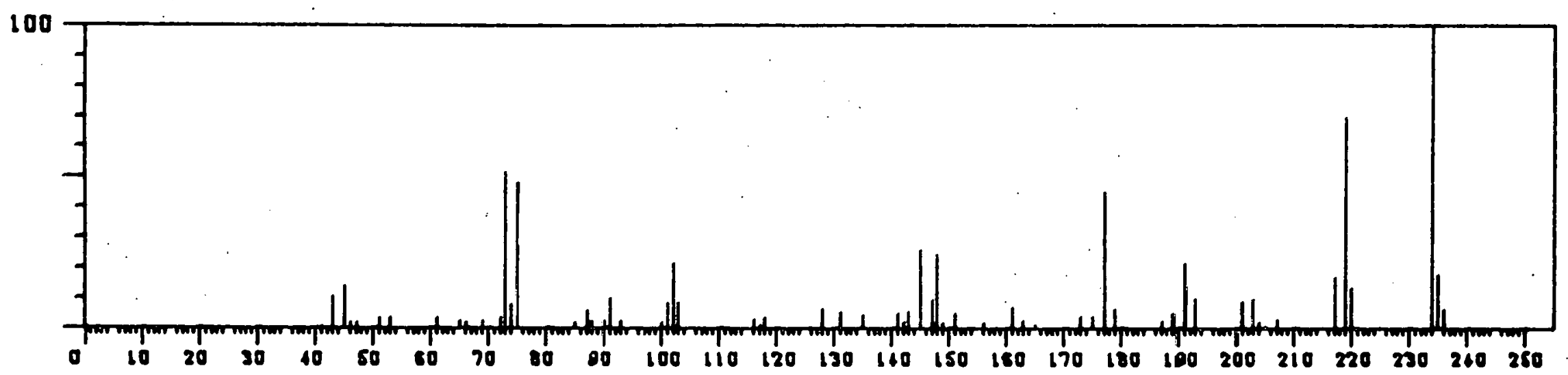

$\mathrm{C}_{3}$-Hydroxystyrene, TMS ether

Retention Time 73.8

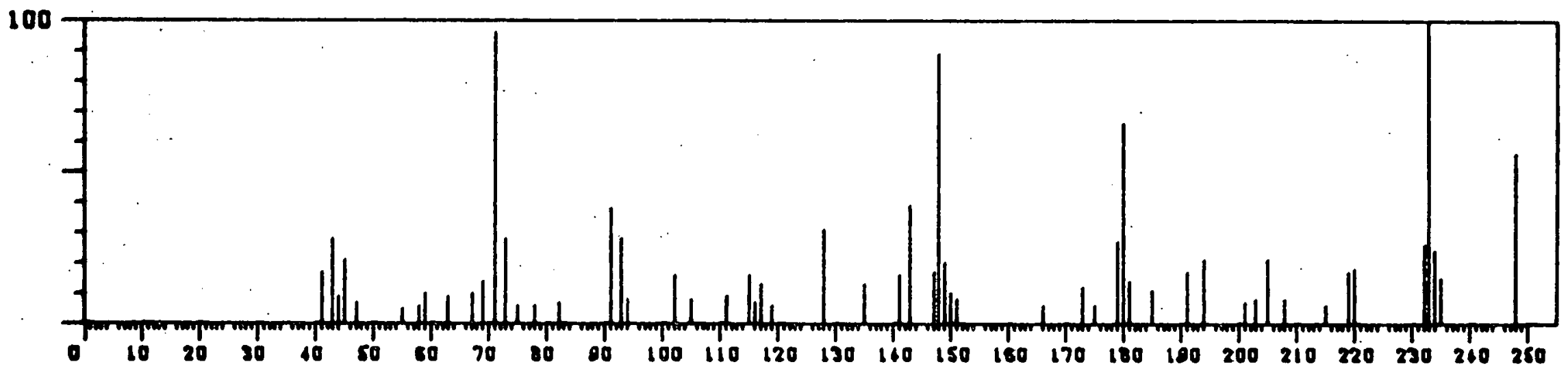

$\mathrm{C}_{4}$-Hydroxystyrene, TMS ether

Retention Time 74.8 


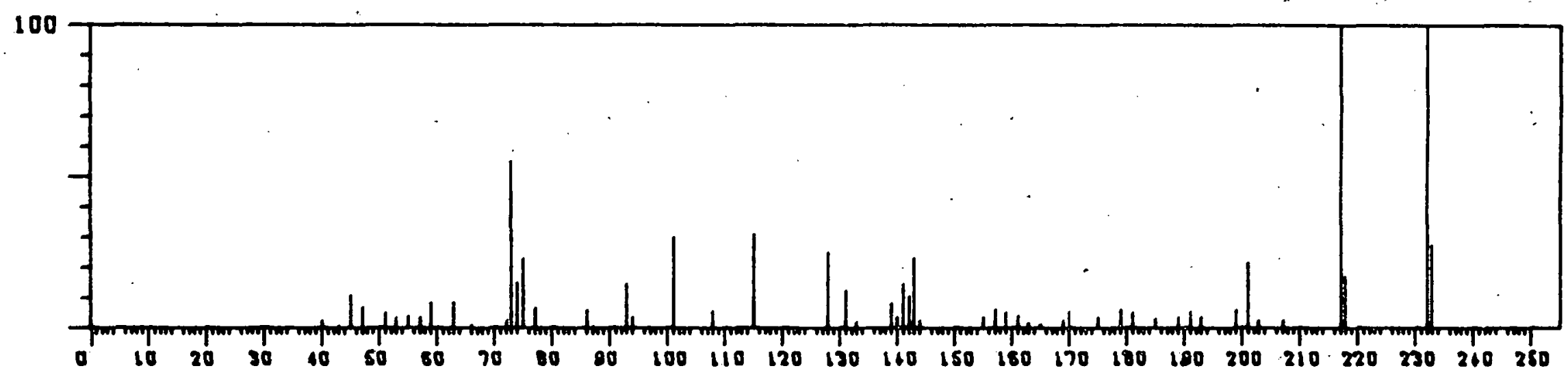

$\mathrm{C}_{2}$-Hydroxyindene, TMS ether

Retention Time 76.9

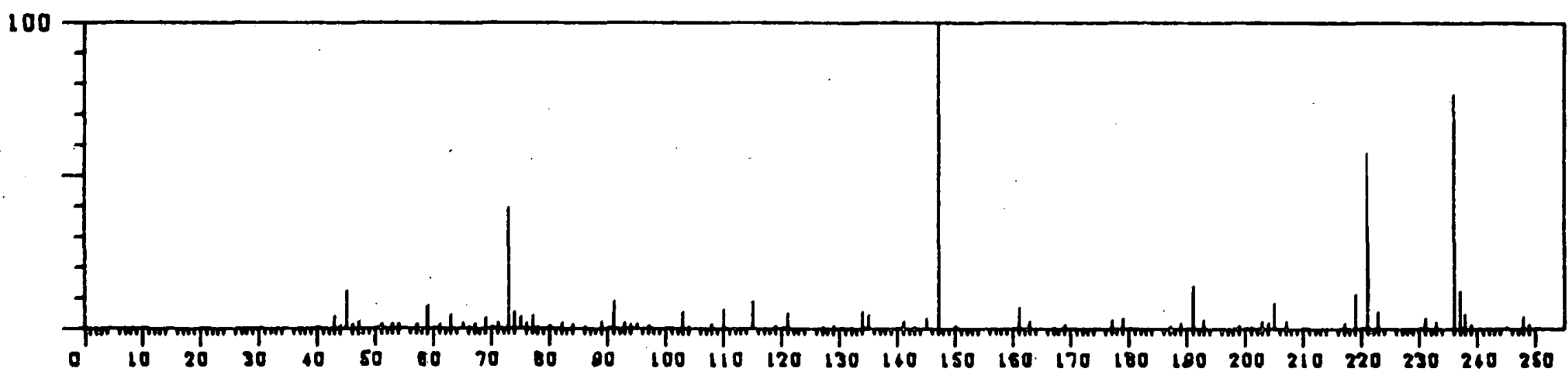




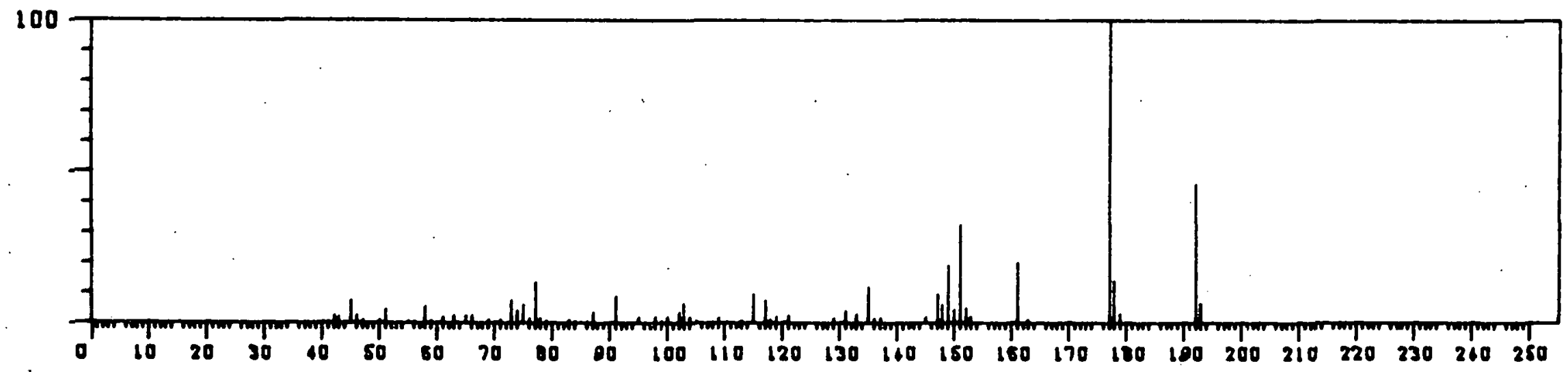

Hydroxystyrene, TMS ether

Retention Time 53.0

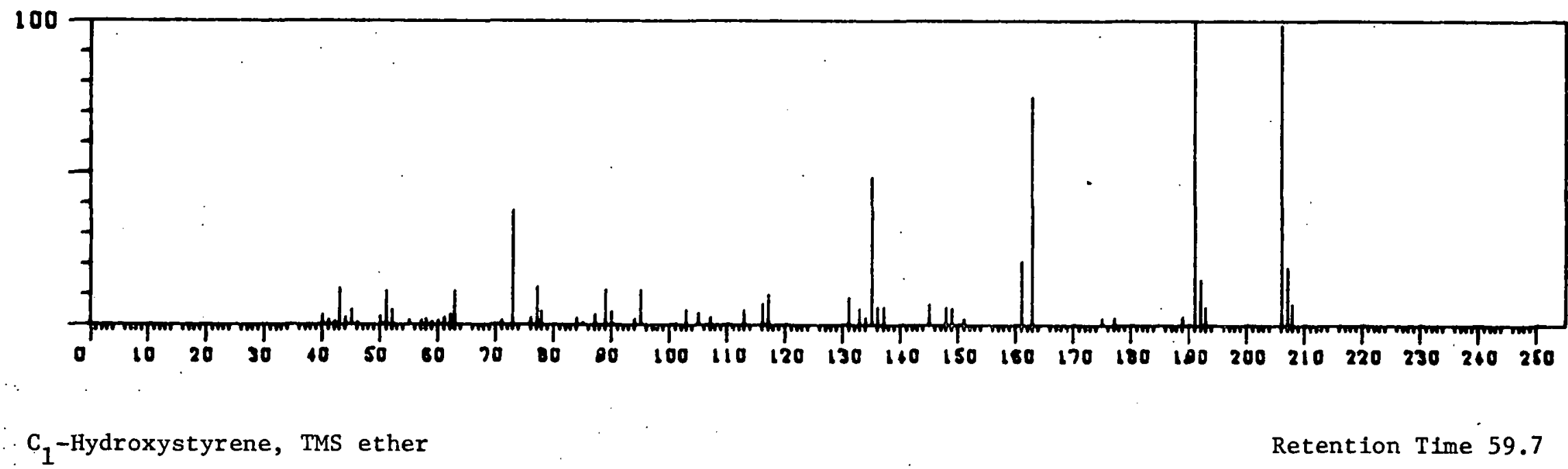



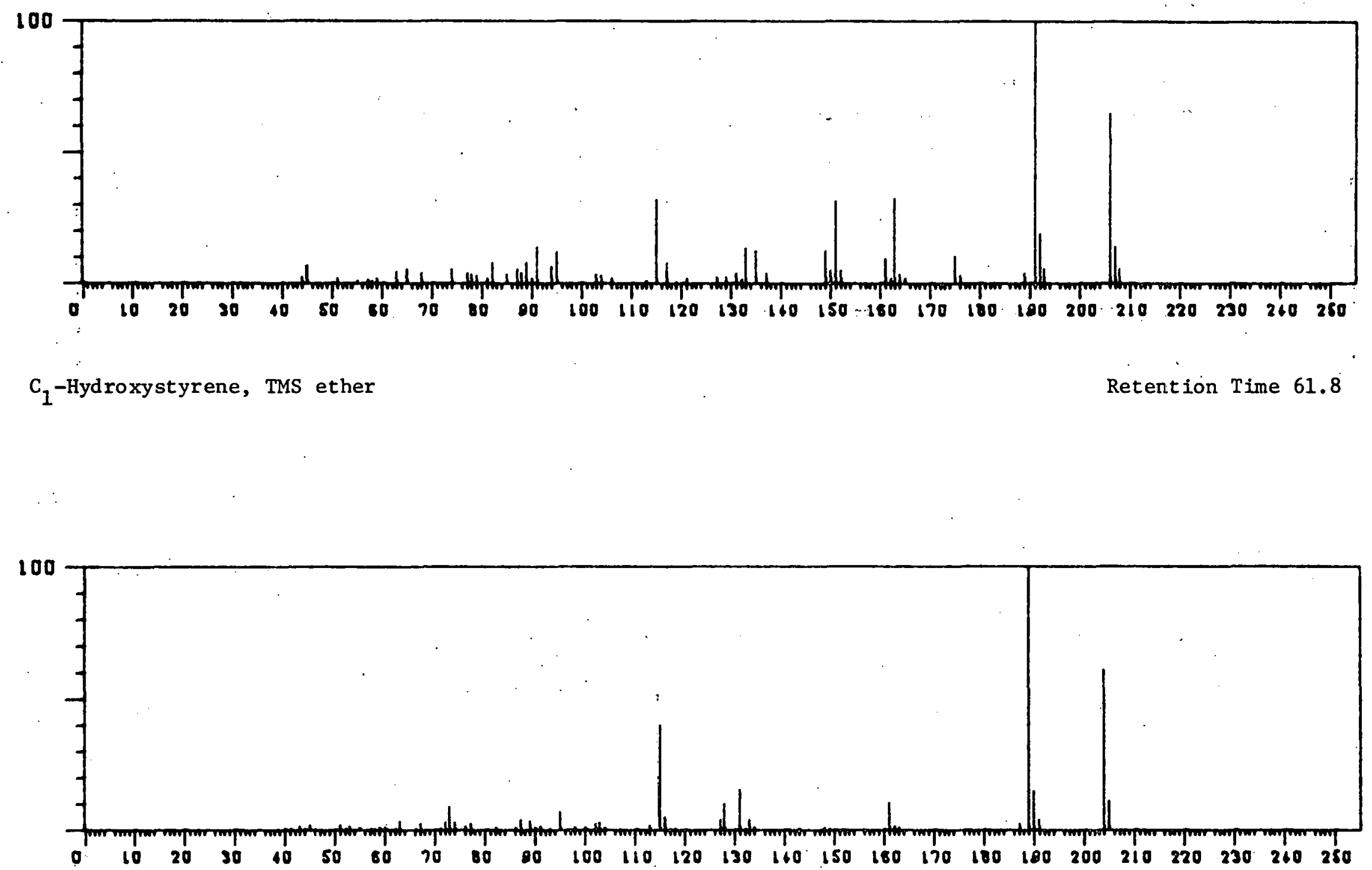

Hydroxyindene, TMS ether

Retention Time 64.1 


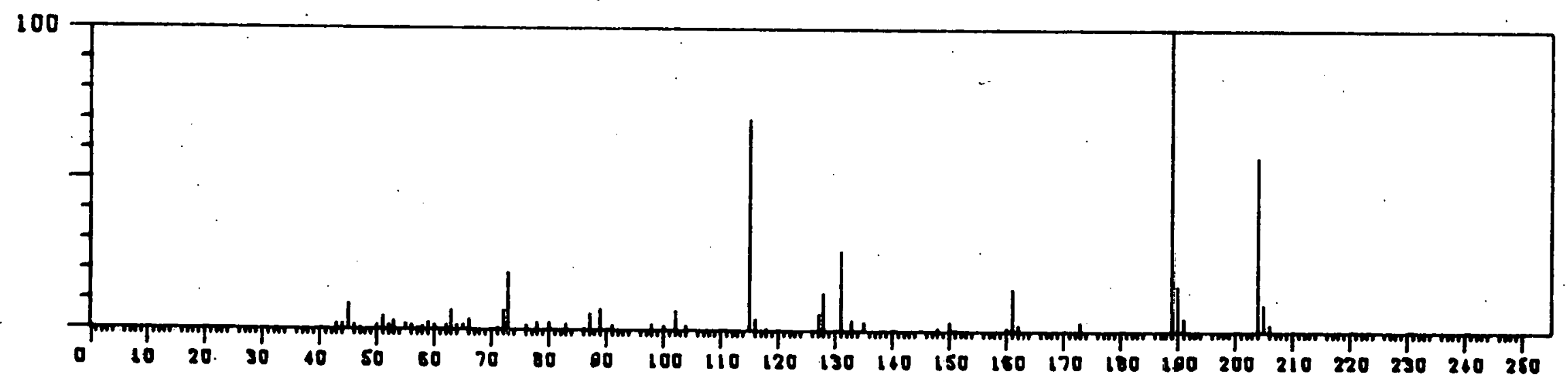

Hydroxyindene, TMS ether

Retention Time 64.3

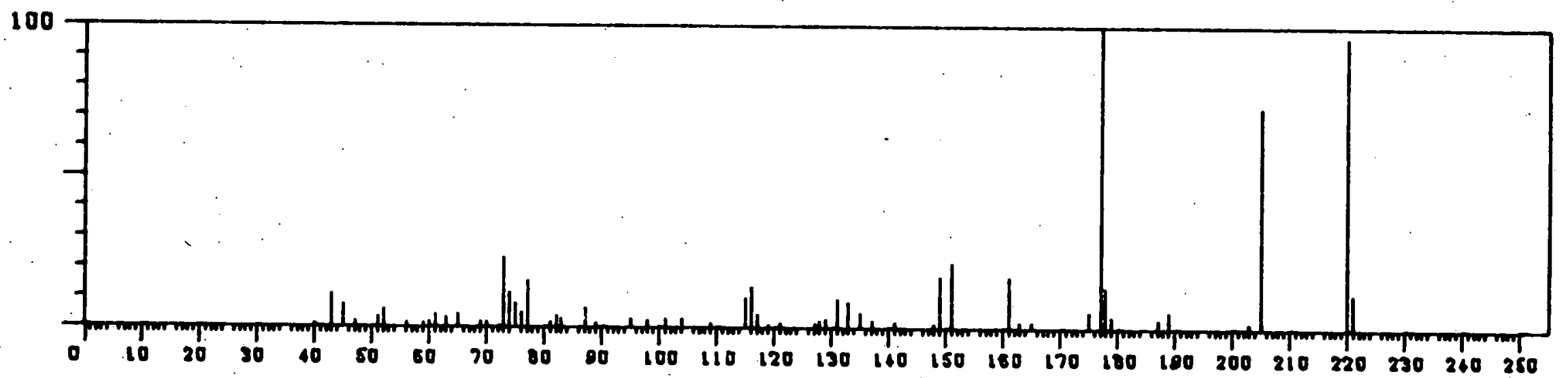

$\mathrm{C}_{2}$-Hydroxystyrene, TMS ether 


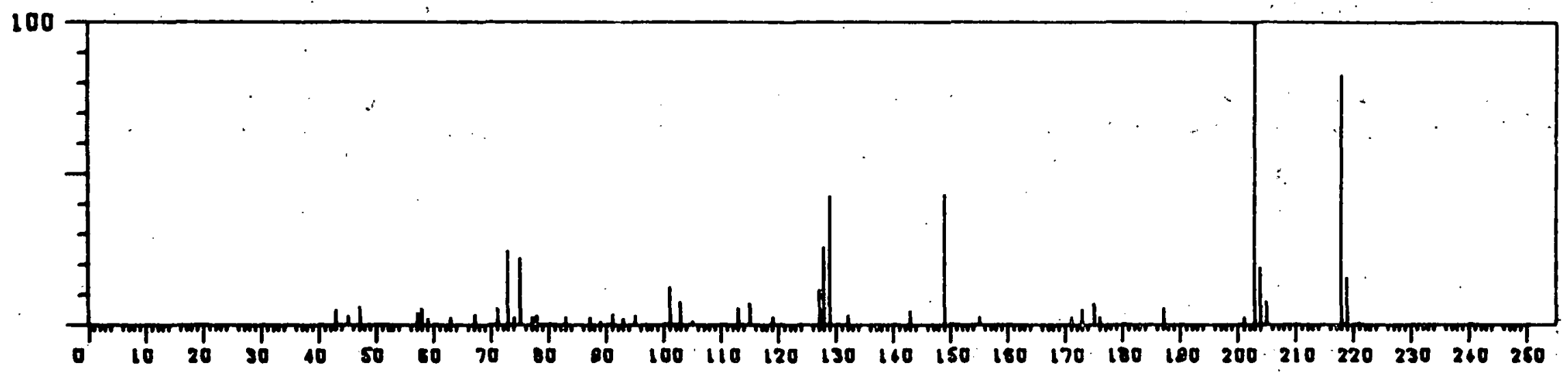

Methyl hydroxyindene, TMS ether

Retention Time 70.1

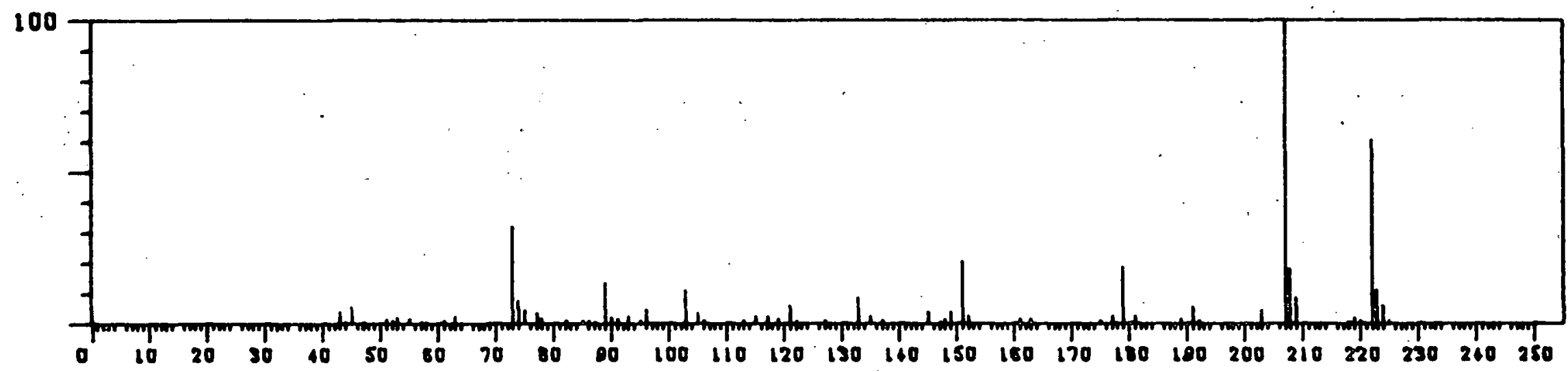

Hyd roxybenzothiophene, TMS ether

Retention Time 71.1 


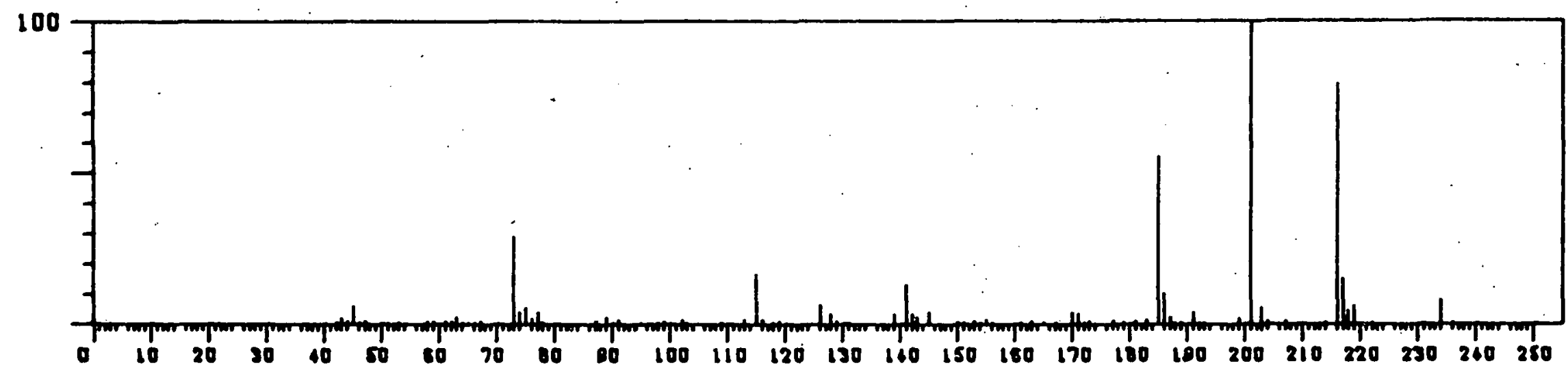

Naphthol, TMS ether

Retention Time 71.8

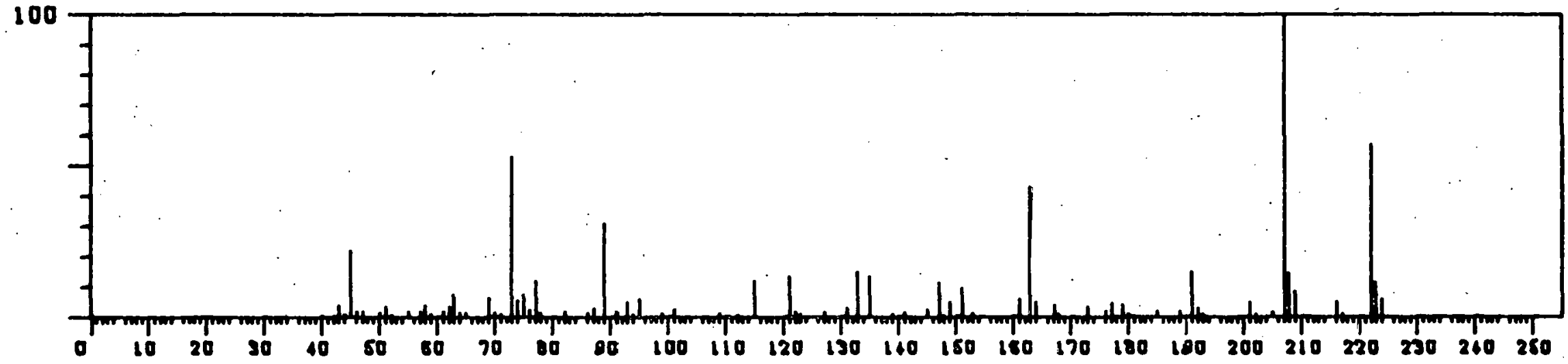

Hydroxybenzothiophene, TMS ether

Retention Time $\mathbf{7 2 . 2}$ 


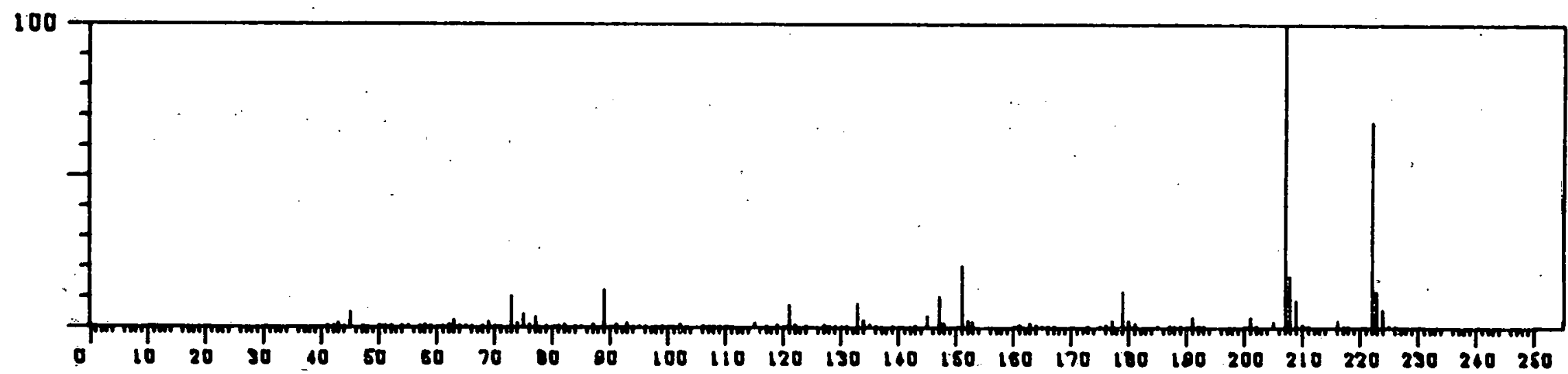

Hydroxybenzo thiophene, TMS ether

Retention Time 74.0.

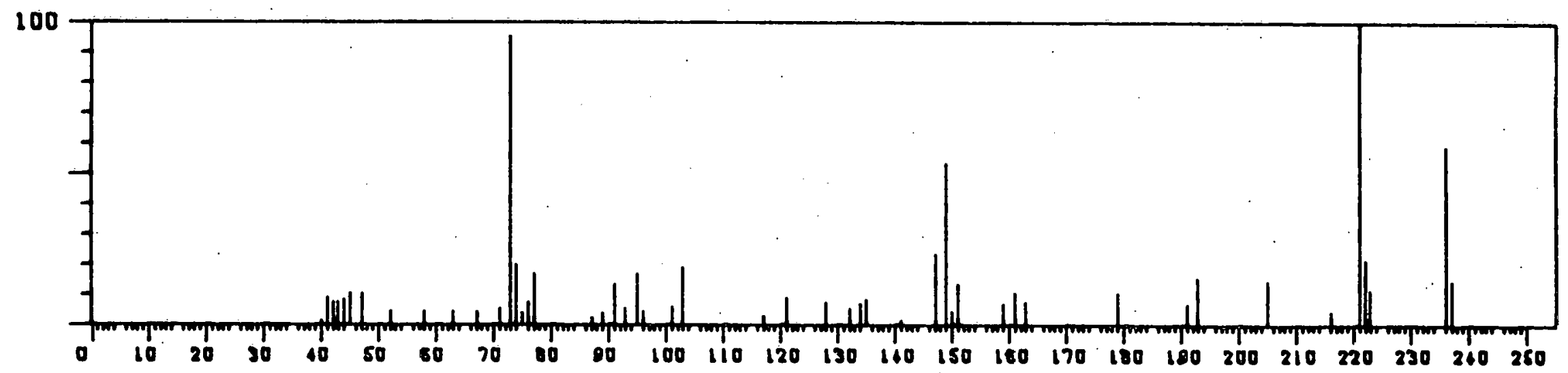

Methyl hydroxybenzothiophene, TMS ether

Retention Time 76.2 


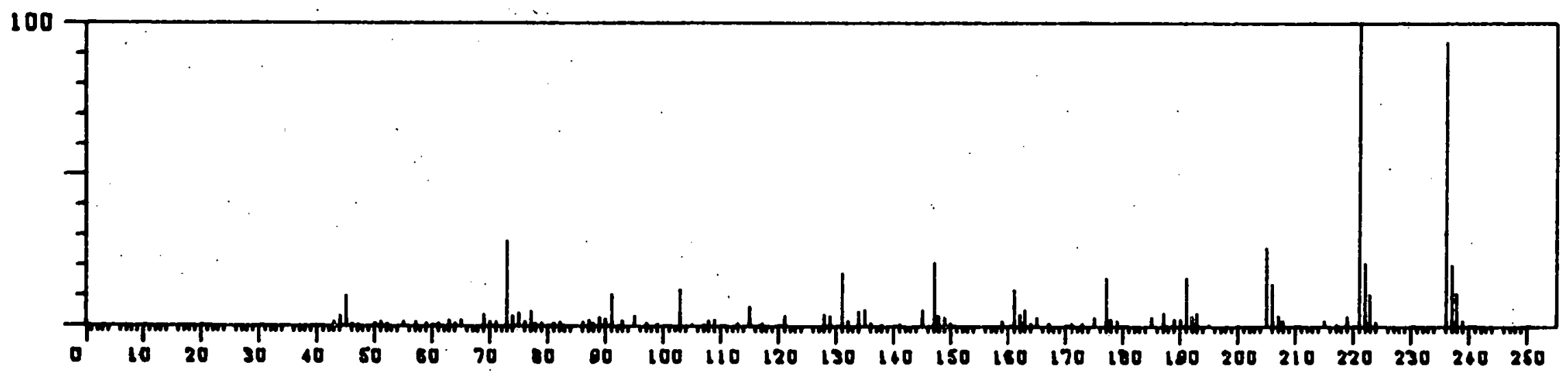

Methyl hydroxybenzothiophene, TMS ether

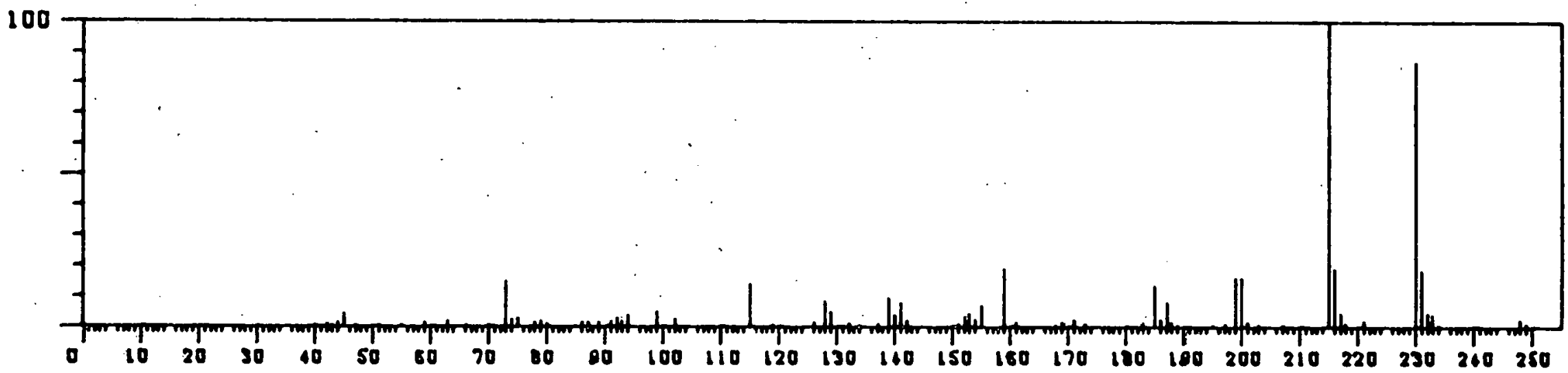




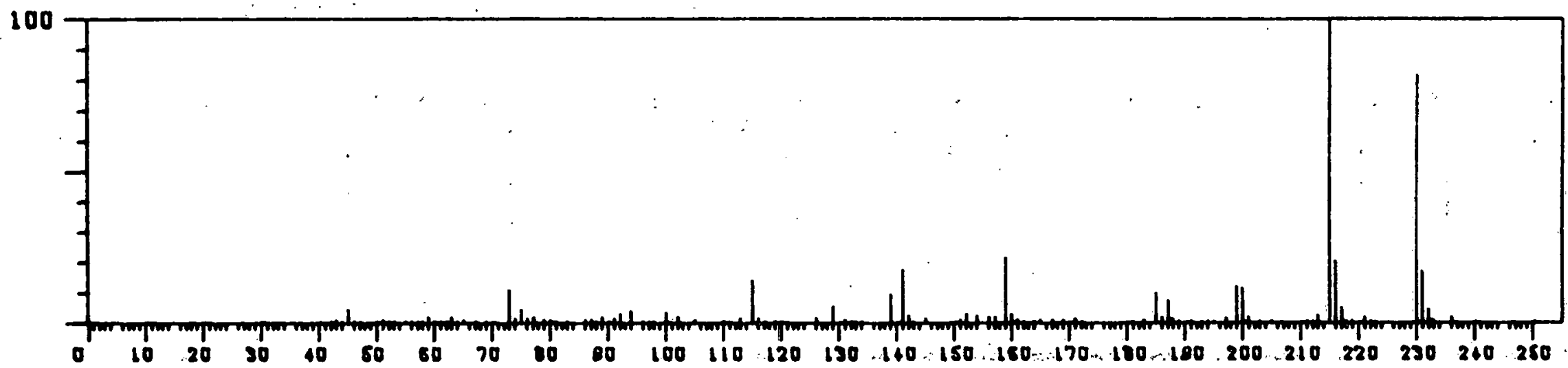

Methyl naphthol, TMS ether

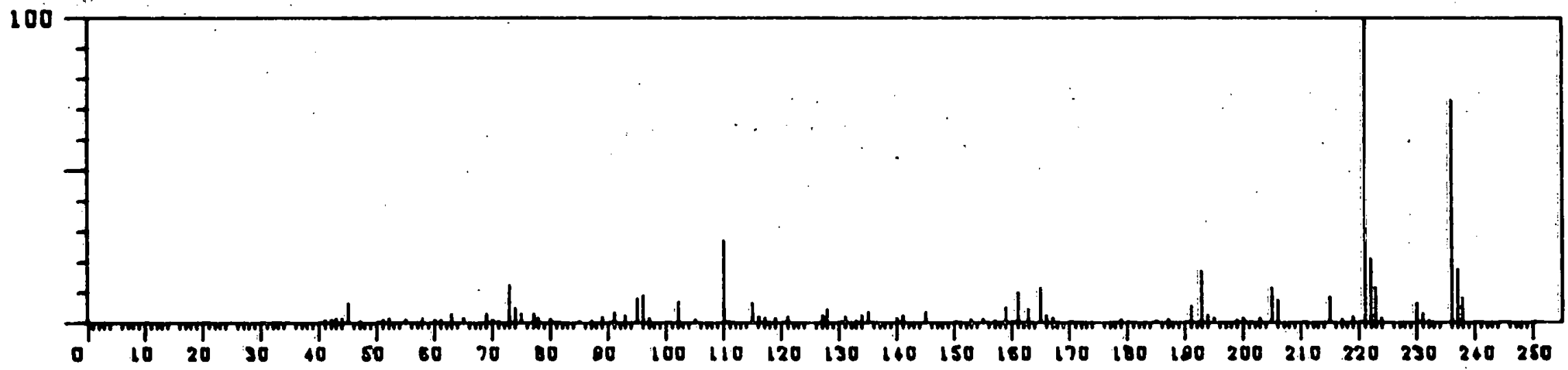




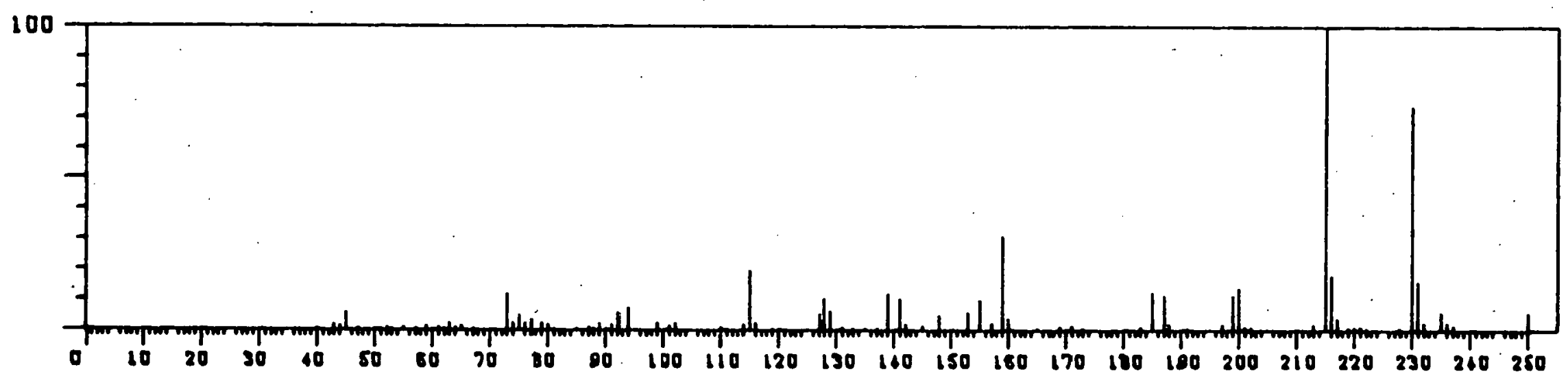

Methyl naphtho1, TMS ether

Retention Time 80.8

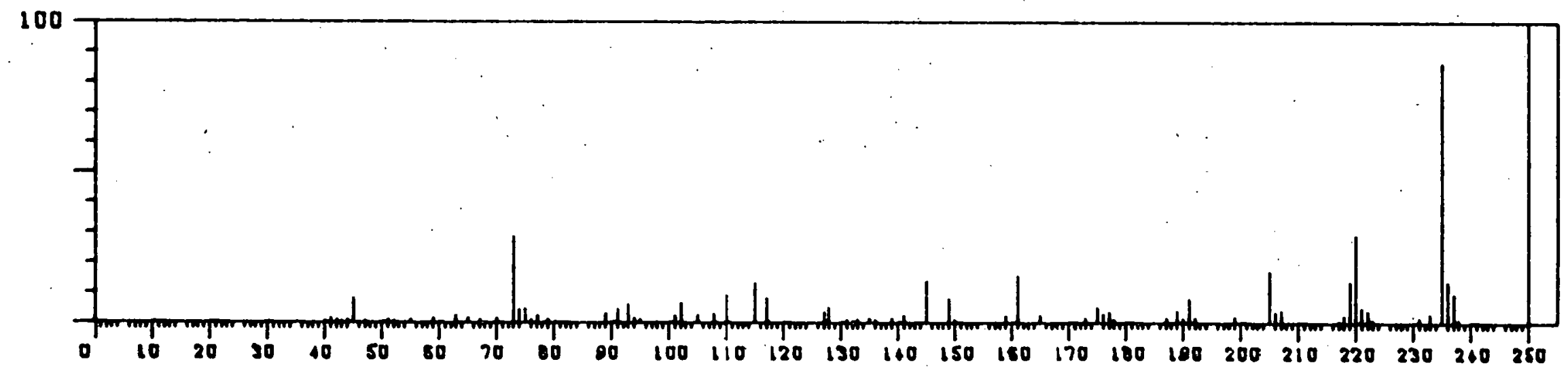

$\mathrm{C}_{2}$-Hydroxybenzothiophene, TMS ether

Retention Time $\mathbf{8 1 . 8}$ 


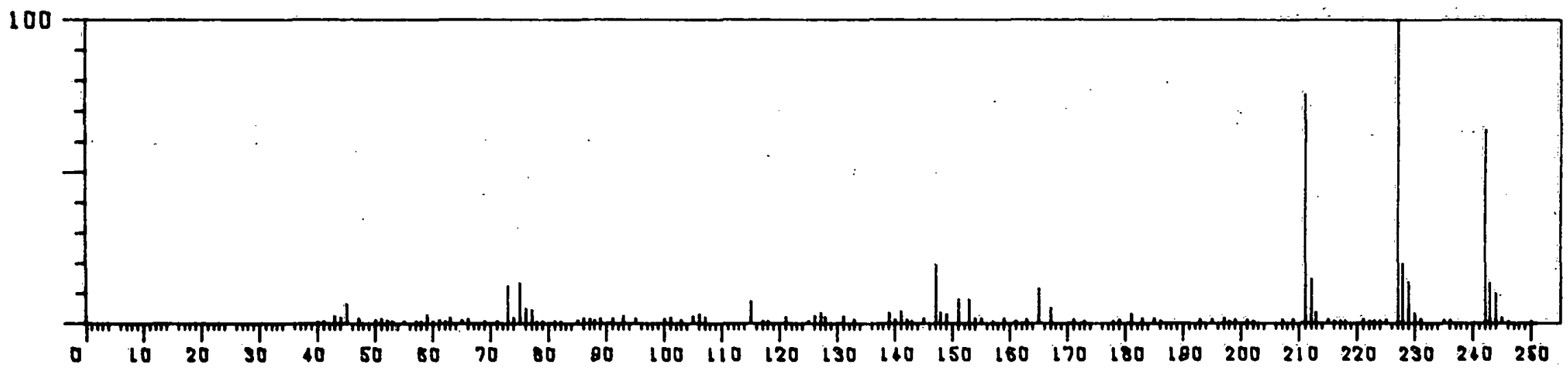

Hydroxybiphenyl, TMS ether

Retention Time 83.0

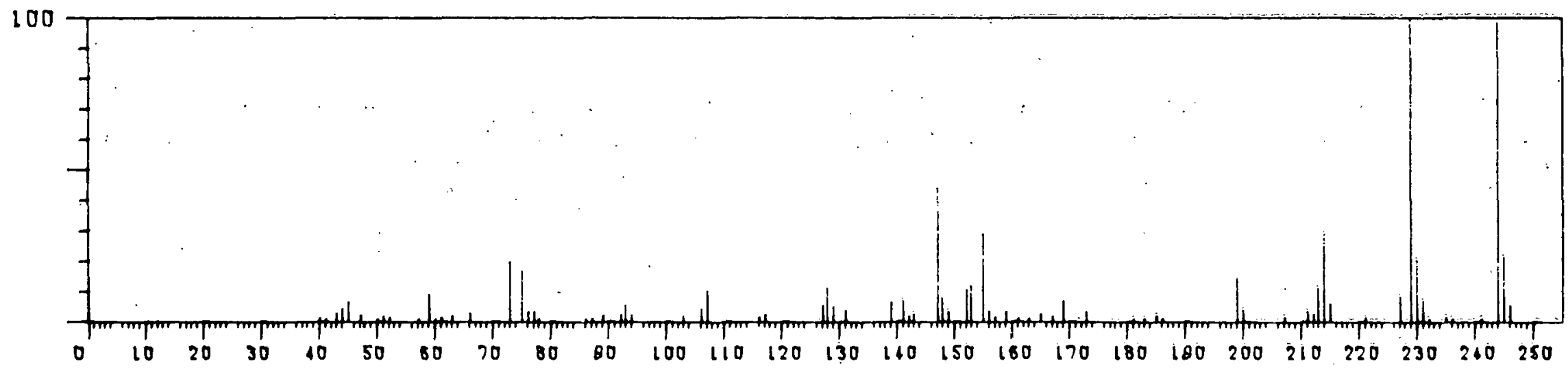

$C_{2}$-Naphthol, TMS ether 


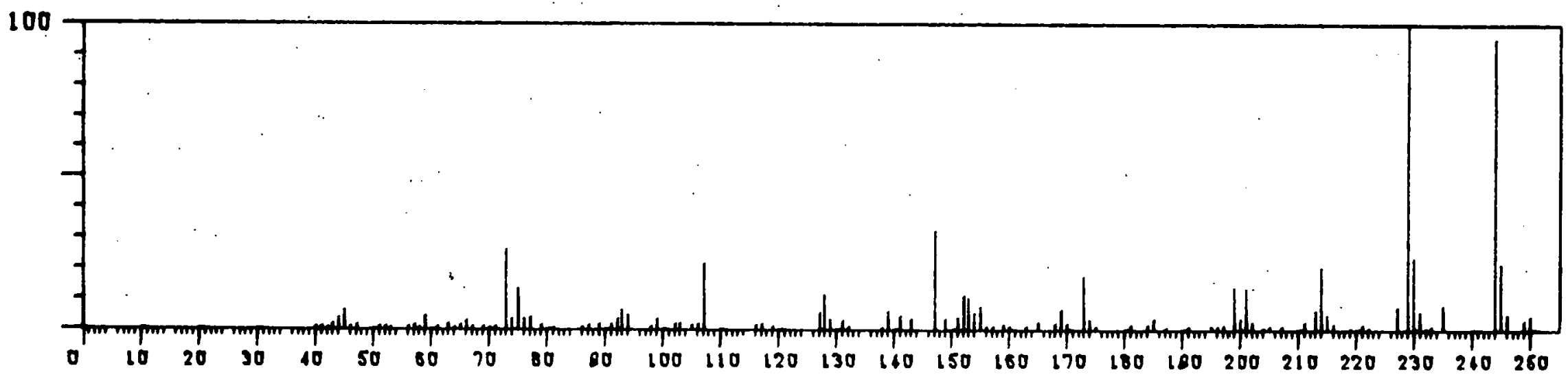

$C_{2}$-Naphthol, TMS ether

Retention Time 86.4

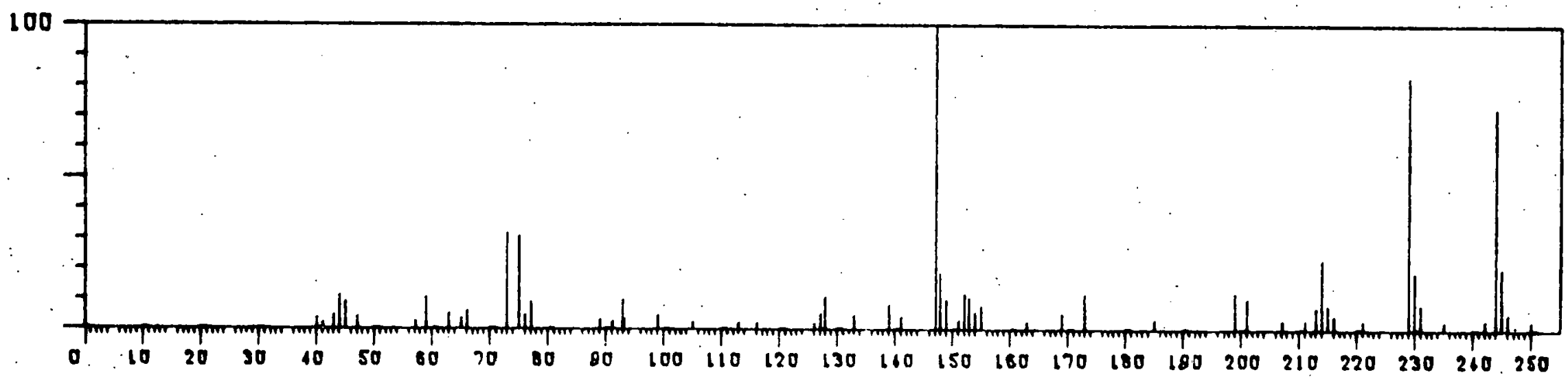

$C_{2}$-Naphthol, TMS ether

Retention Time 87.0 

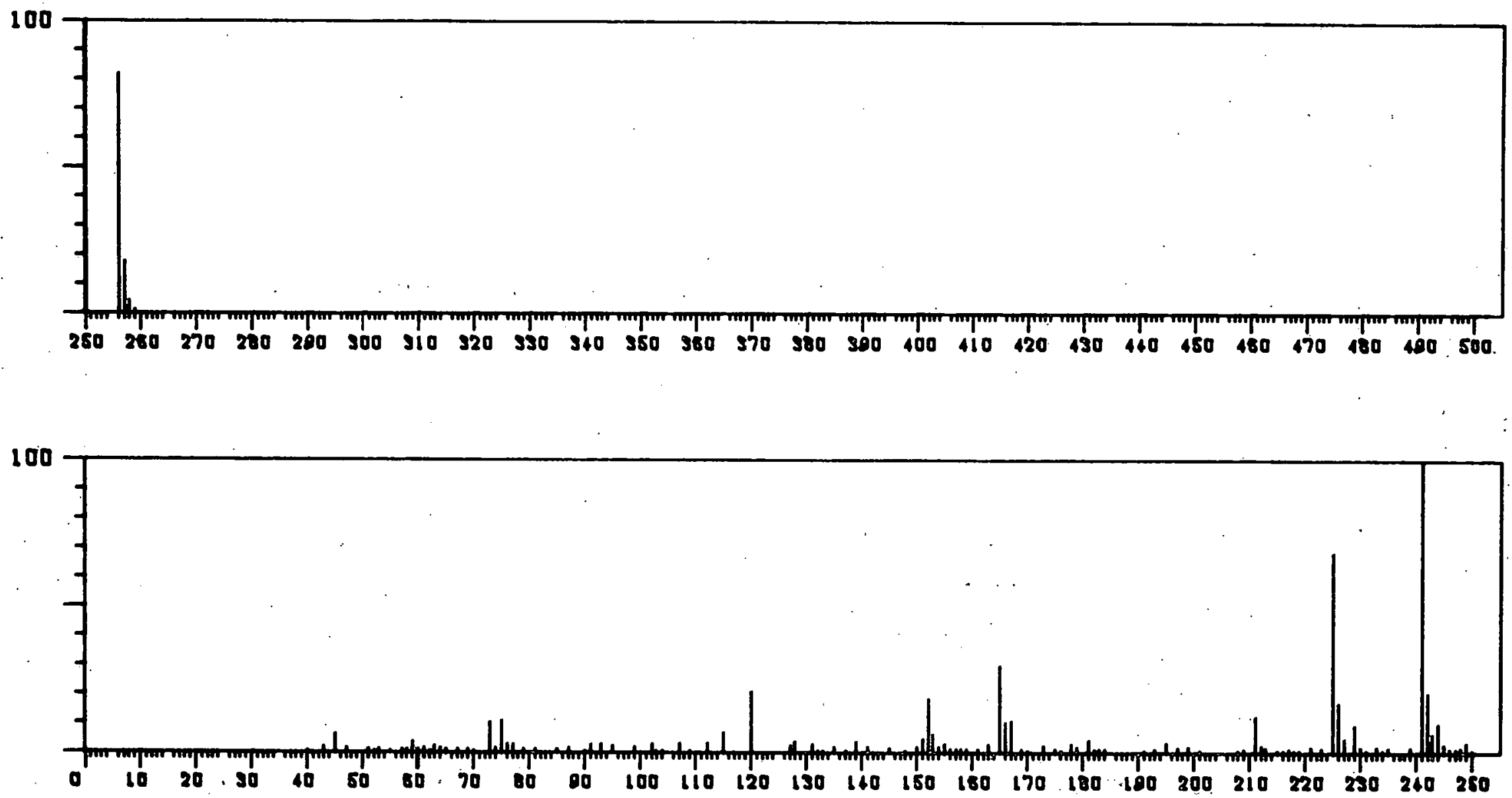

Methyl hydroxybiphenyl, TMS ether

Retention Time 87.4 


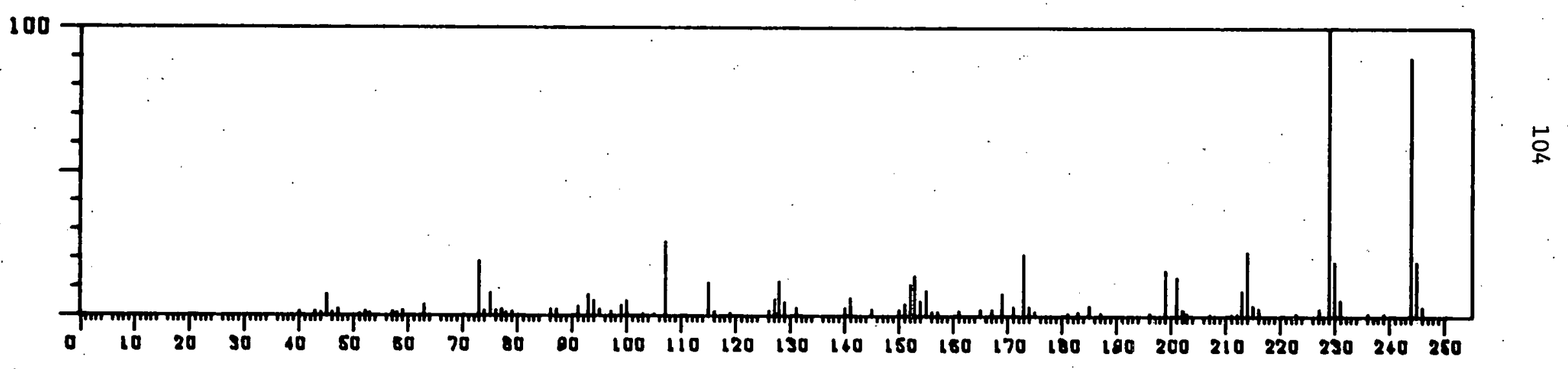

$\mathrm{C}_{2}$-Naphtho1, TMS ether

Retention Time 87.7 

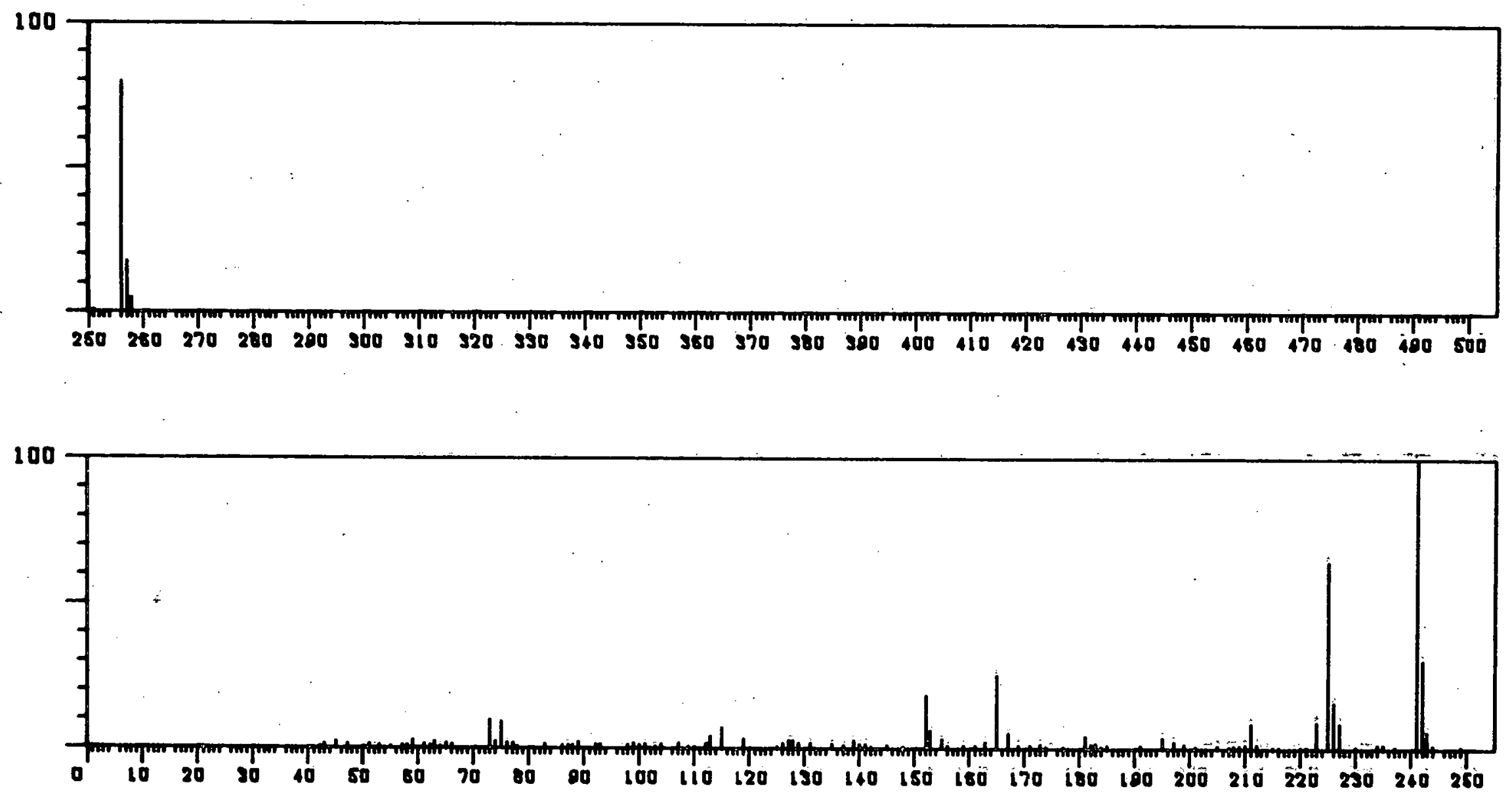


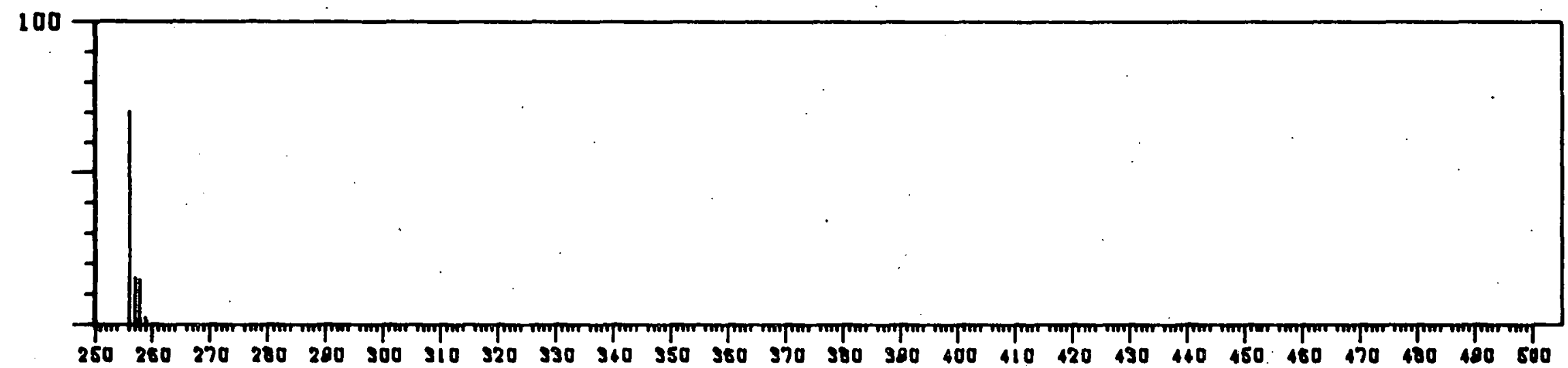

100

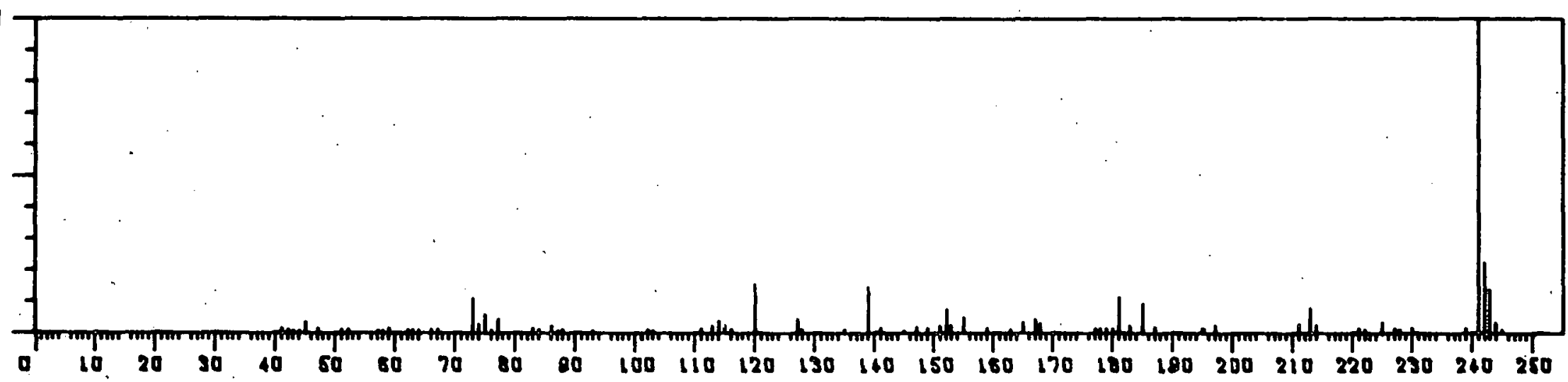

Methyl hydroxybiphenyl, TMS ether

Retention Time 91.9 

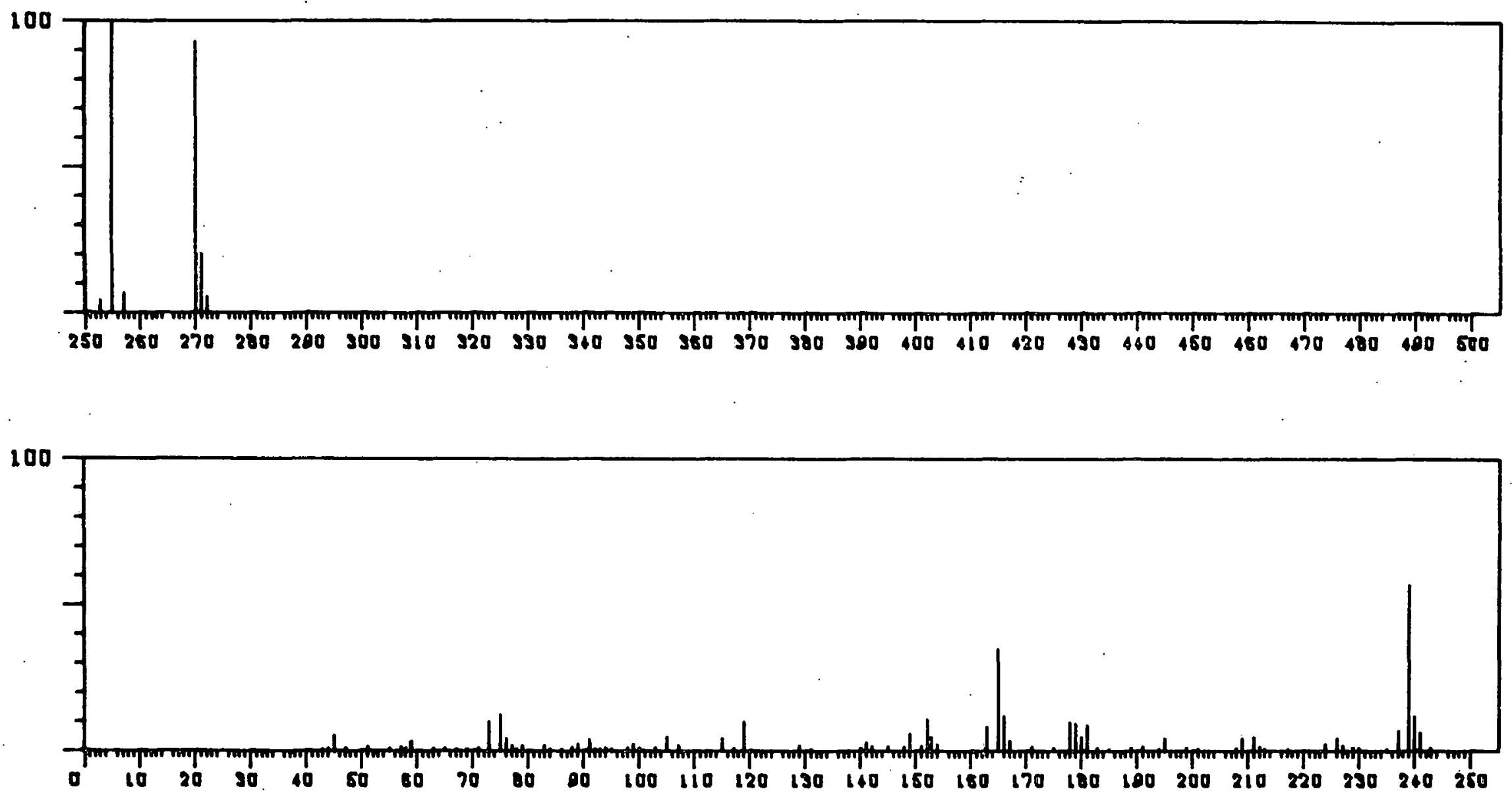

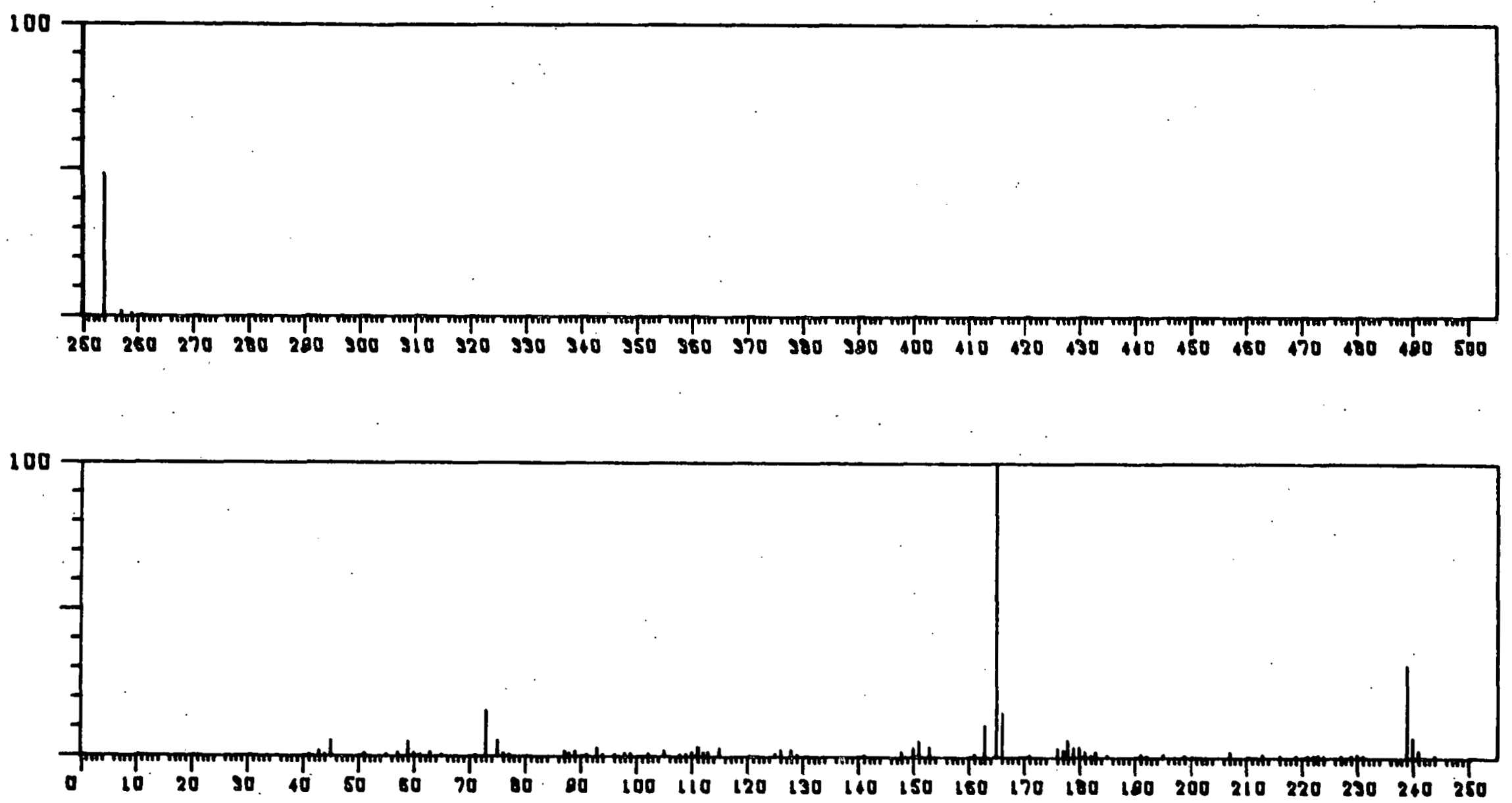

Hydroxyfluorene, TMS ether 


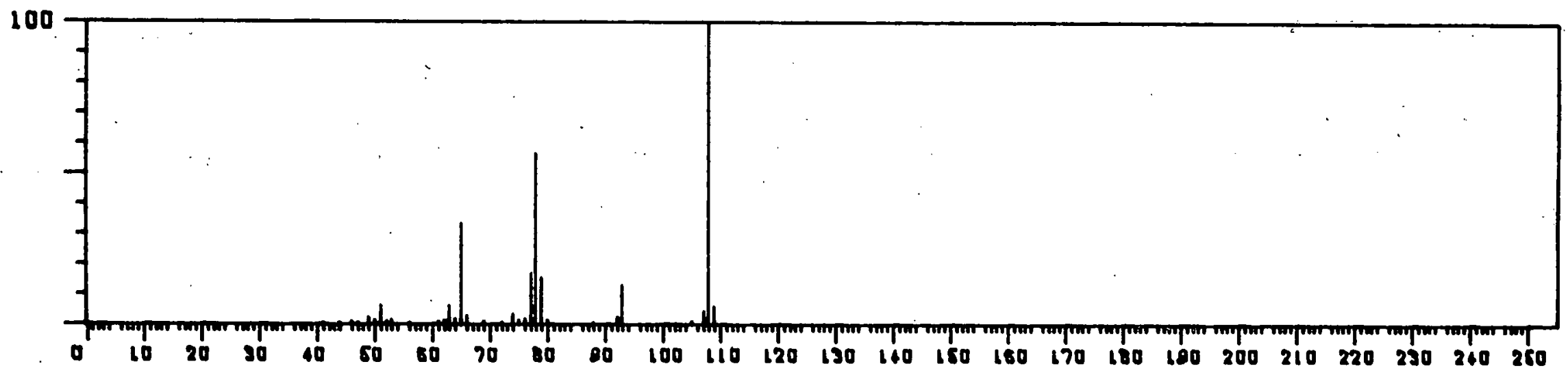

Anisole

Retention Time 28.1

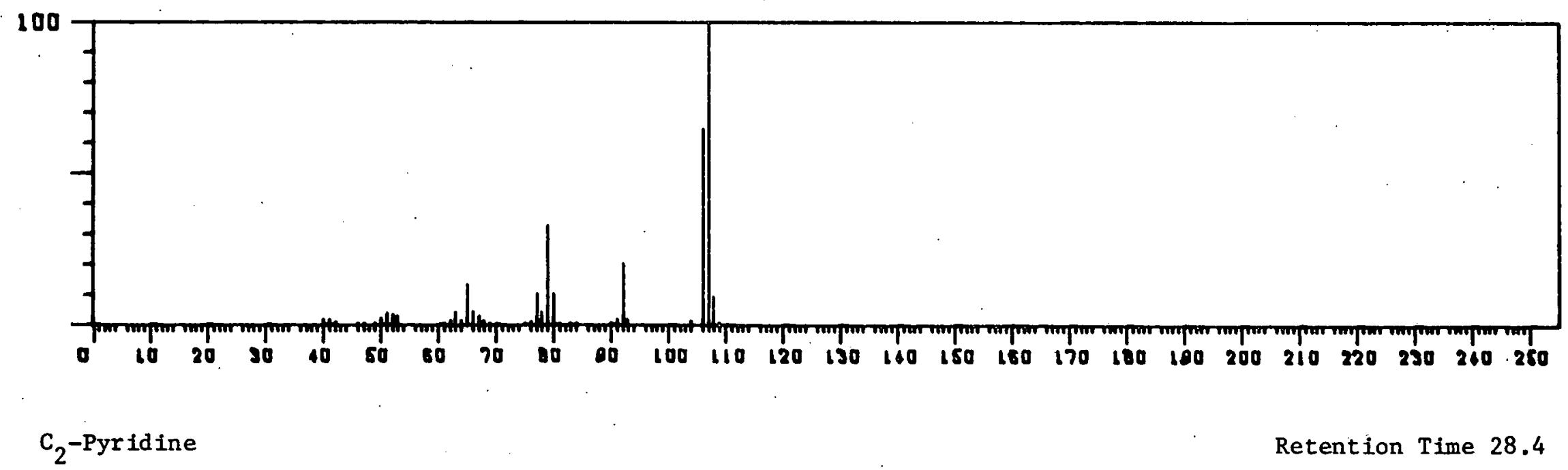




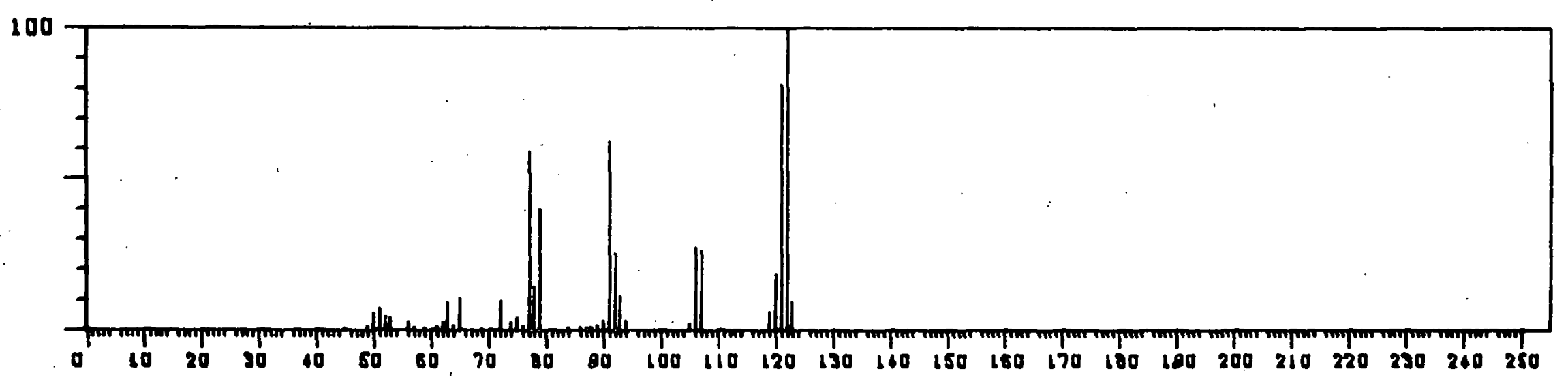

Methyl anisole

Retention Time 35.1

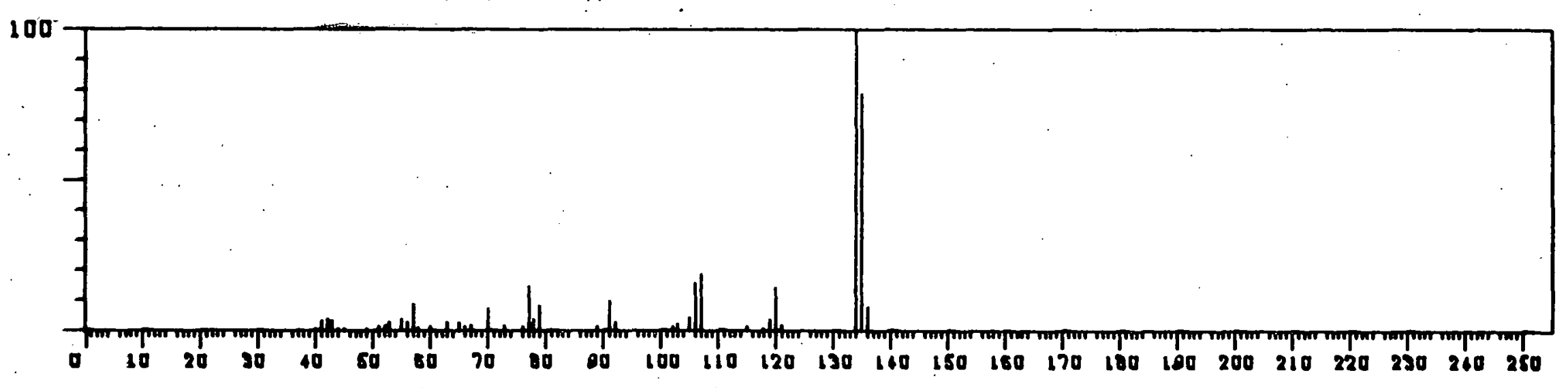

Styrene, methy1 ether

Retention Time 39.4 


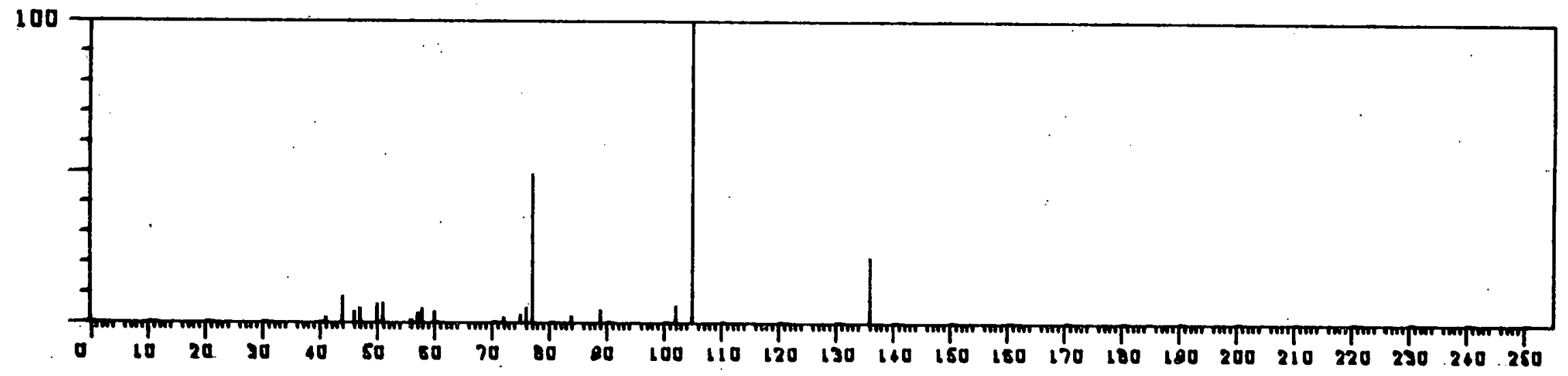

$C_{2}$-Anisole

Retention Time 40.9

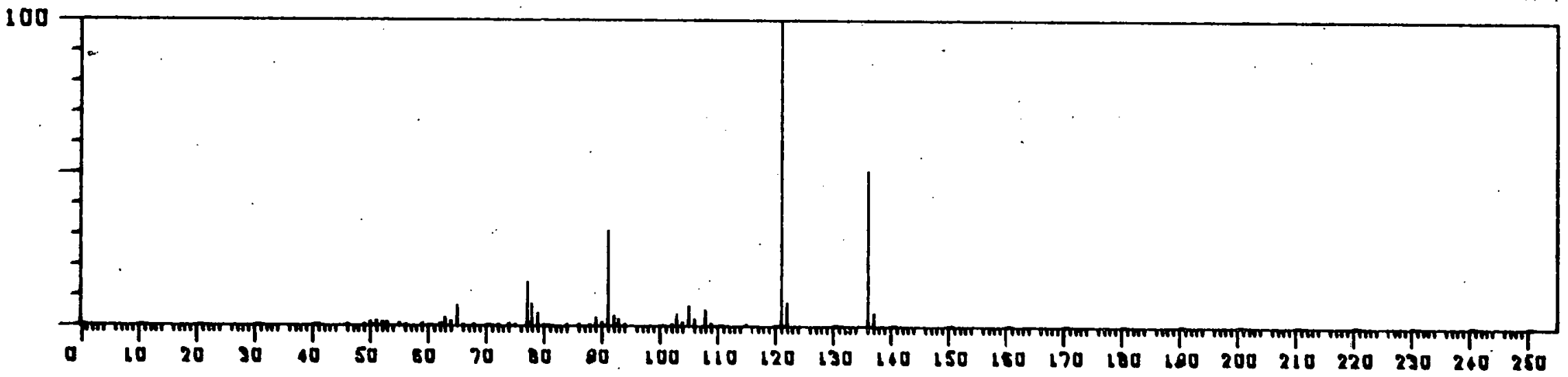

$C_{2}$-Anisole

Retention Time 41.6 


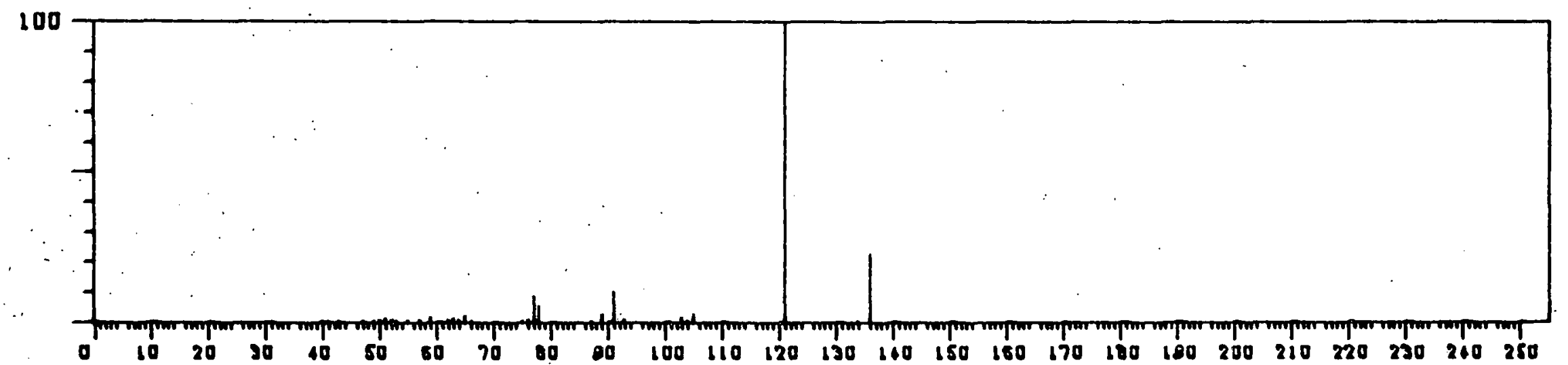

$c_{2}$-Anisole

Retention Time 41.8

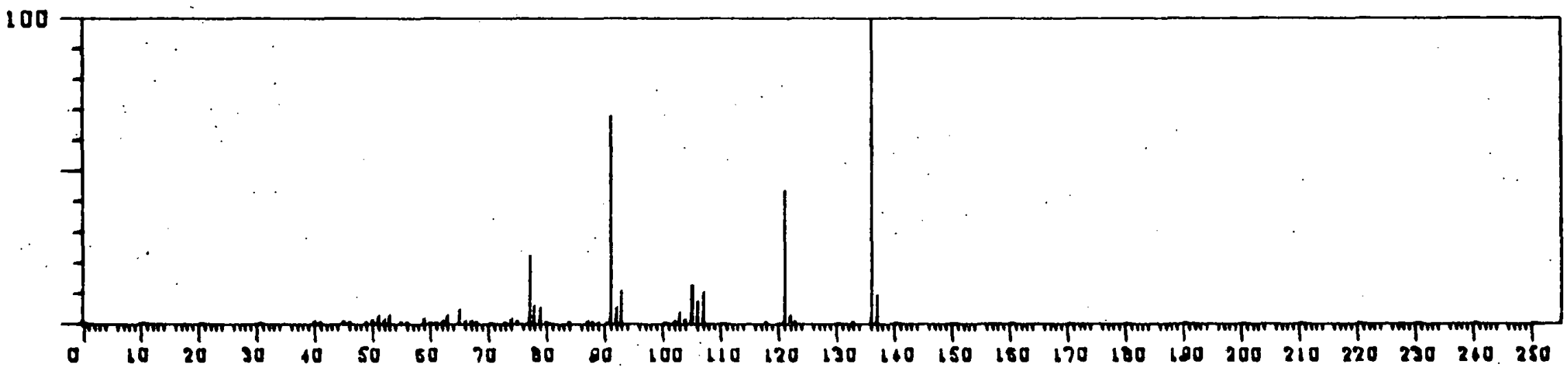

$C_{2}$-Anisole

Retention Time 42.6 


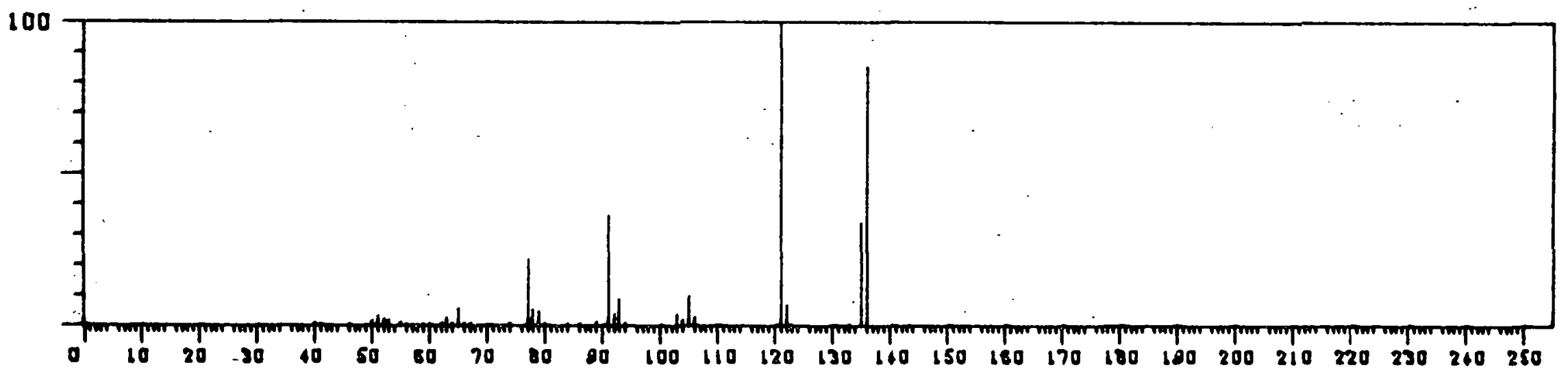

$C_{2}$-Anisole

Retention Time 44.2

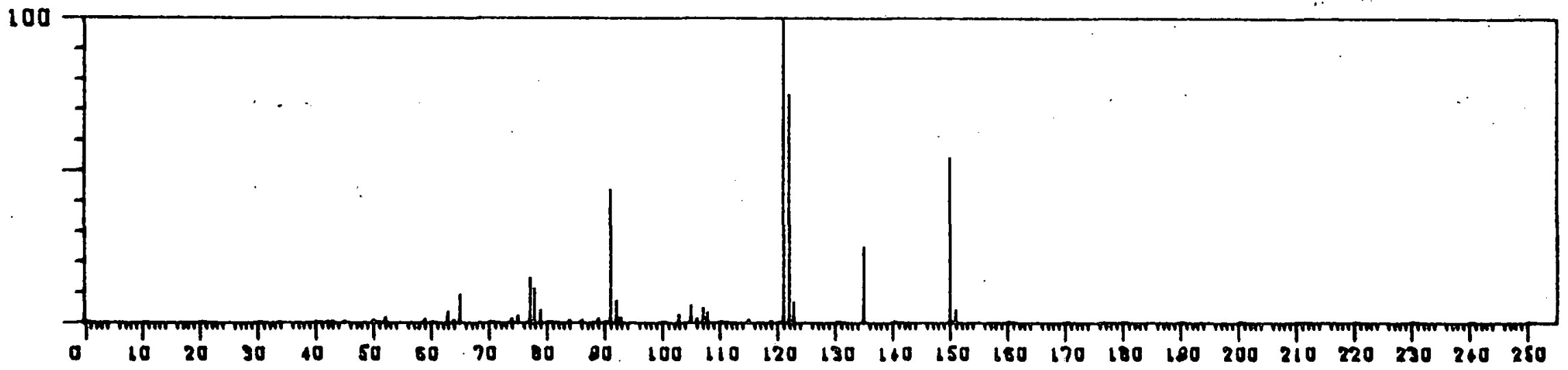

$C_{3}$-Anisole

Retention Time 48.1 


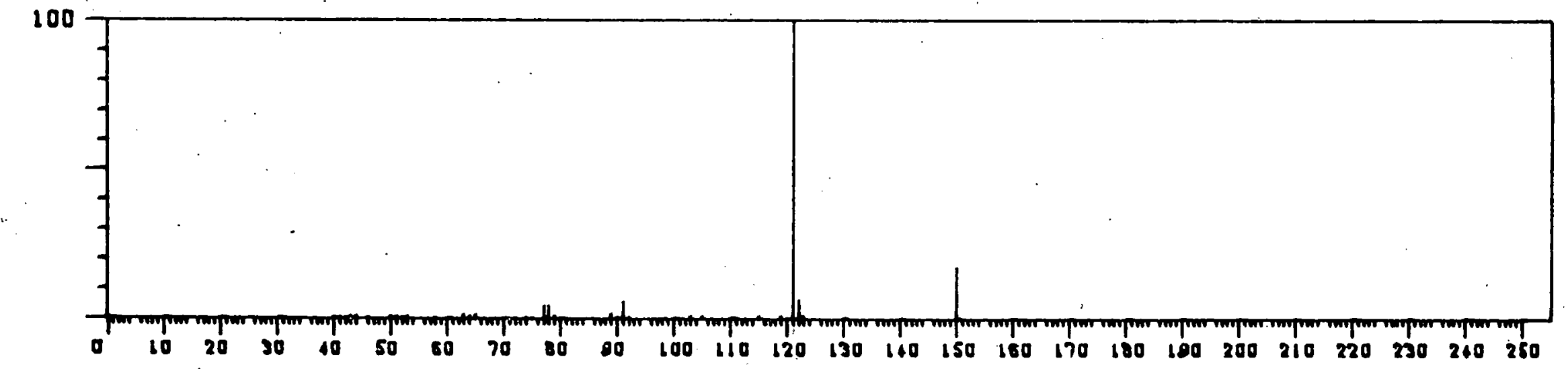

$C_{3}$-Anisole

Retention Time 48.4

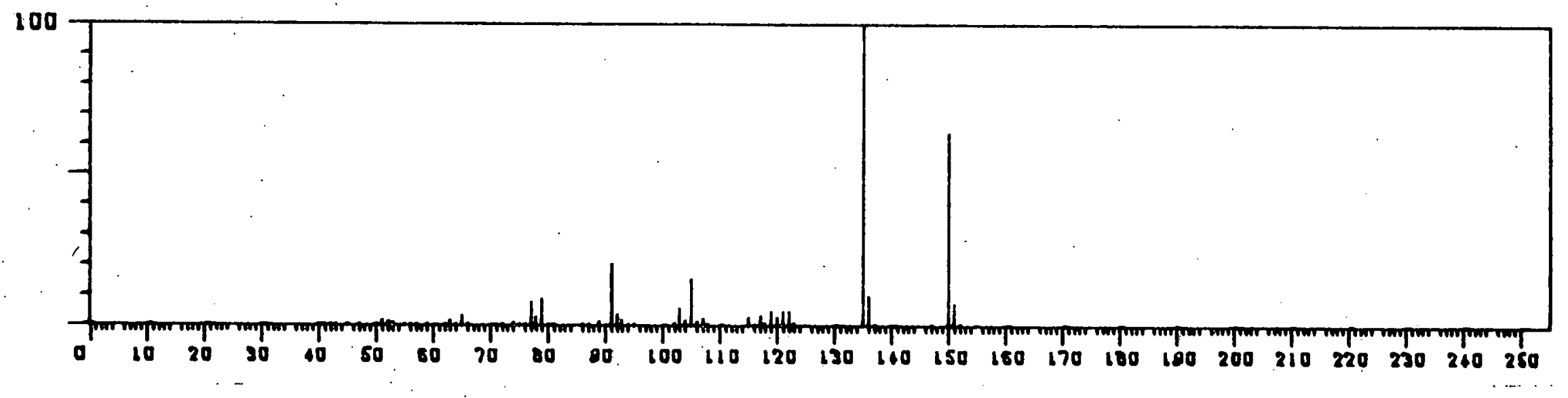

$C_{3}$-Anisole

Retention Time 48.7 


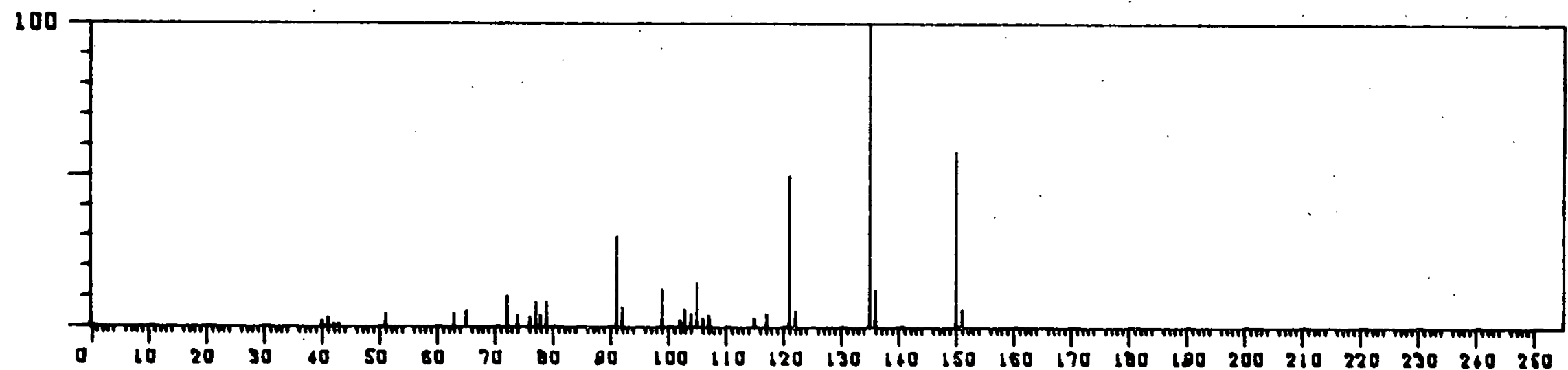

$\mathrm{C}_{3}$-Anisole

Retention Time 50.1

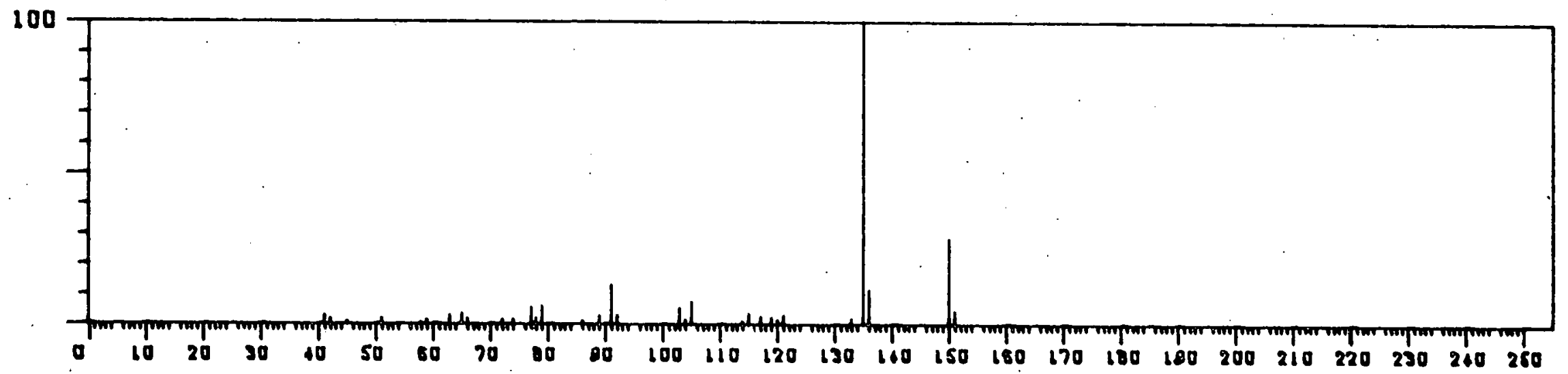

$C_{3}$-Antsole

Retention Time 50.3 


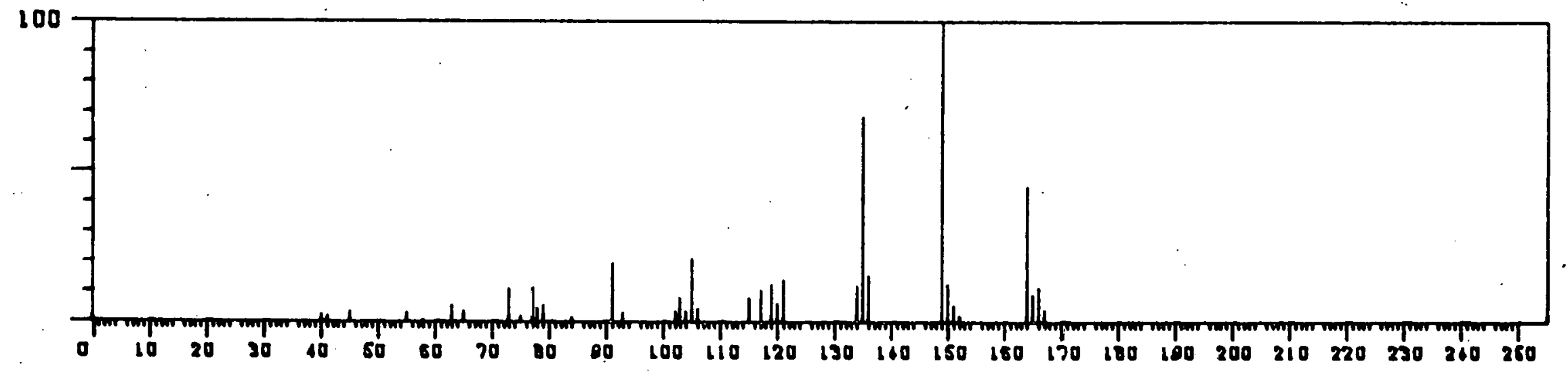

$C_{4}$-Anisole

Retention Time 52.5

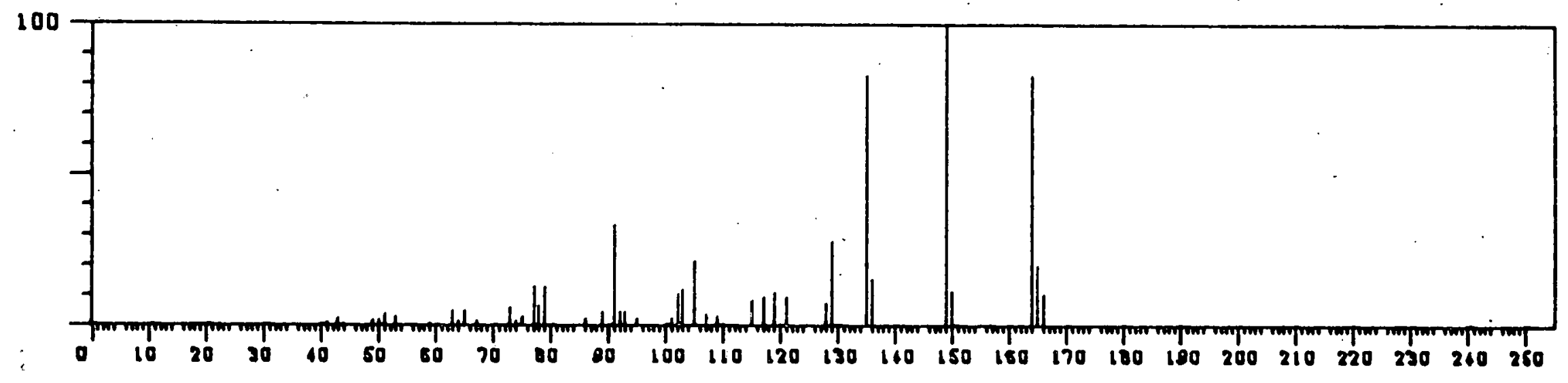

$\mathrm{C}_{4}$-Anisole

Retention Time 54.5 


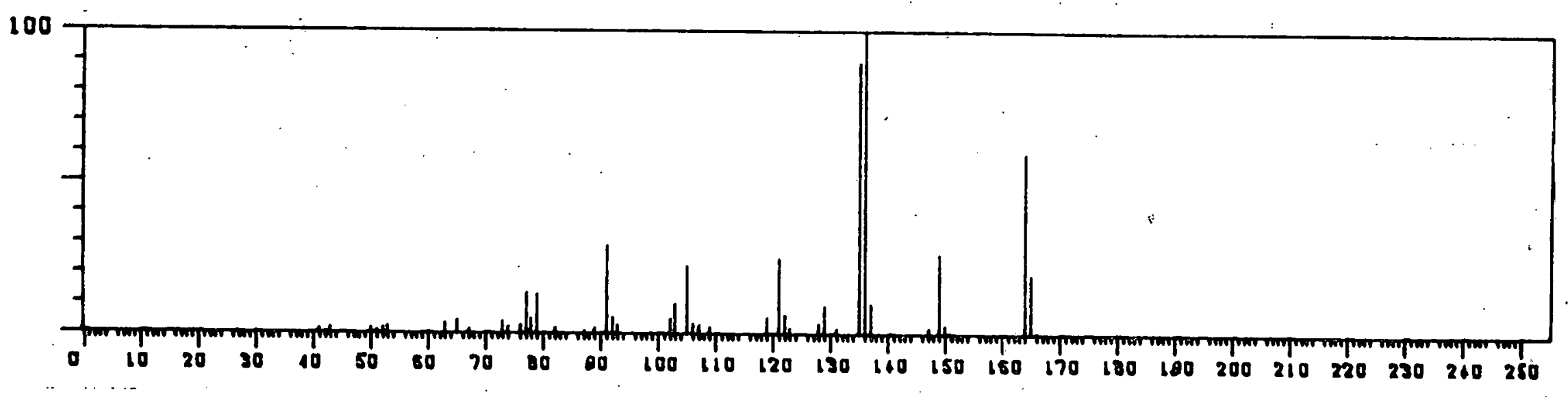

$\mathrm{C}_{4}$-Anisole

Retention Time 54.8

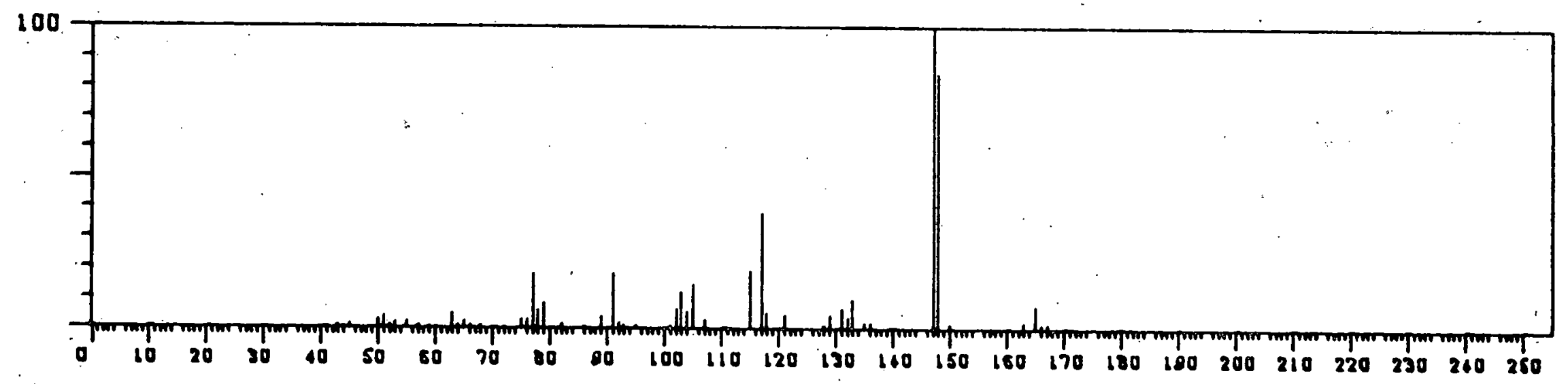




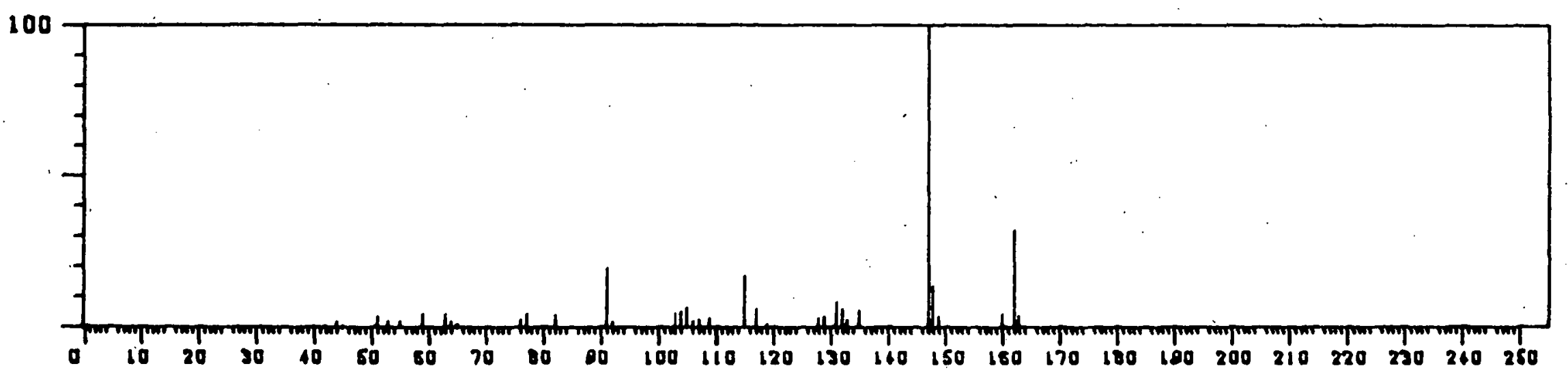

$\mathrm{C}_{2}$-Hydroxystyrene, methyl ether

Retention Time 58.1

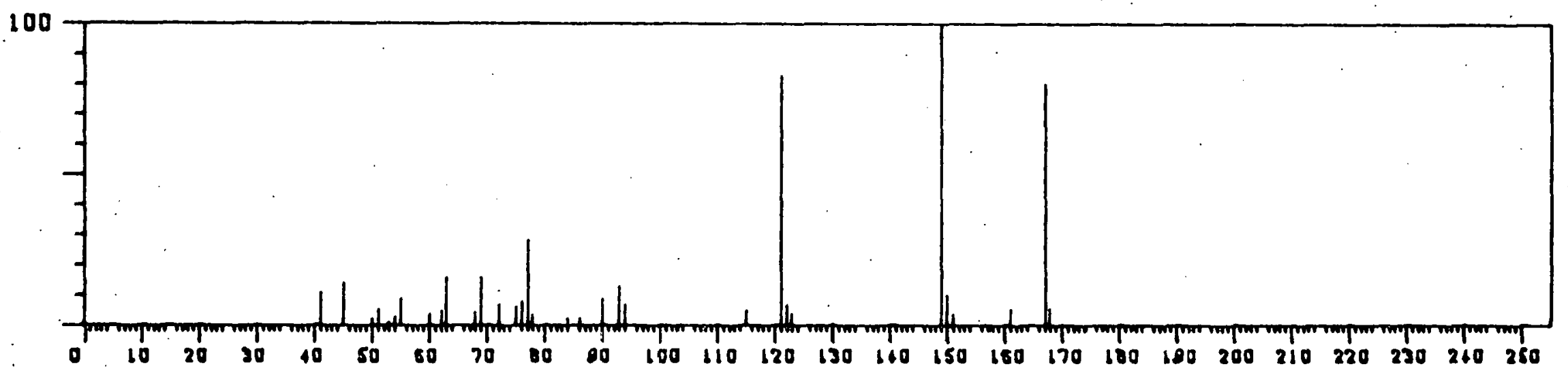

Hydroxybenzo thiophene, methyl- $\mathrm{d}_{3}$ ether

Retention Time 68.7 


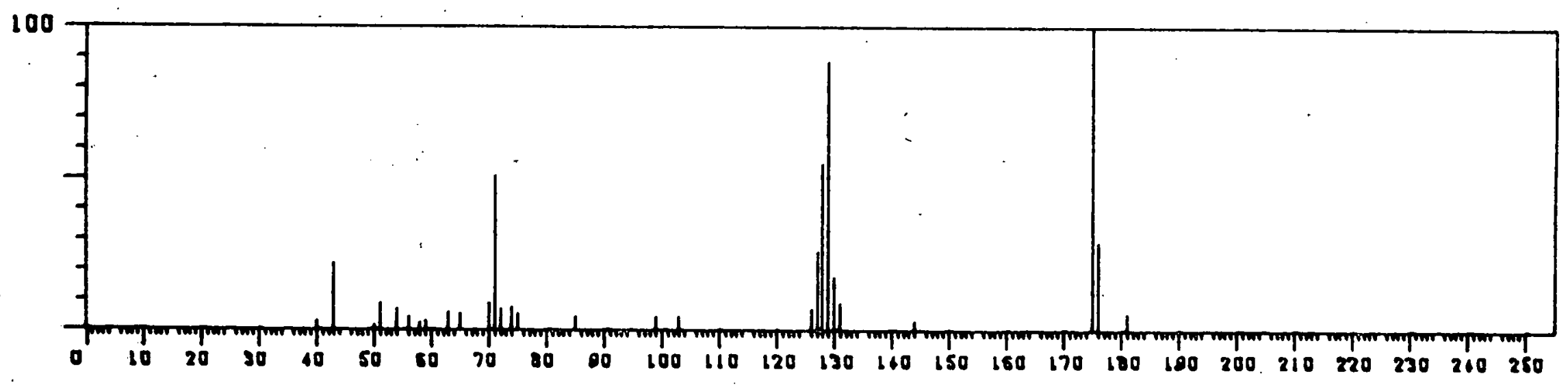

Methyl naphthol, methyl-d 3 ether

Retention Time 75.1

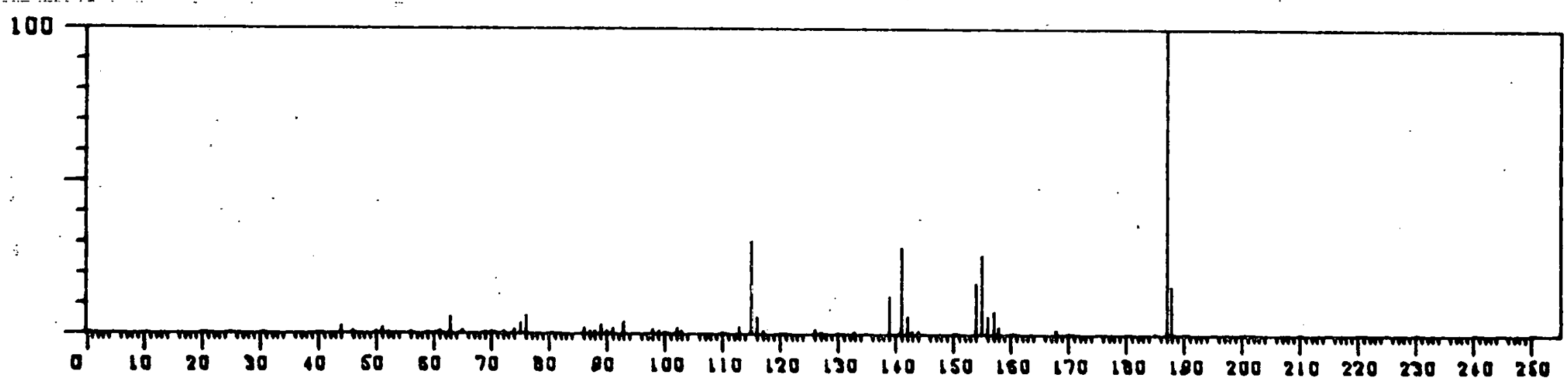

Hydroxybiphenyl, methyl-d 3 ether 


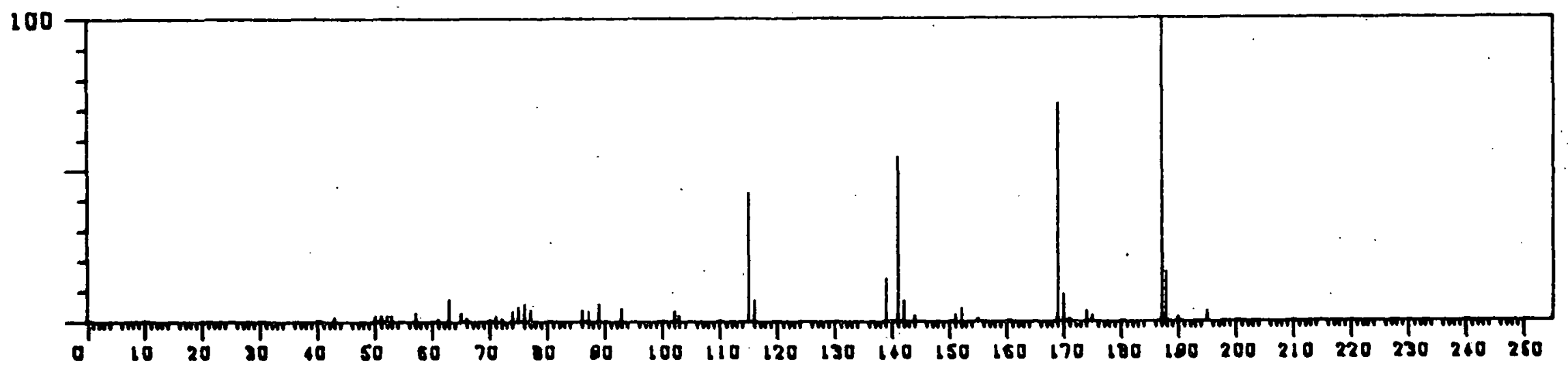

Hydroxybipheny1, methyl- $\mathrm{d}_{3}$ ether

Retention Time 79.3

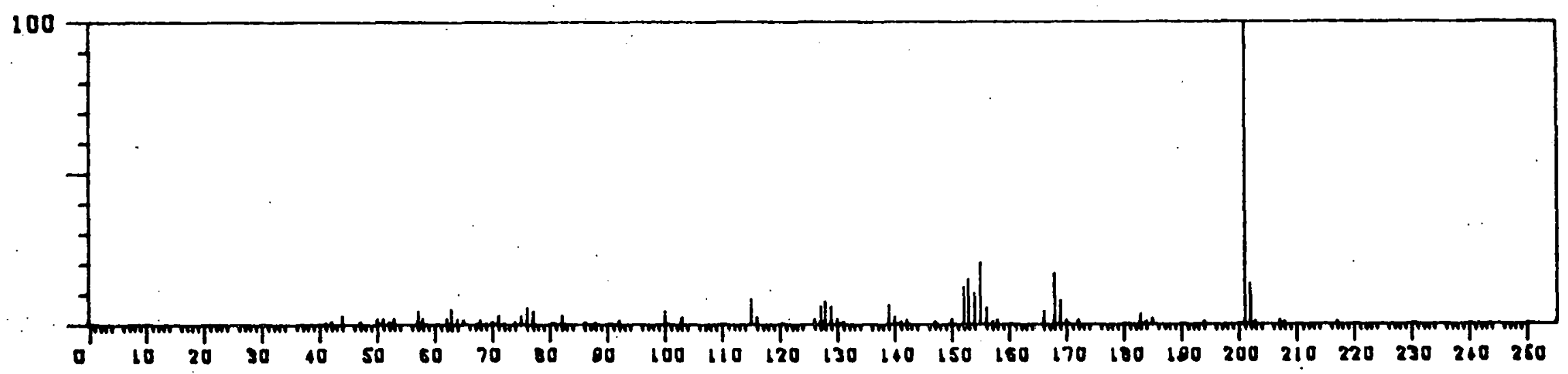

$C_{1}$-Hydroxybipheny 1 , methyl- $d_{3}$ ether

Retention Time 83.8 


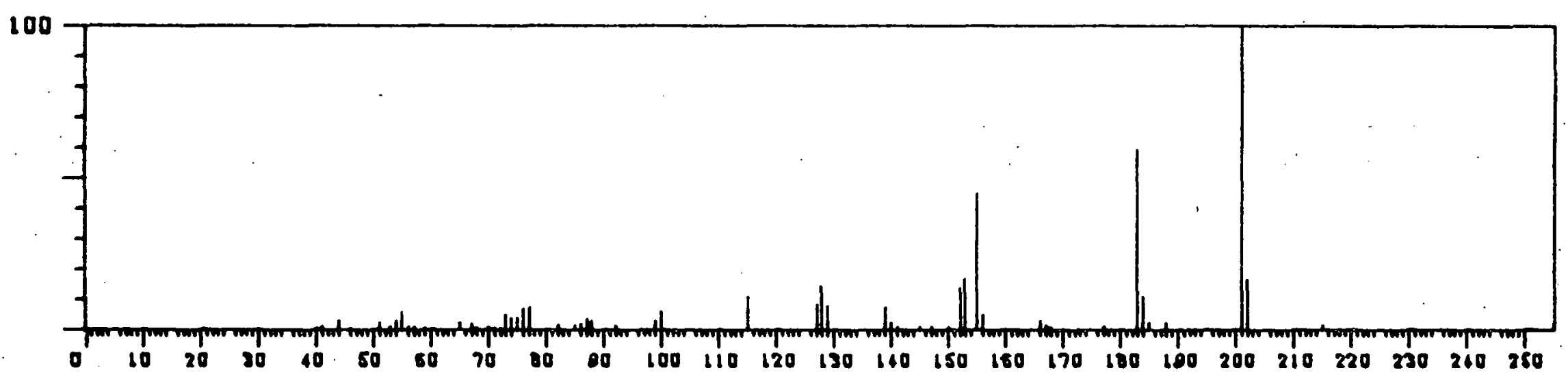

$c_{1}$-Hydroxybiphenyl, methyl-d 3 ether

Retention Time 85.1

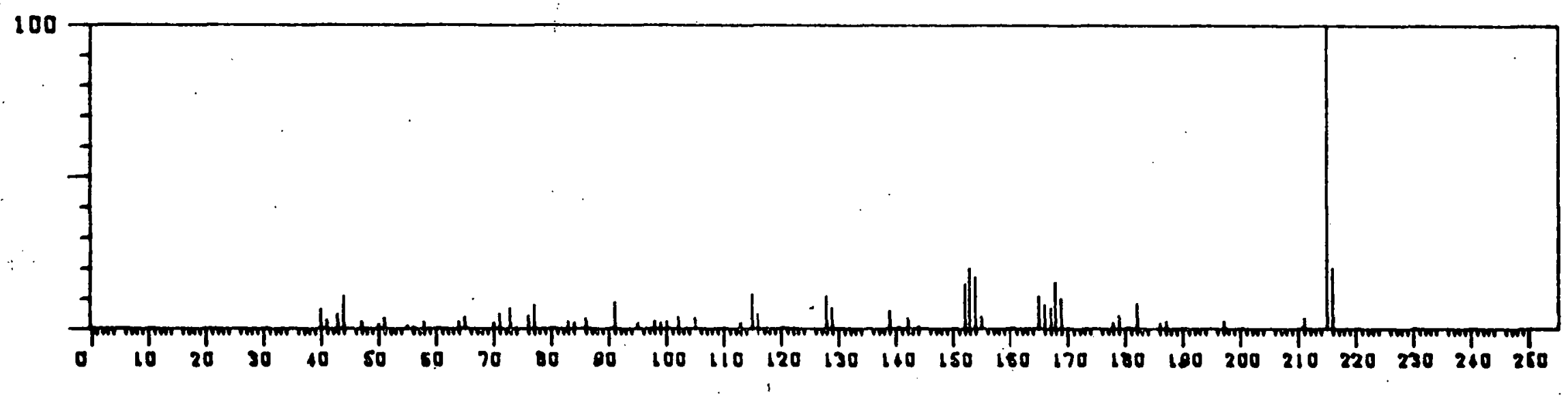

$C_{2}$-Hydroxybiphenyl, methyl-d 3 ether

Retention Time 89.0 


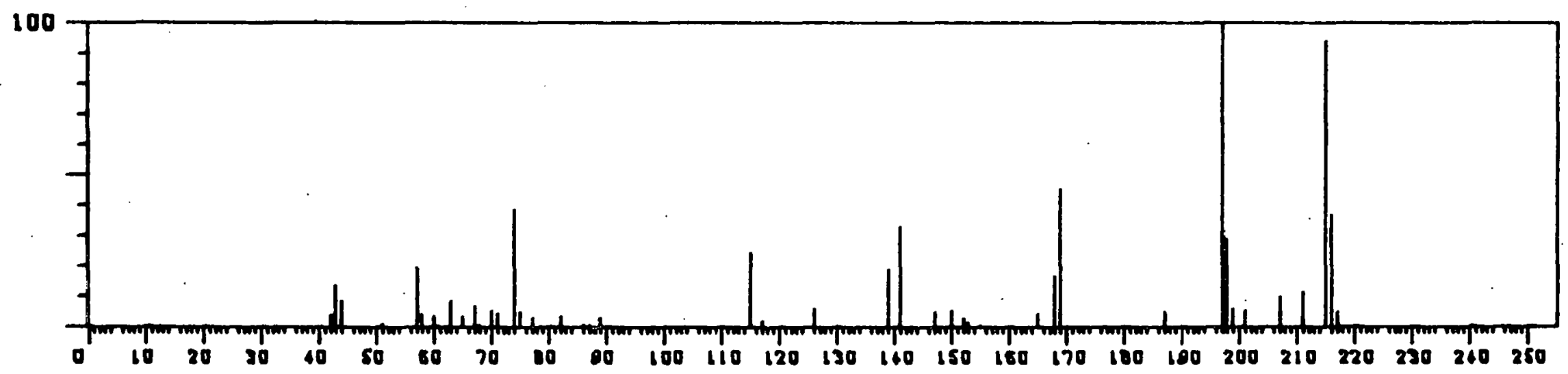

$\mathrm{C}_{2}$-Hydroxybiphenyl, methyl-d $\mathrm{d}_{3}$ ether

Retention Time 91.8

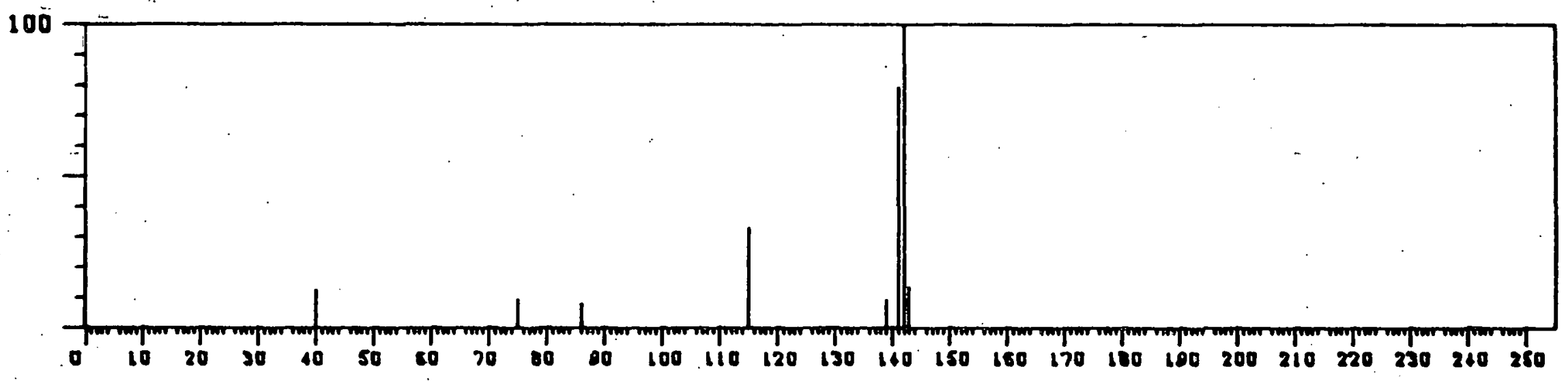

Methyl naphthalene

Retention Time 55.2 


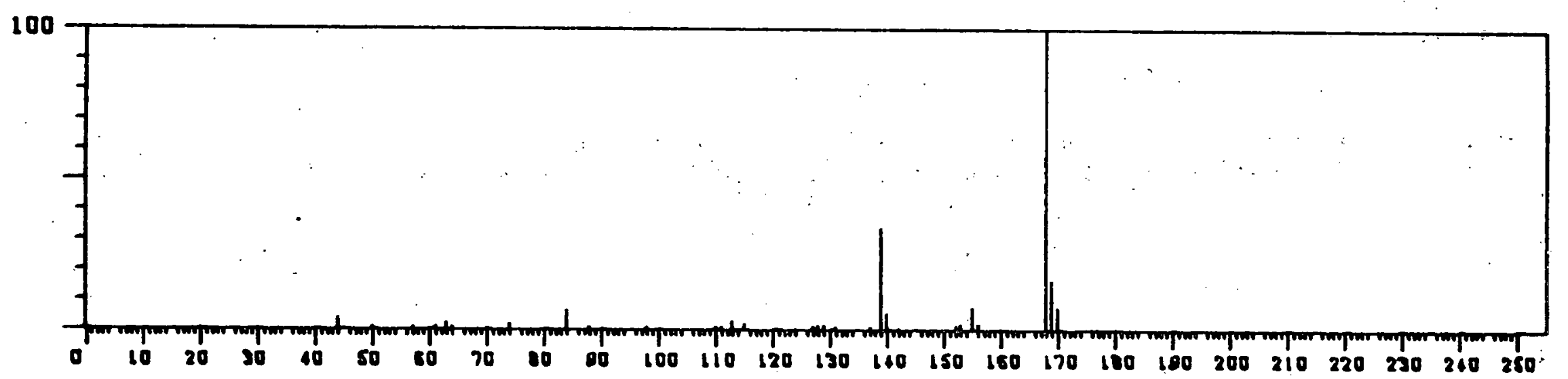

$\mathrm{C}_{2}$-Naphthalene

Retention Time 63.5.

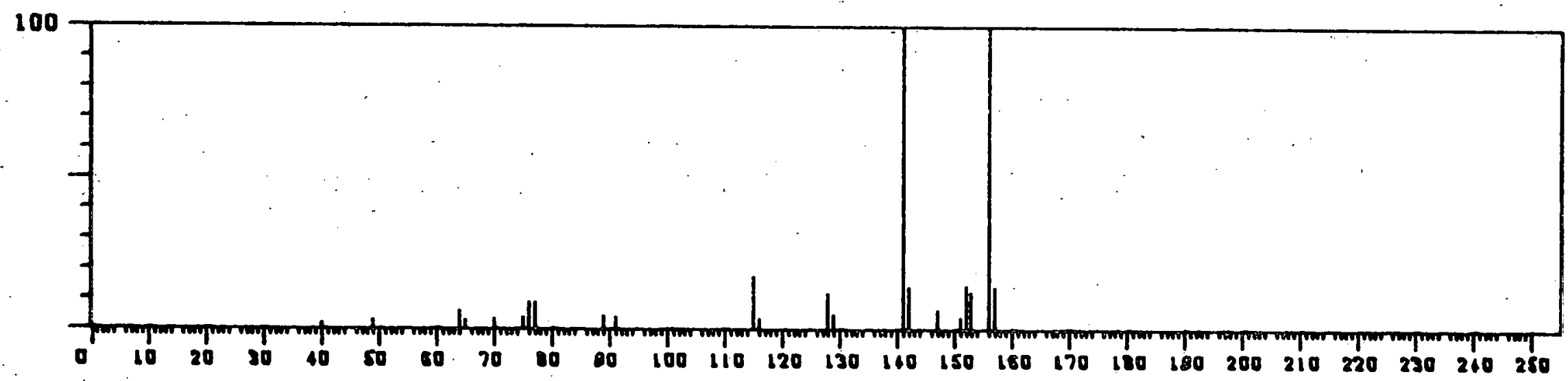

Methyl biphenyl

Retention Time 70.4 


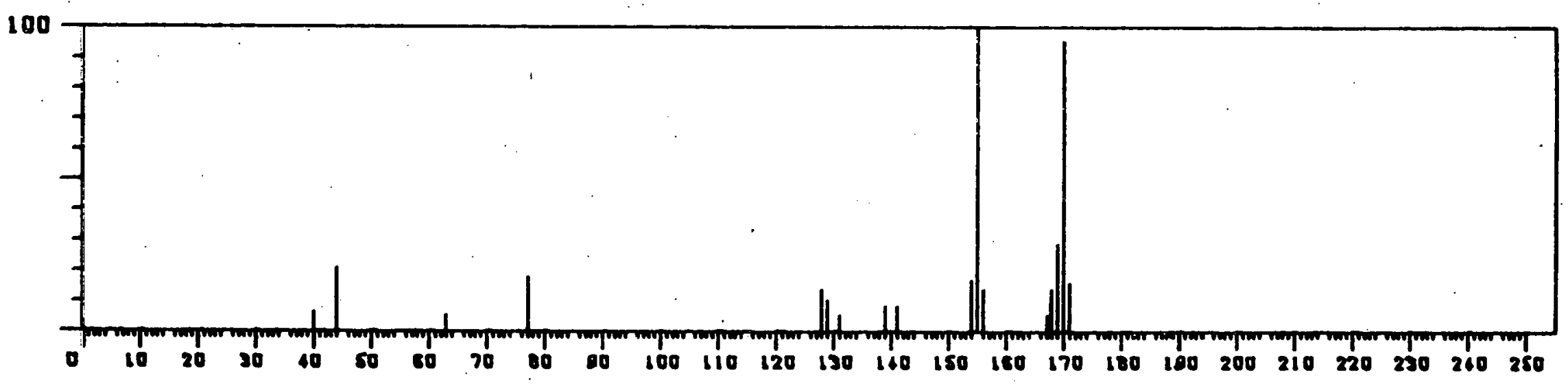

$\mathrm{C}_{3}$-Naphthalene

Retention Time 70.9

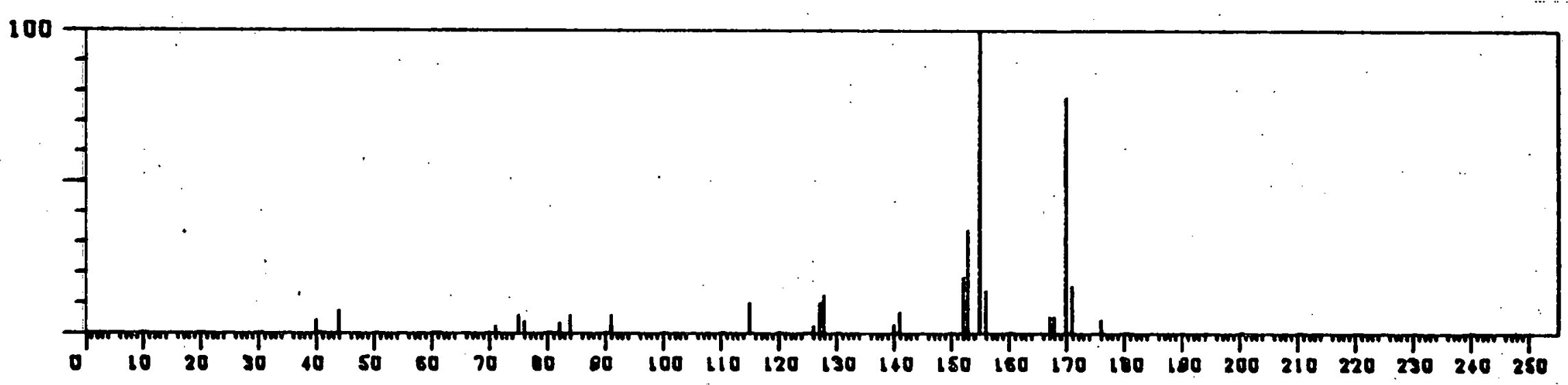

$C_{3}$-Naphthalene

Retention Time 72.7 


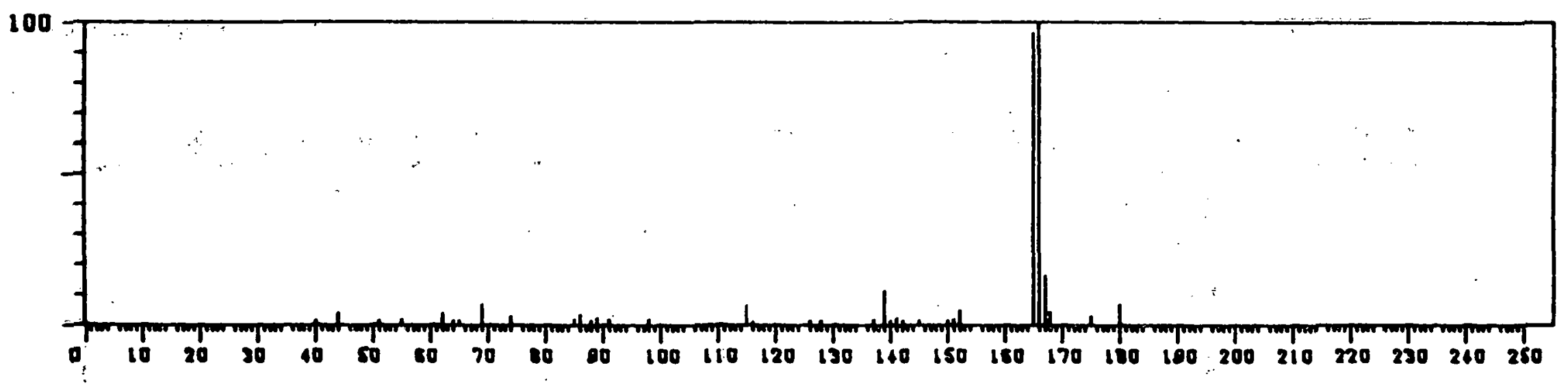

Fluorene

Retention Time 74.5

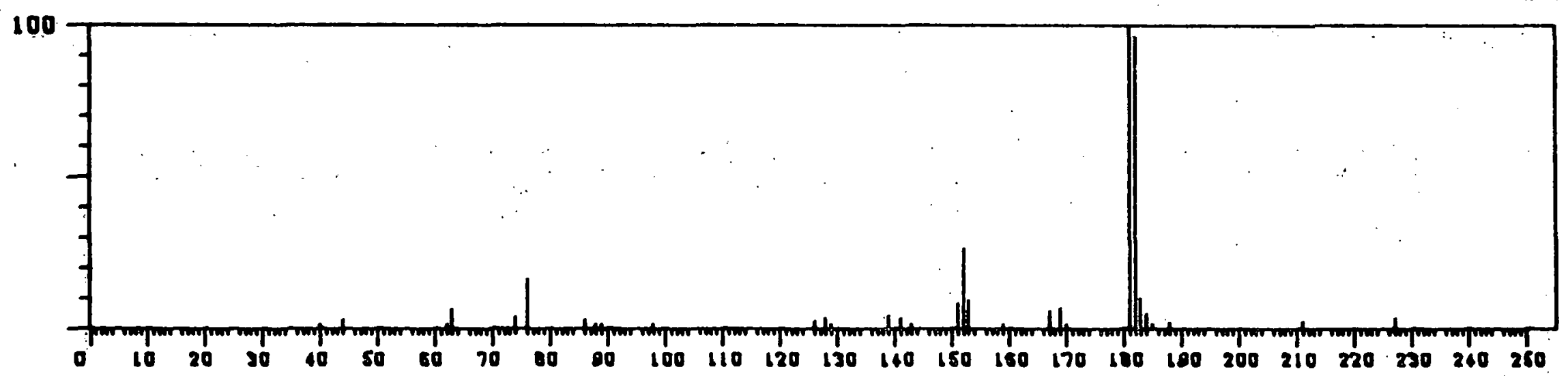

$c_{2}$-Acenaphthene

Retention Time $\mathbf{7 6 . 6}$ 


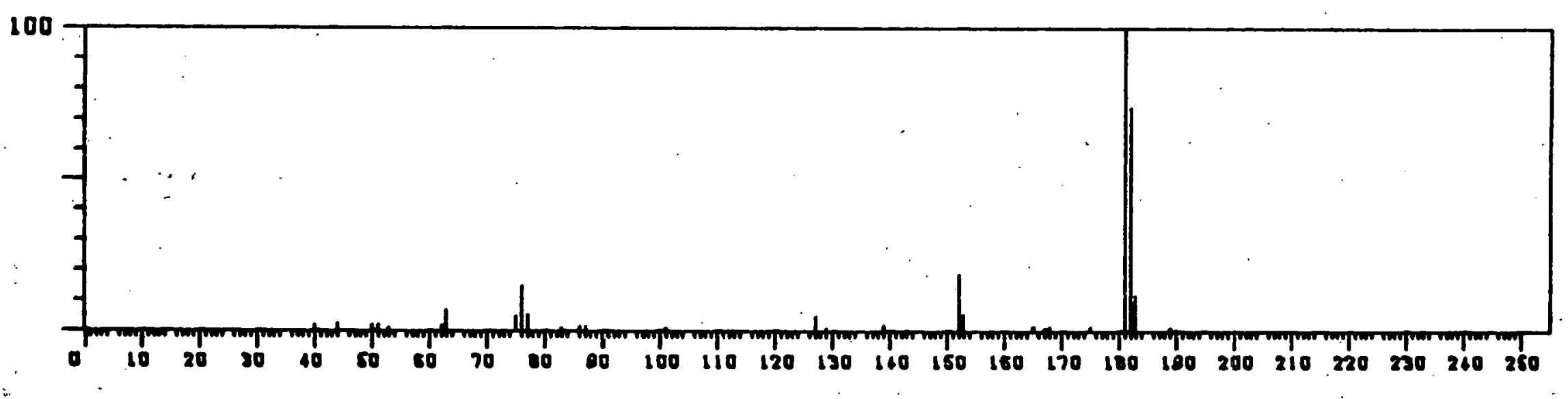

$C_{2}$-Acenaphthene

Retention Time 77.6

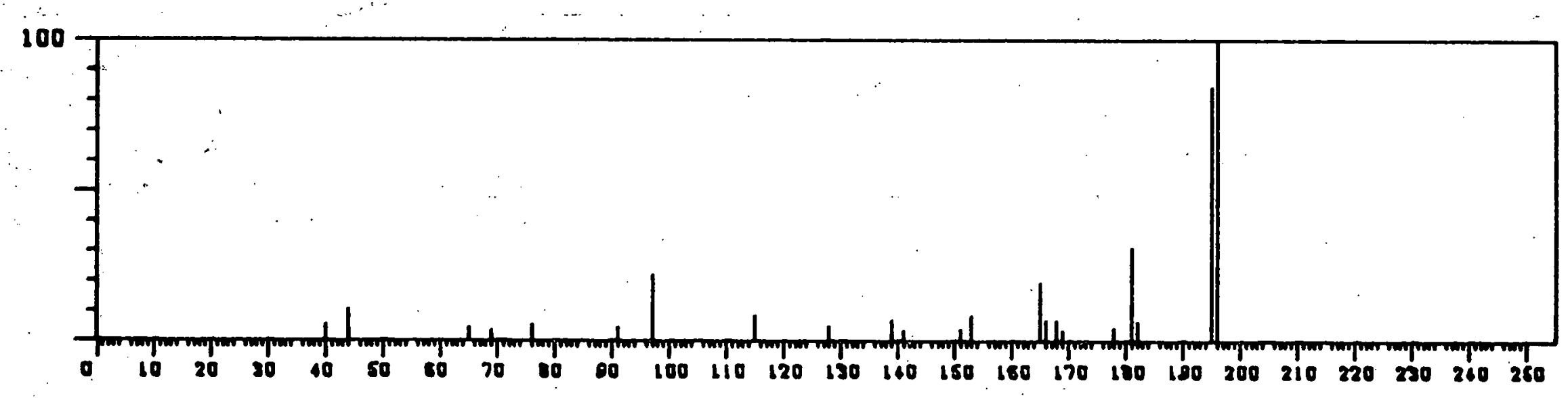




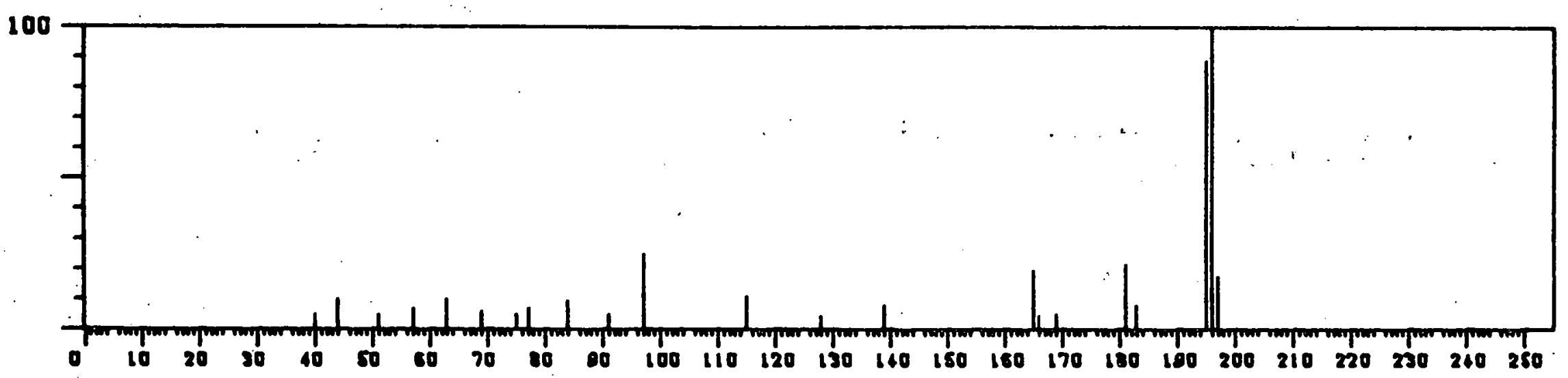

$C_{3}$-Acenaphthene

Retention Time $\mathbf{8 4 . 2}$

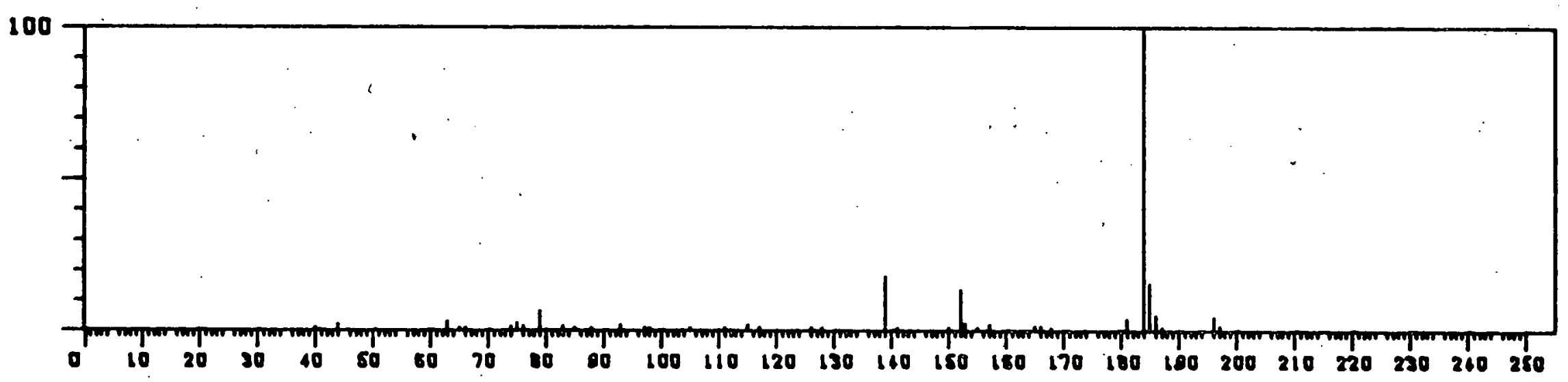

$\mathrm{C}_{2}$-Bipheny1

Retention Time 84.7 


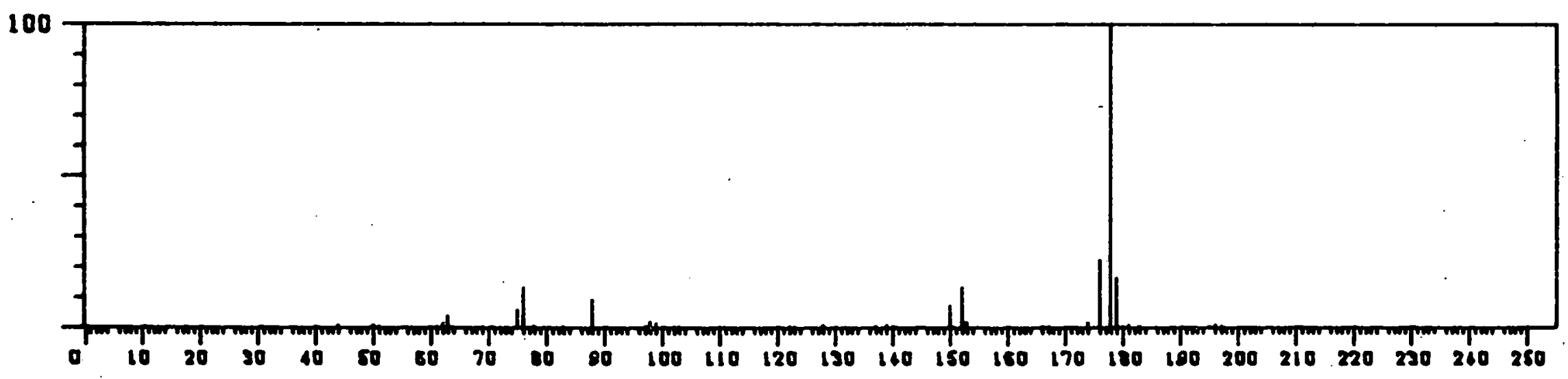

Phenanthrene

Retention Time 86.5

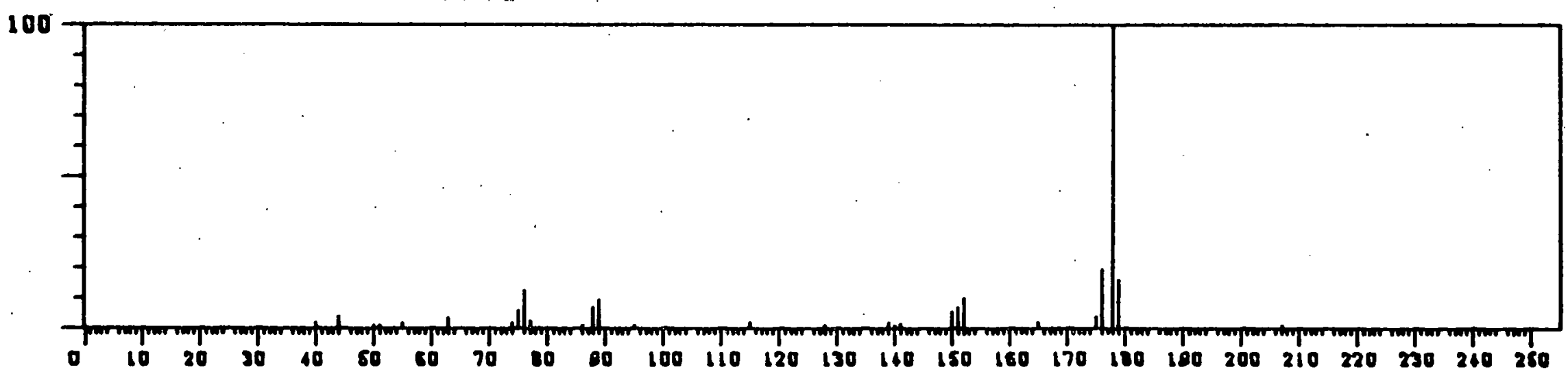




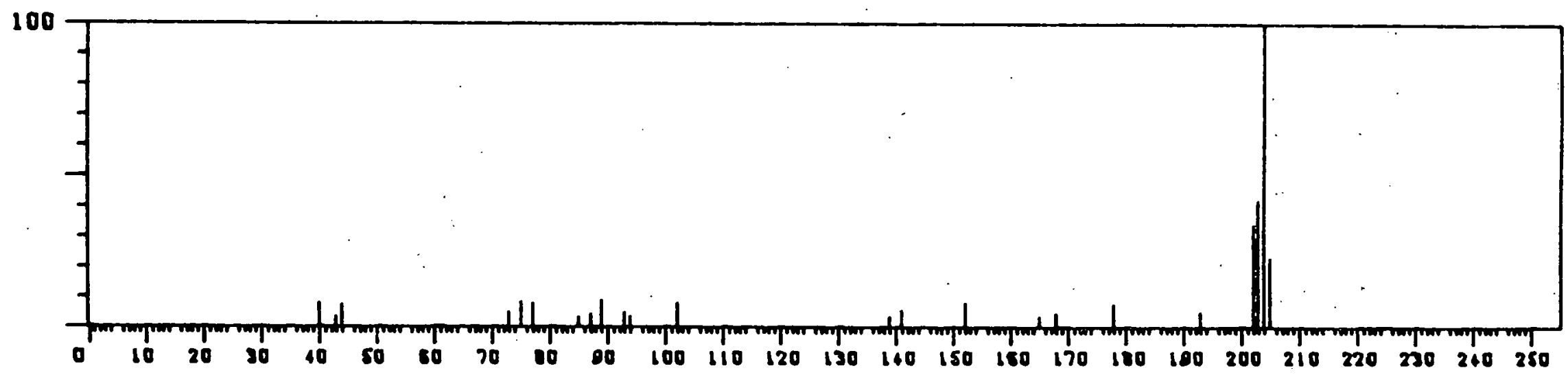

Aceanthrene/acephenanthrene

Retention Time 96.2

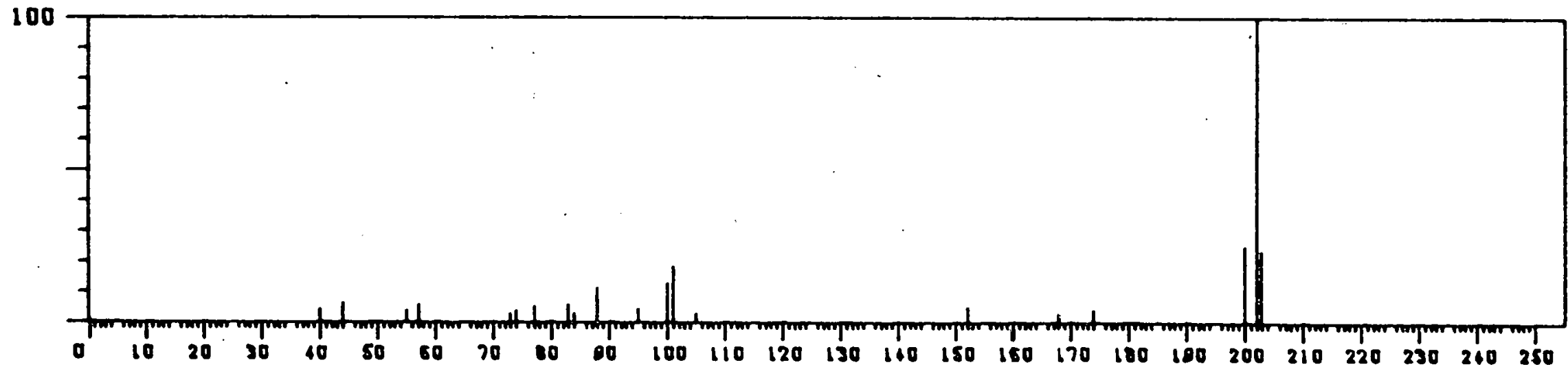


Distribution for ANL/EMR-4

Internal:

S. Bourne

R. P. Carter

E. J. Croke

P. Cunningham

S. Danyluk

J. D. Ditmars

R. D. Flotard

D. Grahn

P. F. Gustafson

L. Habegger

J. Harkness

W. Harrison (3)
B. Hass

L. J. Hoover

D. 0. Johnson

A. B. Krisciunas

K. S. Macal

D. L. McCown

D. McGregor

W. E. Massey

W. Norr is

R. A. Paddock

E. G. Pewitt
L. A. Raphaelian (20)

J. J. Roberts

D. M. Rote

W. K. Sinclair

V. C. Stamoudis

C. Tome

L. S. Van Loon

S. Vargo (10)

K. Wilzbach

ANL Contract Copy

ANL Libraries (5)

TIS Files (6)

\section{External:}

DOE-TIC, for distribution per UC-90c (278)

Manager, Chicago Operations and Regional Office, DOE

Chief, Office of Patent Counsel, DOE-CORO

President, Argonne Universities Association

Energy and Environmental Systems Division Review Committee:

E. E. Angino, U. Kansas

R. E. Gordon, U. Notre Dame

W. W. Hogan, Harvard U.

L. H. Rodd is, Jr., Charleston, S.C.

G. A. Rohlich, U. Texas at Austin

R. A. Schmidt, Booz, Allen, \& Hamilton

J. H. Gibbons, Office of Technology Assessment, U.S. Congress

D. E. Kash, USGS, Reston, Va.

John Abrahams, Fossil Energy Program, USDOE (3)

Mayo Carrington, Fossil Energy Program, USDOE (3)

Paul Duhame1, OHER, USDOE

George Stapleton, OHER, USDOE

Michael Massey, Environmental Research and Technology, Pittsburgh (2)

John Craun, Environmental Research and Technology, Pittsburgh

Lou is Anastasia, Inst. Gas Technology, Chicago

Richard Biljetina, Inst. Gas Technology, Chicago

Myron Gottlieb, ECTD/USDOE

Thomas Atkins, Mittelhauser, Inc., Downers Grove, I11.

Armand Thomas, A. F. Meyer Assoc., McLean, Va. 